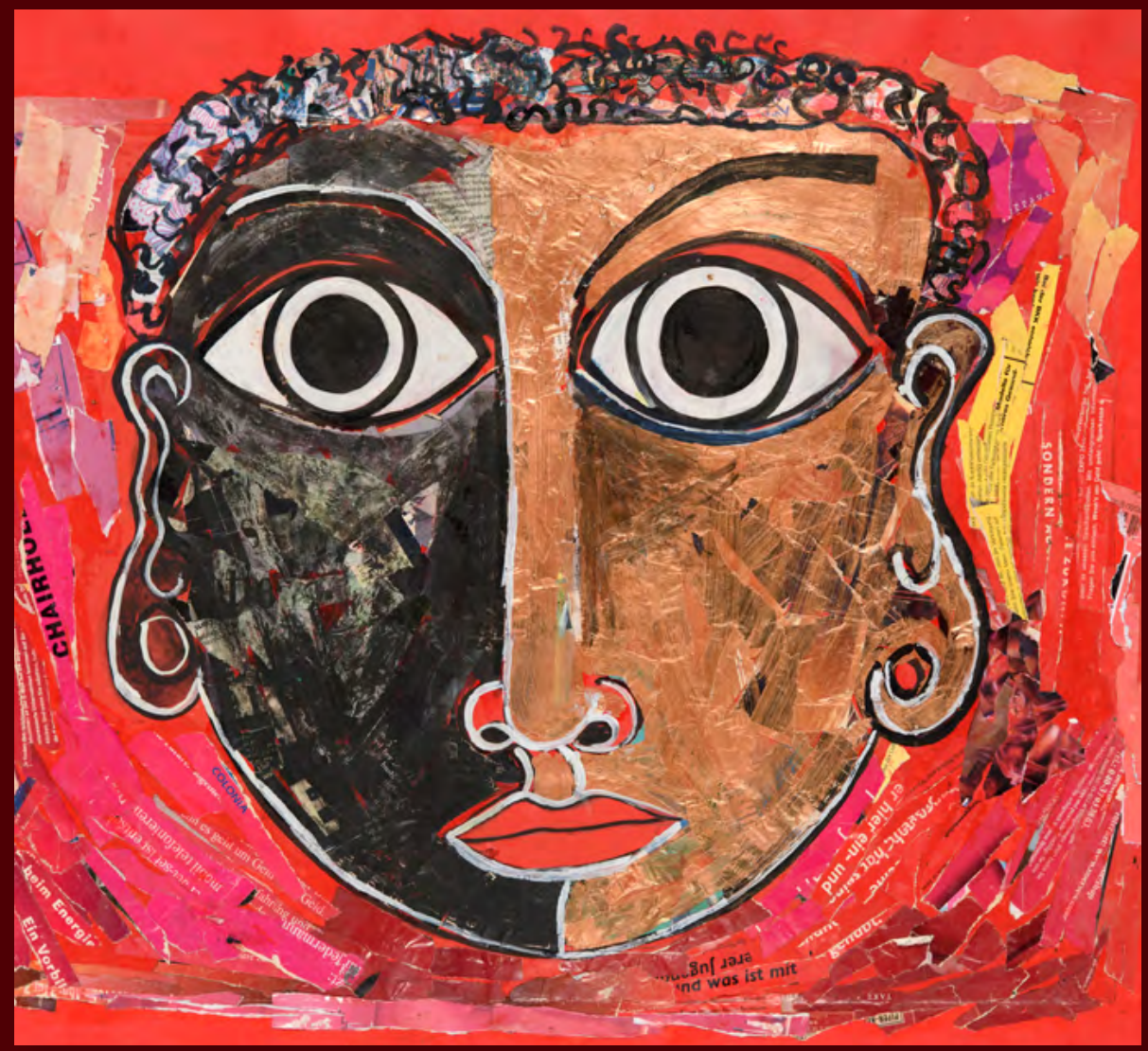

\title{
INCLUSION MATTERS IN AFRICA
}

Maitreyi Bordia Das

Sabina Anne Espinoza 



\section{INCLUSION MATTERS IN AFRICA}

Maitreyi Bordia Das

Sabina Anne Espinoza

(4) WORLD BANK GROUP 
() 2020 International Bank for Reconstruction and Development / The World Bank 1818 H Street NW, Washington, DC 20433

Telephone: 202-473-1000; Internet: www.worldbank.org

Some rights reserved

This work is a product of the staff of The World Bank with external contributions. The findings, interpretations, and conclusions expressed in this work do not necessarily reflect the views of The World Bank, its Board of Executive Directors, or the governments they represent. The World Bank does not guarantee the accuracy of the data included in this work. The boundaries, colors, denominations, and other information shown on any map in this work do not imply any judgment on the part of The World Bank concerning the legal status of any territory or the endorsement or acceptance of such boundaries.

Nothing herein shall constitute or be considered to be a limitation upon or waiver of the privileges and immunities of The World Bank, all of which are specifically reserved.

\section{Rights and Permissions}

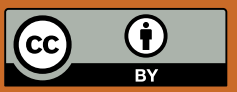

This work is available under the Creative Commons Attribution 3.0 IGO license (CC BY 3.0 IGO) http:// creativecommons.org/licenses/by/3.0/igo. Under the Creative Commons Attribution license, you are free to copy, distribute, transmit, and adapt this work, including for commercial purposes, under the following conditions:

Attribution—Please cite the work as follows: Das, Maitreyi Bordia and Sabina Anne Espinoza. 2020."Inclusion Matters in Africa." World Bank, Washington, DC. License: Creative Commons Attribution CC BY 3.0 IGO.

Translations-If you create a translation of this work, please add the following disclaimer along with the attribution: This translation was not created by The World Bank and should not be considered an official World Bank translation. The World Bank shall not be liable for any content or error in this translation.

Adaptations_-If you create an adaptation of this work, please add the following disclaimer along with the attribution: This is an adaptation of an original work by The World Bank. Views and opinions expressed in the adaptation are the sole responsibility of the author or authors of the adaptation and are not endorsed by The World Bank.

Third-party content-The World Bank does not necessarily own each component of the content contained within the work. The World Bank therefore does not warrant that the use of any third-party-owned individual component or part contained in the work will not infringe on the rights of those third parties. The risk of claims resulting from such infringement rests solely with you. If you wish to re-use a component of the work, it is your responsibility to determine whether permission is needed for that re-use and to obtain permission from the copyright owner. Examples of components can include, but are not limited to, tables, figures, or images.

All queries on rights and licenses should be addressed to World Bank Publications, The World Bank Group, 1818 H Street NW, Washington, DC 20433, USA; e-mail: pubrights@worldbank.org.

Cover photograph: Geoffrey Ernest Katantazi Mukasa, Red Face A, 21st century, mixed-media collage on paper. Artist from Uganda. Image courtesy of the World Bank Group Art Program.

Cover design: Takayo Muroga Fredericks. 


\section{CONTENTS}

Foreword

Acknowledgments

Abbreviations

viii

\section{Overview}

Main Messages

Why Social Inclusion? Why Now?

Social Inclusion: A Primer

What Does Social Inclusion Add to Poverty Reduction?

Africa Is Striding: Who's Left Behind? 8

How Does Social Exclusion Play Out in Africa? 18

Social Inclusion Can Be Achieved If It Is a Conscious Choice for Societies 22

Change toward Social Inclusion Is within Reach 23

Notes

CHAPTER 1 Motivation and Conceptual Clarity 36

What Do We Mean by Social Inclusion?

What Does Social Inclusion Add to Poverty Reduction? 43

Costs of Social Exclusion: What Are the Channels? 45

Analytic Strategy and Road Map 51

Notes

CHAPTER 2 Africa Is Striding: Who's Left Behind?

Demographic Trends and Human Capital Accumulation $\quad 56$

$\begin{array}{ll}\text { Economic Transitions } & 61\end{array}$

Technology and Digital Inclusion $\quad 69$

$\begin{array}{ll}\text { Climate-Related Events and Trends } & 76\end{array}$

$\begin{array}{ll}\text { Conflict and Fragility: Challenges to Social Inclusion } & 78\end{array}$

$\begin{array}{ll}\text { Political and Civic Participation and Social Movements } & 80\end{array}$

Concluding Reflections 83

Notes

CHAPTER 3 How Does Social Exclusion Play Out in Africa? 86

Legal, Administrative, and Social Structures 88

Concluding Reflections 109

Notes 110

CHAPTER 4 Toward Greater Inclusion in Africa 112

Who Drives Change, and How? 114

Programs and Policies toward Social Inclusion: Reflections on the African Experience 121

Concluding Reflections 136

Notes 144

CHAPTER 5 Final Reflections $\quad 146$

$\begin{array}{ll}\text { Appendixes } & 150\end{array}$

Appendix A. Engaging around Social Inclusion with World Bank Partners in Africa 151

Appendix B. Social Inclusion in the World Bank's Environmental and Social Framework 152

Appendix C. Addressing Gender-Based Violence in Africa: Snapshot of World Bank Engagement 153

References 154 


\section{BOXES}

Box $0.1 \quad$ Does Ethnicity Matter for Poverty in Africa? $\quad 7$

Box $\mathbf{0 . 2}$ Disability in Africa: The Importance of Advocacy, Data, and Analysis 12

Box $\mathbf{0 . 3}$ The Importance of Place and Peace for Social Inclusion 14

Box 0.4 Legal Reform for Women in Africa 24

Box 1.1 World Bank Regional Strategy for Africa 39

Box 2.1 Ability, Opportunity, and Dignity for African Youth 59

Box 2.2 Albinism and Human Capital Outcomes 62

Box 2.3 Ethnicity and Poverty in Rural and Urban Africa 64

Box 2.4 Areas and Peoples: North and Northeast Kenya 74

Box 2.5 Urban Floods: Disproportionate Effects 77

Box 4.1 Talking About Change: Stigma and Discrimination in Africa 116

Box 4.2 Talking About Change: Female Genital Mutilation 118

$\begin{array}{lll}\text { Box } 4.3 & \text { Participatory Budgeting in West Pokot, Kenya } & 120\end{array}$

Box 4.4 Legal Reform for Women in Africa 124

Box 4.5 In the Sahel: Focus on Young Women 130

Box 4.6 Reintegration for Ex-combatants in DRC and Liberia 132

Box 4.7 Building Infrastructure Does Not Ensure That It Will Be Used 133

\section{TABLES}

Table $0.1 \quad$ Illustrative Interventions for Social Inclusion in Markets, Services, and Spaces 28

Table 1.1 Costs of Social Exclusion: Mapping Some Channels 46

Table 4.1 Illustrative Interventions for Social Inclusion in Markets, Services, and Spaces 138 


\section{FIGURES}

Figure 0.1 The Social Inclusion Framework 5

Figure 0.2 The Coming of the Urban Age, 1950-2050 11

Figure 0.3 Smartphone Usage by Gender, Age, Education, and Income by Country, $2017 \quad 17$

Figure $\mathbf{0 . 4}$ Perceptions of Unequal Treatment under the Law by Country 21

Figure B0.4.1 Improvement in the Women, Business and the Law Index, 2009-2018 25

Figure 1.1 The Social Inclusion Framework 41

Figure 1.2 Identity Is Salient to Social Inclusion 42

Figure 2.1 Fertility Decline across the Globe, 1950-2100 56

Figure 2.2 Female and Male Literacy Rates, Ages 15 and Above, $2016 \quad 60$

Figure 2.3 Poverty Rates in Fragile and Nonfragile Countries, 1996-2012 63

Figure 2.4 Distribution of Ethnic Groups in Bottom Wealth Quintile 64

Figure 2.5 Depth of Food Deficit, 1992-2016 66

$\begin{array}{lll}\text { Figure 2.6 Top Problems Facing Countries across Africa, } 2016 & 67\end{array}$

Figure 2.7 Smartphone Usage by Gender, Age, Education, and Income by Country, $2017 \quad 70$

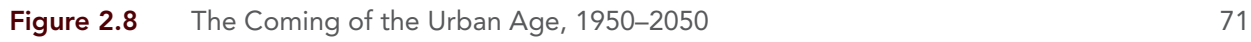

Figure 2.9 Access to Electricity and Water Services, 2008-2015/16 73

Figure 2.10 Forcibly Displaced Persons, 2012-2017 79

Figure 2.11 Forcibly Displaced Africans, 2012-2017 79

Figure 2.12 Civic Engagement among 18- to 35-Year-Olds in 16 Countries, 2002-2015 81

Figure 3.1 Laws and Policies (I) 90

$\begin{array}{lll}\text { Figure 3.2 Laws and Policies (II) } & 91\end{array}$

Figure 3.3 Groups Reporting Avoidance of Health Care due to Stigma and Discrimination 96

Figure 3.4 Women's Acceptance of Domestic Violence by African Country 97

Figure 3.5 Attitudes toward Sexual Minorities and People of a Different Religion by Country 100

Figure 3.6 Attitudes toward Different Languages and Immigrants or Foreign Workers 101

Figure 3.7 Attitudes toward Female and Male University Education and Female Tertiary 103 Enrollment by Country

Figure 3.8 Salience of National versus Ethnic Identity and Feelings of Belonging by Country 104

Figure 3.9 Perceptions of Unequal Treatment under the Law by Country 105

Figure 3.10 Hope and Optimism around the Globe, 2017

Figure 3.11 Burkinabes' Satisfaction with Economy, $2016 \quad 108$

Figure B4.1.1 Stigma and Discrimination in Eastern and Southern Africa, 2000-2016 116

Figure B4.2.1 Female Genital Mutilation in Burkina Faso, 1998-2015 118

Figure B4.2.2 Prevalence of Female Genital Mutilation in Eight African Countries 118

Figure B4.4.1 Improvement in the Women, Business and the Law Index, 2009-2018 124

$\begin{array}{lll}\text { Figure 4.1 Social Safety Net Programs in Africa } & 129\end{array}$ 


\section{FOREWORD}

Over recent years, African countries have seen impressive gains in health, nutrition, education, and women's empowerment. In fact, the pace of progress in some areas has been faster in Africa than in any other region. Innovation abounds in Africa and is reflected in multiple areas. Some of these are the next generation of social safety nets; new platforms that provide services to remote and fragile communities; the spread of digital technology; and advocacy movements that bring previously ostracized people into public acceptance.

Although positive developments in Africa hold promise, the continent still faces major challenges: from reducing poverty to overcoming fragility and managing the growing impacts of climate change. Where there have been development gains, many groups of people have not benefited from them. Who are these groups? Why have they not benefited equitably from progress and development? Why are they more likely to be poor or lack human capital? In many cases, the answer to these questions is social exclusion.

The World Bank's 2013 global flagship report, Inclusion Matters: The Foundation for Shared Prosperity, helped guide us toward better analyses and actions to combat social exclusion. Inclusion Matters in Africa draws on the global report, as Africa finds itself at the center of rapid social and economic change, with the potential for even greater transformation. The current report on Africa resonates with the main message of the Sustainable Development Goals: Leave no one behind. This report also complements the World Bank Group's strategy for Africa, which has increased the emphasis on social inclusion through focusing on building human capital, advancing women's empowerment, strengthening the digital economy, combating climate change, and addressing the underlying drivers of fragility.

Inclusion Matters in Africa tells us that peace and security are inexorably linked to social inclusion. Moreover, although we need to focus on reducing poverty, doing only that will not end the exclusion of some individuals and groups. This report draws attention to the structures and processes that drive social exclusion and, too often, condition people's attitudes, perceptions, feelings, and behaviors. 
A key finding of the report is that, even though exclusion is costly, building an inclusive society is not cost free. It is a conscious decision for any country. And the decision to be inclusive must be made with a clear appreciation of the costs and benefits. As hundreds of initiatives across the continent demonstrate, with a strong social contract and greater accountability of the state and service providers to citizens, social inclusion in Africa is well within reach.

The report is grounded in the experience of African countries but also shows that Africa's challenges in social inclusion are not unique or exceptional. Our hope is that it will change the ways that policy-makers, citizens, and global partners think about development; and help us all live up to the promise of equal opportunity for everyone in Africa.

Hafez Ghanem

Vice President, Africa Region
Laura Tuck

Vice President, Sustainable Development 
This report was written by Maitreyi Bordia Das and Sabina Anne Espinoza, under the strategic guidance of World Bank directors Diarietou Gaye (Director, Strategy and Operations, Office of the Africa Regional Vice Presidency [AFRVP]), Maninder Gill (Global Director, Environmental and Social Framework), and Ede Ijjasz-Vasquez (Africa Regional Director, Sustainable Development). The authors are grateful for the support received from Louise Cord (Global Director, Social), Simon Ehui (Africa Regional Director, Sustainable Development), Sameh Wahba (Global Director, Urban, Resilience and Land), Anna Wellenstein (Regional Director, Latin America and the Caribbean [LAC] Region), and Albert G. Zeufack (Chief Economist, Africa Region). The Africa Regional Management Team, led by Hafez Ghanem (Vice President), held a dedicated meeting to discuss this report and provided advice for which the authors are immensely thankful.

This report benefitted from the continuous engagement and substantive contributions of Senait Assefa (Practice Manager, Africa Region), Robin Mearns (Practice Manager, Africa Region), Aly Rahim (Practice Manager, Africa Region), and Varalakshmi Vemuru (Lead Social Development Specialist, Africa Region).

Peer reviewers for this report were Tom Bundervoet, Helene Carlsson Rex, Shanta Devarajan, German Freire, and Angela Khaminwa from the World Bank, and Cyprian Fisiy (Founder, Fisiy Foundation and Leadership Center, Cameroon). The authors deeply appreciate their insightful comments and the additional discussions held with them. Furthermore, the authors would like to thank Emcet Tas (World Bank) for his contribution to chapter 2, and Angela Khaminwa (World Bank) for her contribution to appendix B. Soumya Kapoor's (senior consultant) and Shruti Majumdar's (UN Women) detailed readings of previous versions of the report were invaluable.

Additional colleagues shared their wisdom and advice and sent background inputs and written comments at various stages of the report preparation. They include Kathleen Beegle, Chifundo Chilera, Louise Cord, Clifton Cortez, Gina Cosentino, Raphael A. Espinoza, Patricia Fernandes, Jana El-Horr, Kamila Galeza, Michael Gboyega Ilesanmi, Marek Hanusch, Bernard Harborne, Somik Lall, Gloria Malia Mahama, Gayle Martin, Charlotte McClain-Nhlapo, Erwin de Nys, Helidah Refiloe Atieno Ogude, Daniel Owen, Margarita Puerto Gomez, Siddhartha Raja, Deepti Samant Raja, Lisa Schmidt, Ruchi Singh, Nicholas Meitaki Soikan, Simon Sottsas, Victor Sulla, and Najat Yamouri. Very instructive discussions of the early 
messages coming from the report were held with Andre Bald, Paolo Belli, Adrian Cutler, Kevin Heraniah, Muratha Kinuthia, Emma Mistiaen, Johan Mistiaen, Shamis Musingo, Abdu Muwonge, Margaret Ombai, Annette Omollo, Utz Pape, Abla Safir, Nadia Selim, and Vanessa Tilstone.

Discussions with various partners from government, civil society, and academia enriched this report. Appendix A describes some of these engagements. In addition, the authors are indebted to Wanjiru Kamau-Rutenberg (AWARD), Winnie Mitullah and Karuti Kanyinga (Institute for Development Studies, University of Nairobi), Shadrack Musyoka (Kitui County, Kenya), Munawwar Alam (United States Agency for International Development [USAID]/Kenya), Honorable Members of the Parliament of Sierra Leone, Yvonne Aki-Sawyerr (Mayor of Freetown, Sierra Leone) and the members of the UN System in Sierra Leone, with whom they discussed early results from the report.

Paul Gallagher, Maura Leary, Kristyn Schrader-King, and Andy Shuai Liu offered outstanding inputs in framing key messages and advice on communications around the report. Elizabeth Acul and Lucie Albert-Drucker provided critical administrative assistance, and Michelle Morandotti provided outstanding support throughout the editing and production process of the report. Flavia Carbonari's inputs to the Portuguese translations of the Overview are deeply appreciated. Dina Towbin and Associates and Alicia Hetzner supported the editorial process. Finally, Takayo Muroga Fredericks provided outstanding services for typesetting and report design. 


\title{
ABBREVIATIONS
}

\author{
AfDB African Development Bank \\ AFIC \\ Africa Freedom of Information Centre \\ AIDS \\ $A U$ \\ acquired immunodeficiency syndrome \\ BBBEE \\ African Union \\ BMI \\ Broad-Based Black Economic Empowerment \\ BRAC \\ body mass index \\ BWC \\ Building Resources across Communities \\ CAN \\ Business Women Connect \\ CBR \\ CBR Africa Network \\ CSA \\ community-based rehabilitation \\ DHS \\ Country Social Analysis \\ ELA \\ Demographic and Health Survey \\ EMC \\ Empowerment and Livelihood for Adolescents (Uganda) \\ EPD \\ Continuous Multisectoral Survey \\ ESF \\ End Poverty Day \\ ESS \\ Environmental and Social Framework \\ FAO \\ Environmental and Social Standards \\ FCC \\ Food and Agricultural Organization of the United Nations \\ FCS \\ Federal Character Commission (Nigeria) \\ FGM \\ Federal Civil Service (Nigeria) \\ FOI \\ female genital mutilation \\ FRA \\ freedom of information \\ GBV \\ European Union Agency for Fundamental Rights \\ GDP \\ gender-based violence \\ GLR \\ GRP \\ HCP \\ gross domestic product \\ Great Lakes Region (Africa) \\ gross regional product \\ HIV \\ Human Capital Project \\ ICT \\ human immunodeficiency virus \\ ID4D \\ information and communications technology \\ IDMC \\ Identification for Development (World Bank) \\ IDP \\ Internal Displacement Monitoring Centre \\ IIED \\ internally displaced person or people \\ ILO \\ International Institute for Environment and Democracy \\ IMF International Monetary Fund \\ IP \\ indigenous person or people \\ $\mathrm{KPBI} \quad$ Kenya Participatory Budgeting Initiative \\ LGBTI lesbian, gay, bisexual, transgender, and intersex \\ LOGiCA Learning on Gender and Conflict in Africa \\ LOGOSEED Local Governance and Service Delivery Project (South Sudan) \\ LOI language of instruction \\ LSMS Living Standards Measurement Study \\ LTR land tenure regularization \\ MFD Maximizing Finance for Development \\ MICS Multiple Indicator Cluster Survey MP Member of Parliament
}


men who have sex with men

NBER

NURC

NYSC

OECD

$\mathrm{OHCHR}$

OLL

PB

PNDDR

PPP

PSIA

SAR

SCD

SDGs

SGBV

SHEDD

SiAT

SOGI

$\mathrm{SRH}$

SSN

SWEDD

TCSS

TFR

TRC

TRRC

UDL

UN

UNAIDS

UN DESA

UNDP

UNDPI

UNESCO

UNFPA

UNGA

UN-Habitat

UNHCR

UNICEF

UNMIL

UVR

WASH

WB

WBG

WDI

WG

WHO

WVS
National Bureau of Economic Research

National Unity and Reconciliation Commission (Rwanda)

National Youth Service Corps (Nigeria)

Organisation for Economic Co-operation and Development

Office of the United Nations High Commissioner for Human Rights

Organic Land Law (Rwanda)

participatory budgeting

National Program for Disarmament, Demobilization, and Reintegration

(Congo, Democratic Republic of)

purchasing power parity

Poverty and Social Impact Analysis

special administrative region

Systematic Country Diagnostic

Sustainable Development Goals

sexual and gender-based violence

Sahel Women Empowerment and Demographic Dividend

Social Inclusion Assessment Tool

sexual orientation and gender identity

sexual and reproductive health services

social safety net

Sahel Women's Empowerment and Demographic Dividend

Transitional Constitution of South Sudan

total fertility rate

Truth and Reconciliation Commission (South Africa)

Truth, Reconciliation and Reparations Commission (The Gambia)

Universal Design for Learning

United Nations

Joint United Nations Programme on HIV/AIDS

United Nations Department of Economic and Social Affairs

United Nations Development Programme

United Nations Department of Global Communications

(formerly Department of Public Information)

United Nations Educational, Scientific and Cultural Organisation

United Nations Population Fund

United Nations General Assembly

United Nations Human Settlements Programme

United Nations High Commissioner for Refugees

United Nations Children's Fund

United Nations Mission in Liberia

ultraviolet radiation

water supply, sanitation, and hygiene

World Bank

World Bank Group

World Development Indicators

Washington Group on Disability Statistics

World Health Organization

World Values Survey 


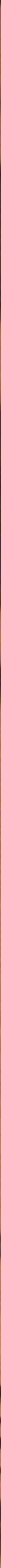




\section{OVERVIEW}

\section{Main Messages}

1. Africa has seen significant progress towards social inclusion in the past few decades, in many areas moving at a pace faster than seen globally.

2. Some groups and areas have been left out of the progress in Africa and continue to remain at risk. Social inclusion helps us understand who is left out, from what, in what ways, and why.

3. Social inclusion draws attention to the drivers of poverty in Africa and explains that while we need to focus on poverty, this is only a starting point to end the exclusion.

4. Structures and processes that aid and abet social exclusion often have historical and cultural roots.

5. Areas that are affected by conflict and fragility stand out as having the poorest outcomes related to social inclusion. Conversely, peace and security matter for social inclusion.

6. Societies incur significant costs from social exclusion. Yet, achieving social inclusion also has costs. Therefore, investing in social inclusion has to be a conscious choice for states and societies.

7. With a strong social contract, social inclusion in Africa is eminently within reach, as hundreds of initiatives across the continent demonstrate. 


\section{Why Social Inclusion? Why Now?}

Africa today is under a global spotlight for its many achievements and its dynamism, but also for its substantial challenges. Poverty has declined; human development outcomes have improved; and dynamic social movements are helping to transform communities and bringing attention to stigmatized issues and peoples. Technological innovation has spread to many remote areas. New policies and programs across the continent have highlighted the importance of social inclusion. Some African countries have led the charge toward progress; for instance, in the past decade, Africa has implemented the most reforms promoting gender equality of any region globally.

Yet, as in other parts of the world, positive developments have been uneven in Africa, too. Many areas and groups have been left behind. For instance, digital technology can leave further behind those who do not have mobile phones or Internet connections. Similarly, improved infrastructure has provided better lives but also carries risks, such as lands being unfairly taken from the most powerless or of damage to the environment or livelihoods. Improvements in education and health can be concentrated in certain locations and for some groups. Areas that experience state and societal fragility also fall behind in a spectrum of development outcomes.

The push toward social inclusion has garnered extensive support over the past several years. The rallying cry of the Sustainable Development Goals (SGDs) leave no one behind - has generated a groundswell of demands and actions at multiple levels. During the post-Millennium Development Goals conversations, the World Bank published its flagship report on social inclusion, Inclusion Matters: The Foundation for Shared Prosperity (2013). The report clearly defined social inclusion. More recently, the World Bank Group (WBG) announced its new Regional Strategy for Africa, ${ }^{1}$ which also is rooted in the tenets of social inclusion. The upsurge of thought and action both within the World Bank and globally has led to several structured engagements between the WBG and a range of its partners. For example, the WBG has conducted regular Systematic Country Diagnostics (SCDs) for each of its partner countries that have shown social inclusion issues to be intrinsic to, but not the same as, poverty reduction. This report builds on these diagnostics as well as other documentation.

The report is intended for a wide array of readers, including governments, the private sector, civil society, academics, and media, and others. It is also expected to influence the ways that the Bank Group conducts its business in Africa. Like all Regional reports, it can do only limited justice to the vast heterogeneity of the continent. 


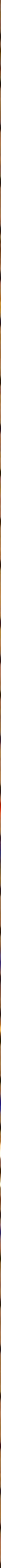




\section{Social Inclusion: A Primer}

The term social inclusion (or just inclusion) has gained inexorable traction in development and broader policy debates. Thus it is important to define what we mean. This report defines social inclusion as the process of improving the terms for individuals and groups to take part in society (World Bank 2013). In articulating social inclusion, this report emphasizes disadvantage based on social identity. Although such emphasis can be politically sensitive, acknowledging that disadvantage often is based on social identity is important to advance social inclusion. Markers of social identity can be derived from gender, age, disability, sexual orientation, gender identity, location, occupation, race, ethnicity, religion, or citizenship status, among others. Nevertheless, no single identity totally describes an individual. The intersection of identities bestows the real advantage or disadvantage. In answer to the question, "Inclusion in what?" the World Bank (2013) answers: in markets, services, and spaces. Markets comprise land, housing, labor, and credit. Services comprise, among others, education, health, transport, water, social protection, electricity, information, communication, and technology. The notion of space encompasses both physical space and space in a broader sense: social, political, and cultural spaces all solidify exclusion or foster inclusion. Moreover, social inclusion enhances the ability, opportunity, and dignity of individuals and groups to take part in society. The importance of ability and opportunity long has been recognized by development economists. However, the social inclusion perspective draws particular attention to the idea of dignity, which, when compromised, can have severe and unexpected consequences for individuals and groups and for society and the economy as a whole.

This report frames its key questions using the approach of the Social Inclusion Assessment Tool (World Bank 2017d; Das 2016). It asks, in the wake of the enormous advances that Africa has made over the years, who is excluded, from what, how, and why. It follows the analysis by highlighting what has been attempted in African countries' quest for social inclusion. The report highlights the major trends and transitions that shape the context for social inclusion in Africa.

Building on recent evidence and using data from the Demographic and Health Survey (DHS), World Development Indicators (WDIs), Afrobarometer surveys, and World Values Survey (WVS), the report highlights key issues and identifies groups who may be left behind. Furthermore, it points to the processes that underlie exclusion and inclusion and reflects on attitudes and perceptions. The report addresses important questions: Who are the key actors? What are some of the innovations that promote social inclusion in Africa? What evidence do we have on what has made a positive difference? Finally, the report gives directions on framing the right questions for inclusive solutions (figure 0.1). 
Figure 0.1 The Social Inclusion Framework

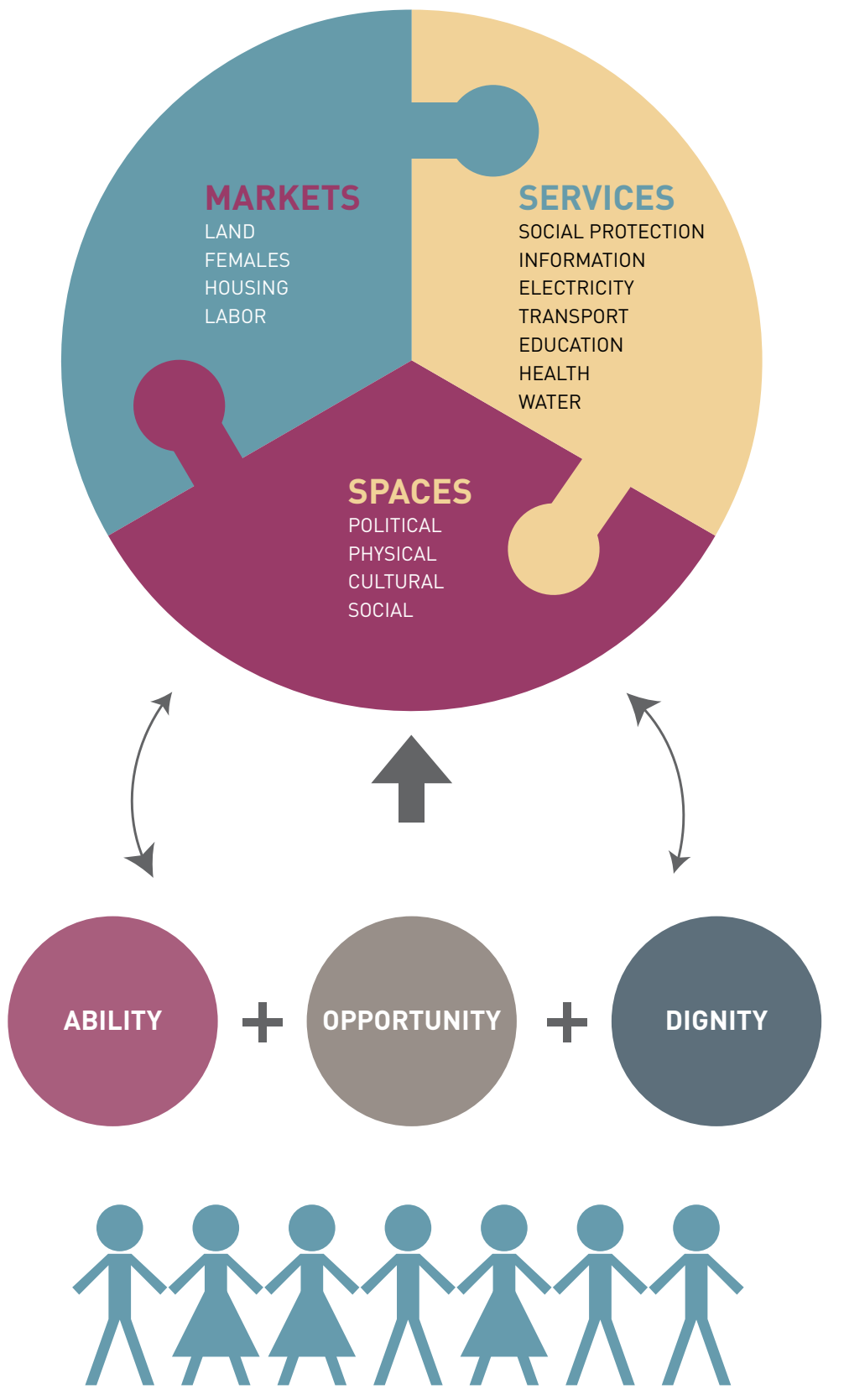

Source: World Bank 2013. 


\section{To sum up, this report:}

- Places the notion of social inclusion front and center in an analysis of Africa's achievements and its challenges in confronting poverty reduction and human capital formation.

- Takes an interdisciplinary approach, using evidence from varied sources and bringing empirical weight to issues that are being debated through advocacy and contestation.

- Addresses with granularity who is left out, from what, and how. The report garners and integrates evidence on historically invisible groups such as persons with disabilities, persons with albinism, LGBTI persons, certain ethnic and occupational groups, persons who live in "lagging areas," and especially young people. The report also focuses on the intersectionality of social identity.

- Is grounded in the experience of African countries but also shows that Africa's social inclusion challenges are neither unique nor exceptional.

- Shows the channels through which individuals and economies may incur the costs of social exclusion. The report points out that these costs may be direct or indirect, short or long term. When taken cumulatively, the costs can impede the best efforts of governments and societies.

- Provides examples of the remarkable innovations that abound in Africa and of the policy and programmatic movement toward social inclusion. The report shines a light on areas in which deeply entrenched norms and practices have changed.

- Asserts that social inclusion must be a conscious choice for societies and their governments. It must be based on a clear social contract that recognizes both the costs and benefits of policies and interventions that move toward social inclusion.

\section{What Does Social Inclusion Add to Poverty Reduction?}

Most discussions of social inclusion in Africa have taken place within the context of poverty reduction and in response to humanitarian crises. These discussions are driven by the fact that, despite significant progress in decreasing poverty, more than 400 million people are estimated to still live in poverty (Beegle and Christiaensen 2019). Poverty is an outcome; social exclusion is both a process and an outcome. Processes of exclusion can have long-term effects on mindsets, psyches, and the dignity of subordinate or excluded groups. This exclusion in turn affects the ability of these groups to access the chances given to them. Slavery was one of the most egregious processes of exclusion, as were apartheid 
and untouchability (in South Asia). Less overt practices also can have devastating effects on subordinate groups. Consider bullying as an example of an insidious exclusionary process: the world over, some groups are bullied into subjugation. These groups may include lesbian, gay, bisexual, transgender, and intersex (LGBTI) people; individuals who may speak with a different accent than the dominant group's, eat different food, or have other unique characteristics. Bullying can stymie the educational opportunities of those subject to it, cause serious mental health problems and other devastating consequences, and ultimately lead victims to opt out of a system that they perceive as condoning bullying. All this may, and does, occur in an otherwise well-functioning educational system. In other words, victims of bullying may not be affected by poverty but in such cases they are affected by exclusionary practices that prevent them from reaching their full potential. As another example, a person with mobility limitations who is part of rich household is not affected by poverty but may be excluded from doing activities outside the home by inaccessible infrastructure and services. Therefore, it is important to acknowledge that although social exclusion may well have roots in poverty, at times, it does not. Social inclusion adds another dimension to the discourse on poverty and inequality.

\section{Box 0.1 Does Ethnicity Matter for Poverty in Africa?}

Using the Demographic and Health Survey (DHS), which has data on ethnicity and wealth based on a household's ownership of selected assets, we analyzed data from nine countries: Democratic Republic of Congo, Kenya, Malawi, Mozambique, Nigeria, Sierra Leone, South Africa, Uganda, and Zambia. Looking at the 10 largest ethnic groups in rural and urban areas, we found that ethnicity does indeed matter for wealth outcomes, but that the effects are more pronounced in rural areas than in cities and towns.

- In all nine countries, certain ethnic groups are overrepresented in the poorest wealth quintile. Disparities between ethnic groups are larger in rural areas than in urban areas.

- Size of the ethnic groups does not seem to matter. This is unsurprising, because across the world, the size of an ethnic group seldom has a linear association with its welfare outcomes.

- The greatest dispersion along ethnic lines in the poorest quintile in rural areas appears to occur in Kenya, Nigeria, and Uganda, followed by lesser dispersion in Mozambique and Zambia. In urban areas, the greatest dispersion is found in Kenya, Mozambique, and South Africa. Although the overrepresentation of some ethnic groups in the lowest wealth quintile is more pronounced in some countries than in others, this may or may not reflect absolute gaps in wealth between these groups. 
Asking "who are the poor?" and breaking down the poverty numbers, we find greater complexity. A case in point is the relationship between gender and poverty, which has a long tradition of analysis. Overall, women are not necessarily poorer than men, nor are male-headed households necessarily better off. Moreover, in many countries in Africa, female-headed households have experienced faster poverty reduction than male-headed households (Milazzo and van de Walle 2017).

However, more nuanced findings emerge when we look at gender jointly with age and marital status: young married women, but more so those who are young and widowed, are especially vulnerable (Milazzo and van de Walle 2017). Similarly, a recent analysis in Kenya found that compared to men, poverty rates are higher for women who are separated, divorced, or widowed (World Bank 2018c). Yet, older men are on average 8 percentage points poorer than their female counterparts in Africa (Munoz Boudet and others 2018). In addition to gender, other markers such as disability status, race, and ethnicity also matter for poverty.

\section{Africa Is Striding: Who's Left Behind?}

Social, economic, and political transformations are sweeping the African continent. We discuss transitions under some broad categories: demographic changes and their relationship to the accumulation of human capital; economic changes, of which poverty reduction is a big part; spatial transitions and their social ramifications, including urbanization, spatial inequality, and climate change; the growth of technology and its implications for social inclusion; and the pervasive nature of conflict and fragility, with its implications for a range of outcomes. Finally, we draw attention to the nature of political and civic participation and dynamic social movements.

\section{Demographic Trends and the Accumulation of Human Capital}

Africa has the fastest population growth in the world, but fertility is falling in almost every country. Half of the population in the Region is under 25 years of age; by 2050 , the continent will have 362 million young people who are between 15 and 24 years of age (World Bank 2014). Simultaneously, many African countries will see aging of the population: by 2050 , Africa's over- 60 population is expected to more than triple, from 69 million in 2017 to 226 million (UN DESA Population Division 2017a). Although youth inclusion is the immediate challenge facing the Region, the inclusion of older cohorts of Africans will soon be a part of the picture. Nevertheless, today Africa's growing young population has the potential to dramatically drive development and further reduce poverty if the right policies and opportunities are in place.

As with fertility, Africa has seen improvements in health and longevity, but underfive mortality is still high. Children's survival until age five is a core indicator of welfare, but also has other ramifications: for example, high rates of infant and

8 OVERVIEW 
child mortality are associated with higher fertility. Moreover, countries with high levels of child mortality are bogged down by the most basic imperative of keeping children alive so are less able to invest in human capital. Based on United Nations (UN) child mortality estimates, according to the Our World in Data project and AfricaInData.org, there has been a sharp decline in child mortality from 1980 to $2015 .^{2}$ In fact, compared to other Regions, Africa has seen the fastest decline between 1990 and 2016. Despite these improvements, Africa still has the highest under-five mortality rate, at 78 deaths per 1,000 live births in 2016. In other words, approximately 1 child in 13 still dies before her/his fifth birthday (Suzuki and Kashiwase 2017). There is considerable variation across countries, and fragile states have the highest rates of under-five mortality.

In education, too, Africa has made significant progress, but, as in other parts of the world, there are stark inequalities in educational outcomes based on identity markers. The average primary school gross enrollment ratio in the Region increased from 68 percent in 1990 to 98 percent in 2015, and the number of enrolled students grew from 63 million to 152 million. Nevertheless, despite the increase in primary school enrollment rates, an estimated 52.3 million primary, and lower secondary school-age children (ages 6-14 and 7-15) are out of school, accounting for 45 percent of the world's out-of-school child population across the world (Bashir and others 2018). Literacy is the most basic educational outcome, yet some people are left out. There is a significant gap in literacy between males and females. Western Africa has the highest gender gaps, and Southern Africa has the lowest.

The overlay of gender with other identity markers confers additional disadvantage in education, as it does in other outcomes. Using census data, Taş, Reimão, and Orlando (2014) show that ethnic minority women in Senegal and Sierra Leone suffer cumulative disadvantages in literacy, primary school completion, and secondary school completion. In Senegal, for example, women are 10 percentage points less likely to complete primary school for being female, 1.6 percentage points for being ethnic minority, and an additional 3.8 percentage points for being ethnic minority women. Therefore, cumulatively women of ethnic minority groups are approximately 15.4 percentage points less likely to complete primary school than men belonging to majority ethnic groups in Senegal. In South Africa, despite significant progress since the end of apartheid, education outcomes among black and colored South Africans remain low. Although the white population reached close to full attainment of 12 years of education in 1920, the black population has yet to achieve that level today-100 years later-perpetuating the legacy of a racial divide in education in South Africa, which remains a main driver of poverty and inequality (World Bank 2018f, 13). The Benin Systematic Country Diagnostic (SCD), similarly, notes that the lack of maternal language teaching in primary school puts indigenous children at a disadvantage and leads them to abandon school prematurely (World Bank 2017b, 57). 


\section{Economic Transitions: Poverty and Employment}

The period since the 1990s has seen an impressive reduction in poverty. However, during the same period, absolute numbers of the poor have increased dramatically. Although the poverty head count declined steadily from 57 percent of the African population in 1990 to 41 percent in $2015,{ }^{3}$ the absolute number of people living in poverty increased from approximately 278 million to over 413 million. There is significant divergence in performance across African countries, driven by several factors, among which fragility, conflict, and endowment of natural resources stand out (Beegle and others 2016).

\section{Spatial Transitions and Social Implications}

Africa's social geography is changing rapidly. For example, Africa is the fastest urbanizing region in the world (figure 0.2 ). Approximately 472 million people live in cities and towns-a number that is expected to double over the next 25 years (Lall and others 2017). There are, however, large subregional variations. Most people in North and Southern Africa already live in cities. West Africa is projected to reach an urban majority just after 2020. In contrast, in East Africa, urbanization rates are still below 20 percent (UN-Habitat 2014). Nigeria is among the top three urbanizing countries in the world. Together with India and China, Nigeria is estimated to account for 35 percent of the projected growth of the world's urban population from 2018 to 2050, adding 189 million urban dwellers (UN DESA Population Division 2019).

Urbanization holds both prospects and challenges for social inclusion. Migration from villages to cities and towns tends to be accompanied by aspirations for a new life; greater social and economic mobility; and increased access to markets, services, and spaces. Migration also often means separation from family and social networks and loneliness for those who do not have networks in their new abodes. A study from South Africa shows that rural-urban migration between 2008 and 2012 was accompanied by an 8.3 percent decrease in the subjective well-being of migrants (Mulcahy and Kollamparambil 2016). Furthermore, because cities often lack careful planning, approximately 60 percent of Africa's urban population live in informal settlements, compared to 34 percent in other developing countries (UN DESA Statistics Division 2015; cited in Lall and others 2017, 38). Finally, informal workers such as waste pickers, domestic workers, and street vendors experience serious barriers to doing business in most cities. On the other hand, cities often provide a more anonymous space than do rural areas and so enable individuals from excluded groups to escape discrimination and to pursue job and education opportunities that they would not have had in a rural context. Although additional research is needed to understand the mechanisms through which these outcomes obtain, box 0.2 explains that wealth disparities among ethnic groups are less pronounced in urban than in rural areas. 
Figure 0.2 The Coming of the Urban Age, 1950-2050 (\%)
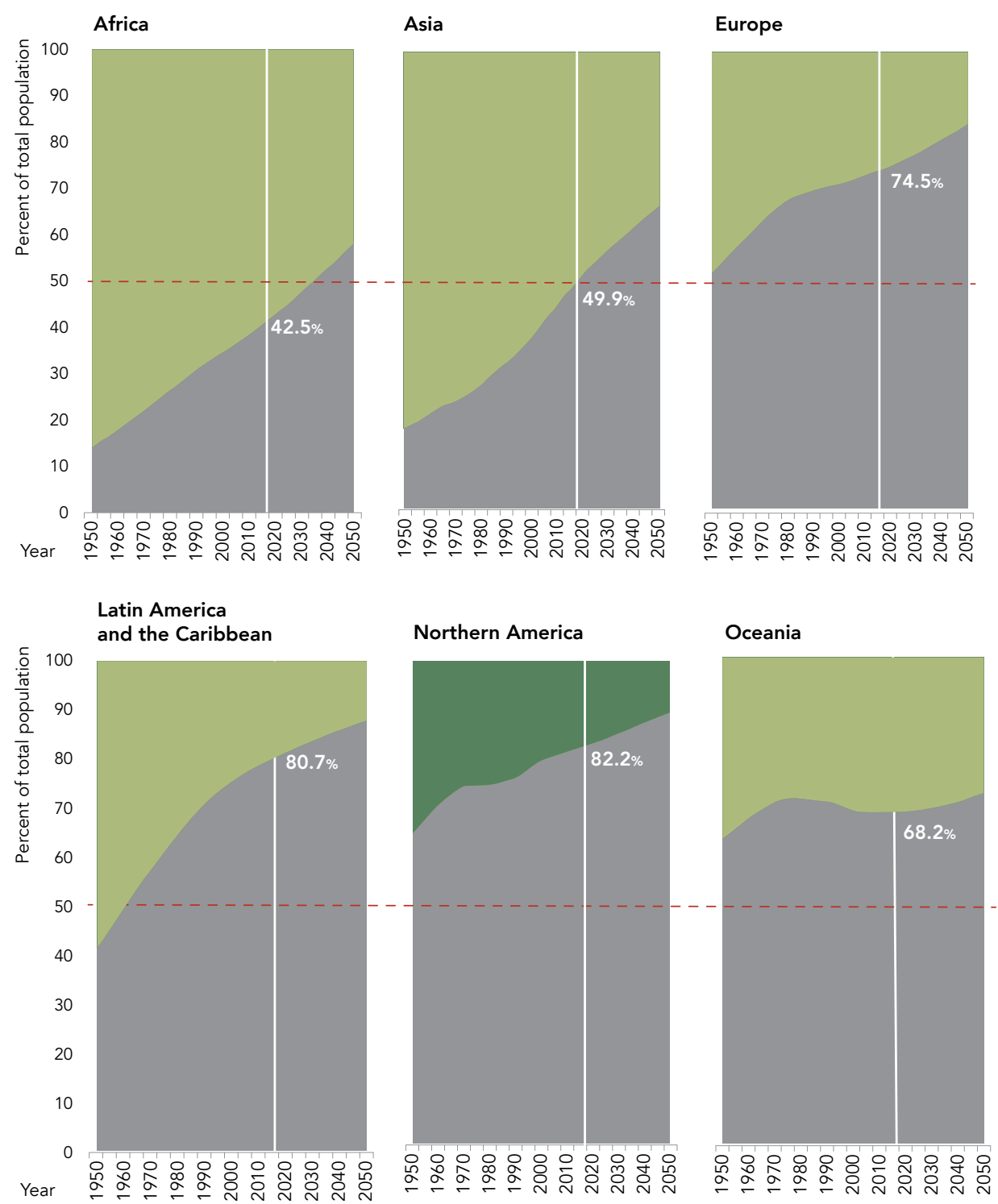

Urban population Rural population

Source: UN DESA Population Division 2018. 
At the same time, ethnic groups and migrants tend to cluster residentially and occupationally in urban areas, with varying effects for social inclusion.

Although considerable attention is given to Africa's urban growth and advances in service delivery, evidence also exists that location matters and that many areas lag behind. In general, countries and areas that are experiencing conflict or

\section{Box 0.2 Disability in Africa: The Importance of Advocacy, Data, and Analysis}

Approximately 15 percent of the world's population has disabilities. Africans are no exception. Yet, intervening on behalf of persons with disabilities requires nuanced understanding of disability and of the ways in which type and intensity of disability, gender, place in the life cycle, location, ethnicity, sexual orientation, gender identity, marital status, socioeconomic status, and other factors intersect to convey disadvantage or advantage.

The disability rights movement in Africa arguably is one of the most dynamic contemporary social movements in the continent. Using the axiom, "Nothing for us without us," the movement has influenced budget allocations and research priorities, raised awareness, and helped reduce the widespread stigma against persons with disabilities. The advocacy movement for albinism also is unfolding before our eyes.

The importance of data and analysis has benefited from advocacy and, in turn, strengthens the hand of advocacy movements. The availability of data in some African countries has enabled an empirical focus on the poorer outcomes for persons who have disabilities. Several studies show that persons with disabilities are more likely to be self-employed in agriculture and less likely to be employees (Hoogeveen 2005; Mitra 2018). There also are variations in employment outcomes across different types and intensities of disability. In a study using data from Ethiopia, Malawi, Tanzania, and Uganda, Mitra (2018) found the largest gaps in Tanzania. There, 53 percent of persons with severe functional difficulties are employed, compared to 85 percent of persons with no functional difficulty. Poverty outcomes are similarly nuanced: "...while persons with functional difficulties are a disproportionately large share of the poor, not all persons with functional difficulties are poor" (Mitra 2018, 156).

There also is evidence on lower educational attainment of persons with disabilities in Africa (Eide and Mmatli 2016; Filmer 2008; Hoogeveen 2005; Loeb and Eide 2004; Loeb and others 2008; Mitra 2018; Mitra and others 2013; Mizunoya and others 2016). When disability status is combined with gender, we see the real effects of intersectional disadvantage. Outcomes differ further by type of disability, but lack of reliable data presents serious constraints to analysis and action. For instance, data on intellectual disabilities are particularly scarce, as are services for persons with such disabilities. 
fragility have poorer outcomes than do others. Clearly, there are lagging regions within countries, and people who live in such regions may have other defining characteristics, such as belonging to particular ethnic or other groups. Across the world, lagging areas also are those in which people have less voice and political power than in other regions. African countries are no exception. The popular discourse in many African countries makes explicit links between political power and uneven regional development, pointing to the fact that areas with better political connections to those in power tend to fare better.

Finally, the majority of Africa's population still lives in rural areas, and there is a significant rural-urban divide in opportunity. For example, approximately 56 percent of the rural population around the world lack health coverage, compared to 22 percent of the urban population, with the most deprived rural population living in Africa (Scheil-Adlung 2015, 6). Within rural areas, exclusion from health services also may be more severe for women, the elderly, some ethnic groups, and migrants (Scheil-Adlung 2015, 30). In South Africa, despite provision of free antenatal care, nonwhite women and those living in rural areas are less likely to receive antenatal care or to have a skilled attendant present during delivery than white women in urban areas (Burgard 2004; Say and Raine 2007; Silal and others 2012; all cited in World Bank 2013, 95).

Climate-related transitions are likely to affect many aspects of life globally, and certainly in Africa. Extreme weather events destroy infrastructure and affect livelihoods, health, education, and general well-being. These extreme events could reverse many of the gains that African countries have made. Some climate events also contribute to large-scale, involuntary population movements. Africa is expected to host 86 million persons who likely will migrate due to the effects of climate change by 2050 (Rigaud and others 2018). Rapid-onset events such as extreme storms or floods tend to lead to short-term displacement, followed by return to affected areas, although they also can generate a combination of shortand longer-term displacement and out-migration. In contrast, slow-onset events including droughts and desertification, such as of the Sahel, tend to lead to gradual, long-term out-migration. Many internal migrants move to major cities so that internal migration is a significant contributor to urbanization (Tacoli and others 2015; cited in Rigaud and others 2018, 18). Nairobi is an example of a city likely to see increased climate-driven in-migration. Low-lying cities, along with coastlines vulnerable to sea level rise and areas of high water and agriculture stress, also are at risk of climate-induced out-migration. Addis Ababa and Dar el Salaam are among the cities likely to see dampened population growth due to rising sea level and storm surges (Rigaud and others 2018). As we design programs for adaptation to climate change and mitigation of its impacts, we need to be cognizant that emergencies often exacerbate existing inequalities and asymmetrical power relations and that both prevention and response need to take them into account. 
Peace is not just the absence of conflict; peace is the creation of an environment where all can flourish, regardless of race, colour, creed, religion, gender, class, caste, or any other social markers of difference. Religion, ethnicity, language, social and cultural practices are elements which enrich human civilization, adding to the wealth of our diversity. ${ }^{a}$

—Nelson Mandela, 2018

The congruence of conflict and fragility with poorer development outcomes is well understood by policy-makers, aid workers, activists, and communities. Individuals and groups who reside in areas prone to, or in the midst of, conflict struggle for access to markets, services, and spaces. The least powerful among them sometimes face terrible atrocities.

Although neither conflict nor humanitarian emergencies are exclusively African problems or problems that affect only poor and fragile situations, Africa faces some unique challenges. In 2016, Africa saw 3.9 million new internal displacements due to conflict, violence, and sudden-onset disasters. Together with the Middle East and North Africa Region, Sub-Saharan Africa (SSA) hosts the largest numbers of forcibly displaced groups, with a sharp increase over the past several years. For example, although each of the two regions had approximately 8 million displaced people in 2012, this number increased to 21.5 million in the Middle East and North Africa and 18.4 million in sub-Saharan Africa in 2017. Within sub-Saharan Africa, most forced displacement took place domestically: of the 18.4 million displaced people in 2017, 12.5 million were internally displaced persons (IDPs) and 5.9 percent were refugees (Connor and Krogstad 2018).

After controlling for other country traits, countries that were rich in natural resources had 13 percentage points faster poverty reduction than countries that were not resource rich. Between 1996 and 2012, poverty decline in fragile states was smaller when compared to the decline in nonfragile states in Africa. After controlling for a set of country characteristics, poverty reduction in fragile states was 15 percentage points lower than it was in nonfragile states (Beegle and others 2016). A caveat is in order here. Countries that are endowed with natural resources also can fall prey to the "resource curse," which can exacerbate fragility and conflict, unless institutions are robust enough.

Conflict, the threat of conflict, and the pursuant displacement affect both the displaced and their host communities. To start, although displacement comes with tremendous suffering, fleeing can mitigate the detrimental effects of conflict (Etang-Ndip and others 2015), and displaced persons are not always the poorest (Beegle and others 2016). Moreover, host communities are affected by the inflow of forced migrants; and in some places, especially in remote and underdeveloped borderlands, the hosts are poorer than the internally displaced persons (IDPs) and refugees. 
The effects of displacement on host communities take place through different channels. The Kakuma refugee camp in Kenya, for instance, is based in Turkana County, which has a poverty rate of close to 80 percent, compared to the national average of 36 percent (KNBS 2015). In Tanzania, the 1990s influx of refugees from Burundi and Rwanda adversely affected Tanzanian casual laborers due to the increased labor competition and surging prices of various goods.

Women and young girls in conflict-affected areas may have greater exposure to sexual violence and may be actively targeted by opposing groups. Evidence from the Great Lakes Region (GLR) shows that female ex-combatants who try to reintegrate in their communities are stigmatized. One underlying cause is their increased exposure to sexual violence during conflict. In some parts of the GLR, this stigma is so strong that some female ex-combatants avoid selfidentifying as ex-combatants and so forfeit their access to targeted assistance for ex-combatants (Rhea 2014, 28).

Finally, the effects of climate change may exacerbate inequality and exclusion. These effects are pronounced in some areas. When extreme weather events hit areas with high levels of state and societal fragility, the whole population suffers, but some groups are affected more. These groups may include persons with disabilities, young children and the elderly.

a. UN DPI 2018.

\section{Technology Can Spearhead Social Inclusion, but Can Leave Some People Further Behind}

Now is the global age of technology, but its benefits to countries, regions, communities, and households depend on whether they have access to this potent medium. In many respects, Africa seems to have leapfrogged into the digital economy, but there is great variation across countries. For example, despite a relatively faster increase in mobile cellular subscriptions in fragile countries, the number of mobile cellular subscriptions remains higher in nonfragile countries (Calderon and others 2019, 49). Similarly, financial technology ("fintech") also has expanded across Africa. Twentyone percent of adults in Africa now have mobile money accounts, with numbers having doubled since 2014, the highest share of any region globally (DemirgüçKunt and others 2018). M-PESA is one of the earliest and perhaps most prominent examples of fintech in Africa. Digital technology also can spearhead employment, as the recent World Bank report on the future of work in Africa points out (Choi and others 2019). 
As would be expected, the proportion of individuals who have access to the Internet in each African country is highly correlated with the country's income level. South Africa is the only African country in which almost 60 percent of the population is online (Pew Research Center 2018b). Furthermore, the Pew Research Center Spring 2017 Global Attitudes Survey in 6 countries showed that males and persons with higher education and higher income levels were more likely to use smartphones (figure 0.3). This means that nonusers of smartphones are left out of many opportunities to access markets, services, and spaces.

\section{Political Participation and Social Movements}

Social inclusion often advances when individuals or groups who feel excluded assert their agency through social and political participation. The nature of such participation has changed in many African countries. Recent surveys draw attention to declining participation in formal political and civic processes, particularly among youth and women in Africa; but the picture is complex. The likelihood of voting is lower among African youth than among their elders, and data from the Afrobarometer survey suggest that the political participation of young people has declined over the past decade and a half (Lekalake and GyimahBoadi 2016). African youth also are less likely than their elders to participate in civic activities. Young women participate even less in public affairs. Compared to their male counterparts, they report significantly less interest in public affairs and discussions around them (Lekalake and Gyimah-Boadi 2016).

Such decreasing participation in formal political processes may signal several different things. It may mean disenchantment or lack of faith in the processes. It also may mean that young people use different channels to express their preferences. The importance of social media bears special mention here. The Internet affords anonymity, which allows groups who would otherwise not have a voice to express themselves through digital media. Youth in Africa are far more active on social media and digital platforms than are their elders. The rise of social movements also shows that young people may use other civic channels to act on what they care about. Even so, the likely disenchantment with political processes may be an indication of broader disenchantment with the state.

Although participation in formal political processes seems to be declining, social movements continue to raise the profile of social inclusion across Africa. That Africa has a vibrant history of social and political movements is well known. These include the legendary movements for independence and decolonization, the critical movements in academia against Eurocentrism, and movements for peace and civil liberties and against various economic policies. The 2015/2016 studentled Fees-Must-Fall-movement in South Africa points to the fact that, although young people may not participate in formal political processes, they nevertheless 
Figure 0.3 Smartphone Use by Gender, Age, Education, and Income by Country, 2017 (\%)

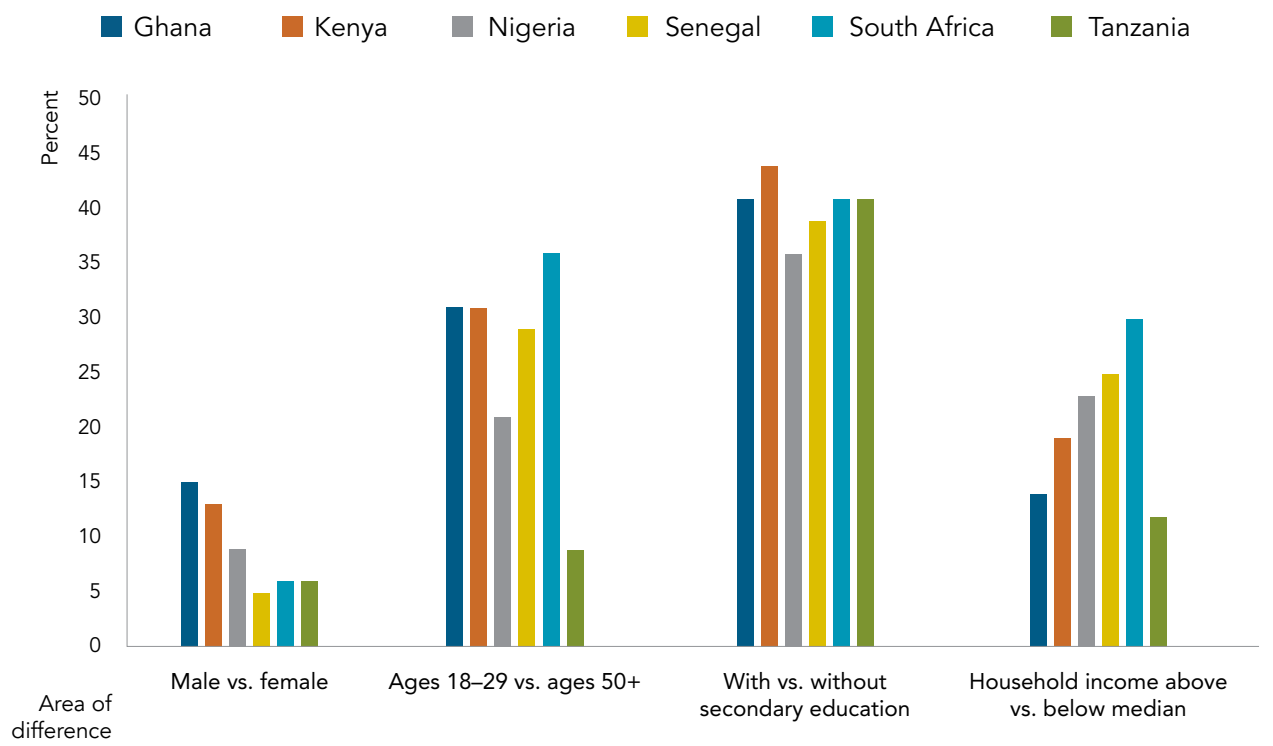

Source: World Bank calculations based on data from Pew Research Center, Spring 2017 Global Attitudes Survey (Silver and Johnson 2018).

Note: The graph displays the percentage differences in mobile phone ownership, between men and women, different age groups, people with different educational attainment, and those from different income groups. For age, differences are between the youngest (18-29 years old) and the oldest (50+ years) age groups sampled. For education, differences are between those with less than secondary education, and those with secondary education and above. For income, differences are between those with an income below the approximate country median, and those at or above the approximate country median.

are politically very vibrant. Similarly, the movement that asserts the rights of indigenous peoples to their culture, lands, and unique identity also has a strong history. Two contemporary social movements also deserve mention: the first brought attention to HIV/AIDS, and the second to the rights of persons with disabilities. Each demonstrates that advocacy and public education help to change norms and practices. Furthermore, civil society also has galvanized citizens against corruption in several countries in Africa. In South Africa, for instance, civil society organizations (CSOs) started campaigning against corruption in the late 1990s, which led to the first anticorruption summit by the government in 1999 and the launch of the National Anti-Corruption Forum in 2001. The latter marshalled civil society, business, and government (Essoungou 2013). In Kenya, 
CSOs mobilized protests (Occupy Parliament) against the salaries of Members of Parliament (MPs) and brought about salary cuts of MPs and the president in 2013. Other countries have had similar forms of protest. Finally, radical feminist movements have gathered strength over the years and have organized to hold the state and society accountable for the poorer opportunities for girls and women.

\section{How Does Social Exclusion Play Out in Africa?}

Fundamentally, social exclusion is about power relationships. The world over, societies devise intricate ways to solidify social structures and uphold the status quo. Attitudes, beliefs, perceptions, and practices, including superstitions, stigmas, and rituals, are among the processes through which societies assign some groups to subordinate, and others to dominant, status. Structures and systems comprise, among others, families, communities, legal systems, labor, land markets, and knowledge systems. It is also important to note that structures and processes reinforce one another and are solidified by formal and informal institutions.

Across the world, belief systems, superstitions, stigmas, and other practices bar the inclusion of specific groups. Intimidation and harassment instill fear that prevents some groups from reaching their full potential and "keeps them in their place." Social norms may assign males and females to particular occupations or may render some practices (or bodily functions) "unclean." Other practices such as stigma and shunning may render invisible groups such as persons with disabilities or persons with albinism. Relatedly, some cultures may hide persons with disabilities. This lack of visibility can have several consequences, including not counting these groups in official statistics. Thus, they remain hidden and unattended to at both the familial and the national levels. Often, these exclusionary practices are sanctified by religion or by those who interpret religious texts. In many cultures, persons who have a nonconforming sexual identity are excluded to the point of being criminalized. Excluding and criminalizing them often is upheld invoking religious texts. Taboos surrounding menstruating women are common in many parts of the world; beliefs about purity and pollution exclude certain groups at certain times or at all times. Overall, these practices are mechanisms to enforce social order and control.

Why do processes and practices matter for policies and programs? They matter because they affect the actions and behaviors of dominant and subordinate groups, of service providers, and of the state itself. For their part, groups who historically are excluded may respond in different ways. One possibility is that they "opt out" or reject the terms on which they are included. Excluded groups may drop out of school or the labor market or disengage from political processes. A second, related possibility is that grievances may accumulate, creating social tensions and having long-term effects on the economy and society. A third possibility is that 
groups who feel excluded organize themselves into formidable lobbies and use the political space to demand change. Processes and structures have strong effects on feelings and perceptions of individuals and groups. In our quest to leave no one behind, attain universal access, and eradicate extreme poverty, we need to be cognizant of behavior, which is the first step to lasting change. Yet, even as we know that belief systems, feelings, and perceptions affect behaviors, measuring and interpreting such systems and the underlying affective foundations is a complex undertaking that requires a deep understanding of the context as well as robust data and analytic tools.

Violence is one of the gravest manifestations of exclusion and a mechanism to show subordinate groups "their place." Physical offensives often are justified by an intricate set of beliefs and taboos that serve to create a "logic of exclusion," which may be sanctified by religion. For example, many religions regard a woman's place as being in the home and may implicitly condone violence against women who dare to transgress this norm. Overall, the acceptance of domestic violence against women remains high in Africa, although acceptance has decreased over time. Beegle and others (2016) find that, between 2000-2006 and 2007-2013, acceptance of domestic violence by women in Africa declined by almost 10 percentage points. Nevertheless, at 30 percent, acceptance of domestic violence in the Region is still exceptionally high. There is considerable heterogeneity across countries, however. Some practices, such as female genital mutilation (FGM), which hold cultural value for some groups, also are examples of violence and extreme symbols of exclusion and have devastating effects on health, education, and life chances. FGM can have direct effects on reproductive and mental health and cause infectious disease. Sanctified and upheld by religion and culture, FGM serves to solidify the subordinate status of women and girls.

Culture plays a central role in the political, economic and social life of communities. Indeed, culture may be the missing link in the development of Africa. Culture is dynamic and evolves over time, consciously discarding retrogressive traditions, female genital mutilation (FGM), and embracing aspects that are good and useful.

-Wangari Maathai, 2004

Attitudes, perceptions, and feelings can point to the extent to which people feel included in markets, services, and spaces. Belonging to an ethnic group can create affinity and comfort among members. In the same vein, expressing affinity with a national identity is an indication that respondents feel connected to their country. The Afrobarometer 2014/2015 asked respondents who disclosed their ethnic identity at the beginning of the survey whether they regarded their national or their ethnic identity as more important. The results are instructive: only a small 
minority of respondents appeared to give precedence to their ethnic identity alone. Feelings of national or ethnic identity may be driven by several factors related to the extent of pluralism or of competition in society, the history of the nation-state or of conflict, and the current political milieu. These questions also could elicit socially or politically acceptable responses so they should not be taken as "truths" and must be interpreted with caution.

In many parts of Africa, negative feelings about the state are widespread. This disaffection is apparent in newspaper columns, social media, and casual conversations. Disaffection also is reflected in perception surveys. The Afrobarometer 2014/2015 asked respondents how often they feel that people in their country are being treated unequally "under the law" (that is, by the state). Their answers likely indicate grievances and feelings of injustice and exclusion. Figure 0.4 presents the results. There are, as expected, large variations across African countries. Botswana and Namibia stand out as countries in which almost 60 percent of the respondents felt that people were never or rarely treated unequally under the law. In Malawi, Mauritius, and Tanzania, approximately 50 percent of respondents felt that unequal treatment under the law was never or rarely manifested. At the other end of the spectrum, in Mali and São Tomé and Príncipe, over half the respondents felt that unequal treatment under the law was always manifested. Overall, in most countries, more than half the respondents felt that people were often or always treated unequally under the law.

When the majority of citizens feel that people in their country are treated unequally, it often points to elite capture. In other words, the state is perceived as catering to the needs of a small section of society. In this circumstance, exclusion is not a minority issue but affects many or most citizens. Several recent World Bank Systematic Country Diagnostics (SCDs) in Africa identify elite capture and a lack of public trust as important obstacles to the delivery of inclusive services and a stable social contract more broadly. See, for example, SCDs for Benin (World Bank 2017b), Guinea-Bissau (World Bank 2016), Liberia (World Bank 2018e), and Madagascar (World Bank 2015). Other surveys and anecdotal evidence also point to perceptions that the state and its institutions are opaque and that they benefit only a few. A perception survey conducted by the Pew Research Center found that 64 percent of Kenyans, 63 percent of Nigerians, and 69 percent of South Africans surveyed felt that many jobs go to people with connections (Wike and others 2016).

Emerging evidence shows that, despite serious misgivings about their economies and often about their governments, people living in several African countries have high levels of optimism. For instance, as part of the Pew Research Center Spring 2017 Global Attitudes Survey, roughly half of the Africans (median of 49 percent) and Latin Americans (48 percent) surveyed said their day was "particularly good," whereas other regions overwhelmingly described their day as "typical." 
Figure 0.4 Perceptions of Unequal Treatment under the Law by Country (\%)

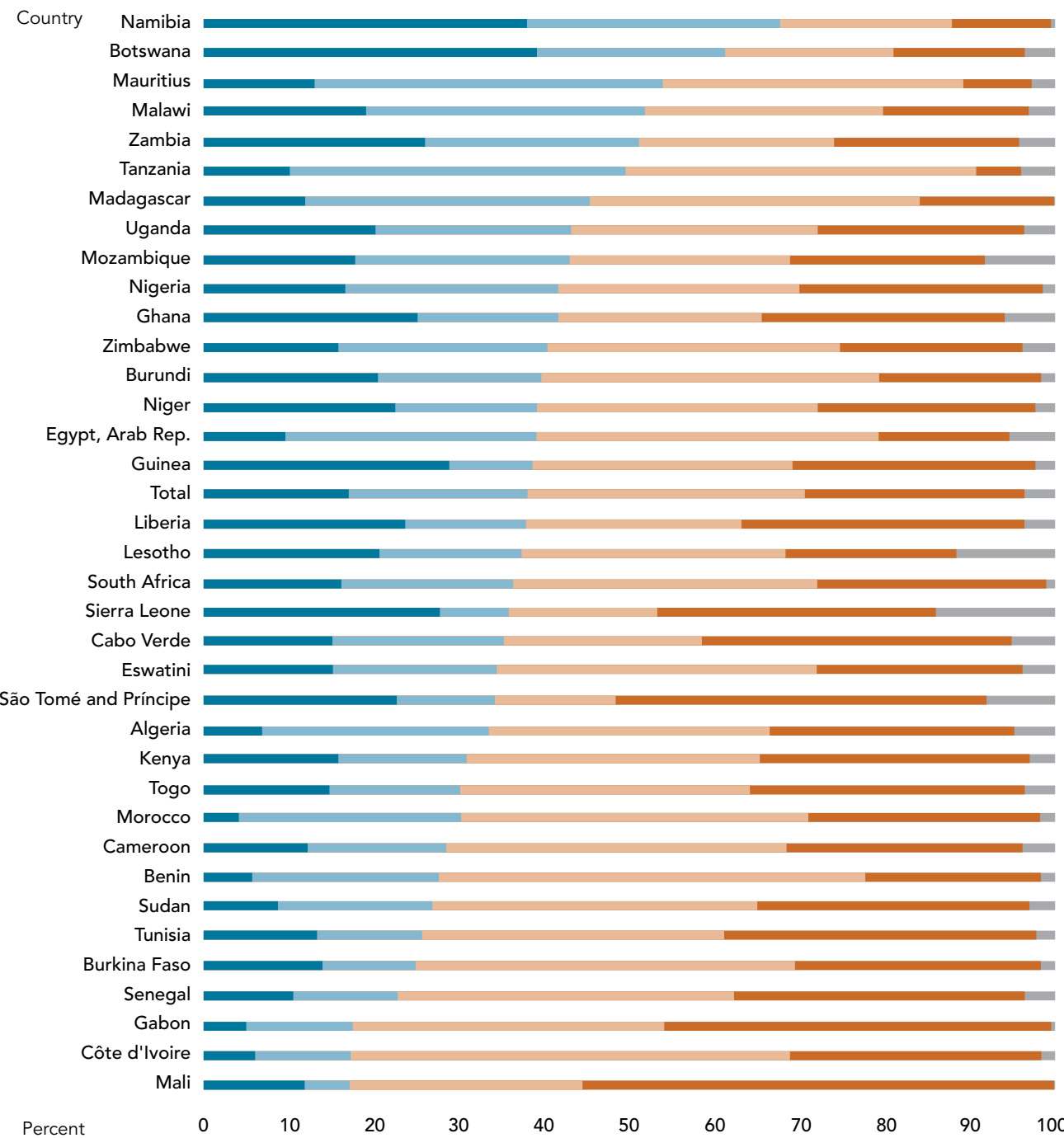
Never
Rarely
Often
Always
Don't know

Source: World Bank calculations based on data from Afrobarometer 2014/2015, Round 6 http:// afrobarometer.org/sites/default/files/summary_results/ab_R6_afrobarometer_global_release_ highlights.pdf.

Note: Respondents were asked: "In your opinion, how often in this country are people treated unequally under the law?" 
Similarly, based on Afrobarometer data, Graham and Hoover (2006) found levels of optimism in Africa that surpassed other regions. The levels of optimism were particularly high among the poorest and most insecure respondents, who had high hopes for the future of their children. In keeping with this finding, the Liberia SCD (World Bank 2018e, 72) cites a 2014 survey that found that most Liberians believe their country is headed in the right direction, driven in part by Liberia's return to relative peace and stability.

\section{Social Inclusion Can Be Achieved If It Is a Conscious Choice for Societies}

Social inclusion is important because exclusion impedes the ability, opportunity, and dignity of some individuals and groups and is costly to societies and economies. Nevertheless, measuring the costs of social exclusion is no mean undertaking. When assessing the cost of exclusion, some estimates focus on specific groups. These groups include women, persons with disabilities, ethnic or racial groups, individuals in same-sex relations, and migrants. This report lays out some of the channels and levels through which costs are obtained. Costs can be surmised at the level of the individual, the household, the group, or the community. Costs also may be estimated at local, subnational, and national levels. The costs of social exclusion may be direct or indirect, short term or long term. The cumulative long-term costs can be significant and can affect the growth trajectories of entire economies. For example, lower earnings or employment outcomes at the individual level may be driven by lower human capital endowments, which in turn may be caused by prior disadvantage in education or by discrimination in hiring or in the workplace (for example, Buckup 2009; Lamichhane and Sawada 2013; Morgon Banks and Polack 2015). The experience of exclusion can have physical and mental health costs at the individual, household, group, and, ultimately, national level (for example, Lereya and others 2015). Finally, foregone benefits also can be costly. Hunt and others (2015) and Hunt and others (2018) find that companies in the top quartile for gender, racial, and ethnic diversity are 15 percent to 35 percent more likely to have financial returns above national industry medians. Gains from the inclusion of excluded groups occur not only from adding workers to the labor force; diversity itself may increase productivity (Ostry and others 2018).

Ultimately, social inclusion must be a conscious choice of societies and governments, made with a clear understanding of the costs and benefits. Investing in an inclusive society is not free and needs concerted action to transform the investment into a win-win. Social programs, for instance, can be expensive and impact fiscal sustainability. Governments often need to make trade-offs, either by cutting costs on other initiatives or by raising taxes. There may be political costs as well because initiatives that focus on historically excluded groups can upset power relations. Governments and politicians need to craft clear social contracts 
with citizens to ensure support for social inclusion. There are examples the world over of citizens willing to pay for a more inclusive society. The most powerful form of support is through the fiscal realm, whereby citizens pay taxes that they know will fund policies and programs for greater social inclusion. For instance, in Brazil, Mexico, and Nepal, there is strong support for social protection programs. In Bangladesh, poverty reduction is recognized as a national priority, with the elite supporting antipoverty initiatives (Hossain and Moore 2002). Tentative evidence from Ghana, Kenya, Nigeria, and Uganda shows that attitudes toward redistribution may be favorable overall (Langer and others 2016).

\section{Change toward Social Inclusion Is within Reach}

How does change take place? Who are the main actors? What are the channels through which progress toward social inclusion is achieved? What can we learn for the future and for the countries that want to make greater progress? We draw from the World Bank's social inclusion framework (World Bank 2013) and address inclusion in markets, services, and spaces. Inclusion how? Here we repeat what we have said earlier in this report: by raising the ability, opportunity, and dignity of individuals and groups most likely to be left out. This report outlines some of the policy and program efforts being made by African countries to pursue social inclusion. Sometimes, documenting process helps others in their quest to design workable solutions. Therefore, we focus on some innovations and generic solutions that African countries have tried.

There are other important drivers of change toward social inclusion in Africa, as elsewhere. These include a host of nonstate actors: religious groups, nongovernmental organizations (NGOs), the private sector, and, most importantly, organizations of historically subordinated groups. Lasting change usually comes when state and nonstate actors join forces. Elites often are part of both state and nonstate actions and play a critical role in propelling social inclusion. The importance of the HIV/AIDS epidemic in many parts of the continent presents an interesting case in point. What started as attention to a public health emergency quickly moved to identify affected groups. These included gay and bisexual men, men who have sex with men (MSM), widows, and orphans. This attention to sexual orientation in many African countries was legitimized because it was linked to a public health crisis, and groups previously invisible were rendered visible. This is not to say that stigma no longer exists, and sometimes the stigma may only have changed its form. Nevertheless, the epidemic was a catalyst. It presented an opportunity that enabled previously excluded groups to mobilize and be partners in the change that policy and programs propelled. Through attacking the epidemic, governments and civil society co-opted elites and community members alike. Innovative methods of using information and communication technology (ICT) to solicit anonymous responses to questions have become increasingly popular. Such 
technology also can be used to amplify voice. In Tanzania and South Sudan, two pilot initiatives referred to as "Listening to Africa" have been highly successful in collecting panel data through mobile phone interviews.

Regardless of which actor sponsors a program that is intended to promote social inclusion, few programs can succeed without community ownership. Communities who own the movement toward social inclusion and can visualize a new society for themselves are most likely to be invested in the success of such programs. Conversely, when programs are designed without community involvement, they may take longer to take off and even face resistance from the community. Abolishing FGM in Burkina Faso is illustrative. Together with criminalizing the practice in 1997, the government implemented a broad array of measures that promoted community ownership of the change. In addition to training lawyers, judges, police, and security officers to ensure their buy-in, the government supported "community patrols," who raised awareness of the harmful consequences of FGM and informed communities of its criminalization.

Most countries in Africa, as elsewhere, have a plethora of policies, programs, and projects to advance social inclusion. These policies may be targeted at certain groups or areas; or they may be universal, accessible to everyone. At the highest level, the constitutions of most countries guarantee equality and basic freedoms. Laws are the next level of actions that promote change; they can be progressive or regressive. Box 0.4 shows that Africa has made the world's fastest progress in enacting laws that promote gender equality. Broad-vision documents, manifestos, and pronouncements give a more defined indication of a government's priorities. Still lower down are policies, which lay out directives and show the clearer path of a government's focus on social inclusion. Many policies signal the groups whom they privilege or ignore by their silence on certain topics or groups or by the intensity of implementation of certain policies. Thus, although policies may

\section{Box 0.4 Legal Reform for Women in Africa}

Africa has implemented the most reforms promoting gender equality of any region globally: 71 reforms over the last 10 years. Most of these reforms (over 50 percent) concerned laws affecting gender-based violence. Burundi, the Comoros, Rwanda, São Tomé and Príncipe, and Zambia all introduced laws that addressed both workplace sexual harassment and domestic violence. Among the top reforming economies in the Region over the past decade are the Democratic Republic of Congo (DRC), Guinea, Malawi, Mauritius, São Tomé and Príncipe, and Zambia (figure B 0.4.1). 
Figure B0.4.1 Improvement in the Women, Business and the Law (WBL) Index, 2009-2018

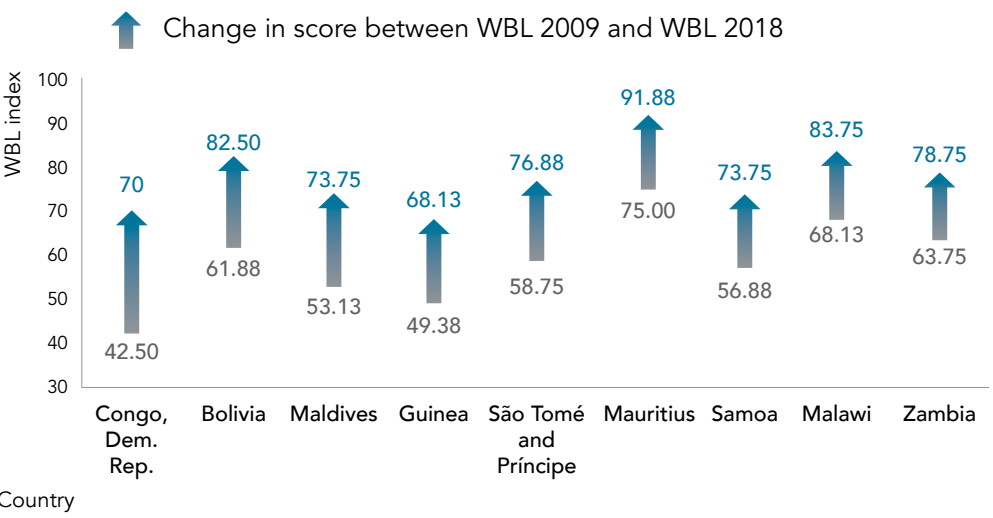

Source: World Bank 2018g, 11, based on WBL database.

Note: $\mathrm{WBL}=$ Women, Business and the Law database.

The Democratic Republic of Congo saw the largest increase in its Women, Business and the Law index (from 42.5 in 2009 to 70.0 in 2018). Improvements in DRC were based on reforms allowing married women to register businesses, open bank accounts, sign contracts, get jobs, and choose where to live in the same ways that men do. The legal requirement for wives to obey their husbands was removed, as were restrictions on women working in specific industries such as mining, manufacturing, and construction. DRC also introduced gender nondiscrimination laws in employment and access to credit.

Mauritius began reforms in 2008 by introducing civil remedies for sexual harassment at work, prohibiting the dismissal of pregnant workers, introducing paid paternity leave, and prohibiting discrimination in access to credit based on gender. The government mandated equal remuneration for work of equal value in 2013 and increased the length of paid maternity leave from 12 to 14 weeks in 2015. Due to these reforms, Mauritius' score increased by 16.88 points: between 2009 and 2018, the female labor force participation rate went up by 6.82 percent relative to men's.

São Tomé and Príncipe introduced a domestic violence law in 2009; implemented a workplace sexual harassment law that included criminal penalties in 2012; and reformed its retirement laws for men and women to entitlement to full pension benefits and making the mandatory retirement age for men and women equal in 2014. Between 2009 and 2018, female labor force participation increased by 1.75 percent relative to that of men.

Source: World Bank 2018g. 
not actively exclude individuals or groups, they may passively do so, either by not expressly indicating who is included or by not investing adequate resources or attention to implementation. ${ }^{4}$ Some examples of policies and programs are presented in table 0.1 .

Well-designed and implemented programs across the globe have changed the face of social exclusion. Of these, social safety nets have a track record of historically shielding households from the negative effects of shocks and, more recently, of building household and community assets. Such programs started in Africa in response to food crises and humanitarian emergencies and still complement emergency responses to crises or shocks, consequently reducing the cost and increasing the effectiveness of humanitarian actions. Social safety nets often provide ready vehicles through which to intervene in crises. In response to the Ebola emergency, governments leveraged the existing modest programs and scaled up cash transfers and public works programs (Beegle and others 2018, 67). Over time, Africa has become a leader in the design and delivery of social safety nets. Every country in the Region has at least one social safety net program. A broad array of programs, loosely classified as "empowerment programs," often are targeted to historically excluded groups and can have large positive impacts. In Uganda, the Empowerment and Livelihood for Adolescents (ELA) program was developed and implemented by Building Resources Across Communities (BRAC) to provide training for small-scale enterprises and education for health and reduction of risky behaviors. The Sahel Women Empowerment and Demographic Dividend (SWEDD) project, which spans Burkina Faso, Chad, Côte d'Ivoire, Mali, Mauritania, and Niger, has used several innovations to attain its objective of empowering women and adolescent girls through access to quality reproductive and child and maternal health services and working with local partners to improve their capacities. The project has garnered the support of religious leaders on child marriage, maternal and child health, family planning, girls' education, genderbased violence, and women's economic and social empowerment. In yet another initiative, the project gives bicycles, school kits, and sanitary kits to girls. The project also organizes coaching classes in select areas so that girls can keep up in school and trains young women in nontraditional trades.

Another way of focusing on specific individuals or groups is through affirmative action or quotas. Special provisions for individuals and groups are common in OECD (Organisation for Economic Co-operation and Development) and nonOECD countries alike. Although sometimes controversial, especially in the context of stubborn group-based inequalities, affirmative action policies still are considered among the more effective policy mechanisms (Langer and others 2016). Many African countries have affirmative action policies for women and persons with disabilities. Uganda enshrined a quota system for Parliament in the 1995 Constitution (Article 78) stating that Parliament should include a woman 
representative in every district, as well as representatives from the army, youth, workers, persons with disabilities, and "other groups as Parliament may define." Similar provisions were made to ensure seats for women in local government (Muriaas and Wang 2012, 311). South Africa, of course, has the most prominent and comprehensive set of initiatives.

The changing development context of the continent, as demonstrated by select regional trends, portends new opportunities and challenges for African countries over the next few decades. First, the decline of poverty almost across the board, the enhancement of education, and the improvements in health have meant (and increasingly will mean) that policy-makers need to focus on those who have not benefited from this aggregate progress. Of these, people who are affected by conflict and fragility stand out, but some groups in nonfragile contexts also are at risk of being left out. These include some categories of women, sexual and gender minorities, persons with disabilities, older persons, some categories of youth and children, certain ethnic and racial groups, and those who live in "lagging" regions. Some of these groups are more assertive; others may have festering grievances.

Second, development spearheads aspiration. As individuals and groups do better, they will seek more. This has implications for how governments respond to these heightened aspirations. The report shows that citizens in many countries in Africa are simultaneously disenchanted with the state and filled with optimism and hope for better lives. As more countries graduate to middle-income status, they will focus on "second-generation" issues of prosperity. In the years ahead, the trends and transitions that shape and tame Africa's dynamism are likely to have significant implications for social inclusion. Although a focus on poverty must be front and center in addressing social inclusion issues, states and societies also will need to consider the drivers of poverty and why some groups are left out.

Africa has made enormous progress toward economic development and social inclusion, but it needs to do much more. Indeed, there are several areas in which some of the fastest progress globally is in African countries. However, as the World Bank (2013) points out, social inclusion is not a linear process. Progress can stall for unanticipated reasons, but it may pick up again. Groups who once were disempowered may gain power and may upstage earlier dominant groups, who in turn may work to impede progress toward social inclusion because it hurts their interests. Social inclusion is always work in progress (World Bank 2013). 


\begin{tabular}{|c|c|c|c|}
\hline $\begin{array}{l}\text { Domain of } \\
\text { inclusion }\end{array}$ & $\begin{array}{l}\text { Channel for } \\
\text { intervention }\end{array}$ & $\begin{array}{l}\text { Illustrative actions targeting } \\
\text { those most likely to be left } \\
\text { behind }\end{array}$ & $\begin{array}{l}\text { Illustrative examples of policies, } \\
\text { programs, and projects }\end{array}$ \\
\hline \multicolumn{4}{|l|}{ MARKETS } \\
\hline \multirow[t]{3}{*}{ Labor } & $\begin{array}{l}\text { Legal } \\
\text { provisions } \\
\text { enabling } \\
\text { access to } \\
\text { the labor } \\
\text { market }\end{array}$ & $\begin{array}{l}\text { Ensuring access of } \\
\text { excluded groups to } \\
\text { jobs and their ability to } \\
\text { open bank accounts and } \\
\text { businesses. } \\
\text { - Removing the obligation } \\
\text { of women to obey their } \\
\text { husbands. } \\
\text { - Lifting restrictions on } \\
\text { women working at night. } \\
\text { - Enshrining } \\
\text { nondiscrimination } \\
\text { in employment law } \\
\text { (including hiring, pay, and } \\
\text { promotions). } \\
\text { Banning harassment at } \\
\text { work. } \\
\text { - Establishing legal remedies } \\
\text { for sexual and other } \\
\text { forms of harassment in } \\
\text { employment. } \\
\text {. Prohibiting dismissal of } \\
\text { pregnant employees. } \\
\text { Establishing paid maternity } \\
\text { and paternity leave. }\end{array}$ & $\begin{array}{l}\text { Congo, Dem. Rep. of Reforms } \\
\text { of family code to improve gender } \\
\text { equality; gender nondiscrimination } \\
\text { reforms in employment. } \\
\text { Zambia Gender Equity and } \\
\text { Equality Act; establishment of } \\
\text { Gender Equality Commission. } \\
\text { Ethiopia Reforms of property law, } \\
\text { requiring both spouses' consent } \\
\text { in the administration of marital } \\
\text { property; simultaneous change } \\
\text { to raise women's minimum age of } \\
\text { marriage. } \\
\text { Burundi, Comoros, Mauritius, } \\
\text { Rwanda, São Tomé and Príncipe, } \\
\text { and Zambia Laws against } \\
\text { workplace sexual harassment and } \\
\text { domestic violence. } \\
\text { Mauritius Prohibition of dismissal } \\
\text { of pregnant workers; introduction } \\
\text { of paid paternity leave; extension } \\
\text { of paid maternity leave. }\end{array}$ \\
\hline & $\begin{array}{l}\text { Affirmative } \\
\text { action and } \\
\text { quotas }\end{array}$ & $\begin{array}{l}\text { Implementing measures to } \\
\text { attract, develop, and retain } \\
\text { individuals from historically } \\
\text { disadvantaged groups. } \\
\text { - Considering job quotas for } \\
\text { underrepresented groups. } \\
\text { - Establishing data and } \\
\text { monitoring and evaluation } \\
\text { systems to monitor and } \\
\text { assess impact of affirmative } \\
\text { action. } \\
\text { Setting up institutions that } \\
\text { can address grievance. }\end{array}$ & $\begin{array}{l}\text { South Africa } 1998 \text { Employment } \\
\text { Equity Act and } 2003 \text { broad-based } \\
\text { black economic empowerment } \\
\text { legislation for "Blacks (including } \\
\text { African, Coloured [mixed race] and } \\
\text { Indians), women and people with } \\
\text { disabilities"(Burger and Jafta 2010). } \\
\text { Nigeria Federal Character } \\
\text { Commission (FCC) established in } \\
\text { 1996. Oversees implementation of } \\
\text { affirmative action in bureaucracy, } \\
\text { social services, infrastructure } \\
\text { development, and the private } \\
\text { sector. }\end{array}$ \\
\hline & $\begin{array}{l}\text { Skills and } \\
\text { training }\end{array}$ & $\begin{array}{l}\text { Supporting income- } \\
\text { generating activities for } \\
\text { excluded groups (ex- } \\
\text { combatants, youth, and } \\
\text { women). } \\
\text { - Developing soft and hard } \\
\text { skills training. }\end{array}$ & $\begin{array}{l}\text { Congo, Dem. Rep. of Strengthen- } \\
\text { ing socioeconomic reintegration } \\
\text { opportunities for vulnerable house- } \\
\text { holds of ex-combatants demobi- } \\
\text { lized through the PNDDR. } \\
\text { Liberia Ministry of Public Works } \\
\text { (with support from UNMIL, UNDP, } \\
\text { and WB) initiated labor- intensive } \\
\text { employment scheme to rehabilitate } \\
\text { roads, offering jobs to ex- } \\
\text { combatants and war-affected youth. }\end{array}$ \\
\hline
\end{tabular}


Table 0.1 continued

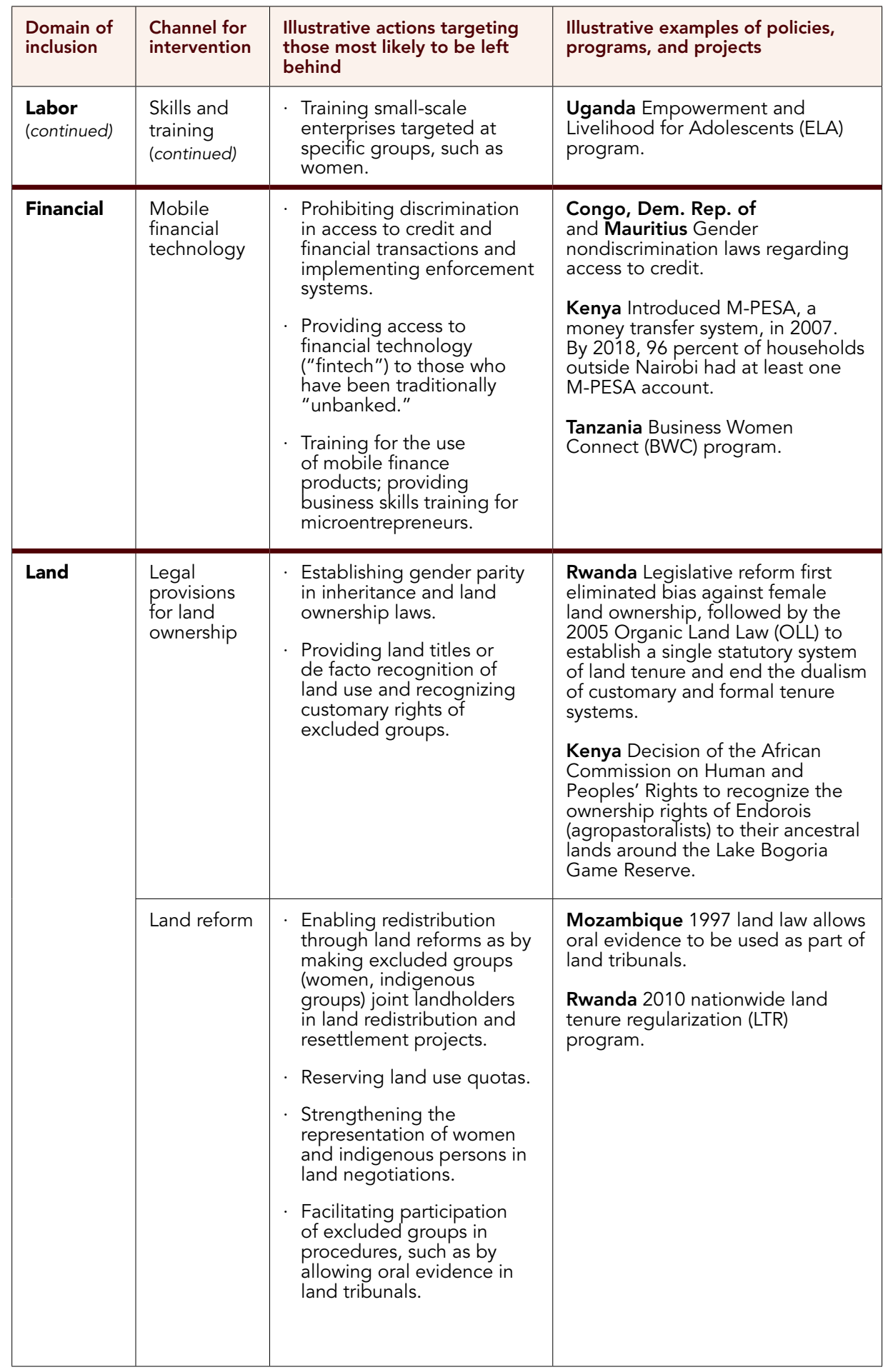




\begin{tabular}{|c|c|c|c|}
\hline $\begin{array}{l}\text { Domain of } \\
\text { inclusion }\end{array}$ & $\begin{array}{l}\text { Channel for } \\
\text { intervention }\end{array}$ & $\begin{array}{l}\text { Illustrative actions targeting } \\
\text { those most likely to be left } \\
\text { behind }\end{array}$ & $\begin{array}{l}\text { Illustrative examples of policies, } \\
\text { programs, and projects }\end{array}$ \\
\hline \multicolumn{4}{|l|}{ SERVICES } \\
\hline \multirow[t]{4}{*}{$\begin{array}{l}\text { Cross- } \\
\text { cutting } \\
\text { services }\end{array}$} & $\begin{array}{l}\text { Documenta- } \\
\text { tion }\end{array}$ & $\begin{array}{l}\text { Ensuring that all } \\
\text { groups have relevant } \\
\text { documentation to access } \\
\text { services. }\end{array}$ & $\begin{array}{l}\text { World Bank Group-supported } \\
\text { ID4D initiative (Botswana, } \\
\text { Cameroon, Chad, the Democratic } \\
\text { Republic of Congo, Côte d'Ivoire, } \\
\text { Ethiopia, Guinea, Kenya, Liberia, } \\
\text { Madagascar, Morocco, Namibia, } \\
\text { Nigeria, Rwanda, Sierra Leone, } \\
\text { Tanzania, and Zambia). }\end{array}$ \\
\hline & $\begin{array}{l}\text { Emergency } \\
\text { responses } \\
\text { to protect } \\
\text { vulnerable } \\
\text { groups }\end{array}$ & $\begin{array}{l}\text { Scaling up cash transfer } \\
\text { and public works programs. }\end{array}$ & $\begin{array}{l}\text { Multicountry responses to Ebola } \\
\text { emergency, extreme weather } \\
\text { events, and conflict. }\end{array}$ \\
\hline & $\begin{array}{l}\text { Engaging } \\
\text { commu- } \\
\text { nities and } \\
\text { training } \\
\text { govern- } \\
\text { mental } \\
\text { authorities }\end{array}$ & $\begin{array}{l}\text { Training regional and } \\
\text { municipal governments in } \\
\text { participatory budgeting. } \\
\text { Requiring and enabling } \\
\text { participation of excluded } \\
\text { groups (such as women, } \\
\text { pastoralist groups) in } \\
\text { budget consultation } \\
\text { meetings. }\end{array}$ & $\begin{array}{l}\text { Kenya Participatory budgeting in } \\
\text { West Pokot. } \\
\text { South Sudan Local Governance } \\
\text { and Service Delivery Project } \\
\text { (LOGOSEED). }\end{array}$ \\
\hline & $\begin{array}{l}\text { Targeted } \\
\text { attention } \\
\text { to his- } \\
\text { torically } \\
\text { excluded } \\
\text { groups }\end{array}$ & $\begin{array}{l}\text { Ensuring equal rights to } \\
\text { quality services. } \\
\text { Prohibiting } \\
\text { discrimination in } \\
\text { services. } \\
\text { - Establishing monitoring } \\
\text { and enforcement } \\
\text { mechanisms. } \\
\text { Making services free and } \\
\text { compulsory. }\end{array}$ & $\begin{array}{l}\text { Nigeria Federal Character } \\
\text { Commission (FCC) oversees } \\
\text { affirmative action, including in } \\
\text { social services. } \\
\text { Ghana Inclusive Education Policy. } \\
\text { Uganda Persons with Disability } \\
\text { Act } 2006 \text {. } \\
\text { Tanzania Primary education } \\
\text { made both free and compulsory. } \\
\text { Kenya Cash Transfer for } \\
\text { Orphans and Vulnerable } \\
\text { Children. }\end{array}$ \\
\hline Education & Accessibility & $\begin{array}{l}\text { Ensuring that educational } \\
\text { infrastructure is accessible } \\
\text { to persons with disabilities. } \\
\text { - Adapting education systems } \\
\text { to ensure the inclusion of all } \\
\text { learners, in particular those } \\
\text { with special educational } \\
\text { needs, including physical } \\
\text { accessibility of schools. } \\
\text { - Promoting Universal Design } \\
\text { for Learning (UDL) and } \\
\text { learner-friendly school } \\
\text { environments to enhance } \\
\text { the quality of education for } \\
\text { all learners. }\end{array}$ & Ghana Inclusive Education Policy. \\
\hline
\end{tabular}




\begin{tabular}{|c|c|c|c|}
\hline $\begin{array}{l}\text { Domain of } \\
\text { inclusion }\end{array}$ & $\begin{array}{l}\text { Channel for } \\
\text { intervention }\end{array}$ & $\begin{array}{l}\text { Illustrative actions targeting } \\
\text { those most likely to be left } \\
\text { behind }\end{array}$ & $\begin{array}{l}\text { Illustrative examples of policies, } \\
\text { programs, and projects }\end{array}$ \\
\hline $\begin{array}{l}\text { Education } \\
\text { (continued) }\end{array}$ & $\begin{array}{l}\text { Teacher } \\
\text { training and } \\
\text { curriculum } \\
\text { develop- } \\
\text { ment }\end{array}$ & $\begin{array}{l}\text { Training teachers to } \\
\text { respond to diverse } \\
\text { educational needs. } \\
\text {. Providing teacher training } \\
\text { in local languages. } \\
\text { Considering bilingual } \\
\text { education. } \\
\text { Ensuring that curricula are } \\
\text { designed in a way that } \\
\text { is sensitive to excluded } \\
\text { groups. }\end{array}$ & $\begin{array}{l}\text { Ethiopia Language-of-instruction } \\
\text { (LOI) policy. } \\
\text { Ghana Inclusive Education Policy. } \\
\text { Guinea-Bissau and Niger Pilots of } \\
\text { transitional bilingual programs. }\end{array}$ \\
\hline \multicolumn{4}{|l|}{ SPACES } \\
\hline Physical & $\begin{array}{l}\text { Safety } \\
\text { in public } \\
\text { places }\end{array}$ & $\begin{array}{l}\text { Generating forums such as } \\
\text { women's and girls' clubs } \\
\text { that provide safe spaces for } \\
\text { survivors of gender-based } \\
\text { violence and offer access to } \\
\text { sexual health services, legal } \\
\text { aid, and empowerment } \\
\text { training. }\end{array}$ & $\begin{array}{l}\text { Uganda BRAC Nkingo girls' clubs } \\
\text { in Kemwenge and Kabarole. }{ }^{a}\end{array}$ \\
\hline $\begin{array}{l}\text { Political } \\
\text { and social }\end{array}$ & $\begin{array}{l}\text { Consti- } \\
\text { tutional } \\
\text { and legal } \\
\text { provisions }\end{array}$ & $\begin{array}{l}\text { Explicitly acknowledging } \\
\text { equal status and rights } \\
\text { of different groups in the } \\
\text { government constitution. } \\
\text { Creating legal provisions } \\
\text { to institutionalize equality } \\
\text { and inclusion of formerly } \\
\text { excluded groups. } \\
\text { Establishing quota for } \\
\text { excluded groups, as with } \\
\text { political representation. }\end{array}$ & $\begin{array}{l}\text { South Africa LGBTI equality in } \\
\text { constitution. } \\
\text { Mozambique and Seychelles } \\
\text { Decriminalized same-sex relations } \\
\text { (2015 and 2016, respectively). } \\
\text { Botswana } 2017 \text { Supreme Court } \\
\text { decision requires government } \\
\text { to legally recognize transgender } \\
\text { people's gender self- identification. } \\
\text { Namibia Courts' decision to allow } \\
\text { official recognition of gender } \\
\text { change. } \\
\text { Bans on anti-LGBTI discrimination } \\
\text { (Angola, Botswana, Cabo } \\
\text { Verde, Mauritius, Mozambique, } \\
\text { Seychelles, South Africa). } \\
\text { Kenya Domestic violence law. } \\
\text { Uganda } 1995 \text { Constitution (Art.78) } \\
\text { stating that Parliament should. } \\
\text { include a woman representative } \\
\text { in every district as well as } \\
\text { representatives from the army, } \\
\text { youth, workers, persons with } \\
\text { disabilities, and "other groups as } \\
\text { Parliament may define." }\end{array}$ \\
\hline
\end{tabular}




\begin{tabular}{|c|c|c|c|}
\hline $\begin{array}{l}\text { Domain of } \\
\text { inclusion }\end{array}$ & $\begin{array}{l}\text { Channel for } \\
\text { intervention }\end{array}$ & $\begin{array}{l}\text { Illustrative actions targeting } \\
\text { those most likely to be left } \\
\text { behind }\end{array}$ & $\begin{array}{l}\text { Illustrative examples of policies, } \\
\text { programs, and projects }\end{array}$ \\
\hline \multirow[t]{2}{*}{$\begin{array}{l}\text { Political } \\
\text { and social } \\
\text { (continued) }\end{array}$} & $\begin{array}{l}\text { Changing } \\
\text { social norms } \\
\text { and tackling } \\
\text { discrimina- } \\
\text { tion }\end{array}$ & $\begin{array}{l}\text { Building coalitions among } \\
\text { government, civil society, } \\
\text { judiciary, and communities. } \\
\text { - Promoting information } \\
\text { campaigns, such as through } \\
\text { national radio broadcasts, } \\
\text { television, newspapers, and } \\
\text { social media. } \\
\text { - Putting in place systems } \\
\text { to ensure participation of } \\
\text { multiple stakeholders. } \\
\text { Fostering community buy- } \\
\text { in through ongoing contact } \\
\text { and conversation with } \\
\text { communities. } \\
\text { - Ensuring that the law } \\
\text { is understood by all; } \\
\text { translation of law, rules, } \\
\text { and procedures into local } \\
\text { languages. } \\
\text { Training and fostering } \\
\text { normative change among } \\
\text { state personnel (including } \\
\text { lawyers, judges, police, and } \\
\text { security officers. } \\
\text { Providing space for } \\
\text { movements that advocate } \\
\text { for excluded groups to } \\
\text { engage on policy reform. }\end{array}$ & $\begin{array}{l}\text { Congo, Dem. Rep. of } \\
\text { Strengthening socioeconomic } \\
\text { reintegration opportunities for } \\
\text { vulnerable households of ex- } \\
\text { combatants demobilized through } \\
\text { the PNDDR. } \\
\text { Burkina Faso Criminalization } \\
\text { of FGM and measures for } \\
\text { enforcement and normative } \\
\text { change. } \\
\text { Information campaigns around HIV } \\
\text { across the region. }\end{array}$ \\
\hline & $\begin{array}{l}\text { Opportu- } \\
\text { nities for } \\
\text { intergroup } \\
\text { cohesion }\end{array}$ & $\begin{array}{l}\text { Sending young citizens to } \\
\text { live in different regions of } \\
\text { the country. } \\
\text { Considering truth and } \\
\text { reconciliation commissions } \\
\text { (TRCs) to overcome } \\
\text { conflict. }\end{array}$ & $\begin{array}{l}\text { Nigeria National Youth Service } \\
\text { Corps (NYSC). } \\
\text { TRCs in The Gambia, Mauritius, } \\
\text { Rwanda, and South Africa. }\end{array}$ \\
\hline
\end{tabular}




\begin{tabular}{|c|c|c|c|}
\hline $\begin{array}{l}\text { Domain of } \\
\text { inclusion }\end{array}$ & $\begin{array}{l}\text { Channel for } \\
\text { intervention }\end{array}$ & $\begin{array}{l}\text { Illustrative actions targeting } \\
\text { those most likely to be left } \\
\text { behind }\end{array}$ & $\begin{array}{l}\text { Illustrative examples of policies, } \\
\text { programs, and projects }\end{array}$ \\
\hline & $\begin{array}{l}\text { Empower- } \\
\text { ment and } \\
\text { dignity }\end{array}$ & $\begin{array}{l}\text { Establishing cash transfers } \\
\text { and other social protection } \\
\text { programs that boost self- } \\
\text { confidence and imbue a } \\
\text { sense of dignity. } \\
\text { - Using social media and } \\
\text { technology to amplify } \\
\text { voices of excluded groups. } \\
\text { - Promoting reproductive } \\
\text { rights and services. } \\
\text { - Enabling survivors of } \\
\text { gender-based violence to } \\
\text { report anonymously. }\end{array}$ & $\begin{array}{l}\text { Kenya, Mozambique, and Zambia } \\
\text { Cash transfer programs. } \\
\text { South Sudan and Tanzania } \\
\text { "Listening to Africa" initiative. } \\
\text { Sahel Women Empowerment and } \\
\text { Demographic Dividend (SWEDD). } \\
\text { Uganda BRAC Empowerment and } \\
\text { Livelihood for Adolescents (ELA) } \\
\text { program. } \\
\text { Community-based rehabilitation } \\
\text { (CBR) for persons with disabilities. }\end{array}$ \\
\hline & $\begin{array}{l}\text { Better data } \\
\text { and analysis }\end{array}$ & $\begin{array}{l}\text { Collecting better } \\
\text { disaggregated data } \\
\text { on social groups and } \\
\text { processes } \\
\text { - Promoting platforms that } \\
\text { make data public } \\
\text { - Fostering innovations } \\
\text { in data collection, such } \\
\text { as high frequency data } \\
\text { collection through mobile } \\
\text { phones } \\
\text { - Investing in geospatial data } \\
\text { and other forms of big data } \\
\text { - Encouraging and financing } \\
\text { better analysis }\end{array}$ & $\begin{array}{l}\text { World Bank's Gender Innovation } \\
\text { Lab } \\
\text { Listening to Africa initiative }\end{array}$ \\
\hline
\end{tabular}

a. Via the Supporting Children's Opportunities through Protection and Empowerment Project, implemented by the Ministry of Gender, Labor and Social Development.

Note: $\mathrm{BRAC}=$ Building Resources Across Communities; FGM = female genital mutilation; ID4D = Identification for Development; LGBTI = lesbian, gay, bisexual, transgender, and intersex; PNDDR = National Program for Disarmament, Demobilization, and Reintegration; UNDP = United Nations Development Programme; UNMIL = United Nations Mission in Liberia; WB = World Bank. 


\section{Notes}

1 See https://www.worldbank.org/en/region/afr/overview\#2.

2 See https://africaindata.org/\#/2.

3 Based on $\$ 1.90$ a day in 2011 purchasing power parity (PPP). http://iresearch. worldbank.org/PovcalNet/.

4 For a discussion of active and passive exclusion, see Sen 2000. 



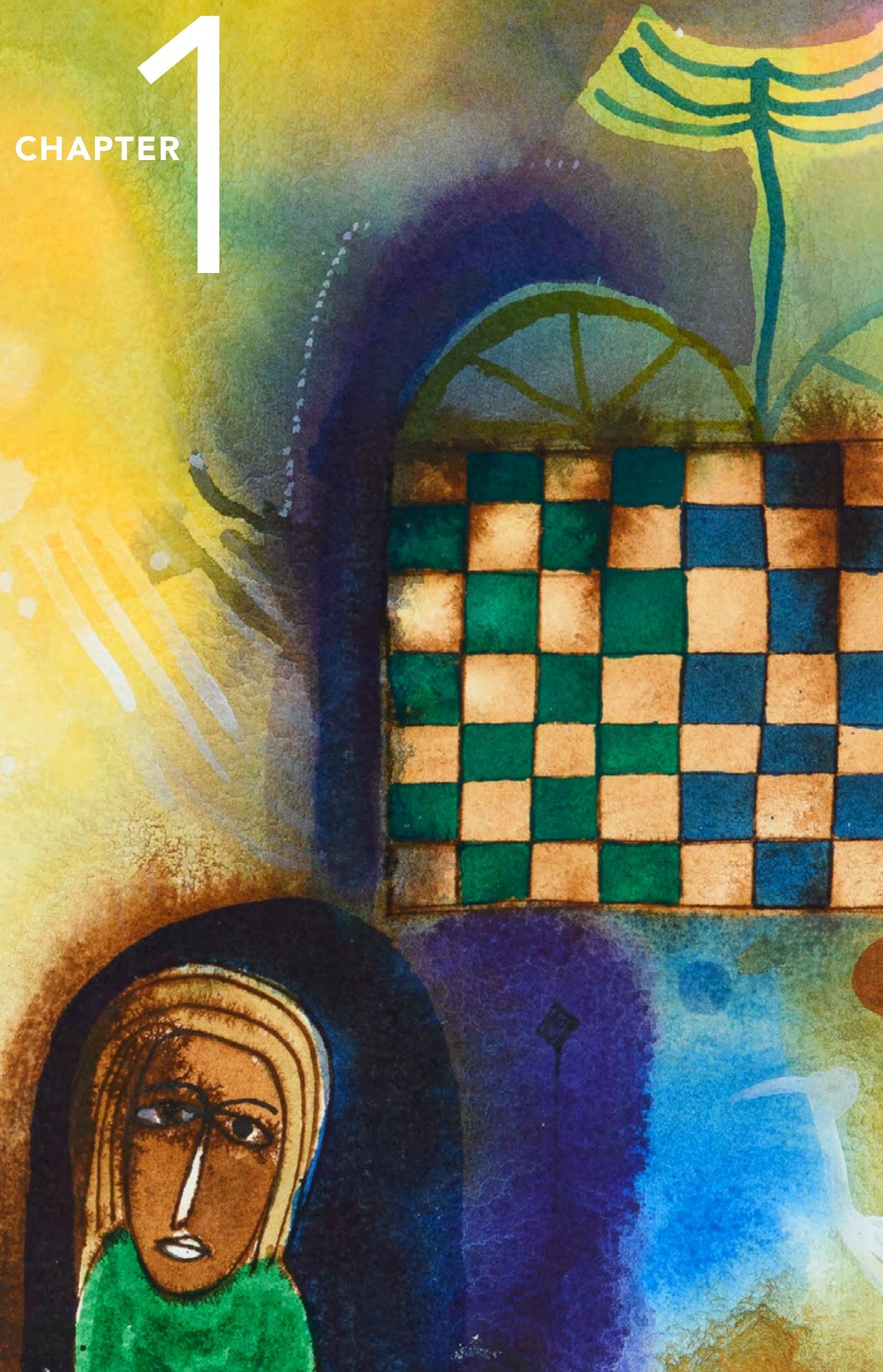




\section{The Motivation and Conceptual Clarity}

Africa is increasingly recognized for its dynamism, its innovation and for social change. The idea of the "African Century" has pervaded national and international policy and advocacy circles. Across Africa there have been impressive gains in health, nutrition, education, and women's empowerment. Innovation, which abounds in Africa, is reflected in a plethora of areas: the spread of digital technology, advocacy movements that bring previously ostracized and invisible persons into public view, and social enterprises and fresh answers to intractable questions. As incubation hubs that create solutions to stubborn challenges, African countries are the arena in which global development challenges will play out and likely be overcome. 
Nevertheless, positive developments and prosperity have left some individuals and groups behind; a reality across the world, in OECD (Organisation for Economic Cooperation and Development) and non-OECD countries alike. This realization led to the formulation of the idea of social exclusion and its converse, inclusion, which has taken different forms across varied regions. In Europe, social inclusion has been associated largely with the job market, homelessness, and chronic poverty, with an increasing focus on ethnicity and migrant status. In Latin America, indigenous identity, race, disability status, and sexual identity have grown to prominence in national discourses. In South Asia, caste, ethnicity, religion, and disability status are key axes of exclusion. In Africa, most discussions of social inclusion have taken place within the context of poverty reduction and in response to humanitarian crises. These conversations are driven by the fact that despite significant progress in decreasing poverty, more than 400 million people are estimated to still live in poverty (Beegle and Christiaensen 2019). As in other places, in Africa, "the poor" is a heterogenous category. Some groups tend to be overrepresented or underrepresented among them, and they systematically lack access to markets, services, and spaces. These groups have a weaker voice when it comes to asserting their needs with governments and elites. They often live in areas of conflict and fragility. It behooves us to ask: Who are these groups? Are they being left out of peace and prosperity? If so, why? Answers to these questions can significantly aid programs and policies intended to reduce poverty and boost human capital accumulation.

Additional motivation for a spotlight on social inclusion is embedded in four related developments in the global policy arena. First, the Sustainable Development Goals (SDGs) with their philosophy of leaving no one behind have permeated the policy space. Second, the WBG's focus on ending extreme poverty, combined with its twin goal of boosting shared prosperity, has moved the policy conversation to issues that go beyond poverty. Third, the World Bank's flagship report on social inclusion, Inclusion Matters (World Bank 2013), has influenced the global conversation, and, although attribution is not clear, funding agencies have increasingly focused their grantmaking on issues of social inclusion, using language from the report. Last, the idea of social inclusion has pride of place in the new World Bank Environmental and Social Framework (ESF) that has applied to WBG projects since October 2018 (appendix B). The ESF defines social sustainability squarely in terms of social inclusion, stating that "social development and inclusion are critical for all of the World Bank's development interventions and for achieving sustainable development." It further states that "inclusion...embraces action to remove barriers against those who often are excluded from the development process, such as women, children, persons with disabilities, youth and minorities, and to ensure that the voice of all can be heard" (World Bank 2017d, 1). 


\section{Box 1.1 World Bank Regional Strategy for Africa}

- Empowering women to change fertility dynamics and accelerate human capital gains: Through the new Human Capital Project (HCP) the World Bank Group is committed to investing more and better in people.

- Accelerating Africa's digital economy: With digital economy investments and reforms, Africa may be able to accelerate, possibly even leapfrog the traditional growth model, and transition from an agriculture-based economy to a digital economy, while building core infrastructure, systems, and competencies.

- Climate change: In the face of increasing climate- related risks, investing in climate change adaptation and resilience mechanisms and disaster risk management will remain a top priority.

- Regional integration: Regional integration in Africa remains a critical emphasis of the WBG regional strategy to improve connectivity, leverage economies of scale, and facilitate collective action by countries to address shared challenges.

- Maximizing finance for development: At a time when public resources are increasingly scarce and the aspirations of African populations are rising, WBG has embraced the Maximizing Finance for Development approach to systematically leverage all sources of finance, expertise, and solutions that will help create an enabling environment for investors, particularly those in the private sector.

- Boosting resilience to conflict and violence: With violent conflict surging, the fight to end extreme poverty in Africa will require a stronger focus on addressing the underlying drivers of fragility to create opportunities for peace and shared prosperity.

- Knowledge: Knowledge is essential to our effort to improve development outcomes and make aid more effective.

Source: World Bank 2019b.

Finally, the Africa Region of the World Bank announced its new strategy, which is rooted in the tenets of social inclusion. The strategy is outlined in box 1.1. Much of this report directly or indirectly addresses the issues that have been raised in the Africa Regional strategy. The contribution of this report will be in its application of the social inclusion framework to the problems articulated in the strategy and its identification of the underlying structures and processes that exacerbate social exclusion. 


\section{What Do We Mean by Social Inclusion?}

The prolific use of "social inclusion" (or just "inclusion") as a framing construct over the last decade has been somewhat of a double-edged sword so it is important to define what we mean. Essentially, the usage "social inclusion" and its variants seems to have "become a catch-all...for any positive welfare outcome-from poverty to equality to better education, health, housing, transport, among others." (Das 2016). Yet, users of the term seem to want to convey something that is different from, or more than, poverty or inequality reduction or better human capital outcomes. Although this prolific use points to a new and broader lexicon in global development, the usage is fraught with lack of conceptual and policy clarity. This report draws its conceptual foundation from the World Bank (2013) (figure 1.1). We define social inclusion as the process of improving the terms for individuals and groups to take part in society. An expanded definition takes into account how and for whom the terms of social inclusion can be improved: the process of improving the ability, opportunity, and dignity of people disadvantaged on the basis of their identity to take part in society. In answer to the question "inclusion in what?" World Bank (2013) answers: in markets, services, and spaces. Markets comprise land, housing, labor, and credit; and services include education, health, transport, water, social protection, electricity, information, communication, and technology. Spaces include physical space but also spaces in a broader sense: social, political, and cultural spaces may solidify exclusion or foster inclusion. Moreover, social inclusion works to enhance the ability, opportunity, and dignity of individuals and groups to take part in society. Of particular significance is dignity. When compromised, it can have severe and unexpected consequences for individuals, groups, and the society and economy.

It is clear from the definition of social inclusion that disadvantage based on social identity is salient. Although such salience can be political and controversial, its acknowledgment is important to advance social inclusion. Social identity may be derived from gender, age, location, occupation, race, ethnicity, religion, citizenship status, disability, and sexual orientation and gender identity (SOGI) (figure 1.2). Even so, no single identity really describes an individual. The context determines the identity that assumes dominance at different times (such as place in the life cycle) and in various places (such as the public or the private sphere). Even more important, the real advantage or disadvantage is bestowed by the intersection of identities.

To close this initial discussion about the importance of social identity, we quote Sen (2008), who emphasizes the importance of the "non-economic characteristics" that often drive outcomes. 
Figure 1.1 The Social Inclusion Framework

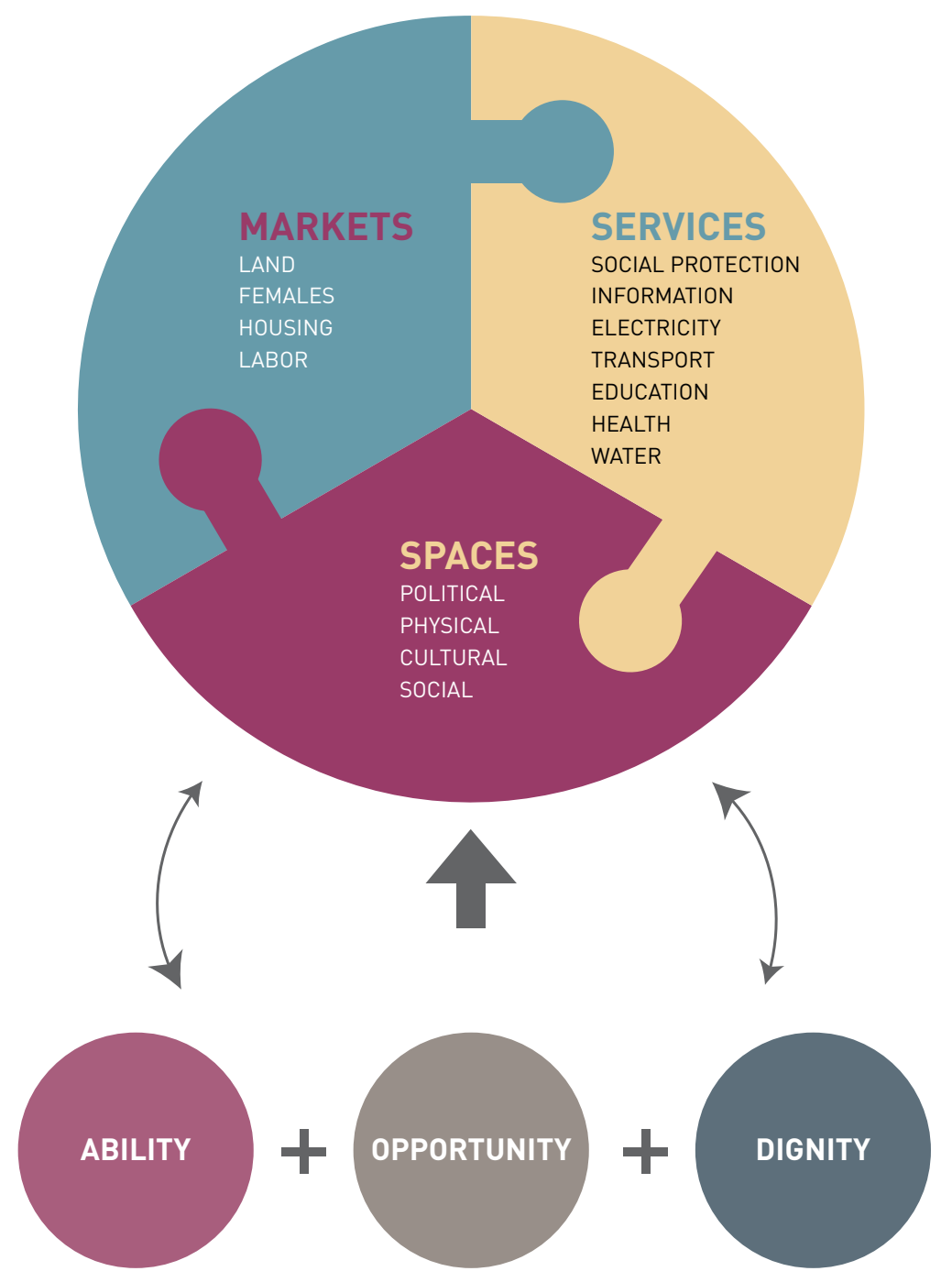

Source: World Bank 2013. 


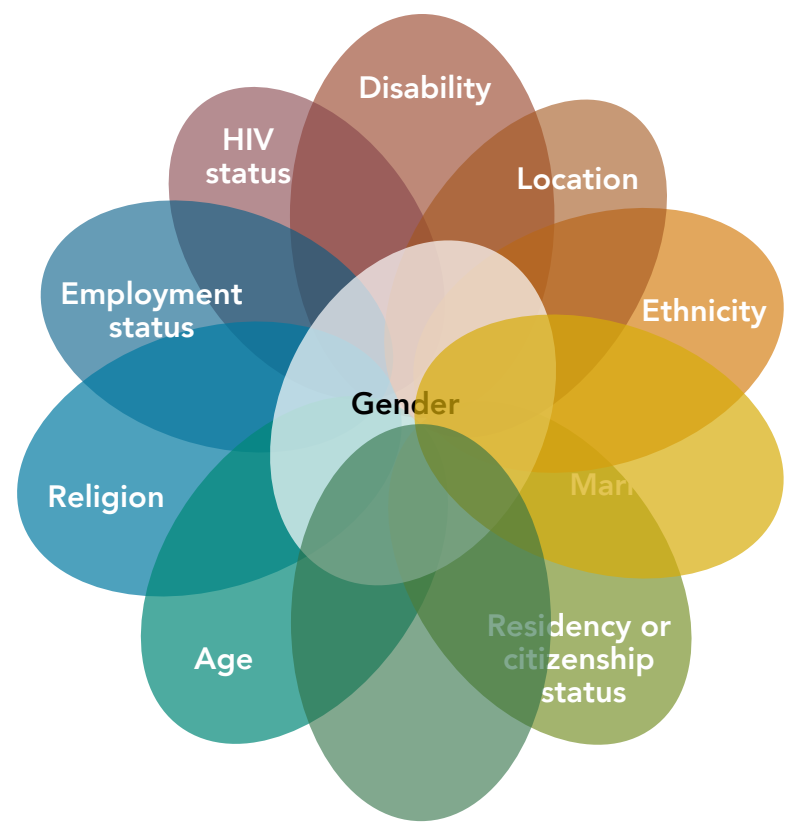

Note: Size or placement of shape does not reflect importance of identity.

Purely economic measures of inequality, such as the Gini coefficient or the ratio of incomes of top and bottom groups, do not bring out the social dimensions of the disparity involved. For example, when the people in the bottom income groups also have different non- economic characteristics, in terms of race (such as being black rather than white), or in immigration status (such as being recent arrivals rather than older residents), then the significance of the economic inequality is substantially magnified by its "coupling" with other divisions, linked to noneconomic identity groups. It would be hard, for instance, to have an adequate understanding of the turmoil in the suburbs of Paris and other French cities in the autumn of 2005 only in terms of poverty and deprivation, without bringing in race and immigration. It would be similarly unsatisfactory to try to base a causal explanation only on race and immigration, without bringing in inequality and economic disparity.

-Amartya Sen 2008 


\section{What Does Social Inclusion Add to Poverty Reduction?}

As noted earlier, Africa's development narrative has been inexorably about poverty reduction. Why do we bring social inclusion into it? The reason is that, although social inclusion is intrinsic to poverty reduction, it also is distinct from it. Poverty is an outcome; social exclusion is both a process and an outcome (World Bank 2013). Processes of exclusion can have long-term effects on the collective dignity, mind-sets, and psyches of subordinated or excluded groups. Exclusion, in turn, affects the ability of groups to access the opportunities that are made available to them. Slavery was one of the most egregious processes of exclusion, as were apartheid and untouchability (in South Asia).

Less overt practices also can have devastating effects on subordinated groups. Consider bullying as an example of an insidious exclusionary process: the world over, some students are bullied into failure. They may include lesbian, gay, bisexual, transgender, and intersex (LGBTI) people, or those students who speak with a different accent than that of the dominant groups, may eat different food, or have other unique characteristics. Bullying can stymie the educational opportunities of those subject to it, cause serious mental health and other devastating consequences, and ultimately can lead victims to opt out of a system that they perceive as condoning bullying. All this may, and does, occur in otherwise well-functioning educational systems. Thus, victims of bullying are affected by a process of exclusion that prevents them from reaching their full potential.

This report emphasizes that poverty is deeply rooted, with causes that may be both social and economic, to the vast detriment of peoples and countries. A focus on social inclusion helps promote a better understanding of poverty and attention to those groups most at risk of being left out. It also is important to acknowledge that although social exclusion may well be related to poverty, there are times when it is not. A person with mobility limitations, who is part of rich household and is not affected by poverty, may be excluded if without accessible infrastructure and services are not available. Social inclusion therefore adds to the discourse on poverty and inequality when unpacking the causes and drivers of the hardship of certain individuals and groups. In other words, it adds granularity to poverty analysis.

Finally, social exclusion is sometimes said in the same breath as "vulnerability," but the two are not the same. The latter focuses on identifying those at risk of a shock, such as falling into poverty or being affected by disaster. There are certainly synergies between vulnerability and social exclusion, insofar as both emphasize underlying processes that contribute to persistent poverty. Often, the same groups who are at risk of exclusion also are among the most vulnerable; they also have the least wherewithal to cope with shocks. They include, for instance, persons with disabilities, orphans, HIV- positive persons, the elderly, ethnic minorities, indigenous peoples (IPs), and widows (Hoogeeven and others 2004). However, 
not all groups who are vulnerable to extreme weather events, to violent attacks, or even to poverty are necessarily excluded. For example, people living in seismic zones all are vulnerable, but only some of them may be excluded. The majority of households who reside in fragile ecological zones may be vulnerable to poverty, but, within these households, some individuals may be excluded and others not. Finally, social inclusion is distinct from equality of opportunity. It

"...takes the idea of equality of opportunity further. It argues that both 'supply of opportunity' and 'demand for opportunity' may be constrained by identity. Getting to full or effective opportunity is not only an institutional challenge in many countries, but the process of expanding opportunities can itself be exclusionary"

—World Bank 2013

A social inclusion lens, therefore, emphasizes the importance of addressing heterogeneity across groups and pinpointing whether some individuals or groups may be especially disadvantaged due to an identity marker. For a more in-depth discussion of conceptual issues, see World Bank (2013). 


\section{Costs of Social Exclusion: What Are the Channels?}

Social inclusion is important because exclusion impedes the ability, opportunity, and dignity of some individuals and groups. It also is important because exclusion is costly to societies and economies. But measuring the costs of social exclusion is no mean undertaking. In this section, we review the literature that gives pointers to the many ways in which such costs can be quantified. Some studies focus on specific groups when assessing the cost of exclusion; these groups may include women, persons with disabilities, ethnic or racial groups, people in same-sex relations, and migrants. We highlight the channels through which exclusion affects individuals and society at large. A synthesis of the channels is laid out in table 1.1.

The costs of social exclusion can accrue through different channels and levels; they may be direct or indirect, short term or long term. The cumulative long-term costs can be significant and can affect the growth trajectories of entire economies. It is most common to find calculations at the individual and the national levels, but there may be intermediate levels as well (such as household, community, or subnational). At the individual level, the loss of wages, lifetime earnings, poor education, and employment outcomes are the commonest measures of costs. For instance, Buehren and others (2019), based on an analysis of Ethiopia, show that women lag men by 36 percent in agricultural productivity, by 79 percent in business sales, and by 44 percent in hourly wages (see also Lamichhane and Sawada 2013 and Male and Wodon 2017 on people with disabilities; Sprague and others 2011 on people with HIV; Turner 2013 on racial minorities in the United States; Wodon and others 2018 and Wodon and de la Brière 2018 on gender; and World Bank 2014 on youth employment in Africa).

Drivers of lower earnings or employment outcomes may be lower human capital endowments, which in turn may be caused by prior disadvantage in education but also by discrimination in hiring or in the workplace (Buckup 2009; Lamichhane and Sawada 2013; Morgon Banks and Polack 2015). As noted, social exclusion often is solidified through discrimination and its manifestations. Discrimination can have physical and mental health costs for individuals and households, and, ultimately, national level costs (see, for example, Lereya and others 2015). 


\begin{tabular}{|c|c|c|}
\hline Domain of exclusion & Illustrative channels & Illustrative costs \\
\hline \multicolumn{3}{|l|}{ MARKETS } \\
\hline Labor market & $\begin{array}{l}\text { Members of subordinated groups } \\
\text { who drop out of the labor market } \\
\text { or take up jobs for which they } \\
\text { may be overqualified because of } \\
\text { discrimination in hiring, wages, and } \\
\text { promotion; or the expectation that } \\
\text { the labor market will discriminate. } \\
\text { - Women, sexual minorities, and other } \\
\text { excluded groups who feel unsafe in } \\
\text { jobs because of harassment and lack } \\
\text { of safety. } \\
\text { - Laws that forbid women from } \\
\text { participating in some types of work } \\
\text { or laws that indirectly compel women } \\
\text { to take up lower paid work (for } \\
\text { example some tax laws). } \\
\text { Workers with disabilities who do } \\
\text { not get basic accommodations such } \\
\text { as accessible buildings, toilets, or } \\
\text { information. }\end{array}$ & $\begin{array}{l}\text { Losses in productivity, } \\
\text { innovation, and } \\
\text { entrepreneurship. }\end{array}$ \\
\hline $\begin{array}{l}\text { Land, water, and } \\
\text { other natural } \\
\text { resources }\end{array}$ & $\begin{array}{l}\text { Individuals who are landless also } \\
\text { lack status and power, which makes } \\
\text { them less likely to participate in other } \\
\text { markets, services, and spaces. } \\
\text { - Land is collateral and so is linked } \\
\text { to credit markets. Those who do } \\
\text { not own land may not get loans for } \\
\text { housing or business. } \\
\text { - Ownership of land can enhance } \\
\text { women's voices, including against } \\
\text { domestic violence. } \\
\text { - Land and other natural resources } \\
\text { are the bases for employment and } \\
\text { livelihoods in economies with a large } \\
\text { agrarian base. } \\
\text { Those with poor access to water are } \\
\text { more likely to live in remote and } \\
\text { fragile locations and be poorer, and } \\
\text { less likely to own land. } \\
\text { - Mineral resources may be located } \\
\text { on lands inhabited by poorer or } \\
\text { indigenous communities. They may } \\
\text { lack voice and power to assert their } \\
\text { collective rights on mineral revenues } \\
\text { or on sharing benefits from other } \\
\text { natural resources. } \\
\text { Elite capture of natural resources is } \\
\text { common in many parts of the world. }\end{array}$ & $\begin{array}{l}\text { Accumulated grievances } \\
\text { among those who have } \\
\text { been left out of land and } \\
\text { other natural resources } \\
\text { lead to social tensions and } \\
\text { conflict that can have long- } \\
\text { term social and economic } \\
\text { costs. } \\
\text { Costs of elite capture } \\
\text { include resistance to } \\
\text { reform by elites, with likely } \\
\text { inefficiencies as well as } \\
\text { political costs to state and } \\
\text { society. }\end{array}$ \\
\hline
\end{tabular}




\begin{tabular}{|c|c|c|}
\hline Domain of exclusion & Illustrative channels & Illustrative costs \\
\hline Financial markets & $\begin{array}{l}\text { The "unbanked" often are groups } \\
\text { who have other disadvantages as well } \\
\text { (such as poor access to administrative } \\
\text { spaces and lack of documentation). } \\
\text { Groups with poor access to credit } \\
\text { markets have barriers versus } \\
\text { accumulating additional assets such } \\
\text { as land, housing, and education. } \\
\text { Lack of access to formal payment } \\
\text { systems means that some groups } \\
\text { may be excluded from cash transfers } \\
\text { and other cash benefits. }\end{array}$ & $\begin{array}{l}\text { - Costs to the banking } \\
\text { industry of untapped } \\
\text { financial markets. } \\
\text { - Difficulty in transferring } \\
\text { payments means that } \\
\text { administrative systems rely } \\
\text { on cash, leading to leakages } \\
\text { and corruption. } \\
\text { - Lack of access to credit } \\
\text { leads to productivity losses. }\end{array}$ \\
\hline \multicolumn{3}{|l|}{ SERVICES } \\
\hline Education & $\begin{array}{l}\text { Subordinated groups who drop } \\
\text { out or have frequent absences } \\
\text { from school due to bullying and } \\
\text { name-calling by teachers and other } \\
\text { students in school. } \\
\text { Girls who cannot stay in school due } \\
\text { to norms and societal pressures on } \\
\text { families to marry them off early. } \\
\text { Girls and young women who drop } \\
\text { out of higher levels of education due } \\
\text { to lack of transport, lack of clean } \\
\text { toilets, household chores, and unsafe } \\
\text { commutes and school environments. } \\
\text { Persons with disabilities and groups } \\
\text { such as linguistic minorities who } \\
\text { cannot perform in school and feel } \\
\text { forced to drop out due to lack of } \\
\text { accessible curriculum, infrastructure, } \\
\text { and tutoring assistance. }\end{array}$ & $\begin{array}{l}\text { Low accumulation of skills } \\
\text { that affect labor market } \\
\text { outcomes. } \\
\text { Student absenteeism from } \\
\text { school has longer term } \\
\text { productivity losses and } \\
\text { costs of low human capital } \\
\text { accumulation. } \\
\text { Teacher absenteeism has } \\
\text { administrative costs when } \\
\text { schools or workplaces } \\
\text { function below capacity. } \\
\text { Mental health costs. }\end{array}$ \\
\hline Health & $\begin{array}{l}\text { Rejection of health care by } \\
\text { subordinated groups due to poor } \\
\text { treatment and humiliation at health } \\
\text { facilities. } \\
\text { Norms of shame, stigma, and lack } \\
\text { of privacy that prevent women, girls, } \\
\text { and sexual minorities from seeking } \\
\text { services such as reproductive health } \\
\text { care and contraception. }\end{array}$ & $\begin{array}{l}\text { When groups opt out of } \\
\text { health services, both they } \\
\text { and the economy incur the } \\
\text { high costs of emergency } \\
\text { treatment in lieu of more } \\
\text { efficient preventive and in- } \\
\text { time care. } \\
\text { Poor aggregate health } \\
\text { outcomes (that is, maternal } \\
\text { mortality and child nutrition) } \\
\text { and high burden of disease. } \\
\text { Long-term, intergenerational } \\
\text { costs to society. } \\
\text { Losses in productivity. }\end{array}$ \\
\hline
\end{tabular}




\begin{tabular}{|c|c|c|}
\hline Domain of exclusion & Illustrative channels & Illustrative costs \\
\hline $\begin{array}{l}\text { Water supply and } \\
\text { sanitation }\end{array}$ & $\begin{array}{l}\text { Those with poor access to water } \\
\text { supply and sanitation in their homes } \\
\text { spend more time procuring these } \\
\text { services and are more likely to get } \\
\text { sick. Their children are more likely to } \\
\text { be stunted. } \\
\text { Some groups with poor access } \\
\text { to toilets (such as women, girls, } \\
\text { persons with disabilities or mobility } \\
\text { challenges, and sexual minorities) } \\
\text { cannot go to school or work. }\end{array}$ & $\begin{array}{l}\text { Costs related to health and } \\
\text { welfare. } \\
\text { Stunting has } \\
\text { intergenerational costs and } \\
\text { implies productivity losses. } \\
\text { Absenteeism from school or } \\
\text { work has costs in low human } \\
\text { capital accumulation and } \\
\text { productivity losses. } \\
\text { Absenteeism has } \\
\text { administrative costs when } \\
\text { schools or workplaces } \\
\text { function below capacity. }\end{array}$ \\
\hline \multicolumn{3}{|l|}{ SPACES } \\
\hline Physical & $\begin{array}{l}\text { Some groups may be systematically } \\
\text { concentrated in ecologically or } \\
\text { politically fragile locations or in } \\
\text { informal settlements. } \\
\text { - Persons with disabilities or mobility } \\
\text { challenges may be excluded from } \\
\text { physical spaces because of lack of } \\
\text { accessible infrastructure. } \\
\text { - Groups who reside in remote } \\
\text { locations may be left out of markets } \\
\text { and services unless special efforts are } \\
\text { made. } \\
\text { - Exclusion from physical spaces } \\
\text { also can be deliberate, such } \\
\text { as menstruating women being } \\
\text { prevented from entering "pure" or } \\
\text { ritual spaces and some groups being } \\
\text { prevented from entering clubs or } \\
\text { hotels. }\end{array}$ & $\begin{array}{l}\text { Productivity losses. } \\
\text { Administrative costs due to } \\
\text { inability of governments to } \\
\text { reach their target groups. } \\
\text { Accumulation of grievances } \\
\text { among those who are } \\
\text { prevented from accessing } \\
\text { certain spaces, leading to } \\
\text { long-term economic and } \\
\text { social costs. }\end{array}$ \\
\hline Political & $\begin{array}{l}\text { Groups who have been historically } \\
\text { left out or who have low trust in the } \\
\text { political system are less likely to } \\
\text { participate in political processes. } \\
\text { - In contexts in which elites have } \\
\text { captured political power, they may } \\
\text { actively prevent others from asserting } \\
\text { their voices. } \\
\text { Some groups may have limited } \\
\text { access to information and grievance } \\
\text { redress processes due to lack of state } \\
\text { transparency or lack of avenues for } \\
\text { access. }\end{array}$ & $\begin{array}{l}\text { Accumulated grievances } \\
\text { among those who have } \\
\text { been left out may lead to } \\
\text { social tensions and conflict, } \\
\text { which can have long-term } \\
\text { social and economic costs. } \\
\text { Asymmetrical information } \\
\text { can have costs related to } \\
\text { productivity, human capital } \\
\text { accumulation, and burden of } \\
\text { disease. }\end{array}$ \\
\hline
\end{tabular}


Table 1.1 continued

\begin{tabular}{|c|c|c|}
\hline Domain of exclusion & Illustrative channels & Illustrative costs \\
\hline Cultural & $\begin{array}{l}\text { Minority cultures and their } \\
\text { languages may be underprivileged } \\
\text { and unrecognized, leading to the } \\
\text { members feeling excluded from } \\
\text { society. } \\
\text { Cultural heritage and intellectual } \\
\text { property belonging to minority } \\
\text { groups may be captured or } \\
\text { appropriated by more powerful } \\
\text { groups. }\end{array}$ & $\begin{array}{l}\text { Potentially lost revenues } \\
\text { from tourism and cultural } \\
\text { heritage. } \\
\text { Accumulated grievances } \\
\text { among those whose cultures } \\
\text { have been appropriated } \\
\text { or ignored may lead to } \\
\text { social tensions and conflict, } \\
\text { with long- term social and } \\
\text { economic costs. }\end{array}$ \\
\hline Administrative & $\begin{array}{l}\text { Some groups may systematically } \\
\text { lack documentation, such as proof } \\
\text { of residence, nationality, age, } \\
\text { disability status, or minority status, } \\
\text { which prevents them from accessing } \\
\text { benefits. } \\
\text { Bureaucracies may be biased against } \\
\text { some groups, or groups may not } \\
\text { have the information or ability to } \\
\text { access local governments and other } \\
\text { governmental entities. } \\
\text { Survey personnel who are not trained } \\
\text { to enumerate socially and politically } \\
\text { invisible or ostracized groups multiply } \\
\text { the disadvantages of the latter. }\end{array}$ & $\begin{array}{l}\text { When some groups are } \\
\text { unable to access services } \\
\text { due to administrative } \\
\text { hurdles, the lack of } \\
\text { access can impact health, } \\
\text { education, and other } \\
\text { outcomes, leading to long- } \\
\text { term costs to the economy } \\
\text { and society. } \\
\text { Lack of data on historically } \\
\text { excluded groups has } \\
\text { implications for targeting } \\
\text { and implementing policies } \\
\text { and programs, with } \\
\text { administrative and political } \\
\text { costs. }\end{array}$ \\
\hline
\end{tabular}


Research on mental health in Africa is growing, and some estimates suggest high costs of mental health disorders. In 2015 the World Health Organization (WHO) estimated that 17.9 million years of healthy life in Africa were lost to mental health disabilities (Sankoh and others 2018). Persons with mental health problems also are often subject to discrimination and exclusion.

At the national level, the economic costs of social exclusion can be captured by forgone GDP and human capital wealth. Exclusion, or the perception of exclusion, may cause certain groups to opt out of markets, services, and spaces, with costs to both individuals and the economy. For instance, when groups opt out of health services, both the groups and the economy incur the high costs of emergency treatment in lieu of more efficient preventive and in-time care (FRA 2015; Mbonu and others 2009). Those who opt out of education and the labor market or have lower aspirations for what they can achieve lose potential income; their employers lose productivity; and the country loses GDP. In the United States, Burns (2012) estimates the cost of exclusion of LGBTI people alone at $\$ 64$ billion per year. A recent International Monetary Fund (IMF) paper shows that the current gender gap in the labor force costs countries that rank in the bottom half of gender inequality approximately 35 percent of GDP (Ostry and others 2018). Wodon and de la Brière (2018) estimate that, in 2014, Africa lost $\$ 2.5$ trillion in human capital due to gender inequality and 11.4 percent of total wealth.

We also can draw some lessons from studies that have quantified the economic cost of inequality. Berg and Ostry (2011) demonstrate that inequality is costly for medium and long-term growth. Some estimates show that in countries such as the United States, the United Kingdom, and Italy overall economic growth would have been 6 to 9 percentage points higher in the past two decades if income inequality had not risen (Stiglitz 2016). Closely related are studies on inequality of opportunity driven by differences at birth, such as gender, ethnicity, or parental background. Inequality of opportunity has been arguably particularly detrimental to growth (for example, Ferreira and others 2014; Marrero and Rodriguez 2013; World Bank and Oxford University Press 2006; and for Africa, Brunori and others 2016). Finally, although exclusion is not tantamount to conflict, accumulated grievances due to exclusion may trigger social tensions. The World Bank (2018b) argues that conflict countries experience 2.0 percent to 8.4 percent of annual GDP loss; and that countries bordering conflict zones suffer a 1.4 percent decline in annual GDP and a 1.7 percent rise in inflation.

Forgone benefits also can be costly. Hunt and others $(2015,2018)$ find that companies in the top quartile for gender, racial, and ethnic diversity are 15 percent to 35 percent more likely to have financial returns above their national industry medians. Productivity gains from the inclusion of excluded groups occur due not only to the additional workers but also to diversity itself (Ostry 
and others 2018). Hsieh and others (2013) attribute 25 percent of the increase of productivity in the United States between 1960 and 2010 to the improved allocation of talent in the labor market thanks to the reduction of discrimination against women and blacks. (See also Cavalcanti and Tavares 2015 for estimates of the cost of gender discrimination.)

Ultimately, social inclusion must be a conscious choice of societies and governments, made with a clear understanding of the costs and benefits. Because investing in an inclusive society is not free, to transform the investment into a winwin requires concerted action. Social programs, for instance, can be expensive and impact fiscal sustainability. Governments often must make trade-offs, either by cutting costs on other initiatives or by raising taxes. There may be political costs as well because initiatives that focus on historically excluded groups can upset power relations. Governments and politicians must craft clear social contracts with citizens to ensure support for social inclusion. There are examples the world over of citizens' willingness to pay for a more inclusive society. The most powerful form of support is through the fiscal realm, whereby citizens pay taxes that they know will fund policies and programs for greater social inclusion. In Brazil, Mexico, and Nepal, for instance, there is strong support for social protection programs. In Bangladesh, poverty reduction is recognized as a national priority, and the elite support antipoverty initiatives (Hossain and Moore 1999). Tentative evidence from Ghana, Kenya, Nigeria, and Uganda shows that attitudes toward redistribution may be favorable overall (Langer and others 2016).

\section{Analytic Strategy and Road Map}

This report sets out Africa's development imperatives within a framework of social inclusion. It outlines some of the areas in which Africa has taken major strides and simultaneously asks: who is left behind, from what, in what ways, and what can be done? The key questions in this report are drawn from the Social Inclusion Assessment Tool ${ }^{1}$ and from Das (2016). The report also highlights the many solutions that are already in place in various African countries. It is deeply influenced by the myriad conversations and engagements that World Bank teams have had with partners and counterparts across Africa. The groundswell of thought and action, combined with the strong push from both state and nonstate actors for the World Bank Group (WBG) to articulate social inclusion in the African context, has led to several structured engagements between the WBG and a multitude of its partners. These encounters are laid out in appendix A. Consequently, the audience for this report includes an equally wide array of actors: governments, private sector, civil society, academics, the media, and others. This report also is expected to influence the way that the WBG will conduct its business in Africa going forward. 
Over the years, several macro- and micro-level analyses have been published on issues relevant to social inclusion in Africa. The WBG produces regular Systematic Country Diagnostics (SCDs) for each of its partner countries. These diagnostics from African countries have shown issues of social inclusion to be central to reducing poverty. The diagnostics also have focused on individuals and groups who are at risk of being left out of the progress and prosperity that now sweep most of Africa. This report builds on these macro-level diagnostics and on other regional and country reports focusing on poverty and human development. It also synthesizes other existing evidence to stimulate debate, research, and policies for social inclusion in Africa. Our hope is that this report will enable new questions to be framed and addressed, although, like all regional reports, it can do only limited justice to the vast heterogeneity of the continent. The analytic foundation for this report therefore, comes from a comprehensive review of the literature on social inclusion and data from, among others, poverty assessments, Demographic and Health Surveys (DHS), World Development Indicators (WDI), United Nations, Afrobarometer surveys, and World Values Surveys (WVS).

The report contains five chapters. This first chapter lays out the motivation for this work and clarifies concepts and underlying assumptions. Chapter 2 highlights the major trends and transitions that shape the context for social inclusion in Africa and describes who may be left behind. Chapter 3 provides pointers on the processes that underlie exclusion and those that foster social inclusion. Attitudes, perceptions, and feelings are elaborated. Chapter 4 highlights Africa's movement toward social inclusion. Who are the key actors? Which innovations promote social inclusion in Africa? What evidence do we have about what has made a positive difference? Chapter 5 concludes the discussion and provides guidance on framing the right questions for inclusive solutions. 


\section{Notes}

${ }^{1}$ See World Bank, “The Social Inclusion Assessment Tool (SiAT)," http://pubdocs. worldbank.org/en/478071540591164260/SiAT-Logo-web.pdf. 


\section{CHAPTER}
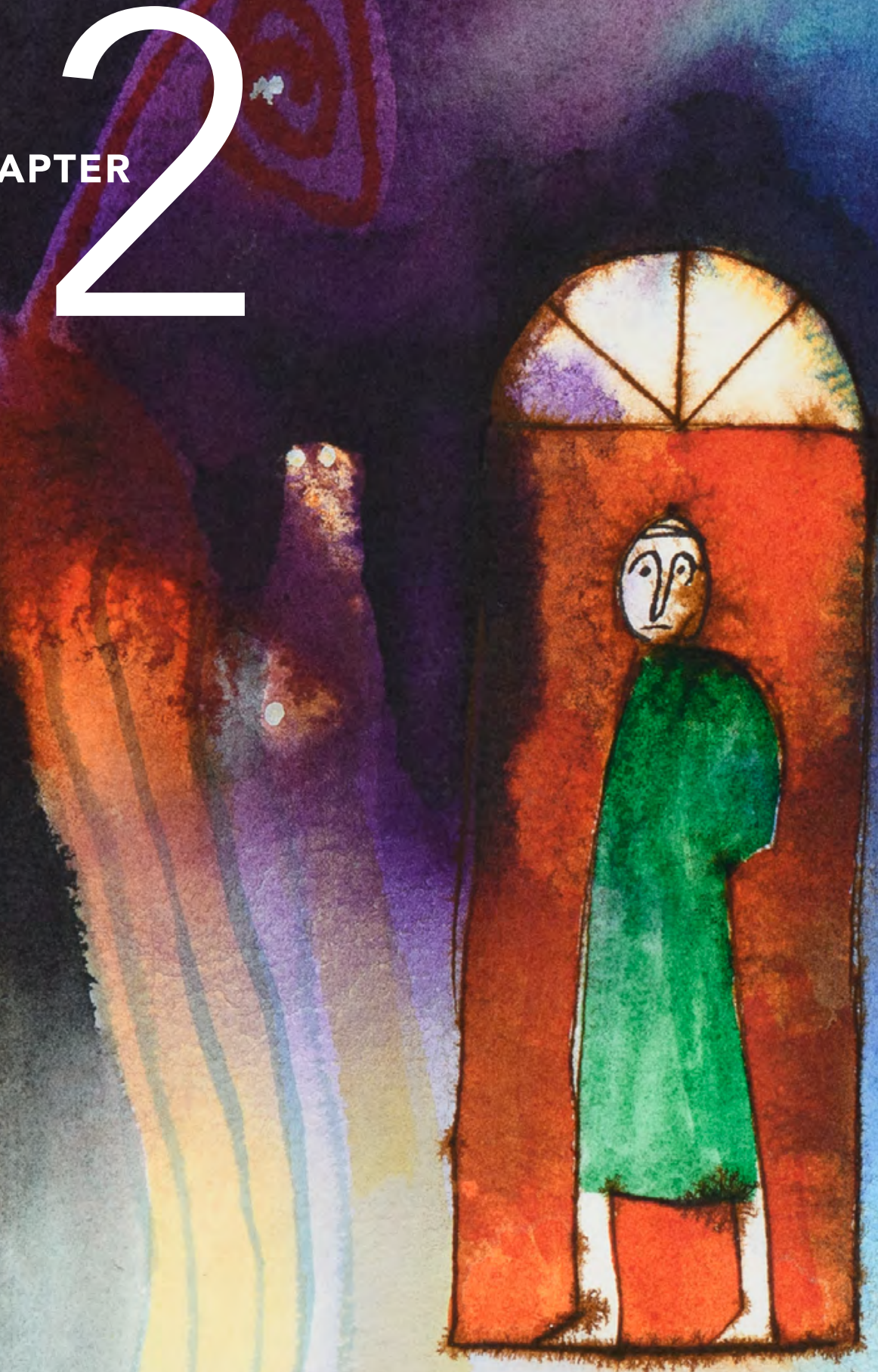


\section{Africa Is Striding: Who's Left Behind?}

As we embark on this great collective journey, we pledge that no one will be left behind. Recognizing that the dignity of the human person is fundamental, we wish to see the Goals and targets met for all nations and peoples and for all segments of society. And we will endeavour to reach the furthest behind first.

-Resolution adopted by United Nations General Assembly on September 25, 2015

Over the past few decades, Africa has seen extraordinary progress. In fact, in some areas, the progress in Africa is faster than it is in any other region, and sometimes faster than we have historically seen anywhere in the world. However, the trends are highly heterogeneous across and within countries. Although they hold the promise of greater heights, they also create new challenges for social inclusion.

Digital technology, for instance, can leave further behind those who do not have mobile phones or Internet connections. Similarly, improved infrastructure has provided better lives, but also carries risks, for instance, of lands being unfairly taken from those most powerless or of damage to the environment or livelihoods. Improvements in education and health can be concentrated in certain locations and for some groups. Areas that experience state and societal fragility also fall behind in various development outcomes.

So, both areas and peoples can be excluded from the gains that the continent has achieved. Chapter 2 discusses the major trends and transitions in Africa with a focus on their potential implications for social inclusion. The chapter begins with a discussion of how poverty reduction, demographic changes, climate change, and conflict in a context of rapid urbanization are likely to affect social inclusion. 


\section{Demographic Trends and Human Capital Accumulation}

\section{Population and Fertility}

Global population is certainly growing, but fertility is falling in every world region (figure 2.1). More than half of the anticipated growth in global population between now and 2050 is expected to occur in Africa (UN DESA Population Division 2019). Yet, Sub-Saharan Africa will see the largest reductions in average total fertility, which is projected to fall from approximately 4.6 live births per woman in 2019 to 3.1 in 2050 and 2.1 by 2100 . Globally, there are 36 countries or areas in which the fertility rates are above 4 births per woman; of these, 33 are in Sub-Saharan Africa. The most populous countries with total fertility rates of more than 4 are, in order of size: Nigeria, Ethiopia, Democratic Republic of Congo, Tanzania, Uganda, and Sudan. By 2050, Niger is expected to be the only country with a total fertility rate (TFR) of 4.0. There are large variations both within and across countries, and countries of Southern Africa have much lower fertility rates than do other areas. Countries with the highest fertility and the slowest decline are those most affected by conflict and fragility. Africa also has the world's highest rates of teen pregnancy; approximately 46 percent of all births to girls and women in the 15 to 19 age group occur in Africa (UN DESA Population Division 2019).

Figure 2.1 Fertility Decline across the Globe, 1950-2100

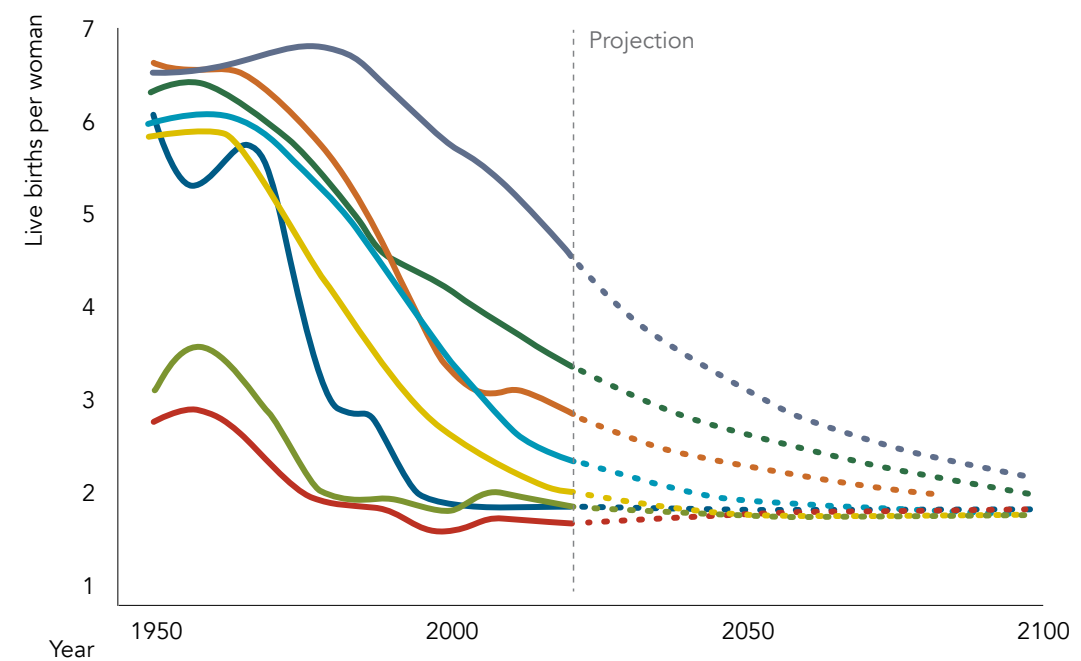

Sub-Saharan Africa

Northern Africa and Western Asia

Central and Southern Asia

Eastern and South-Eastern Asia
Latin America and the Caribbean

Australia/New Zealand

Oceania $^{a}$

Europe and Northern America

Source: UN DESA Population Division 2019.

Note: Regions per UN classification.

a. Excluding Australia and New Zealand. 
Why does fertility matter for social inclusion? It matters because women are the bearers of children and, for the most part, rear them. When to have children, how many to have, and how much space there is between children are all factors that cast inexorable influence on the life chances of women and their children and, to an extent, of men and entire families. Women's ability to control their fertility and their reproductive rights are inseparable from their overall welfare outcomes and those of their children and families. When women do not have access to or information about birth control, their overall agency is diminished. This point is especially salient for adolescent girls, who often have the least power, information, and ability to control their fertility. Although there have been rapid changes in access to contraception in some parts of Africa, the unmet need for family planning is still significant. Between 2000 and 2017, Middle and West Africa saw increases in contraceptive prevalence (from 18 to 23 percent and from 13 to 20 percent, respectively). However, in 2017 unmet needs for family planning remained constant at levels above 20 percent. East Africa, Middle Africa, West Africa, Melanesia, the Federated States of Micronesia, and Polynesia had the highest unmet needs for family planning in 2017. This need indicates a supply side failure, leaving women who may want to control their fertility unable to find the means to do so (UN DESA Population Division 2017b). However, there also may be other factors that affect women's desire for more children.

\section{Health and Mortality}

As in fertility, Africa has seen improvements in health and longevity, but underfive mortality is still high. Children's survival to age five is a core indicator of welfare, but also has additional ramifications. For example, high rates of underfive mortality are associated with higher fertility. Moreover, because countries with high levels of child mortality are bogged down by the most basic imperative of keeping children alive, these countries are less able to invest in human capital. Based on United Nations child mortality estimates, according to the Our World in Data project and AfricaInData.org, from 1980 to 2015, child mortality declined sharply. ${ }^{1}$ In fact, compared to other regions, between 1990 and 2016, Africa saw the fastest decline. Despite these improvements, Africa still has the highest underfive mortality rate, at 78 deaths per 1,000 live births in 2016. In other words, approximately 1 child in 13 still dies before her/his fifth birthday (Suzuki and Kashiwase 2017). There is considerable variation across African countries, and fragile states have the highest rates of under-five mortality.

Life expectancy has also increased in the last few decades, but AIDS has had long-term deleterious impacts. Overall, between 2000 and 2015, compared with South Asia, Latin America, and the Caribbean, Africa saw the largest increase in life expectancy, (UNDP 2016, 96). Yet, in 2019 the countries with the lowest life expectancies also are in Africa. They are Central African Republic, Chad, Lesotho, 
Nigeria, and Sierra Leone, each with life expectancy at birth below 55 years (UN DESA Population Division 2019). African countries also were ravaged by AIDSrelated mortality, which globally declined sharply, driven by the huge improvements in Africa. In most high-prevalence countries, AIDS-related mortality peaked in the last decade. Nevertheless, many countries have not yet recovered fully from the effects of the epidemic. In Southern Africa, life expectancy at birth fell from 62.9 years in 1990 to 52.6 years in 2004 and has since recovered to just above the 1990 level, having reached 63.8 years in 2019. This lower life expectancy at birth represents a loss of two decades of potential improvements in survival rates for Southern Africa. HIV/AIDS continues to have other long-term consequences, and stigma against persons with HIV is still evident. The catastrophic long-term effects for orphans, estimated at 52 million in Africa, ${ }^{2}$ deserve special attention.

As African countries proceed with the demographic transition, the age structure of their populations is poised for transformation. Today, half of the population in the region is under 25 years of age. By 2050 the continent will have 362 million young people who are between 15 and 24 years of age (World Bank 2014). Simultaneously, many African countries will see aging of the population. By 2050 Africa's over-60 population is expected to more than triple, from 69 million in 2017 to 226 million (UN DESA Population Division 2017a). Although youth inclusion is the immediate challenge facing the region, the inclusion of older cohorts of Africans will soon be a part of the picture. This huge increase of persons over 60 is something that policy-makers find difficult to visualize. Nevertheless, today Africa's growing young population has the potential to dramatically drive development and further reduce poverty, if the right policies and opportunities are provided for them (box 2.1).

\section{Education and Accumulation of Human Capital}

In education, too, there has been significant progress, but as in other parts of the world, there are stark inequalities in educational outcomes based on identity markers. The average primary gross enrollment ratio in the region increased from 68 percent in 1990 to 98 percent in 2015, and the number of enrolled students grew from 63 million to 152 million. Yet, despite the increase in primary school enrollment rates, an estimated 52.3 million primary- and lower secondary schoolage children (ages 6-14 and 7-15) are still out of school, accounting for 45 percent of the world's out-of-school child population (Bashir and others 2018). There also is a significant gap in literacy between males and females, with West Africa having the highest gender gaps and Southern Africa having the lowest (figure 2.2). Overall, quality of education is a point of growing concern.

The overlay of gender with other identity markers confers additional disadvantage in education, as it does in other outcomes. Using census data, Taş and others (2014) show that ethnic minority women in Senegal and Sierra Leone suffer cumulative 


\section{Box 2.1 Ability, Opportunity, and Dignity for African Youth}

African countries are abuzz with initiatives that either focus on young people or are run by them, or both.

The youngest among all continents, half of Africa's population is below 25 years of age. These young people are innovators, leaders, entrepreneurs, social media influencers, writers, volunteers, activists, and professionals. Asserting their African identity, they exercise thoughtful leadership at local, national, and global levels in a variety of ways. Nevertheless, evidence from an array of sources, some of which is highlighted in this report, shows their unique needs. This report also portrays the heterogeneity of African youth-the intersectional advantage or disadvantage bequeathed by gender, occupation, religion, ethnicity, socioeconomic status, location, sexual orientation, and marital status. The report also shines a light on certain aspects, including vulnerability to gender-based violence, female genital mutilation (FGM), child marriage, and reintegration of young ex-combatants. Building human capital and hearing these voices are central to the inclusion of youth in Africa, as in the world over.

The World Bank's social inclusion framework highlights the importance of ability, opportunity, and dignity in advancing inclusion (World Bank 2013). These three elements are nowhere more salient than for young people who crave and aspire to the right to make decisions about their own lives and for their communities and countries. While the focus on jobs in Africa is important in the face of high levels of youth unemployment, there is a need for policy that would give young people the status and dignity that they deserve. This report presentsevidence of the changing nature of young persons' participation in political processes.

While the downward trend of youth turnout in elections is indeed worrying, we should not confuse apathy about the political process with a lack of passion about the issues and challenges facing the world. It is clear that the sense of disillusionment that many young people feel for our political institutions reflects the fact that they have been sidelined by them. If young people do not think that they can make a difference through these institutions and processes, should we really be surprised at their ambivalence towards them?

-Kofi Annan, $2013^{\text {a }}$

If young people feel left out of markets, services, and tangible and intangible spaces, their potential dejection and frustration can have long-term consequences for them, their families, and their societies. At the individual level, dejection can lower human capital and increase mental health costs. If it becomes pervasive among a large group of the youth, it can take the form of radicalization and violence. This report describes some of the challenges for youth in Africa, and how young people often are potent change agents in their communities.

Note: a. For more, see "Kofi Annan on International Youth Day: Let the Young Lead," https://www.forbes.com/sites/skollworldforum/2013/08/12/kofi-annan-on-internationalyouth-day-let-the-young-lead/\#38dfff3f2aae 
Figure 2.2 Female and Male Literacy Rates, Ages 15 and Above, 2016

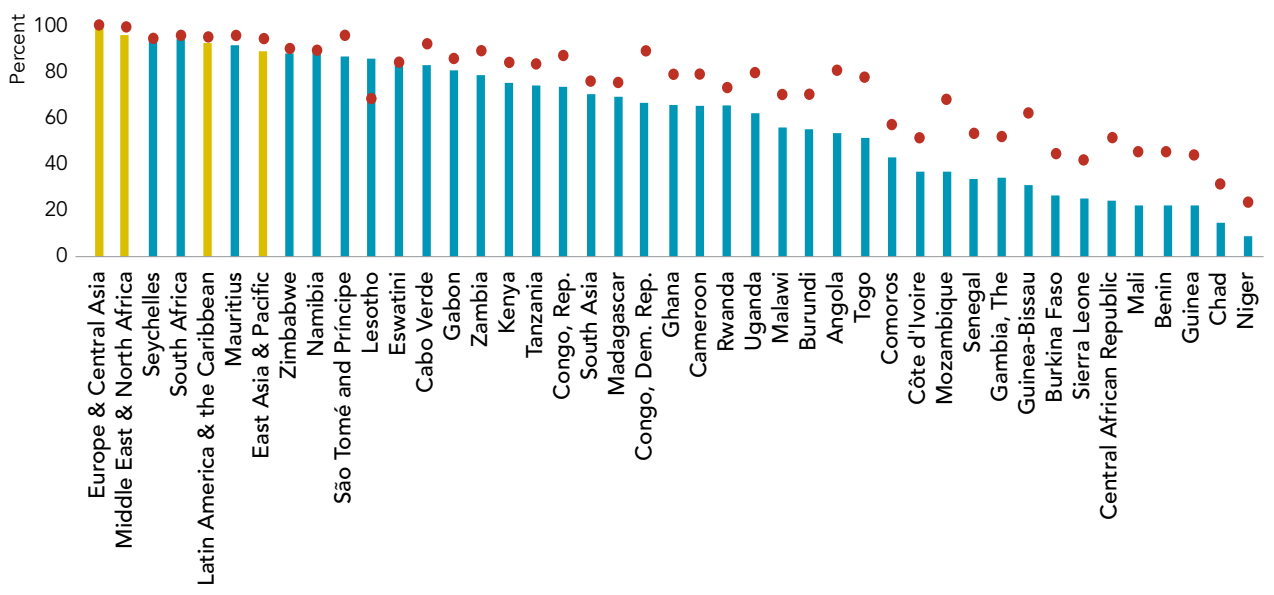

Literacy rate, adult females ages 15 and above

Literacy rate, adult males ages 15 and above

Source: : World Development Indicators (WDI) 2016 or latest available from United Nations Educational, Scientific and Cultural Organization (UNESCO) Institute for Statistics, https://data.worldbank.org/ indicator/SE.ADT.LITR.FE.ZS?view=chart.

disadvantages in literacy, primary school completion, and secondary school completion. In Senegal, for example, individuals are 10 percentage points less likely to complete primary school for being female, 1.6 percentage points for being ethnic minority, and an additional 3.8 percentage points for being ethnic minority women. Therefore, cumulatively, women of ethnic minority groups are approximately 15.4 percentage points less likely to complete primary school than men belonging to majority ethnic groups in Senegal. In South Africa, despite significant progress since the end of apartheid, educational outcomes among black and colored South Africans remain low. Although the white population reached close to full attainment of 12 years of education in 1920, the black population has yet to achieve these levels, perpetuating the legacy of racial division in education in South Africa, which remains a main driver of poverty and inequality (World Bank 2018f, 13). Similarly, the Benin Systematic Country Diagnostic (SCD) notes that the lack of maternal language teaching in primary school puts indigenous children at a disadvantage and leads them to abandon school prematurely (World Bank 2017b, 57).

Disability status is another critical determinant of educational outcomes. Data from the Living Standards Measurement Study (LSMS) in Ethiopia, Malawi, Tanzania, and Uganda suggest that 10 percent to 15 percent of working-age adults in Africa have a disability. "Disability" is defined as moderate or severe functional difficulty with walking, seeing, hearing, cognition, self-care, or 
communication (Mitra 2018). ${ }^{3}$ Multiple studies have presented evidence of lower educational attainment of persons with disabilities in Africa (Eide and Mmatli 2016; Filmer 2008; Hoogeveen 2005; Loeb and Eide 2004; Loeb and others 2008; Mitra 2018; Mitra and others 2013; Mizunoya and others 2016). In the cases of Ethiopia, Malawi, Tanzania, and Uganda, Mitra (2018) finds that both adults with moderate functional difficulties and those with severe functional difficulties are significantly less likely to ever have attended school than adults with no functional difficulties. In Ethiopia, only 15 percent of persons with severe functional difficulties (and 24 percent with moderate functional difficulties) have ever attended school, compared to 48 percent of persons with no functional difficulties. In Uganda, 60 percent of persons with severe functional difficulties and 73 percent with moderate functional difficulties have ever attended school, compared to 89 percent with no functional difficulties. ${ }^{4}$

When disability status is combined with gender, we see the real effects of intersectional disadvantage. The extent of this disadvantage varies across countries. In Malawi, only 35 percent of women with severe functional difficulties have ever been to school, compared to 65 percent of men with severe functional difficulties. In Tanzania, these numbers are 30 percent of women versus 61 percent of men with severe functional difficulties; and in Uganda, 48 percent of women compared to 74 percent of men with severe functional difficulties. In Ethiopia, rates are much lower than in the other three countries for both men and women: 14 percent of women with severe functional difficulties have ever attended school, compared with 16 percent of men with severe functional difficulties. Gender gaps appear to widen with greater functional difficulty. Therefore, a woman with a disability has fewer years of schooling than any other category: men without a functional difficulty, women without functional difficulty, and men with functional difficulty. Outcomes differ further by type of disability, but the lack of reliable data seriously constrains analysis and action. For instance, data for intellectual disabilities are particularly scarce, as are assessment facilities and avenues for accessibility. There has been growing attention to albinism, a genetic disorder that causes severe functional difficulties, but data and evidence are limited. Box 2.2 provides a short overview on how albinism affects human capital outcomes.

\section{Economic Transitions}

\section{Growth and Poverty Reduction}

Since the 1990s, poverty has decreased impressively. However, during the same period, the absolute numbers of the poor have increased dramatically. The poverty head count declined steadily from 57 percent of the African population in 1990 to 41 percent in $2015 .{ }^{5}$ Concurrently, due to growth in the numbers of people overall, the absolute number of people living in poverty increased from approximately 278 


\section{Box 2.2 Albinism and Human Capital Outcomes}

Albinism is a genetic disorder that results in a decrease or absence of pigmentation in the hair, eyes, and skin. Prevalence data are not available for most countries in Africa. Nevertheless, compared to global estimates of approximately 1:20,000, estimates for Africa range from 1:15,000 (1 person with albinism in every 15,000 people) to as high as 1:1,000 in some areas of Tanzania and Zimbabwe. Certain ethnic groups seem to display higher prevalence rates, likely linked to factors that include limited geographic mobility, consanguinity, and certain traditional marriage practices that limit the genetic pool.

The lack of melanin, which has a protective function against ultraviolet radiation (UVR), predisposes individuals with albinism to a range of pathologic conditions, including photophobia, decreased visual acuity, extreme sun sensitivity, and skin cancer. One 2002 study suggested that all persons with albinism had some form of visual impairment, and that the latter had strong implications for their education and overall life chances. Another study in Tanzania found that all individuals with albinism exhibited skin damage in their first year of life and that those ages 20 to 30 had advanced symptomatic cancers. Many of the negative, and even lethal, outcomes for persons with albinism are associated with stigma, ignorance, and superstition. Nevertheless, life expectancy of persons with albinism has increased significantly over the past decades: whereas in the 1980s, it was estimated that fewer than 10 percent of persons with albinism would survive beyond 30 years and fewer than 2 percent would reach 40 years. They now live considerably longer because of advances in preventive sun protection.

Sources: Cruz-Inigo and others 2011; Hong and others 2006; Lund 2001. 
million to over 413 million. There also is significant divergence in performance across African countries driven by several factors, among which fragility, conflict, and endowment of natural resources stand out (figure 2.3). Between 1996 and 2012, poverty decline in fragile states in Africa was less than the decline in the nonfragile states in Africa. After controlling for a set of country characteristics, poverty reduction in fragile states was 15 percentage points less than it was in nonfragile states (Beegle and others 2016). After controlling for other country traits, countries rich in natural resources reduced poverty by 13 percentage points faster than did non-resource-rich countries. A caveat is in order here: Unless their institutions are robust enough, countries that are endowed with natural resources can fall prey to the "resource curse," which can exacerbate fragility and conflict.

Asking "Who are the poor?" and breaking down the poverty numbers, we find greater complexity. For the relationship between gender and poverty, for example, there is a long tradition of analysis. Overall, women are not necessarily poorer than men, nor are male-headed households necessarily better off. Moreover, in many countries in Africa, female-headed households have experienced faster poverty reduction than Asking "Who are the poor?" and breaking down the poverty numbers, we find greater complexity. For the relationship between gender and poverty, for example, there is a long tradition of analysis. Overall, women are not necessarily poorer than men, nor are male-headed households necessarily better off. Moreover, in many countries in Africa, female-headed households have experienced faster poverty reduction than male-headed households (Milazzo and

Figure 2.3 Poverty Rates in Fragile and Nonfragile Countries 1996-2012

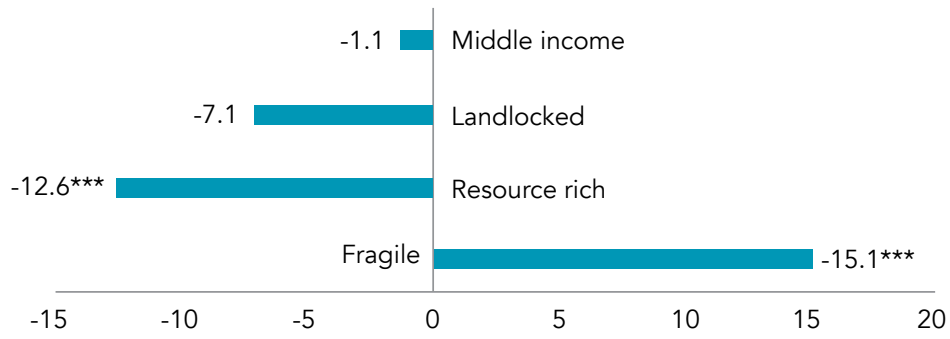

Change in poverty rate (percentage points) compared to alternative category

Note: Figure shows results of a regression on the change in the poverty rate for 43 countries from 1996 to 2012 based on estimated poverty rates using comparable and high-quality surveys.

$\star \star \star=$ Statistically significant at the $1 \%$ level. 
van de Walle 2017). More nuanced findings emerge when gender is looked at jointly with age and marital status. Young married women, but more so those who are young and widowed, are especially vulnerable (Milazzo and van de Walle 2017). However, older men are on average 8 percentage points poorer than their female counterparts (Munoz Boudet and others 2018).

Mitra and others' 2011 study in Burkina Faso, Ghana, Kenya, Malawi, Mauritius, Zambia, and Zimbabwe is possibly the most detailed analysis of disability and poverty. They show that the relationship between disability and poverty varies by the measures of both poverty and disability that are used in the analysis. The most conclusive result is that, when expanded measures of disability are used along with measures of multidimensional poverty, there are "significant disparities in disability prevalence in most countries by poverty status" (39). Figure 2.4 and box 2.3 analyze the extent to which ethnicity matters for poverty in select African countries.

\section{Box 2.3 Ethnicity and Poverty in Rural and Urban Africa}

As in other regions globally, ethnicity can be a fraught idea in many African countries. Some, such as South Africa, expressly and officially acknowledge the importance of race in opportunities and outcomes. Other countries focus purely on citizenship and eschew any focus on ethnicity. The latter often is born of historic conflict that assumed ethnic overtones. However, the literature from regions as diverse as Europe, Latin America, and South Asia shows that

Figure 2.4 Distribution of Ethnic Groups in Bottom Wealth Quintile (\%)
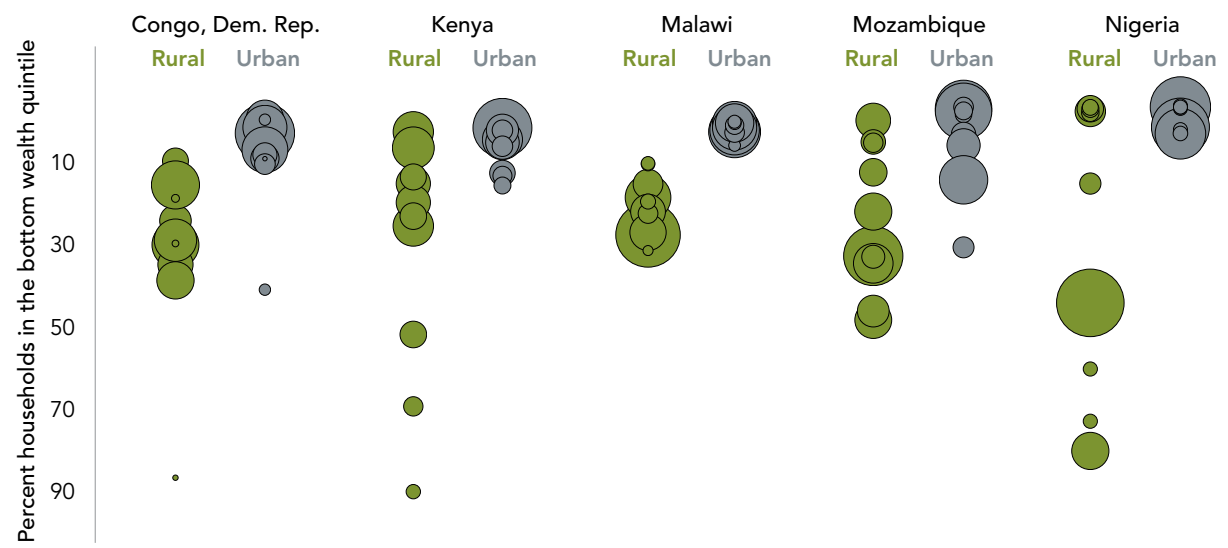

Source: World Bank calculations based on the latest Demographic and Health Survey (DHS) available for countries (Congo, Dem. Rep. DHS-VI 2013/14; Kenya DHS-VII 2014; Malawi DHS-VII 2015/16; Mozambique DHS-VI 2011; Nigeria DHS-VI 2013; Sierra Leone DHS-VI 2013; South Africa DHS-VII 2016; Uganda DHS-VII 2016; Zambia DHS-VI 2013/14). 
certain ethnic groups are overrepresented among the poor. Their locational characteristics often explain their poverty, but this explanation frequently overlooks the political economy of regional development.

Does ethnicity matter for poverty in Africa? Using the Demographic and Health Survey (DHS), which has data on ethnicity and wealth based on a household's ownership of select assets, we analyzed data from nine countries. They were Democratic Republic of Congo, Kenya, Malawi, Mozambique, Nigeria, Sierra Leone, South Africa, Uganda, and Zambia. Looking at the 10 largest ethnic groups in rural and urban areas, we found that ethnicity does indeed matter for wealth outcomes, but mostly in rural areas and significantly less so in cities and towns. The results from figure 2.4 are summarized below:

- Overall, certain ethnic groups are overrepresented in the poorest wealth quintile in all nine countries. Disparities between ethnic groups are larger in rural areas than in urban areas.

- Size of the ethnic groups does not seem to matter. This result is unsurprising because across the world, the size of an ethnic group seldom has a linear association with its welfare outcomes.

- The greatest dispersion along ethnic lines in the poorest quintile in rural areas appears to occur in Kenya, Nigeria, and Uganda, followed by lesser dispersion in Zambia and Mozambique. Although the overrepresentation of some ethnic groups in the lowest wealth quintile is more pronounced in some countries than in others, overrepresentation may or may not reflect absolute gaps in wealth between these groups.
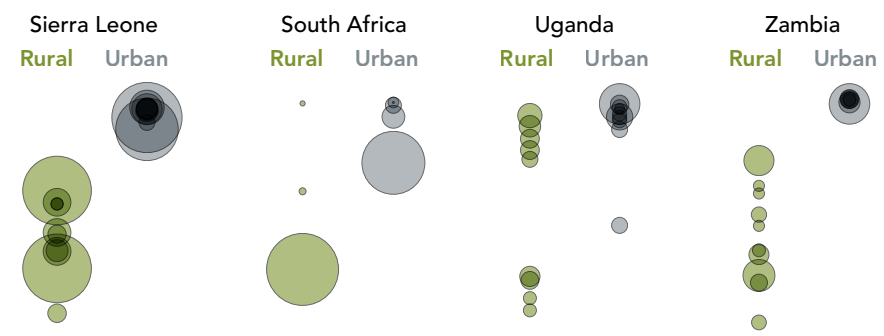

Note: Each bubble represents one ethnic group (as defined in DHS). Area of bubble is proportional to the share of the ethnicity's rural (or urban) population in the total rural (or urban) population. Only the ten largest ethnic groups for each country are displayed. For South Africa, the DHS does not include more than five distinct ethnic groups in total so all groups are displayed. 


\section{Food Security}

Contrary to the Malthusian specter of population growth jeopardizing food production, between 1990 and 2015, Sub-Saharan Africa experienced the steepest decline of food deficit in the world. During this period, the food deficit in African countries halved, ${ }^{6}$ whereas other regions, including South Asia and the Middle East, experienced fluctuations (figure 2.5). Nevertheless, over 50 million children under age five in Africa remain stunted: the Region has the second highest stunting and wasting rates in the world, after South Asia. Africa also is the only Region in which the absolute number of stunted children has increased over time, mainly due to population growth. These children will have difficulty reaching their full potential as adults. Globally, children living in households in the poorest quintile have higher stunting rates than children in other income groups. One study in Tanzania showed that the Maasai were disadvantaged compared to their neighboring ethnic groups on measures of both child nutritional status and disease. Although food insecurity was high throughout the study area, the Maasai fared worse (Lawson and others 2014). Other children, such as orphans, children of parents affected by HIV, or those whose parents engage in precarious occupations (such as waste picking), also are likely to have a higher risk of malnutrition.

\section{Figure 2.5 Depth of Food Deficit, 1992-2016}

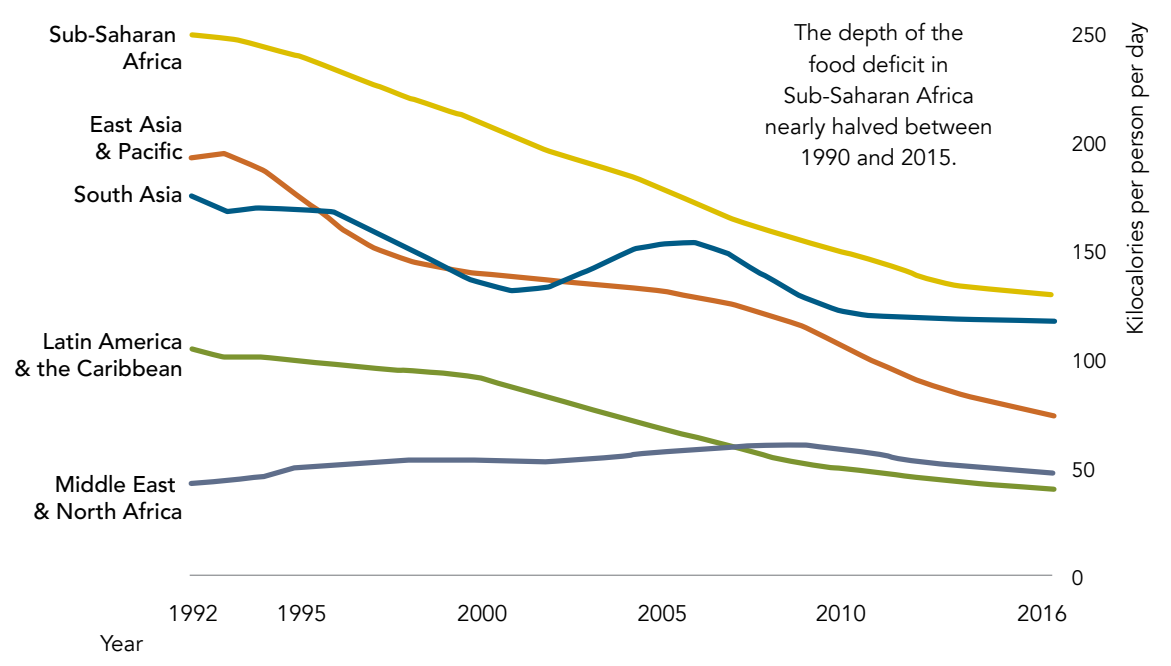

Source: World Bank 2018c, based on FAO data.

Note: "Food deficit" is defined as the amount of food, measured in kilocalories/day, needed for a person not to be considered undernourished. 


\section{Employment}

Income from labor tends to play an important role in poverty reduction. The Afrobarometer (2016) asked respondents to list their top ten priorities or problems. Unemployment emerges as the top concern among urban men and women. Interestingly, the urban-rural difference in priorities trumps the gender difference: males and females give similar responses about their priorities. In Africa overall, the jobs challenge that gains spotlight in the media, in social media, and in political manifestos also is reflected in figure 2.6. This challenge is compounded by the

Figure 2.6 Top Problems Facing Countries across Africa, 2016 (\%)

a. Men's views of top problems

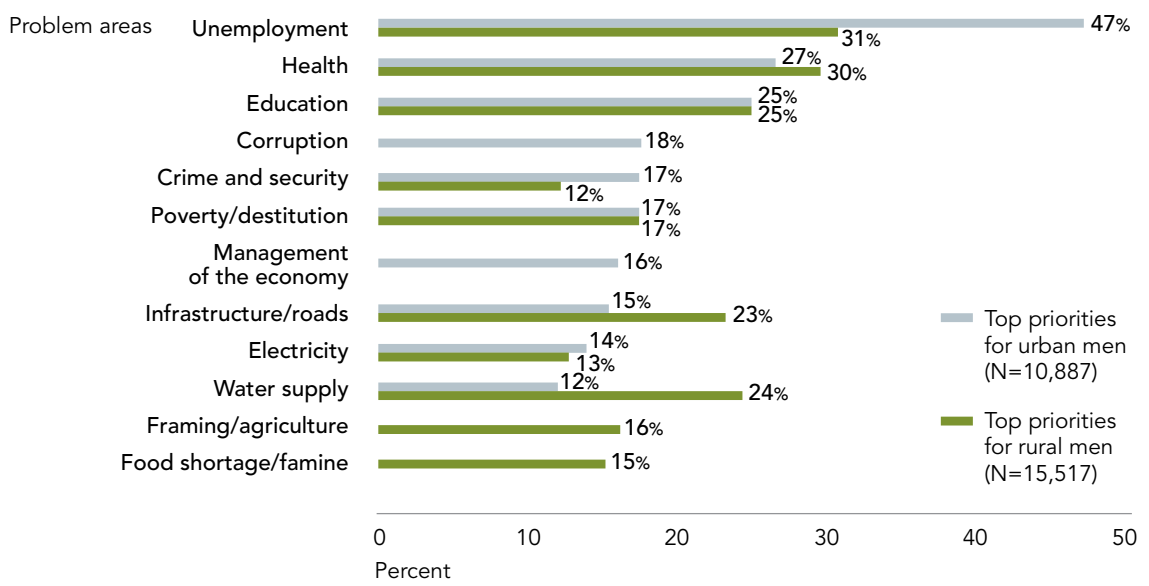

\section{b. Women's views of top problems}

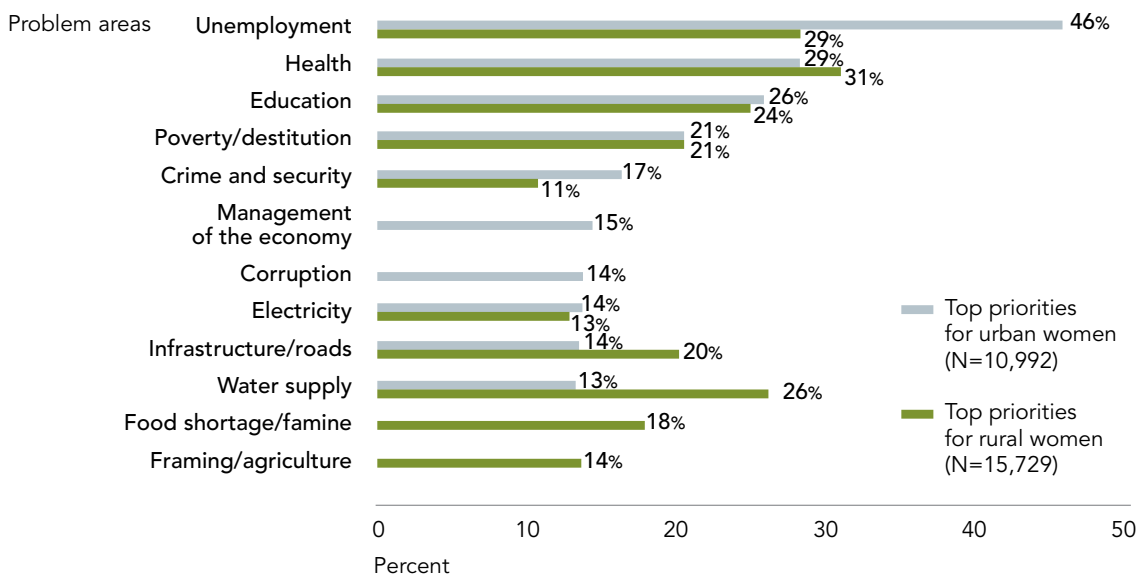

Source: Extracted from Das 2017, based on Afrobarometer Survey 2016. 
fact that labor markets can be notoriously exclusionary. African countries are no exception: employment outcomes vary across groups. This variation is not only caused by exclusion or discrimination. However, it often is difficult to separate the effects of exclusion from those of other factors, such as human capital and effort.

Regardless of the reasons for differential outcomes in the labor market, some groups are systematically under greater stress due to either poor quality jobs or unemployment. Women's labor force participation generally is higher in Africa than in other non-OECD (Organisation for Economic Co-operation and Development) countries, and differentials in labor outcomes are lower. However, Africa does have significant barriers to women's economic empowerment. For example, historically, African women have been very active in agriculture yet have fewer opportunities in other sectors. Labor market outcomes also vary across other groups, such as youth. Most young people in Africa do not have easy transitions into the sustainable jobs that are an intrinsic marker of adulthood (Filmer and Fox 2014). In Zambia, Bhorat and others (2015) found that the youth are disproportionately affected by both unemployment and marginal or underemployment, with stronger effects for young women than for young men. Factors other than gender and age also matter for labor market outcomes. The South African evidence suggests that, despite progress since apartheid, significant earnings differentials persist between African, colored, and white people. Whites earn 40 percent more per additional year of education than Africans and 20 percent more per additional year than colored people (Salisbury 2016).

In addition to the fairly well-known differentials in employment outcomes across gender, age, and race or ethnicity, data availability has revealed the poorer outcomes for persons with disabilities. This focus comes through in several recent studies (for example, Eide and Loeb 2006 for Zambia; Eide and Mmatli 2016 for Botswana; Mitra 2008 for South Africa; and Mitra and others 2013 for 15 developing countries, including Burkina Faso, Ghana, Kenya, Malawi, Mauritius, Zambia, and Zimbabwe). Hoogeveen $(2005,7)$ and Mitra $(2018,104)$ show further that persons with disabilities are more likely to be self-employed in agriculture and less likely to be employees. There also are variations in outcomes across different types and intensities of disability. Using data from Ethiopia, Malawi, Tanzania, and Uganda, Mitra (2018) points to large gaps in employment between persons with severe disabilities and those with no disabilities. The largest gaps were noted in Tanzania, where 53 percent of persons with severe functional difficulties were employed, compared to 85 percent of persons with no functional difficulty. Regarding poverty, Mitra (2018) points out that, although people with functional difficulties are overrepresented among the poor, not all of them are poor (156). 


\section{Technology and Digital Inclusion}

Although this era is the global age of technology, the value of this potent medium to the people is determined by the extent to which countries, regions, communities, and households have access to it. Although, in many respects, Africa seems to have leapfrogged into the digital economy, great variation exists across and within countries. For example, in nonfragile countries, mobile cellular subscriptions increased from 0.67 per 100 persons in 2000 to 83 per 100 persons in 2016 . In fragile countries, on the other hand, subscriptions increased from 0.20 per 100 persons in 2000 to 68 per 100 persons in 2016. Despite a relatively faster rate of increase in mobile cellular subscriptions in fragile countries, the number of mobile cellular subscriptions is still higher in nonfragile countries (Calderon and others 2019, 49). Similarly, financial technology ("fintech") has expanded rapidly across Africa over the past years: 21 percent of adults in Africa now have a mobile money account, with numbers having doubled since 2014, the highest of any region globally (Demirgüç-Kunt and others 2018). M-PESA, a money transfer system in Kenya, is one of the earliest and perhaps one of the most prominent examples of fintech in Africa. Digital technology also can spearhead employment, as the recent World Bank report on the future of work in Africa points out (Choi and others 2019).

ICT [information and communications technology] literacy will give women, especially in rural areas, a chance to join the virtual labor market. For example, many of today's women in Sudan are using social media to exhibit their products. These women saw social media as a platform to sell their products because of the challenges they would face due to cultural and social constraints.

-Moneera Yassien, 2019

Digital technology is a potent vehicle for social inclusion, but it also can be a channel to deepen exclusion. The proportion of individuals who have access to the Internet in each African country is highly correlated with that country's income level. Regionally, Internet use is lowest in Sub-Saharan Africa, where a median of 41 percent of persons across six countries use the Internet. South Africa is the only country in the Region in which almost 60 percent of the population is online (Pew Research Center 2018b). Furthermore, the Pew Research Center Spring 2017 Global Attitudes Survey in six countries showed that males with higher education and higher income levels were more likely to use smartphones (figure 2.7). Nonusers of smartphones are left out of many opportunities to access markets, services, and spaces. 
Figure 2.7 Smartphone Use by Gender, Age, Education, and Income by Country, 2017 (\%)

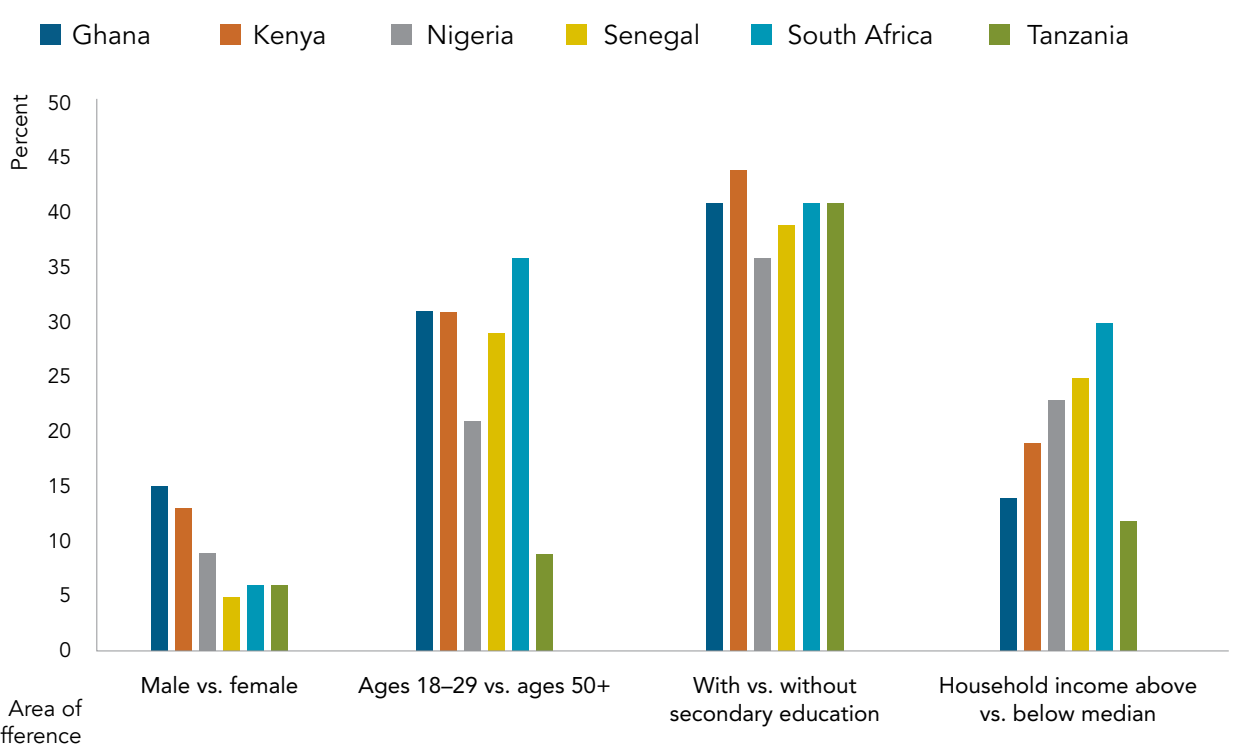

Source: World Bank calculations based on data from Pew Research Center, Spring 2017 Global Attitudes Survey (Silver and Johnson 2018).

Note: The graph displays the percentage differences in mobile phone ownership, between men and women, different age groups, people with different educational attainment, and those from different income groups. For age, differences are between the youngest (18-29 years old) and the oldest (50+ years) age groups sampled. For education, differences are between those with less than secondary education, and those with secondary education and above. For income, differences are between those with an income below the approximate country median, and those at or above the approximate country median.

Africa's social geography is rapidly changing; it is, for example, the fastest urbanizing region in the world (figure 2.8). Currently, approximately 472 million people live in cities and towns-a number that is expected to double over the next 25 years (Lall and others 2017). There are, however, large subregional variations. Most people in North and Southern Africa already live in cities. West Africa is projected to reach an urban majority just after 2020, whereas urbanization rates are still below 20 percent in East Africa (UN-Habitat 2014). Nigeria is among the top three urbanizing countries in the world. Together with China and India, Nigeria is estimated to account for 35 percent of the projected growth of the world's urban population between 2018 and 2050, adding 189 million urban dwellers (UN DESA Population Division 2018).

Cities and towns simultaneously are bastions of inclusion and sites of exclusion. Migration from villages to cities and towns tends to be accompanied by aspirations 
Figure 2.8 The Coming of the Urban Age, 1950-2050 (\%)
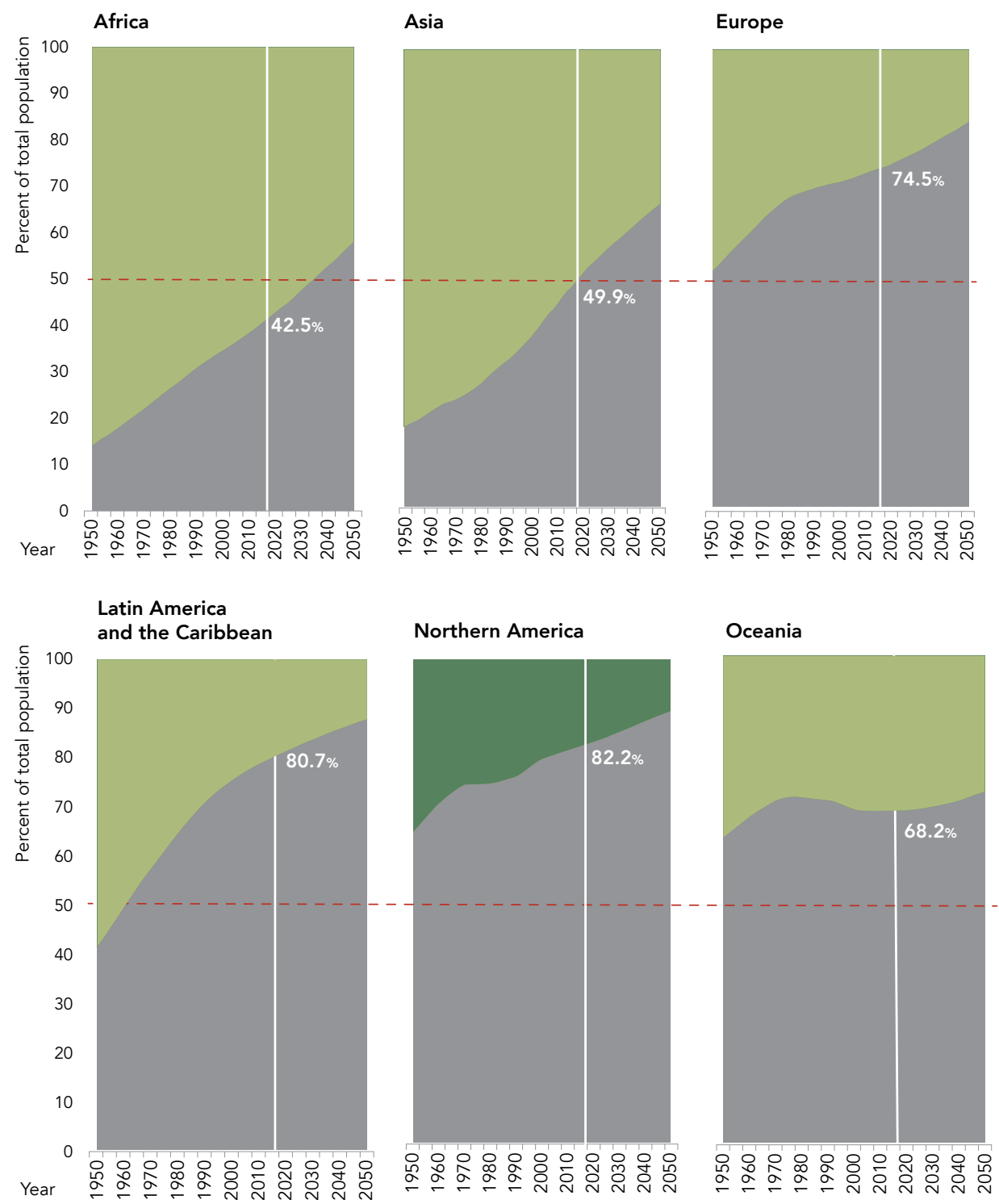

Urban population Rural population

Source: UN DESA Population Division 2018. 
for a new life, greater social and economic mobility, and better access to markets, services, and spaces. It often also means separation from family and social networks and a sense of loneliness for those who do not have networks in their new abodes. A 2016 study from South Africa shows that rural-urban migration between 2008 and 2012 was accompanied by an 8.3 percent decrease in the subjective well-being of migrants (Mulcahy and Kollamparambil 2016). Furthermore, as cities often lack careful planning, approximately 60 percent of Africa's urban population lives in informal settlements, compared to 34 percent in other developing countries (UN DESA Statistics Division 2015, cited in Lall and others 2017, 38). Finally, in most cities, informal workers, such as waste pickers, domestic workers, street vendors, and others, experience serious barriers to doing business. Yet, cities also often provide a more anonymous space than do rural areas. Cities can enable individuals from excluded groups to escape discrimination and to pursue job and education opportunities that they would not have had in a rural context. Although additional research is needed to understand the mechanisms through which these outcomes succeed, figure 2.5 shows that, in urban areas, wealth disparities between ethnic groups are less pronounced than in rural areas. At the same time, in urban areas, ethnic groups and migrants tend to cluster residentially and occupationally, with varying effects for social inclusion.

Despite the considerable attention to Africa's urban growth and advances in service delivery, there also is evidence that location matters and that many areas lag. Figure 2.9 shows the advances in electricity coverage and basic drinking water services in the last decade. Almost every country has seen advances in both (more so for electricity than for water), but some countries have done better than others. South Africa, Cabo Verde, and Gabon are at the higher end of service provision, and Mauritius and Seychelles are at the highest end. In electricity provision, Burundi, Chad, South Sudan, Malawi, and the Central African Republic have the poorest outcomes. For water services, the bottom four countries are Eritrea, Uganda, Ethiopia, and Somalia, where less than 40 percent of the populations have basic drinking water. In general, countries that are in conflict or experience fragility have poorer outcomes than do others. Clearly, there are lagging regions within countries; and individuals and groups who live in these regions may have other defining characteristics, such as belonging to a particular ethnic or other group.

Lagging regions across the world also are those whose people have less voice and political power than people in other regions. African countries are no exception. The popular discourse in many African countries makes explicit links between political power and uneven regional development, pointing out that areas that have better political connections to those in power tend to fare better. Box 2.4 highlights the case of north and northeastern Kenya, which historically have fared worse than the rest of the country. These lagging areas are inhabited by current or previous pastoralists and historically have been prone to being left out of services.

72 CHAPTER 2 AFRICA IS STRIDING: WHO'S LEFT BEHIND? 
Figure 2.9 Access to Electricity and Water Services, 2008-2015/16 (\%)

\section{a. Access to electricity}

Percent of population

NORTH AMERICA

Seychelles

EUROPE \& CENTRAL ASIA

Mauritius

MIDDLE EAST \& NORTH AFRICA

LATIN AMERICA \& THE CARIBBEAN

Cabo Verde

Gabon

SOUTH ASIA

EAST ASIA AND PACIFIC

South Africa

Ghana

Comoros

Equatorial Guinea

Eswatini

São Tomé and Príncipe

Senegal

Côte d'Ivoire

Botswana

Cameroon

Nigeria

Congo, Rep.

Kenya

Namibia

Gambia, The

Togo

Eritrea

Ethiopia

Mauritania

Benin

Angola

Sudan

Zimbabwe

Mali

Guinea

Tanzania

Somalia

Lesotho

Rwanda

Zambia

Uganda

Mozambique

Madagascar

Sierra Leone

Liberia

Burkina Faso

Congo, Dem. Rep.

Niger

Guinea-Bissau

Central African Republic

Malawi

South Sudan

Chad

Burundi

$\begin{array}{llllll}0 & 20 & 40 & 60 & 80 & 100\end{array}$ b. Access to at least basic drinking water

Percent of population

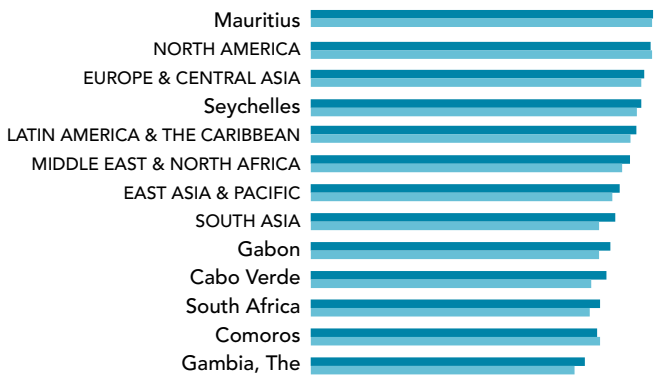

São Tomé and Príncipe

Botswana

Namibia

Ghana

Senegal

Mali

Côte d'Ivoire

Lesotho

Liberia

Mauritania

Guinea-Bissau

Congo, Rep.

Eswatini

Guinea

Nigeria

Malawi

Benin

Zimbabwe

Cameroon

Togo

Zambia

Sudan

Kenya

Sierra Leone

Rwanda

Burundi

Central African Republic

Burkina Faso

Madagascar

South Sudan

Tanzania

Equatorial Guinea

Mozambique

Niger

Chad

Congo, Dem. Rep.

Angola

Somalia

Ethiopia

Uganda

Eritrea
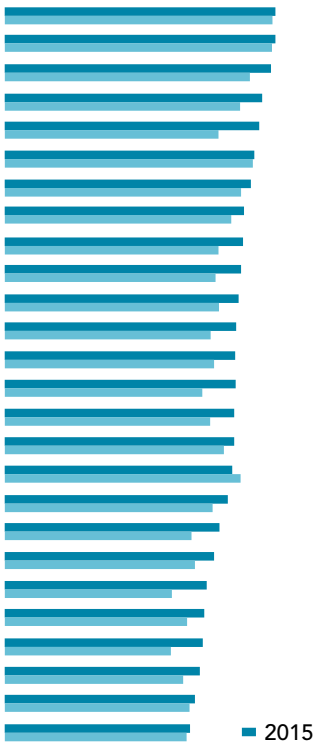

2008
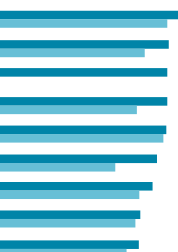

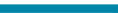
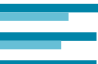

$$
0
$$$$
20 \quad 40 \quad 60 \quad 80
$$

Source: World Bank calculations based on WDI 2008-2015/2016, http://datatopics.worldbank.org/ world-development-indicators/. 
In Uganda, where electricity coverage is low in general, almost half of the Muganda respondents in the 2011 Demographic and Health Survey (DHS) reported having electricity, but less than 5 percent of the Lugbara and Ngakaramajong did. Afrobarometer found similar results by self-reported water insecurity. The Langi, the Ateso, and the Alur reported the highest incidence of having experienced water insecurity "many times or always"; whereas the Mutooro, Mukiga, and Munyankole were most likely to report never having experienced such insecurity (World Bank 2013, 96).

Finally, the majority of Africa's population still lives in rural areas, and there is a significant rural-urban opportunity divide. Take the case of health services: about 56 percent of the rural population around the world lacks health coverage, compared to 22 percent of the urban population, with the most deprived rural population living in Africa (Scheil-Adlung 2015, 6). Within rural areas, exclusion from health services also may be more severe for women, the elderly, some ethnic groups, and migrants (Scheil-Adlung 2015, 30). In South Africa, despite provision of free antenatal care for two decades, nonwhite women and those living in rural areas are less likely to receive antenatal care or to have a skilled attendant present at delivery than white women in urban areas (Burgard 2004; Say and Raine 2007; Silal and others 2012; all cited in World Bank 2013, 95).

\section{Box 2.4 Areas and Peoples: North and Northeast Kenya}

Areas in the north and northeast of Kenya remain largely left out of recent economic progress. The 10 counties of Garissa, Isiolo, Lamu, Mandera, Marsabit, Samburu, Tana River, Turkana, Wajir, and West Pokot remain below the national average of living standards indicators, and regional disparities are stark. The Kenya Integrated Household and Budget Survey 2015-2016 indicates that the average poverty rate in the 10 counties is 68 percent, compared to the national average of 36 percent. Primary school attendance in the north and northeast averages 55 percent, compared to the national average of 82 percent. Secondary school attendance is 19 percent, versus 37 percent nationally. The average literacy rate among women is 41 percent, compared to 89 percent for the country as a whole. Thirty-four percent of births are assisted by a skilled provider, compared to a national average of 71 percent.

Today's disparities can be traced back to colonial rule and the early years of independence. Initial development during British colonial rule was focused on the Kenya-Uganda railway corridor. The north and northeast-then dubbed the Northern Frontier District-were considered a buffer zone against hostile neighboring countries. The lack of infrastructure and services in this area and strict regulation of travel permits served that interest. Secessionist tendencies 
of the Somali minorities in the Northern Frontier District and distrust of the newly formed independent Kenyan state led to the "Shifta War" from 1963 to 1967, after which emergency rule was established in the area and not lifted until 1991. In addition, Sessional Paper No. 10 of 1965 directed public spending to areas with potential for high economic returns to achieve rapid growth. Investments focused on agricultural areas and neglected the social and economic infrastructure in the arid north and northeast.

For decades, the north and northeastern regions have been underserved by infrastructure and government services. Road networks are extremely poor, often cutting off these regions from the rest of the country during the rainy season. In the dry season, it can take on average three days to reach Mandera via Isiolo from Nairobi, a distance of about 983 kilometers. The counties of Isiolo, Wajir, Mandera, and Garissa cover 26 percent of Kenya's land mass but are home to only 6 percent of the total road network in the country. Only 57 percent of households in this region have access to safe water and 34 percent to improved sanitation, compared to the national averages of 72 and 59 percent, respectively.

Pastoralism is the main economic activity in the north and northeastern regions; 90 percent of the population relies on livestock-based livelihoods. These arid or semiarid areas struggle with frequent droughts. Some conflicts among pastoralist communities, such as cattle raiding and rustling, have a long history but have become increasingly destructive due to the proliferation of small arms, organized crime, competition over control and access to natural resources such as water and pasture, land issues, the diminishing role of traditional governance systems, ethnocentrism, increasing levels of poverty and idleness among the youth, and inadequate security. Additionally, low levels of human capital call for capacity to be imported from other parts of the country for public service delivery. However, due to the lack of infrastructure and services in the area, the challenging security situation, and persistent stereotypes and prejudices, it is difficult to attract and retain qualified staff. In 2012 the vacancy rate for health professionals in north and northeastern Kenya was assessed at 79 percent.

Sources: World Bank 2018c; KNBS 2015. 


\section{Climate-Related Events and Trends}

Climate change is forging unprecedented spatial and other transitions and is likely to affect many aspects of life globally, and certainly in Africa. Climate-related events, for instance, affect livelihoods, health, education, and general well-being; they could reverse many of the gains that African countries have made. Extreme weather events also contribute to large-scale, involuntary population movements. Africa is expected to host 86 million persons who, due to the effects of climate change, likely will migrate by 2050 (Rigaud and others 2018). Rapid-onset events such as extreme storms or floods (box 2.5) tend to lead to short-term displacement, followed by return to affected areas. However, such events also can generate a combination of short- and longer term displacement and out-migration. In contrast, slow-onset events including droughts or desertification, such as of the Sahel, tend to lead to gradual long-term out-migration. Many internal migrants move to major cities; indeed, internal migration is a significant contributor to urbanization (Tacoli and others 2015, cited in Rigaud and others 2018, 18). Nairobi is one example of a city likely to see increased climate-driven in-migration. At the same time, low-lying cities, along with coastlines vulnerable to sea level rise and areas of high water and agriculture stress, are at risk of climate-induced out-migration. Addis Ababa and Dar el Salaam are among the cities likely to see dampened population growth due to rising sea level and storm surges (Rigaud and others 2018).

The impacts of climate-related events on individuals and groups go beyond migration and competition for resources to alter social processes. Marriage markets are an example. One study looked at the effects of rainfall variability on age at marriage in Africa and India. The research demonstrated that in Africa drought increased the likelihood of early marriage, whereas in India drought lowered that likelihood. The two contradictory impacts likely are related to the traditional transfers linked to marriage (bride price in Africa and dowry in India). The opposite results reflect the cultural and social mores that underpin household responses to rainfall shocks and the economic hardships that they confer (Corno and others 2016, cited in Das 2017). Another study from South Africa showed that single headship of a household makes it more vulnerable during times of variable rainfall. In particular, households headed by widows, never-married women, and women with a nonresident spouse (for example, "left-behind" migrant households) are especially vulnerable. The results are more significant in areas that tend to rely on rain-fed agriculture (Flatø and others 2017, cited in Das 2017). 


\section{Box 2.5 Urban Floods: Disproportionate Effects}

At the time of writing, Cyclones Idai and Kenneth had wreaked havoc in many parts of Southern Africa. Such shocks have become commonplace as countries struggle to keep apace. Floods account for almost half of natural hazards in most metropolitan areas. Groups that are disproportionately affected are often (though not always) poor; they include, among others, migrant workers, the elderly, persons with disabilities, and people working in trades that are particularly susceptible to disruption during natural hazards, like street vendors and waste pickers. Persons with disabilities may lack access to warnings, evacuation notices, emergency shelters, or food distribution; they may become homebound during floods, be left behind in evacuations, or be separated from family members and caregivers (Das and Majumdar 2019). The disproportionate nature of effects plays out in other ways too. Ajibade and others (2013) found that the impacts of flash floods in Lagos, Nigeria, were differentiated by gender and income level. Women in lower-income neighborhoods had more intense negative impacts and took longer to recover when compared to other groups. Location also matters: urban (and rural) floods may be particularly damaging for groups living on fragile lands, in informal settlements, in low-lying areas, or in precarious housing situations. These groups may lack resilient infrastructure, and their schools, homes, and health centers may be the last to be rehabilitated (Das and Majumdar 2019). As we design programs for adaptation to climate change and mitigation of its impacts, we need to be cognizant of the fact that emergencies can often exacerbate existing inequalities and asymmetrical power relations and that both prevention and response need to take this into account. 


\title{
Conflict and Fragility: Challenges to Social Inclusion
}

\begin{abstract}
Peace is not just the absence of conflict; peace is the creation of an environment where all can flourish, regardless of race, colour, creed, religion, gender, class, caste, or any other social markers of difference. Religion, ethnicity, language, social and cultural practices are elements which enrich human civilization, adding to the wealth of our diversity.
\end{abstract}

—Nelson Mandela, 2004

As do other parts of this report, the preceding discussion highlights that areas that face conflict or fragility have poorer outcomes across a number of domains. Individuals and groups who reside in these areas struggle for access to markets, services, and spaces. The least powerful among them sometimes face terrible atrocities. Although neither conflicts nor humanitarian emergencies are exclusively African problems or only problems of poor and fragile situations, Africa does face some unique challenges. As an example, in 2016, Africa saw 3.9 million new internal displacements due to conflict, violence, and sudden-onset disasters. Together with the Middle East and North Africa Region, Sub-Saharan Africa hosts the largest numbers of forcibly displaced groups, with a sharp increase over the past several years. For example, although in 2012 each of the two regions had about 8 million displaced people, in 2017 this number increased to 21.5 million in the Middle East and North Africa and 18.4 million in Sub-Saharan Africa (figure 2.10). Within Sub-Saharan Africa, most forced displacement took place domestically: of the 18.4 million people displaced in 2017, 12.5 million were internally displaced persons (IDPs) and 5.9 percent were refugees (figure 2.11).

Conflict, the threat of conflict, and the likely pursuant displacement affect both displaced groups and their host communities. To start, although displacement comes with tremendous suffering, displaced persons are not necessarily the poorest (Beegle and others 2016) and fleeing mitigates the detrimental effects of conflict (Etang-Ndip and others 2015). Moreover, host communities are affected by the inflow of these forced migrants; and in some places, especially in remote and underdeveloped borderlands, they are poorer than IDPs and refugees. The effects of displacement on host communities take place through different channels. For instance, the Kakuma refugee camp in Kenya, based in Turkana County, has a poverty rate of close to 80 percent, compared to the national average of 36 percent (KNBS 2015). In Tanzania, the influx of refugees from Burundi and Rwanda in the 1990s adversely affected Tanzanian casual laborers due to an increase in competition in labor markets and surging prices of goods. Public sector institutions also were affected, as numerous employees from hospitals, schools, and government departments left their positions for better job opportunities in 
Figure 2.10 Forcibly Displaced Persons by Region, 2012-2017 (mil.)

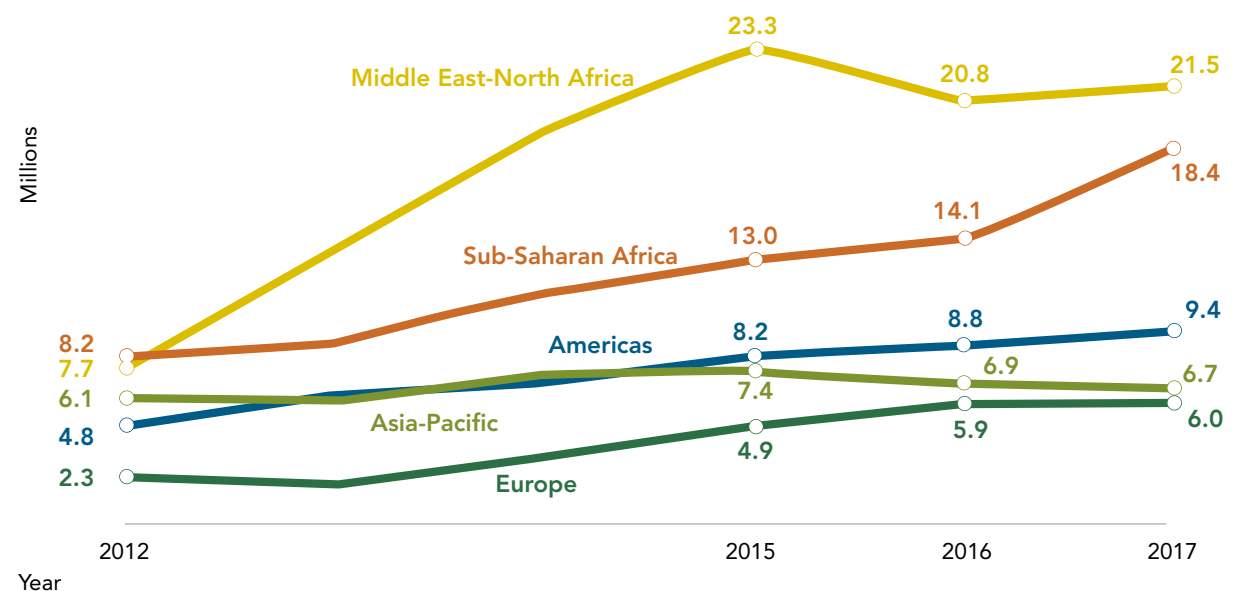

Source: Connor and Krogstad 2018.

Note: Annual figures are as of December 31, 2017. Forcibly displaced populations include IDPs, refugees, and asylum seekers. Palestinian refugees are not included.

Figure 2.11 Forcibly Displaced Africans, 2012-2017 (mil.)

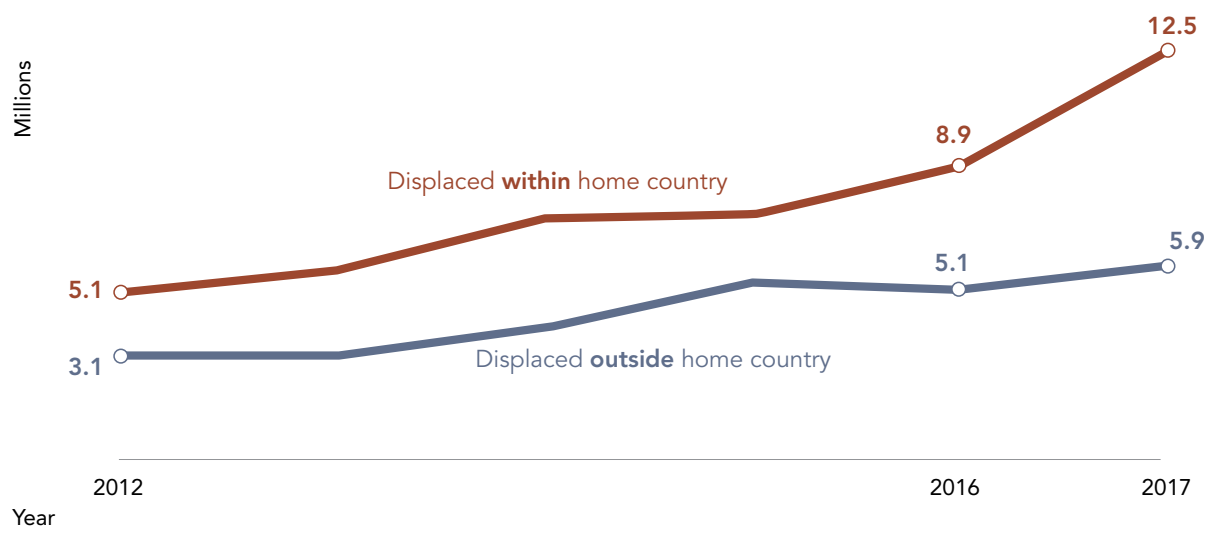

Source: Connor and Krogstad 2018.

Note: Those displaced within their home countries include IDPs. Those displaced outside their home countries include refugees and asylum seekers. Annual figures as of December 31, 2017. 
relief-related sectors (Whitaker 2002, cited in Ogude 2018, 10). The presence of forcibly displaced groups also can benefit host communities. In Tanzania, the influx of additional labor has helped sectors including agriculture, construction, and housekeeping (Maystadt and Verwimp 2014; Whitaker 2002; both cited in Ogude 2018, 10). The gross regional product (GRP) of Turkana (Kenya) increased by 3.4 percent as a result of the refugee presence; total employment increased by 2.9 percent; and consumption measures within $5 \mathrm{~km}$ of the camp were found to be up to 35 percent higher than in other parts of the county (Sanghi and others 2016).

The aftermath of conflict can lead to large numbers of ex-combatants facing challenges when they try to reintegrate in their communities. In 2015, the World Bank estimated that there were 194,000 combatants in armed groups in Africa. Ex-combatants the world over face stigma, discrimination, and other challenges in reintegrating into "normal" social and economic activities. Upon return, they may be subject to suspicion or fears from community members, or to tensions related to lifestyles or values (Baxter and Burrall 2011, 21f). Young ex-combatants (ages 18-30) lag behind average ex-combatants in social and economic reintegration, probably as a result of being mobilized as adolescents and never having established stable social and economic identities. These challenges and some solutions are discussed later in this report.

\section{Political and Civic Participation and Social Movements}

Social inclusion can be advanced when individuals or groups who feel excluded assert their agency through social and political participation. In recent years, the form of participation in many African countries has changed. Recent surveys draw attention to declining participation in formal political and civic processes, particularly among youth and women in Africa. However, the picture is complex. African youth are less likely than their elders to vote, ${ }^{7}$ and Afrobarometer data suggest that the political participation of young people has declined over the past decade and a half (figure 2.12). African youth also are less likely than their elders to participate in civic activities. ${ }^{8}$ On the other hand, they are more likely than their elders to participate in demonstrations and protest marches. Eleven percent of young respondents say they attended at least one protest in the previous year, compared to 8 percent of older respondents. Young women participate even less in public affairs. Compared to their male counterparts, young women report significantly less interest in public affairs and discussions around them.

The decreasing participation in formal political processes may signal several things (box 2.12). It may mean disenchantment or lack of faith in the processes. It also may mean that young people use different channels to express their preferences. The importance of social media bears special mention here. The Internet affords anonymity, which allows groups who would otherwise not have a voice to express 
themselves through digital media. The youth in Africa are far more active on social media and digital platforms than are their older counterparts. Even so, the likely disenchantment with political processes may be an indication of broader disenchantment with the state (chapter 4).

While participation in formal political processes seems to be declining, social movements continue to raise the profile of social inclusion across Africa. That Africa has a vibrant history of social and political movements is well known. These have included the legendary movements for independence and decolonization, critical movements in academia against Eurocentrism, movements for peace and civil liberties, and movements against various economic policies. For example, the Women of Liberia Mass Action for Peace has been recognized for its role in pressing for Liberian warlords to sign a peace agreement in 2003 that ended 10 years of civil war. The student-led Fees Must Fall movement in South Africa

Figure 2.12 Civic Engagement among 18- to 35-Year-Olds in 16 Countries, 2002 $2015(\%)$

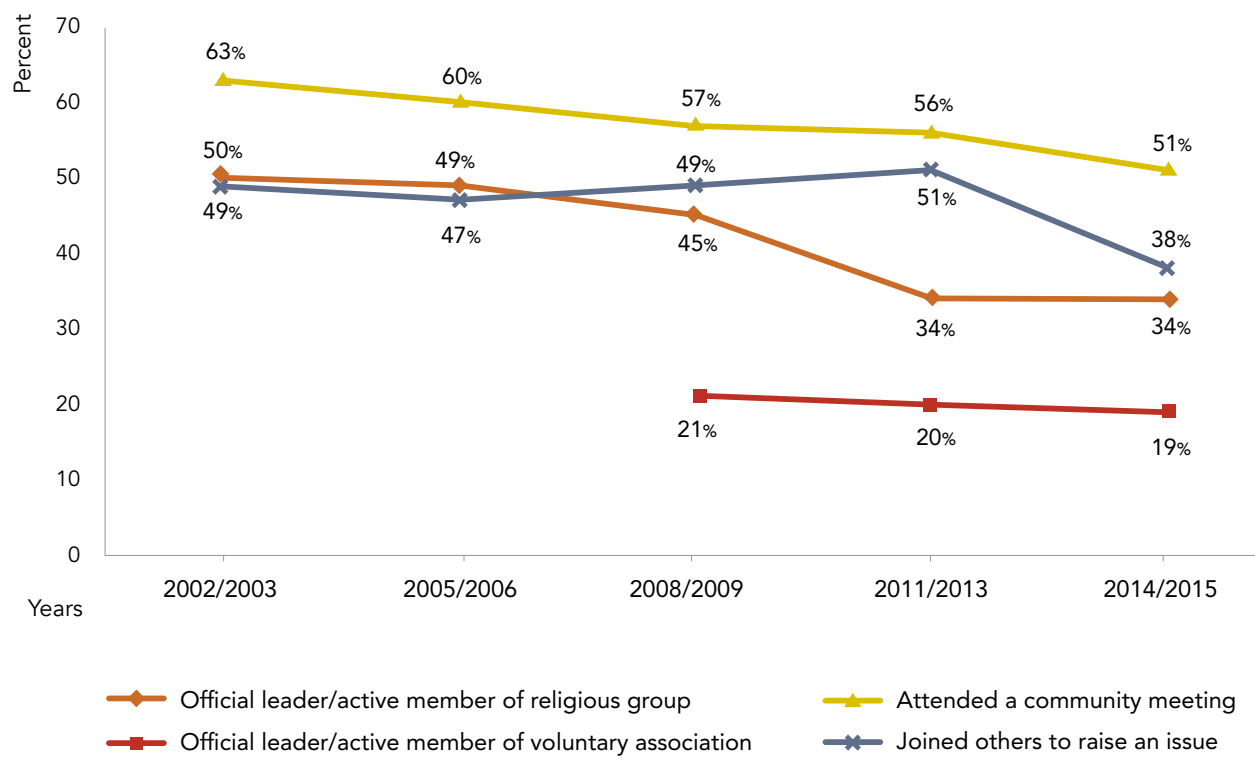

Source: Lekalake and Gyimah-Boadi 2016.

Note: The 16 countries included were Botswana, Cabo Verde, Ghana, Kenya, Lesotho, Malawi, Mali, Mozambique, Namibia, Nigeria, Senegal, South Africa, Tanzania, Uganda, Zambia, and Zimbabwe. Respondents were asked (1) "Now I am going to read out a list of groups that people join or attend. For each one, could you tell me whether you are an official leader, an active member, an inactive member, or not a member?" and (2) "Here is a list of actions that people sometimes take as citizens. For each of these, please tell me whether you, personally, have done any of these things during the past year." Figure 2.12 represents the percents who responded "yes." 
points to the fact that, although young people may not participate in formal political processes, the youth nevertheless are politically very vibrant. Similarly, the movements that assert the rights of indigenous peoples to their culture, lands, and unique identities also have a strong history. Two other contemporary social movements deserve mention: the first brought attention to HIV/AIDS, and the second to the rights of persons with disabilities. Both have used the axiom "Nothing about us without us" to influence budget allocations, research priorities, and accessibility and delivery of services to excluded groups. In the process, the movements raised awareness and reduced the widespread stigma against the people they represented. The advocacy movement for albinism is unfolding before our eyes. Each of these campaigns demonstrates that norms and practices are mutable and continue to influence both the supply side and the demand side of access to markets, services, and spaces.

Civil society also has galvanized citizens against corruption in several countries in Africa. In South Africa, for instance, civil society organizations (CSOs) started campaigning against corruption in the late 1990s, which led to the first anti-corruption summit by the government in 1999 and the 2001 launch of the National Anti-Corruption Forum, which brought together civil society, businesses, and government in the fight against corruption (Essoungou 2013). In Kenya, CSOs mobilized protests (Occupy Parliament) against the salaries of Members of Parliament (MPs) and in 2013 brought about salary cuts of MPs and the president. Other countries have had similar forms of protest. Across Africa radical feminist movements have gathered strength over the years and have organized to hold states and societies accountable for the poorer opportunities for girls and women. The number of countries in Africa that have freedom of information (FOI) laws has grown substantially in the 21st century, from 4 countries in 2004 to 21 in 2017 (AFIC 2017). Civil society groups and citizens since have used the new laws to improve accountability and governance in areas from public and reproductive health information to access to power, sanitation, and water (Odinkalu and Kadiri 2014). 


\section{Concluding Reflections}

The changing development context of the continent, as demonstrated by select regional trends, portends new opportunities and challenges for African countries over the next few decades. First, the decline of poverty almost across the board, the enhancement of education, and the improvements in health have meant (and will mean increasingly) that policymakers will need to focus on those who have not benefited from this aggregate progress. Of these, individuals and groups who are affected by conflict and fragility stand out, but some groups in nonfragile contexts also are at risk. These include some categories of women, sexual and gender minorities, persons with disabilities, older persons, some categories of youth and children, certain ethnic and racial groups, and those who live in "lagging" regions. Some of these groups are more assertive; others may have festering grievances.

Second, development spearheads aspiration. As individuals and groups do better, they will seek more; this has implications for how governments respond to these heightened aspirations. As is discussed in chapter 3, citizens in many African countries are simultaneously disenchanted with the state and filled with optimism and hope for better lives. As more countries graduate to middle-income status, they will focus on "second-generation" issues of prosperity. The trends and transitions that shape and tame Africa's dynamism likely will have significant implications for social inclusion in the years ahead. Although the focus on poverty must be front and center in addressing social inclusion, states and societies also need to consider the drivers of poverty and why some groups are left out. 


\section{Notes}

1 See https://africaindata.org/\#/2.

2 See United Nations Children's Fund (UNICEF) Press center release, https://www. unicef.org/media/media_45279.html.

3 Mitra (2018) draws on the four LSMS panel datasets that include internationally comparable functional difficulty questions: Ethiopia Rural Socioeconomic Survey (2011/2012 and 2013/2014), Malawi Integrated Household Survey (2010/2011), Tanzania National Panel Survey (2010/2011), and Uganda National Panel Survey (2009/2010,2010/2011). Mitra points out that these are the first longitudinal datasets that include the recommended short questionnaire on functional difficulties of the Washington Group on Disability Statistics (WG) and thus provide internationally comparable data on disability using a tool that has been tested in different country contexts. Mitra uses other waves of the LSMS (that do not have the WG questions) to investigate the association between functional difficulties and short-term mortality, including the Malawi Integrated Household Survey (2012/2013), Tanzania National Panel Survey (2012/2013), and Uganda National Panel Survey (2011/2012).

4 In Malawi, 48 percent of persons with severe functional difficulty and 68 percent with moderate functional difficulty have ever attended school, compared to 81 percent with no functional difficulty. In Tanzania, 42 percent of persons with severe functional difficulty and 65 percent with moderate functional difficulty have ever attended school, compared to 80 percent with no functional difficulty (Mitra 2018, 105).

5 Based on \$1.90 a day in 2011 purchasing power parity (PPP). PovcalNet, http:// iresearch.worldbank.org/PovcalNet/.

6 The food deficit is defined as the amount of food needed to not be considered undernourished, measured in kilocalories a day.

7 Two-thirds (65 percent) of 18-to-35-year-old respondents who were old enough to vote in the last national election say they did so, compared to 79 percent of citizens above age 35 . Slightly more than half (53 percent) of African youth report being "very" or "somewhat" interested in public affairs; two-thirds (67 percent) say they discuss politics with friends or family at least "occasionally" (Lekalake and GyimahBoadi 2016, based on Afrobarometer data).

8 Less than half (47 percent) of 18-to-35-year-olds say they attended community meetings at least once during the previous year, whereas 40 percent joined others to raise an issue (vs. 57 and 47 percent for older citizens; Lekalake and Gyimah-Boadi 2016, based on Afrobarometer data). 


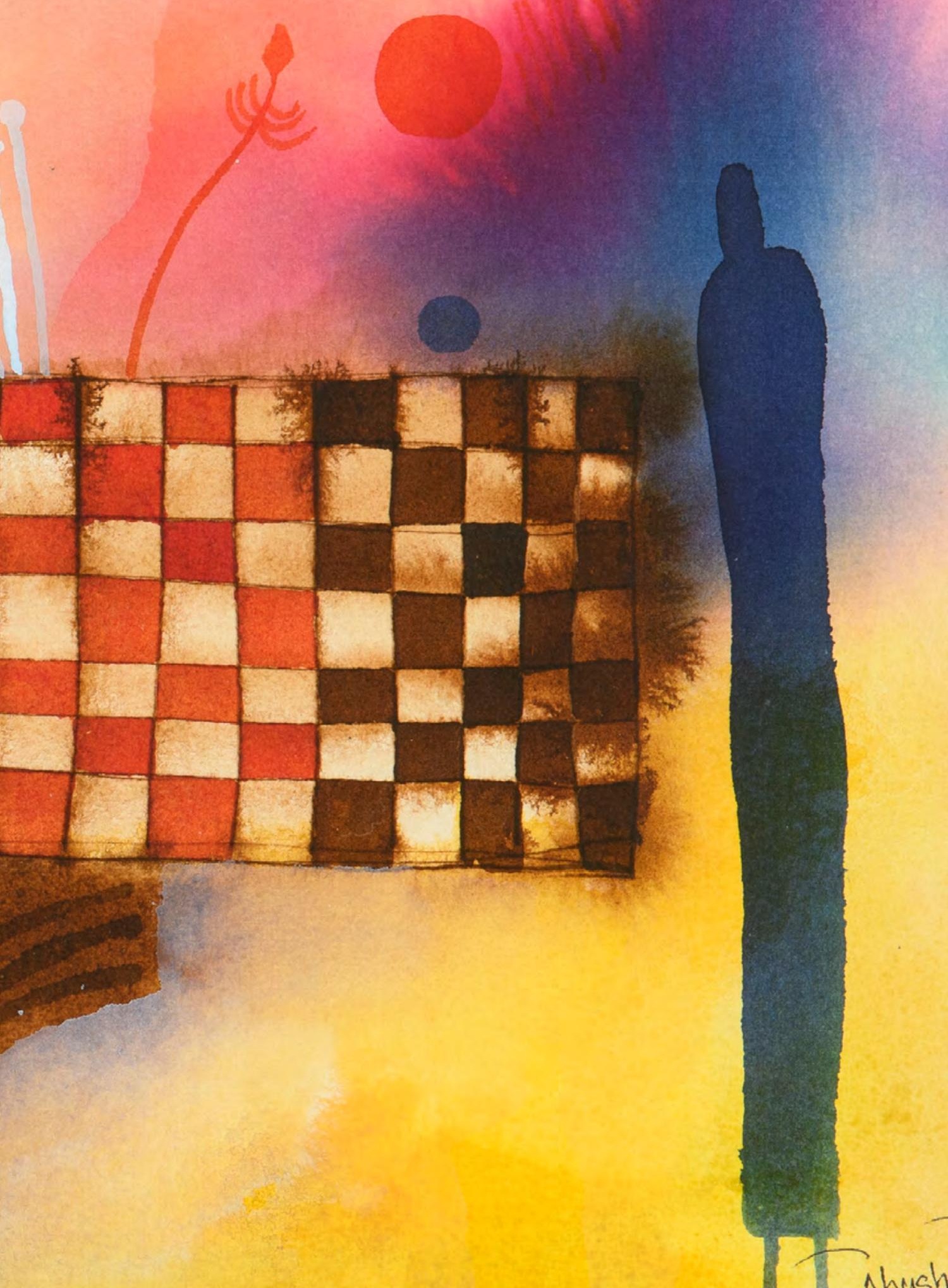




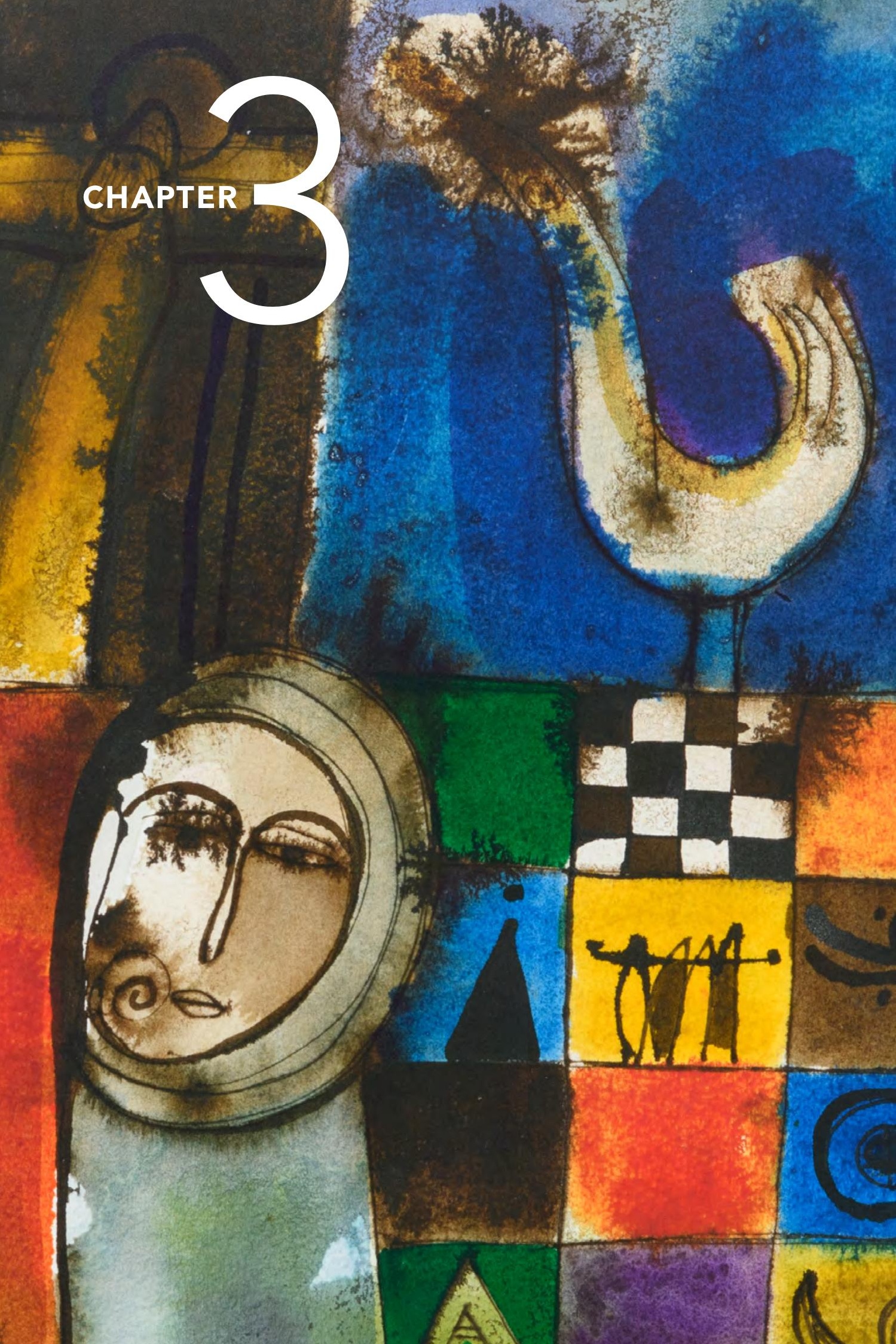




\section{How Does Social Exclusion Play Out in Africa?}

Culture plays a central role in the political, economic and social life of communities. Indeed, culture may be the missing link in the development of Africa. Culture is dynamic and evolves over time, consciously discarding retrogressive traditions, like female genital mutilation (FGM), and embracing aspects that are good and useful. ${ }^{1}$

-Wangari Maathai, 2004

Social exclusion is fundamentally about relations of power. Societies the world over devise intricate ways to solidify social structures and systems and uphold the status quo. Structures and systems comprise, among others, families, communities, legal systems; markets, such as labor and land; and knowledge systems. Norms, beliefs, attitudes and practices are the processes through which societies uphold their structures and relegate some groups to subordinate status. Processes also encompass superstitions, stigmas, and rituals. Structures and processes reinforce each other and are solidified by formal and informal institutions. 
Why do processes and practices matter for policies and programs? They matter because they affect the actions and behaviors of dominant and subordinated groups, of service providers, and of the state itself. Groups who are historically excluded, on their part, may respond in different ways. One possibility is that they "opt out" or reject the terms on which they are included. Excluded groups, therefore, may drop out of school or the labor market or disengage from political processes. A second and related possibility is that grievances may accumulate, creating social tensions and having long-term costs for the economy and society. A third possibility is that groups who feel excluded organize themselves into formidable lobbies and use the political space to demand change. Historically, this choice has led to movements toward social inclusion (chapter 4); this is discussed in greater detail in the next chapter. In one way or another, processes and structures have a strong bearing on feelings and perceptions of individuals and groups with consequent effect on actions and behaviors. In our quest to leave no one behind, attain universal access, eradicate extreme poverty, and promote peace and stability, we need to be cognizant of behaviors. Yet, even though we know that belief systems, feelings, and perceptions affect behaviors, measuring and interpreting these systems and the underlying affective foundations is a complex undertaking that requires a deep understanding of the context as well as robust data and analytic tools.

The second part of this chapter uses data from recent surveys to highlight some of the ways in which individuals and groups across African countries perceive their own lives and the world around them. Subjective indicators of well-being and of feelings and perceptions need to be used and interpreted carefully, fraught as they are with measurement challenges. The responses to questions depend on a variety of related and unrelated factors and events, and context is important. The same response in one country may mean something quite different in another.

\section{Legal, Administrative, and Social Structures}

\section{Legal Structures}

Discriminatory laws that place implicit or explicit barriers on groups can stymie their ability, opportunity, and dignity. In South Africa, the legal exclusion of black South Africans from education and labor markets predates apartheid. The 1913 Natives Land Act (and related acts) prevented self-employment of black people in agriculture. The Native Urban Areas Act suppressed other forms of entrepreneurial activity by black South Africans in urban areas, including in trade and manufacturing. These barriers to entrepreneurial activity help explain why, for instance, the informal sector in South Africa remains smaller than that of other countries in the region. In the same vein, the Job Reservation and Colour Bar Acts ${ }^{2}$ reserved many skilled and semiskilled jobs for white South Africans. Legal regulations in the education sector further enshrined the exclusion of black 
South Africans. Through the 1953 Bantu Education Act, the syllabus was designed deliberately to de-emphasize basic skills in arithmetic and language so as to train black South Africans as unskilled laborers who would not compete with white employees (World Bank 2018f, 13).

As noted earlier, the legacy of colonialism has played a major part in the structure and function of legal systems. For instance, 75 percent of countries in Francophone Africa have regulations restricting women's employment that draw on a 1954 ordinance from the former federation of French West Africa. Among these countries are Benin, Burkina Faso, Cameroon, Central African Republic, Chad, Democratic Republic of Congo, Republic of Congo, Côte d'Ivoire, Gabon, Guinea, Madagascar, Mali, Mauritania, Niger, and Senegal. Similarly, the legacies of Portuguese and Spanish rule have marked many former colonies. Portugal first introduced a series of decrees restricting women's work in the 1890s that stayed in effect in some form until the early 2000s. Currently, almost every country in Lusophone Africa (and Brazil) has at least one restriction on women's work. Similar examples exist in the former Spanish colonies (World Bank 2018g), although many of these retrogressive laws are being dismantled in both former colonizing and former colonized countries.

The extent of criminalization of same-sex relations and attitudes toward people of different sexual orientation or gender identity (SOGI) also reflect the colonial history. For instance, Han and O'Mahoney (2014) analyze the variation in laws that criminalize same-sex relations across 185 countries and find that former British colonies are more likely to have criminalizing laws in place. Former British colonies in Africa are no exception to this pattern. In many Eastern and Southern African countries that were colonized by Britain, same-sex sexual acts are punishable (figures 3.1 and 3.2). In contrast, former French colonies, mostly in Central and Western Africa, are less likely to have such criminalizing laws. ${ }^{3}$ Seventeen of the 45 countries surveyed by UNAIDS (2018b) have either never had laws penalizing same-sex sexual acts or have decriminalized such acts. The majority of these countries are in Central Africa, with some in Western Africa: Angola, Benin, Burkina Faso, Central African Republic, Chad, Congo, Côte d'Ivoire, Democratic Republic of Congo, Gabon, Mali, and Niger. Some countries in Southern Africa also do not criminalize same-sex sexual acts: Madagascar, Mozambique, Rwanda, and South Africa. Mauritania continues to criminalize same-sex sexual acts with the death penalty. Finally, most countries do not criminalize transgender people at all. Globally, much of the improvement in laws related to SOGI over the past few years has been in Africa.

In addition to their underpinning in the colonial past, laws may reflect long-held societal values, prejudices, and proclivities. Figures 3.1 and 3.2 lay out the extent of penalization for acts that go against some "moral values" of a society. For instance, in some countries, drug use, possession of drugs for personal use, and female sex 
Figure 3.1 Laws and Policies (I)

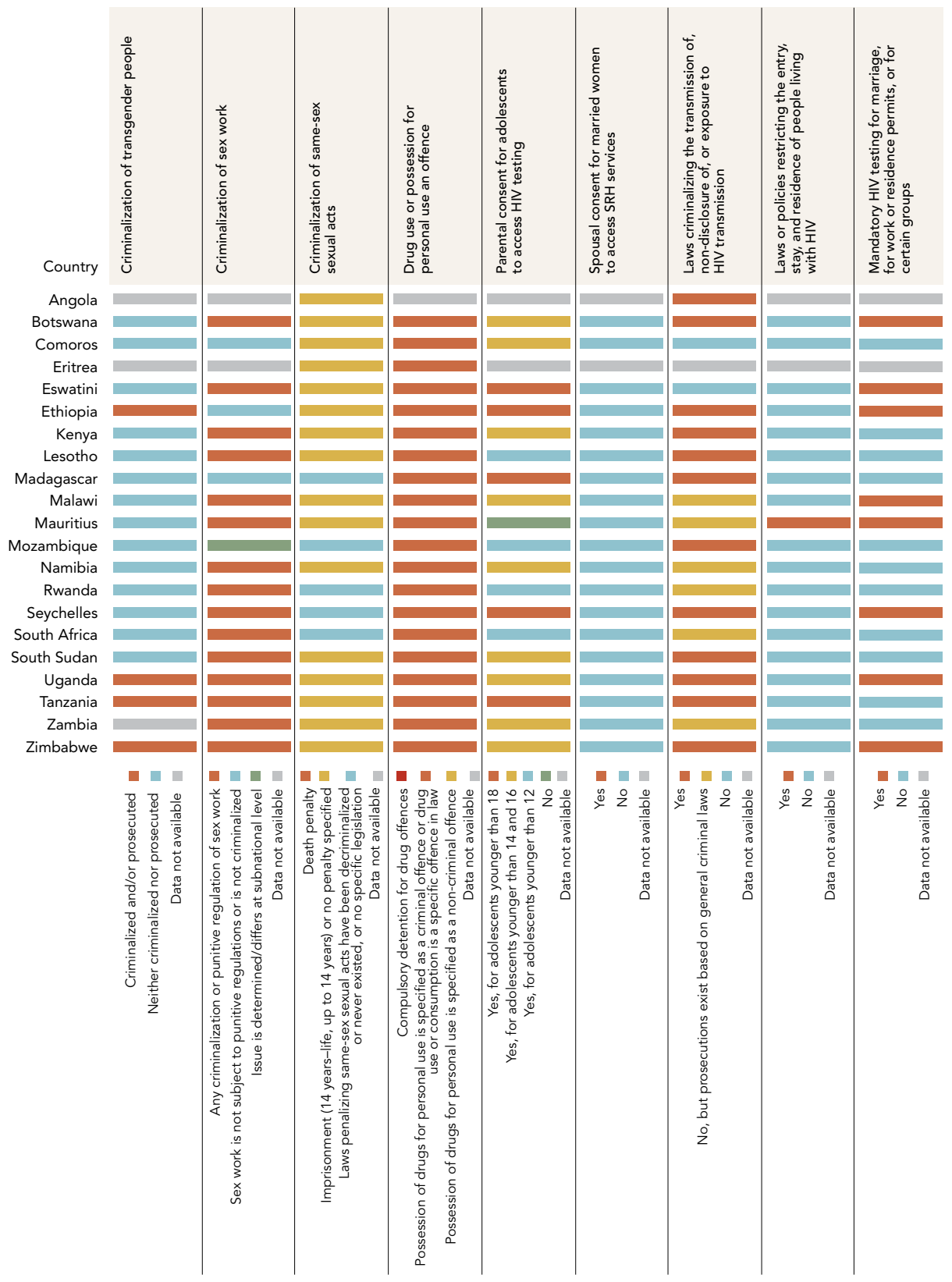

Source: UNAIDS 2018b.

Note: Data on laws restricting the entry, stay, and residence of people living with HIV are currently undergoing a global review that will involve country validation. An update is expected by the end of 2018. SRH = sexual and reproductive health services. 
Figure 3.2 Laws and Policies (II)

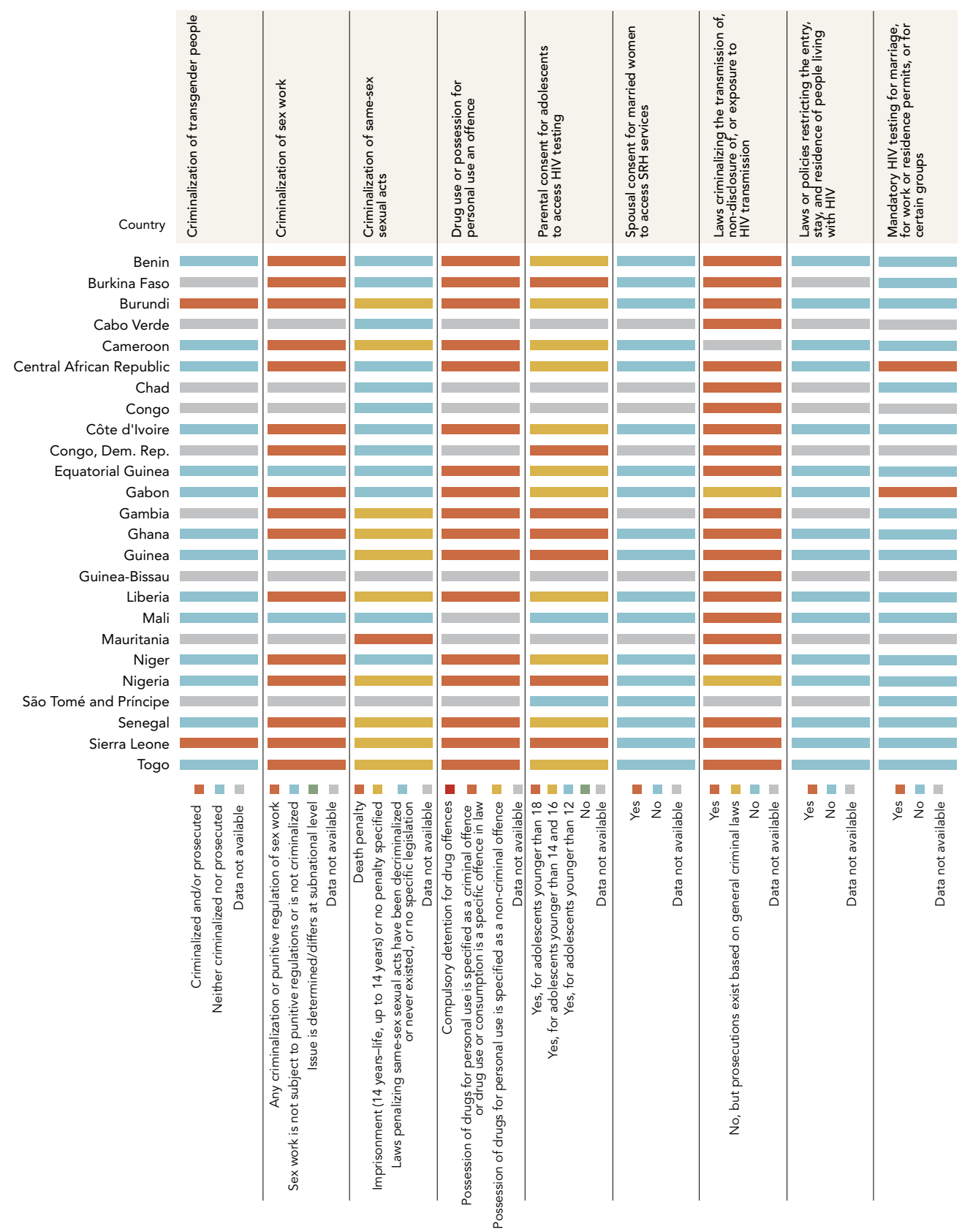

Source: UNAIDS 2018b.

Note: Data on laws restricting the entry, stay, and residence of people living with HIV are currently undergoing a global review that will involve country validation. An update is expected by the end of 2018. SRH = sexual and reproductive health services. 
work attract the highest penalties, as do nondisclosure of HIV positive status and transmission of the disease. Some of these laws are responses to the HIV epidemic. However, in other places, the information campaigns and demystification of the HIV epidemic have led to the loosening of laws against same-sex relations. In other cases, laws may be more progressive and inclusive than existing societal mores and may be social change agents. For example, same-sex sexual acts are not considered criminal in either Rwanda or South Africa, but attitudes toward "homosexual neighbors" 4 vary starkly across the two countries. Rwanda has the highest prevalence of negative attitudes toward homosexuality among African countries surveyed by the World Values Survey (WVS), while South Africa demonstrates the lowest prevalence of such attitudes.

Finally, laws that derive from custom and religion also may be responsible for unequal and discriminatory treatment of some groups. Depending on region or ethnicity, traditional land tenure systems can vary within countries (for GuineaBissau, World Bank 2016d, 30; for South Sudan, Marzatico 2014, 4). Although global data on women's land ownership are limited, women in several countries face serious barriers to ownership (Wellenstein and Stanley 2018). In GuineaBissau, land is administered exclusively by the male head of household or family clan (chefe de tabanca or regulado). Women's land use rights are acquired through birth in their family of descent or through marriage and usually are given only for subsistence horticulture. When a woman separates from her husband, she loses all of her land rights, including those of her family of descent (World Bank 2016d, 30). In South Sudan, customary land tenure continues to restrict women's ability to own land independently of their husbands or male relatives despite formal land provisions that sought to establish women's equal rights to land and property (Marzatico 2014, 8, 15).

Privileging certain cultures and knowledge systems at the expense of others intensifies asymmetrical information and affects the ability, opportunity, and dignity of subordinated groups. The tension between knowledge systems of the majority and the minority is well documented in health service provision. "Traditional" or "folk" knowledge systems may be overlooked, and "modern" systems imposed upon minority groups, who then may well decide not to take part in the health system. Based on a study of maternal and neonatal health care in rural northern Ghana, Hill and others (2014) point out that despite a pluralistic medical system that incorporated traditional and allopathic providers, tensions prevailed. Many allopathic providers were found to be disconnected from the culture of the communities in which they practiced, whereas traditional providers were more in tune with local cultural practices. The two systems of medicine sometimes also came into conflict. A large body of literature highlights the fact that ignoring indigenous systems of knowledge can have deleterious effects on several outcomes, including health, educational attainment, agricultural output, and adoption of new technologies.

92 CHAPTER 3 HOW DOES SOCIAL EXCLUSION PLAY OUT IN AFRICA? 
In the case of education, too, the language of instruction can have great impact on the ability of minority students to succeed in school. A more radical strand of the literature argues that appropriation of knowledge systems has been a tool to solidify social exclusion and to colonize the "ways of knowing" (Belenky and others 1986), constituting an exclusion from spaces that are signified by knowledge, power, status, and authority. By the same token, respect for indigenous systems of knowledge can enhance the dignity and respect accorded to indigenous peoples with the important positive ramifications of social inclusion.

Bureaucracies, with their rules, procedures, and ethos, can exclude or include some individuals and groups. Consider this scenario: an indigenous woman who lives in a remote village and needs a disability certificate may have to go into a district office in a nearby town. She may not speak the dominant language, may not know her way around, may be intimidated by the formal office and its culture, and may have no idea what documents she needs to bring to secure the certificate. Documents of various kinds are indispensable to access services. Proof of identity, for instance, can enable or stymie inclusion in markets, services, and spaces. Documents that establish and other information have perhaps become more important today than they were a decade ago. With greater formalization of governmental systems and procedures, individuals need proof of residence to show that they are eligible to buy and sell property and generally to participate in business and society.

Data from the World Bank Identification for Development (ID4D) project ${ }^{5}$ show that, in Sub-Saharan Africa, those who did not have an account in a financial institution were especially likely to cite documentation requirements as barriers to set up such accounts. The global average for citing documentation as a barrier to financial inclusion is at 20 percent. However, the average is significantly higher in Zambia (35 percent), the Philippines (45 percent), and Zimbabwe (49 percent) (Demirgüç-Kunt and others 2018,40). On average, only 56 percent of adult Africans who lack an account at a financial institution reported having government-issued identification, compared with an average of 85 percent in developing countries globally. But securing relevant documents often can be a challenge because some groups may not be able to navigate administrative rules and procedures or understand the etiquette required when dealing with administrative functionaries; or they may run into accessibility barriers. Government offices or banks that are not accessible and instructions that are published only in the dominant language have the potential to exclude a large number of individuals.

\section{Marriage and Familial Structures}

Across the world, social structures, hierarchies, and norms underpin power relations within the household and the community and can strongly influence the ability of individuals and groups to access opportunities. Structures and rules of tribe, clan, and kinship can exert heavy pressure to maintain customs and behaviors and, in 
turn, determine outcomes. These structures and rules often have been influenced by colonial rule and postcolonial history. A strong body of anthropological literature sheds light on these structures. For instance, in many regions, women are dependent on their husbands or elders regarding the extent to which they can access health care and higher education, whether they can seek market work, and how much leisure time they have. Parental or other familial permission plays a strong role for young men as well. Figures 3.1 and 3.2 showed that several countries require adolescents to get parental permission before they can be tested for HIV/AIDS. Similarly, age at marriage for both men and women often is dictated by family and kin. Such controls have a strong influence on the extent to which less powerful individuals in the family can access markets, services, and spaces. On the other hand, kinship structures can also have salutary effects on inclusion.

As in many other parts of the world, in most African countries, marriage is an important symbol of status, security, and social acceptance. Marriage also affects social inclusion in complex ways. In chapter 2 , we discuss some nuances of marital status and sex of household head and their relationship with household poverty. Take also the case of ex-combatants in the Great Lakes Region (GLR): Uganda, Rwanda, Democratic Republic of Congo, Republic of Congo, and Burundi. Based on survey data collected between 2010 and 2012 from nearly 10,000 excombatants and community members, Rhea (2014) finds that marriage is a core component of social reintegration in the GLR. Marriage is a critical pathway through which ex-combatants extend their familial networks and signal a shift in identity to the community. Marriage also serves as a pathway for access to land, an important indicator of economic stability because most ex-combatants return to work in small-scale agriculture. Although, contrary to popular belief, ex-combatants generally are accepted by their family networks upon returning to their communities, they still have less familial contact overall and are less likely to marry, compared to other community members. Female ex-combatants, although generally accepted back into existing kinship networks, are the group least likely to be married; and most likely to be divorced, separated, or widowed. Over time, male ex-combatants in the GLR have seen improved marriage rates, but the rates for female ex-combatants are near stagnant. Their hyper-exposure to (sexual) violence during conflict contributes to the stigma of female ex-combatants. In some parts of the GLR, this stigma is so strong that some women avoid selfidentifying as ex-combatants and forfeit their entitlement to the assistance that is targeted to ex-combatants.

There are other ways in which marriage and its dissolution, although important for both men and women, has varying forms and connotations. Overall, African men spend much more of their lifetime married than do African women; women are more likely to stay widowed or divorced. There may be several causes, including the higher life expectancy of women. If marriage confers status, its 
breakdown confers disadvantage. Women's continued single status after marital dissolution or widowhood has implications for their inclusion in markets, services, and spaces. ${ }^{6}$ Drawing on Demographic and Health Survey (DHS) data for Mali between 1996 and 2006, van de Walle (2013) shows that widowhood (including the prior widowhood of currently married women) is correlated with lower living standards. Drawing on more recent DHS data (2004-2013), Djuikom and van de Walle (2018) further find that widows and divorcées have worse nutritional status ${ }^{7}$ than do married women in both urban and rural areas. ${ }^{8}$ The detrimental effects of widowhood and divorce also are passed along intergenerationally (van de Walle 2013).

Finally, early marriage deserves special mention because of its impact on the lives of girls and women over their lifetimes. Although early marriage also affects boys and men, the negative effects are different and possibly not as limiting as they are for girls and women. When girls are married too early, they are less likely to attend primary and secondary school, and more likely to be engaged in home care or work. For married girls, outcomes are particularly poor. Compared to boys of similar age, the ratio of married girls finishing primary school is 1:5; and of enrolling in secondary school, 3:5. Low educational attainment of girls and young women is particularly costly for both individuals and societies. Girls dropping out of school early are more likely to marry and have children early, sometimes leading to adverse outcomes for their own and their children's health. Additionally, because younger women have lower levels of agency than older ones, they also are more vulnerable to intimate partner violence (Wodon and others 2017). Therefore, the relationship between early marriage and poor outcomes is mutually reinforcing.

\section{Processes of Exclusion}

Across the world, belief systems, superstitions, stigmas, and other practices present formidable barriers to the inclusion of certain groups. Intimidation and harassment instill fear that prevents some groups from reaching their full potential and "keeps them in their place." Social norms may assign males and females to certain occupations or may render some practices "unclean." Other practices such as stigma and shunning may render some groups, like persons with disabilities, invisible. Relatedly, some cultures may actively hide persons with disabilities. This lack of visibility can have several consequences, including not counting these groups in official statistics. Thus, they remain hidden and unattended to by both their families and at national level. Often, these exclusionary processes are sanctified by religion or by those who interpret religious texts. Persons who have a nonconforming sexual identity are excluded to the point of being criminalized in many cultures. Taboos surrounding menstruating women are common in many parts of the world; beliefs of purity and pollution exclude certain groups at certain times or at all times. Overall, these practices are mechanisms to enforce social order and control. 
Figure 3.3 Groups Reporting Avoidance of Health Care due to Stigma and Discrimination around HIV Treatment, 2014-2017 (\%)

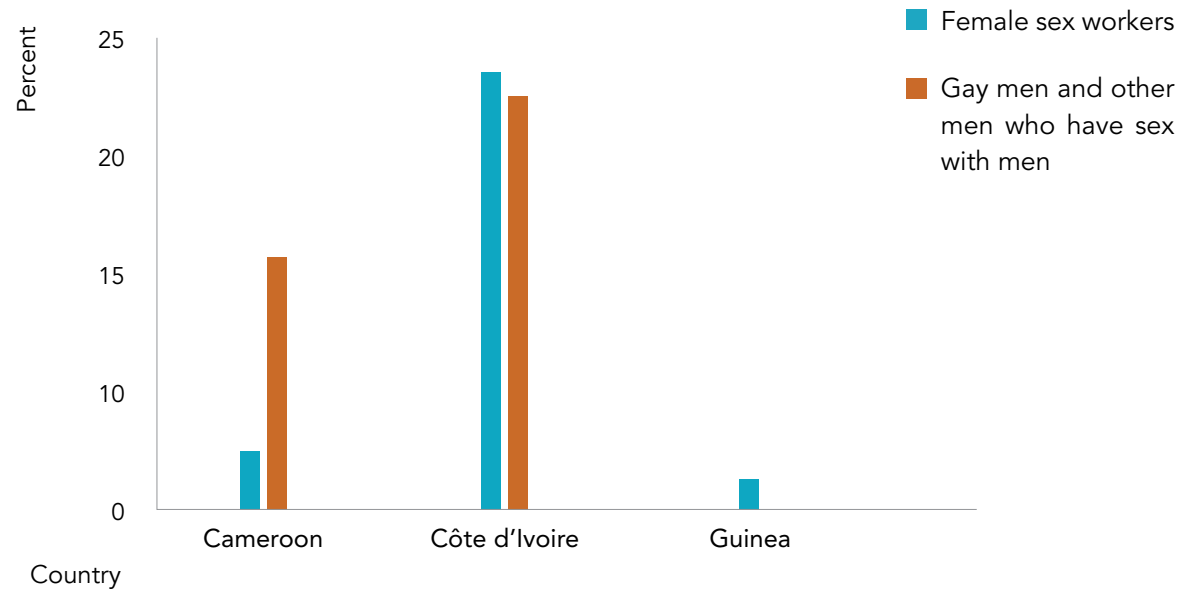

Source: UNAIDS 2018b based on the Integrated Biological and Behavioral Surveys, 2014-2017.

The case of persons with albinism ${ }^{9}$ is instructive. Superstitions surrounding these individuals can have life and death consequences. Box 2.2 in chapter 2 highlights their poorer human capital outcomes; these outcomes are underpinned by processes and practices. In many parts of Africa, persons with albinism are targeted for brutal attacks in the name of witchcraft and superstition (Cruz-Inigo and others 2011; UNGA 2013). Widespread ignorance of the genetic origin of albinism helps sustain myths surrounding it, prevents persons with albinism from receiving adequate health care, and hinders the prevention of disease (CruzInigo and others 2011). Children with albinism may be avoided and neglected by family members and/or ridiculed, threatened, or harmed at school. Mothers of children with albinism may be condemned due to the "uncertain ancestry" of the child, or other superstitions surrounding the condition. A study in Nigeria found individuals with albinism to be more withdrawn from social situations to avoid being noticed, less emotionally stable, and less assertive than persons without albinism. Persons with albinism also were more likely to consider their society to be unkind and rejecting (Cruz-Inigo and others 2011; Hong and others 2006; Lund 2001).

Similarly, the stigma of HIV is still strong in many parts of the world. Not only the persons living with HIV but also the surviving children of HIV/AIDS-affected parents may be treated with hostility, with the latter being left without adequate adult support (Bourdillon 2017). Figure 3.3 shows the differences across three countries in reports by gay men and female sex workers (two groups associated with higher susceptibility to HIV/AIDS) of avoiding health care in the past 12 
months due to stigma and discrimination. The extent of stigma against HIV/AIDS does not always correlate with the legal status of SOGI. Cameroon and Côte d'Ivoire show very high levels of stigma whereas Guinea shows very low levels. In contrast, nonconforming sexual identity is criminalized in Guinea and Cameroon but not in Côte d'Ivoire. Additionally, laws do not always reflect societal attitudes. In sum, although stigma and discrimination against HIV-affected persons are high in Africa, they also are widely prevalent across the world, including in OECD (Organisation for Economic Co-operation and Development) countries. A study assessing self-reported HIV-related discrimination in European health care settings (Nöstlinger and others 2014) found that 32 percent of respondents had experienced HIV-related discrimination in the three prior years, and almost half of them felt that they had been discriminated against by health care providers.

Violence is one of the gravest manifestations of exclusion and a mechanism to show subordinate groups "their place." Physical offensives often are justified by an intricate set of beliefs and taboos that serve to create a "logic of exclusion" that also may be sanctified by religion. For example, many religions regard a woman's place as being in the home and may implicitly or explicitly condone violence against women who dare to transgress this norm. Although there has been change over time, overall, the acceptance of domestic violence against women in Africa remains high. Beegle and others (2016) find that that from 2000-2006 to 20072013, acceptance of domestic violence by women in Africa declined by almost

Figure 3.4 Women's Acceptance of Domestic Violence by African Country (\%)

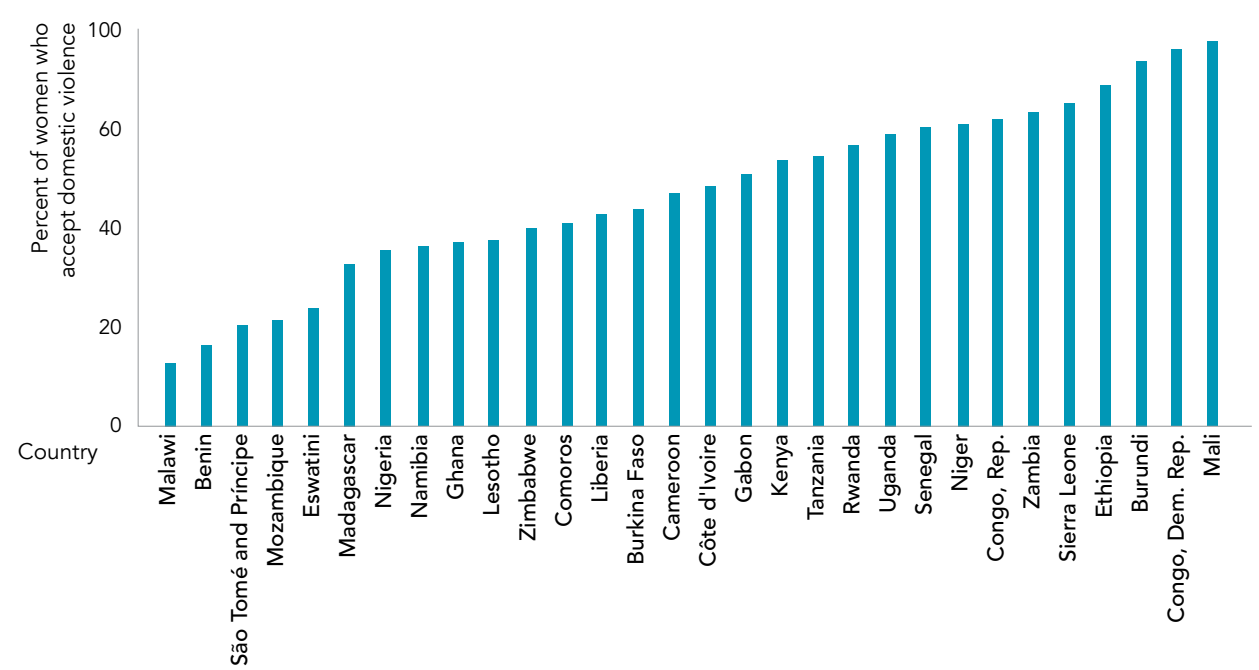

Source: Beegle and others 2016.

Note: Calculated based on Demographic and Health Survey (DHS) data, 2007-2013. 
10 percentage points. However, averaging 30 percent, acceptance of domestic violence in the region is still exceptionally high and more than twice the average in the rest of the developing world (14 percent). There is, however, considerable heterogeneity across African countries. Whereas in Mali and Uganda, 77 percent of women condone violence, only 13 percent in Malawi and 16 percent in Benin do (figure 3.4). Some practices, such as female genital mutilation (FGM), which hold cultural value for some groups, also are examples of violence and extreme forms of exclusion, with devastating effects on health, education, and life chances of women and girls. FGM can have direct effects on reproductive and mental health and cause infectious disease. Sanctified and upheld by religion and culture, FGM serves to solidify the subordinated status of women and girls. The practice matters in and of itself without doubt, but it also matters because it curtails the ability, opportunity, and dignity of survivors. In the long term, FGM affects the ways that survivors accumulate human capital and their future earnings.

\section{Attitudes about Society and Social Inclusion}

Societal attitudes about subordinated groups or minorities are another marker of the extent of inclusion and bring to the surface entrenched prejudices and stereotypes. The World Values Surveys contain questions about groups whom respondents would not like to have as neighbors, including immigrants/foreign workers, "homosexuals," 10 people of a different religion, and people who speak a different language. ${ }^{11}$ The panels in figures 3.5 and 3.6 report the tabulated answers to these questions and compare some African countries with other OECD and non-OECD countries. Negative attitudes toward sexual minorities are high across the world and pervasive in some African countries (figure 3.5, panel a). In Rwanda and Zimbabwe, for example, 88 percent of respondents reported not wanting a "homosexual neighbor"; this is more negative than in certain countries in the Middle East and North Africa, such as Iraq, Morocco, Qatar, and Turkey. Among African countries included in the WVS, South Africa displays the lowest level of antipathy toward sexual minorities; here the proportion of respondents who would not want a "homosexual neighbor" stands at 38 percent, similar to some European countries, including Poland (38 percent) and Slovenia (35 percent).

African countries seem to display greater acceptance of persons belonging to a different religion or speaking a different language, and immigrants or foreign workers, than they do of sexual minorities (figures 3.5 and 3.6). This pattern also is seen in other regions. Interestingly, some African countries that demonstrate the least tolerant attitudes toward "homosexuals" (namely, Rwanda and Zimbabwe) are the most accepting of persons of a different religion or different language. Less than 10 percent of respondents in Rwanda and Zimbabwe would reject a neighbor of a different religion or language, making Rwanda similar to Colombia, New Zealand, and Sweden in this respect. By contrast, over 20 percent of Ghanaians 
and Nigerians would not like a neighbor who belonged to a different religion or language, on par with countries like Cyprus, Estonia, Republic of Korea, and Pakistan. South Africa, where respondents report the least negative attitudes toward sexual minorities, demonstrates the most negative attitudes toward immigrants or foreign workers. Forty-three percent of South Africans do not want such a neighbor, on par with the Republic of Korea and Qatar. In contrast, Ghana and Nigeria, at 21 and 20 percent, respectively, display attitudes similar to those of Germany and the Netherlands (figure 3.6). Attitudes are notoriously difficult to capture and to interpret and can reflect recent events or localized occurrences. This report cannot draw generalized conclusions about the degree of inclusion in a country based on such attitudes. These attitudes do, however, provide nuance and shine a light on which groups are likely to be excluded.

Attitudes affect outcomes, but the relationship between the two is not clear cut. Take the case of attitudes about higher education for women (figure 3.7). Countries in which attitudes toward university education for females are retrogressive tend to have lower gross female tertiary education enrollment. The World Values Surveys ask respondents whether they think university education is more important for boys than for girls. Combined with data from the World Development Indicators (WDI) on gross female tertiary enrollment, ${ }^{12}$ the results in general suggest a clear negative relationship. The higher the percentage of respondents who think university education is more important for boys than for girls, the lower the gross female tertiary enrollment rates. In the Netherlands, New Zealand, Slovenia, and Sweden, for instance, discriminatory attitudes toward female access to higher education are very low: almost no one in these countries believes that men should have greater access to higher education than women. Female gross enrollment in tertiary education is at 76 percent (Netherlands), 83 percent (Sweden), 95 percent (New Zealand), and 104 percent (Slovenia). ${ }^{13}$ By contrast, in India, Pakistan, and Uzbekistan, approximately or more than 50 percent of respondents believe that university education is more important for boys than for girls, and female tertiary enrollment rates are approximately or below 20 percent. Although there is a clear global pattern suggesting a negative relationship between attitudes and enrollment, data from the five African countries for which this indicator was available on the WVS show that the relationship is not clear. Only 15 percent of respondents expressed the view that university education is more important for boys in Zimbabwe, compared to 28 percent in Ghana, 36 percent in Rwanda, 38 percent in South Africa, and 42 percent in Nigeria. Yet, gross female tertiary enrollment varies much less across these countries. In fact, female tertiary enrollment is lower in Zimbabwe (at 5 percent) than in the other countries, despite its more favorable attitude toward female education. However, the number of African countries for which data are available for this indicator in the WVS is too few to draw any inferences about a regional pattern. 
Figure 3.5 Attitudes toward Sexual Minorities and People of a Different Religion by Country (\%)

a. Antipathy toward "homosexuals"a

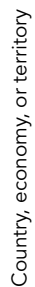

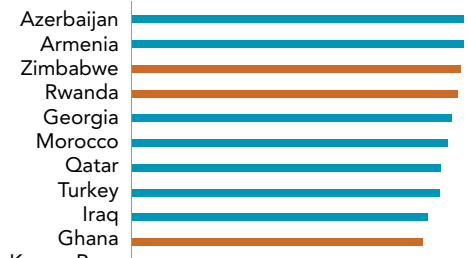

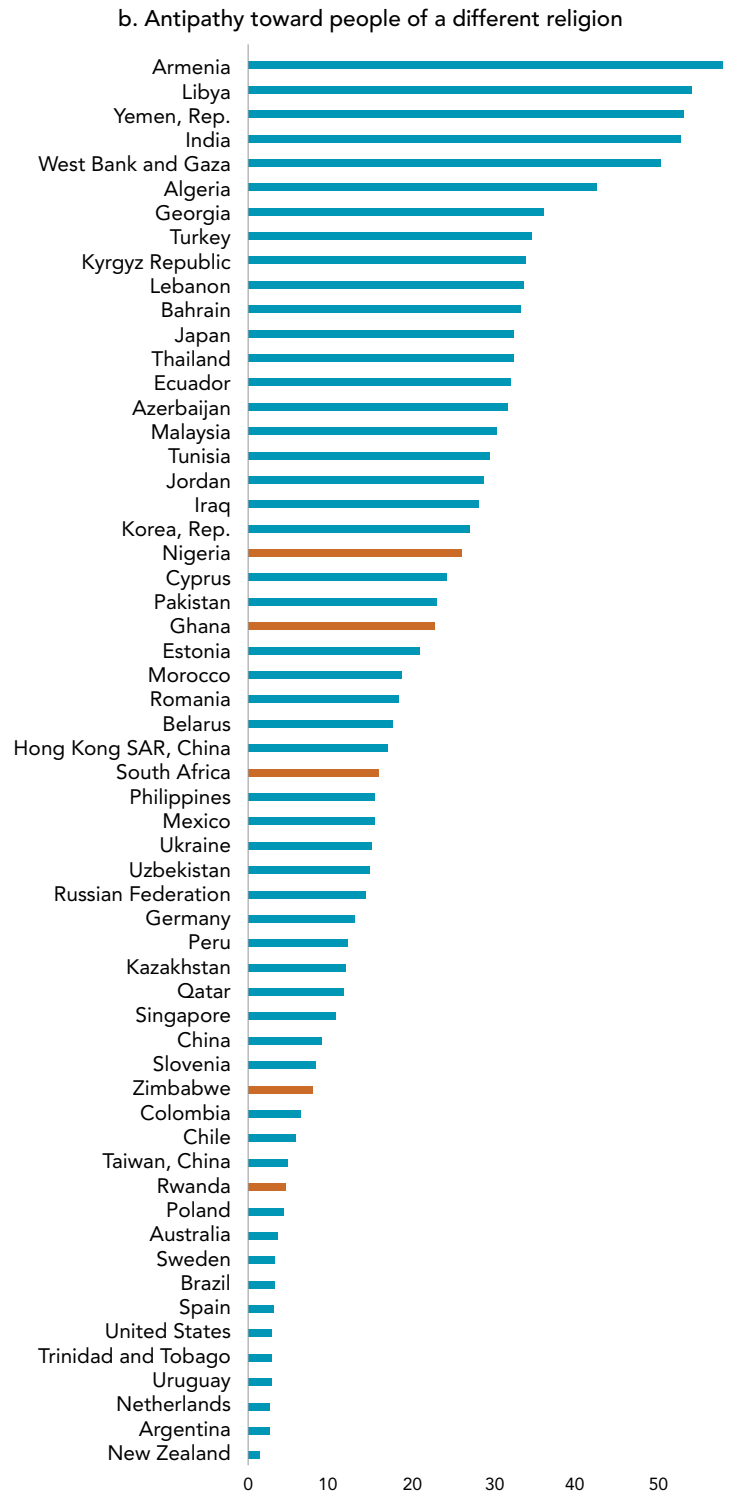

Percent

Korea, Rep.
Kyrgyz Republic

Libya

Kazakhstan

Belarus

Nigeria

Tunisia

Yemen, Rep.

Russian Federation
West Bank and Gaza

Uzbekistan

Ukraine

Malaysia

Lebanon

Algeria

Pakistan

Romania

China

Estonia

Trinidad and Tobago

India

Peru

Taiwan, China

Thailand

Cyprus

Ecuador

Poland

South Africa

Slovenia

Colombia

Hong Kong SAR,

China

Singapore

Philippines

Chile

Mexico

United States

Bahrain

New Zealand

Australia

Brazil

Uruguay

Argentina

Netherlands

Spain

Sweden

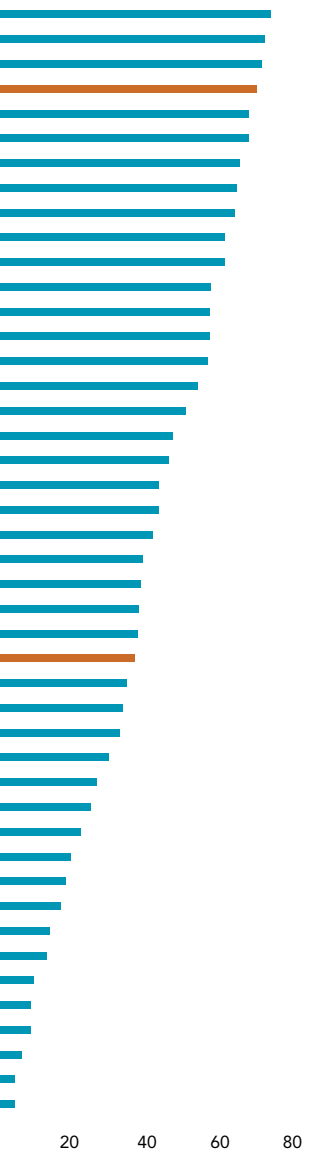

b. Antipathy toward people of a different religion

$$
\text { Libya }
$$

India

d Gaza

Algeria

Georgia

epublic

Bahrain

Malaysia

Tunisia

Iraq

a, Rep.

Nigeria

Ghana

omania

South Africa

Philippines

Mexico

Federation

Germany khstan

Qata

Singapore

China

imbabwe

olombia

Chin

Rwanda

Sweden

Brazil

States

Tobago

Uruguay

therlands

Argentina

$0 \quad 10$

Source: World Bank calculations based World Values Survey (WVS) data, 2010-2014.

Note: Respondents were asked to look at a list of different groups of people and to name those whom they would not like to have as neighbors. The groups included "drug addicts," people of a different race, people who have AIDS, immigrants or foreign workers, "homosexuals," people of a different religion, "heavy drinkers," unmarried couples living together, and people who speak a different language. See also http://www.worldvaluessurvey.org/.

a. "Homosexual" is the terminology used in the WVS. The World Bank generally refers to lesbian, gay, bisexual, transgender, and intersex (LGBTI) people (https://www.worldbank.org/en/topic/sexualorientation-and-gender-identity). 
Figure 3.6 Attitudes toward Different Languages and Immigrants or Foreign Workers by Country (\%)

a. Antipathy toward people of a different language

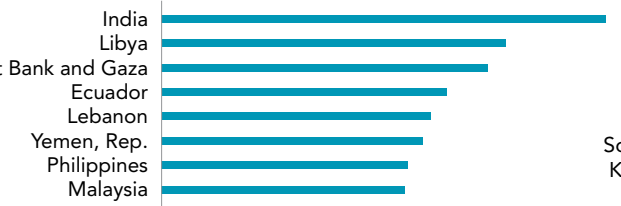

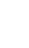

Source: World Bank calculations based on World Values Survey (WVS) data, 2010-2014.

Note: Respondents were asked to look at a list of different groups of people and to name those whom they would not like to have as neighbors. The groups included "drug addicts," people of a different race, people who have AIDS, immigrants or foreign workers, "homosexuals," people of a different religion, "heavy drinkers," unmarried couples living together, and people who speak a different language. See also http://www.worldvaluessurvey.org/. 


\section{Feelings of Belonging and Attitudes toward the State}

Feelings of belonging can indicate the extent that people feel included in different groups and institutions. Belonging to an ethnic group can create affinity and comfort among members. In the same vein, expressing affinity with a national identity is an indication that respondents feel connected to their country. The Afrobarometer 2014/2015 asked respondents who disclosed their ethnic identities at the beginning of the survey if they regarded their national or their ethnic identity as more important. The results are instructive (figure 3.8). Only a small minority of respondents appeared to give precedence to their ethnic identity alone. Over 70 percent of respondents from Eswatini, Guinea, Madagascar, Niger, and São Tomé and Príncipe regarded their national group to be more important that their ethnic group. By contrast, in Botswana, Lesotho, Liberia, Mauritius, and Uganda, nearly or over 70 percent of respondents felt that being a member of their ethnic group and of their national group was of equal importance. Feelings of national or ethnic identity may be driven by several factors, related to the extent of pluralism or of competition in society, the history of the nation-state or of conflict, and the current political milieu. It also is possible that these questions elicit socially or politically acceptable responses. Thus, the responses should not be taken as "truths" and must be interpreted with caution.

There appears to be widespread discontent with the state across Africa. This disaffection is apparent in several countries in newspaper columns, social media, and casual conversations. It also is reflected in perception surveys. Afrobarometer 2014-2015 asked respondents how often they feel that people in their country are being treated unequally "under the law" (that is, by the state). Their responses likely indicate the extent of their grievances and feelings of injustice and exclusion. Figure 3.9 presents the results. There are, as expected, large variations across African countries; Botswana and Namibia stand out as countries in which almost 60 percent of the respondents felt that people were never or rarely treated unequally under the law. In Malawi, Mauritius, and Tanzania, about half or a little more of the respondents felt that unequal treatment under the law was never or rarely manifested. At the other end of spectrum, in Mali and São Tomé and Príncipe, over half the respondents felt that unequal treatment under the law was always manifested. Overall, in most countries, more than half the respondents felt that people were treated unequally under the law often or always. It also is telling that, in some countries, notably Lesotho and Sierra Leone, over 10 percent of the respondents did not answer the question.

When the majority of citizens feel that people in their country are treated unequally, it often points to elite capture. In other words, the state is perceived as catering to the needs of a small section of society. In this situation, exclusion is not a minority issue but affects many or most citizens. Several recent World Bank 
Figure 3.7 Attitudes toward Female and Male University Education and Female Tertiary Enrollment by Country (\%)

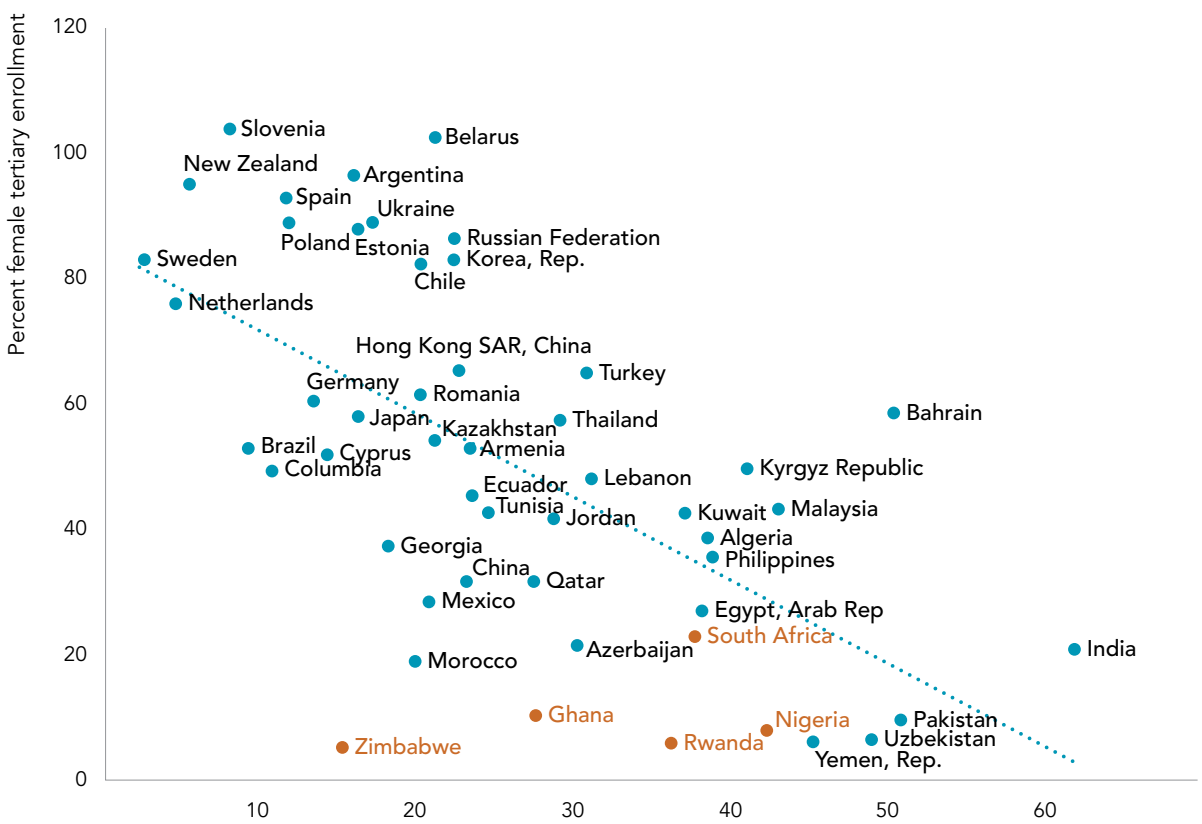

Percent respondents who think university education is more important for boys

Source: World Bank calculations based on World Values Survey (WVS) data, 2010-2014 (for attitudes toward importance of university education for boys vs. girls); World Development Indicators (WDI), 2010-2014 (for gross female tertiary enrollment rates).

Note: African countries are in red.

Systematic Country Diagnostics (SCDs) in Africa identify elite capture and a lack of public trust as important obstacles to the delivery of inclusive services and a stable social contract more broadly. See, for example, SCDs for Benin (World Bank 2017b); Guinea-Bissau (World Bank 2016d); Liberia (World Bank 2018e); and Madagascar (World Bank 2015). Other surveys and anecdotal evidence also point to perceptions that the state and its institutions are opaque and that they benefit only a few. A perception survey conducted by the Pew Research Center found that 64 percent of Kenyans, 63 percent of Nigerians, and 69 percent of South Africans surveyed felt that many jobs go to people with connections (Wike and others 2016). 
Figure 3.8 Salience of National versus Ethnic Identity and Feelings of Belonging by Country (\%)

Country Guinea

São Tomé and Príncipe

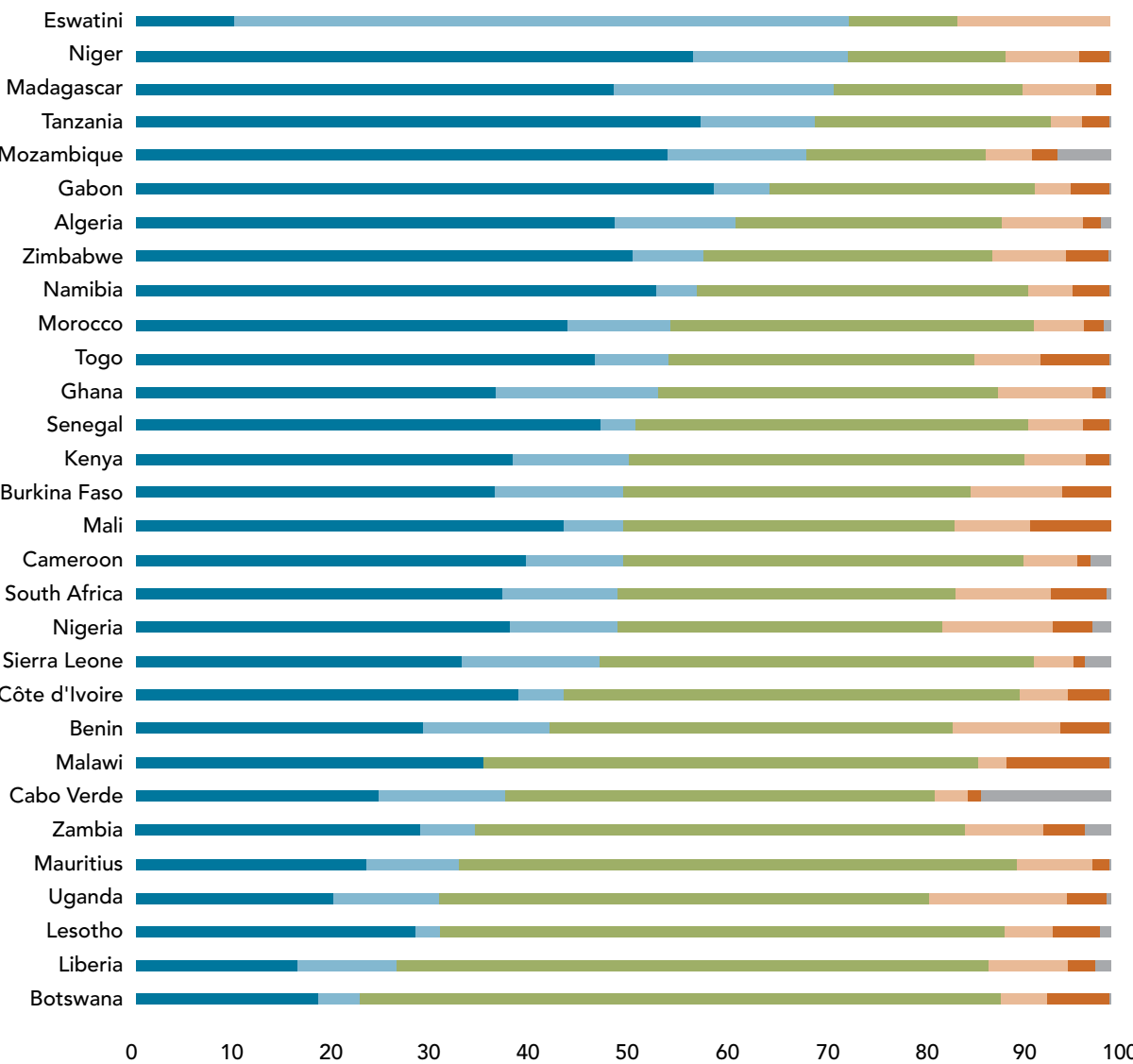

Percent

$60 \quad 70$

Only national

More ethnic
More national

Only ethnic
Equally national and ethnic

Don't know

Source: : World Bank calculations based on Afrobarometer data, 2014-2015.

Note: Respondents who identified as members of an ethnic group were asked "Let us suppose that you had to choose between being a [member of national identity] and being a [member of your ethnic identity]. Which of the following statements best expresses your feelings?" 
Figure 3.9 Perceptions of Unequal Treatment under the Law by Country (\%)

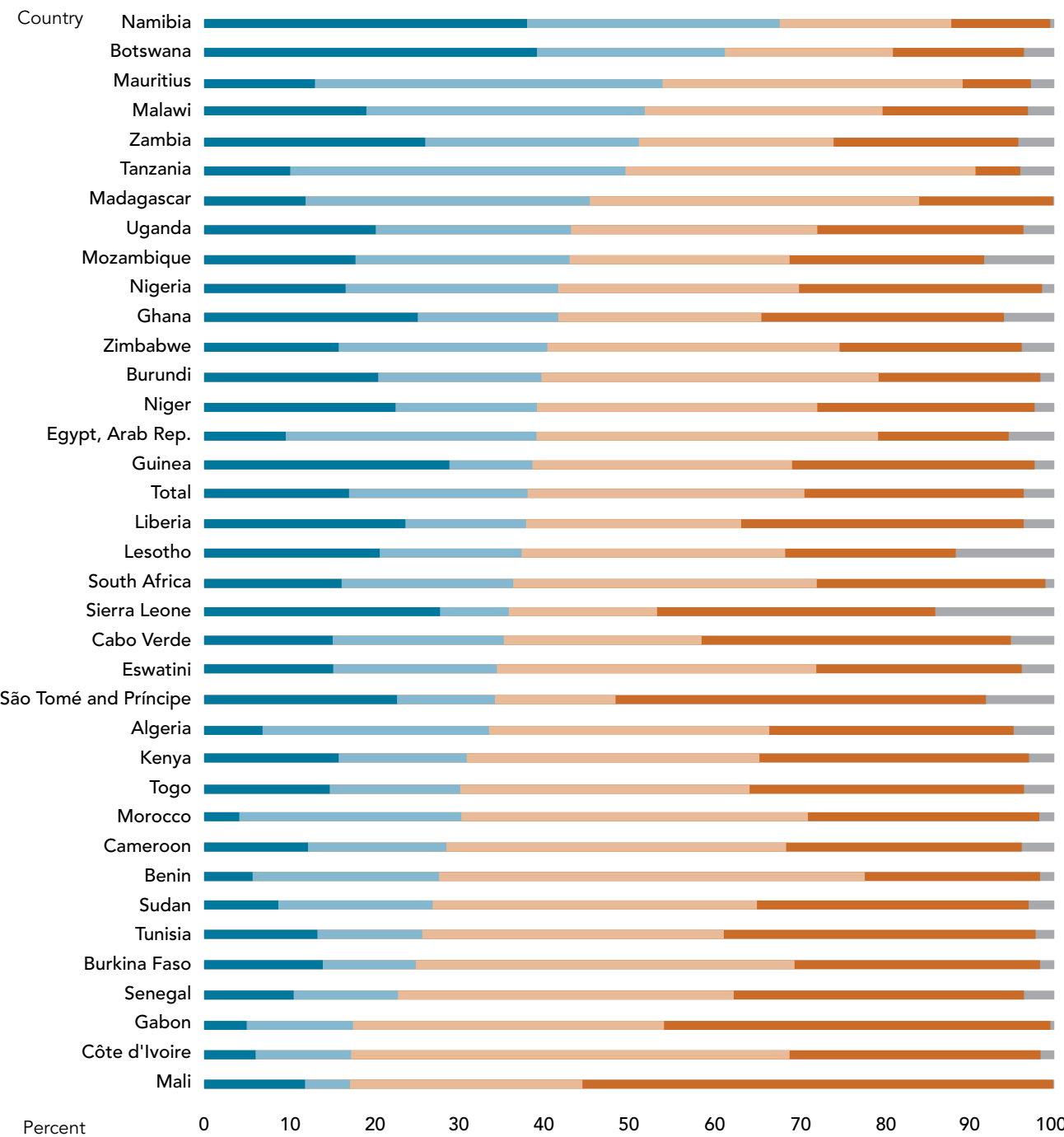
Never
Rarely
Often
Always
Don't know

Source: World Bank calculations based on Afrobarometer data, 2014-2015, Round 6 (http:// afrobarometer.org/sites/default/files/summary_results/ab_R6_afrobarometer_global_release_ highlights.pdf).

Note: Respondents were asked: "In your opinion, how often in this country are people treated unequally under the law?" 


\section{Hope and Optimism}

Despite serious misgivings about their economies and often about their governments, evidence is emerging that people living in several African countries have high levels of optimism. For instance, as part of the Pew Research Center's Spring 2017 Global Attitudes Survey, roughly half of Africans (median of 49 percent) and Latin Americans (48 percent) surveyed said their day was "particularly good" whereas other regions overwhelmingly described their day as "typical" (figure 3.10). ${ }^{14}$ Similarly, Graham and Hoover (2006), based on Afrobarometer data, found levels of optimism in Africa that surpassed other regions, with particularly high levels of optimism among the poorest and most insecure respondents, who had high hopes for the future of their children. In keeping with this finding, the Liberia SCD (World Bank 2018e) cites a 2014 survey that found that most Liberians believed that their country was headed in the right direction, driven in part, by Liberia's return to relative peace and stability. The SCD also notes, however, that as the recent conflict fades into the past, Liberians are likely to have increasing expectations from their government (World Bank 2018e, 72).

Similar optimism is visible in other survey results. For example, ex-combatants in the GLR, despite perceiving themselves as being worse off than community members overall (perceptions that are corroborated by community members), have a positive outlook for their futures and understand that social change occurs over a long period. Interestingly, despite being disadvantaged on nearly all indicators of social and economic reintegration, female ex-combatants report a stronger sense of overall happiness, a stronger sense of overall life satisfaction, and a better outlook for the future than do male ex-combatants. The female ex-combatants also express a higher sense of empowerment and control in their lives and everyday activities than do other women. In Burkina Faso, national consultations, including a telephone survey conducted by the World Bank in October 2016 (World Bank 2017a), found that although the majority (55 percent) of respondents believed that the economic situation in 2016 was worse than at any other point in the past decade, larger numbers (73 percent) believed that the situation would improve in the years to come (figure 3.11; World Bank 2017a, viii). In Kenya, Nigeria, and South Africa, the Pew Research Center found that, despite overall discontent with the economy, respondents were optimistic about the future.

Approximately 60 percent in each of these three countries said that they expected health care and education to be better for the next generation and that the economy would improve in the 12 months following the survey. Furthermore, over 75 percent of those surveyed said that young people who wanted a bright future should stay in the country rather than emigrate (Pew Research Center 2016). 
Figure 3.10 Hope and Optimism around the Globe, 2017 (\%)

Country United States

Canada

Sweden United Kingdom

Netherlands

France

Germany

Greece

Italy

Hungary

Spain

Poland

Median

Russian Federation

Philippines

Australia

India

Indonesia

Vietnam

Korea, Rep.

Japan

Median

Tunisia

Jordan

Lebanon

Israel

Turkey

Median

Nigeria

Ghana

South Africa

Tanzania

Kenya

Senegal

Median

Colombia

Brazil

Peru

Argentina

Venezuela, RB

Mexico

Chile

Median

Global Median
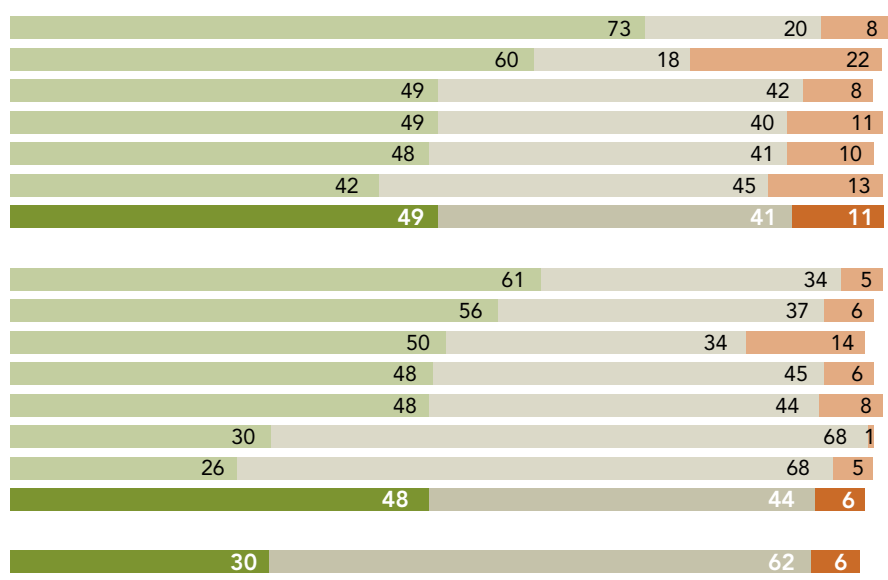

Percent

44

$49 \quad 6$

$54 \quad 8$

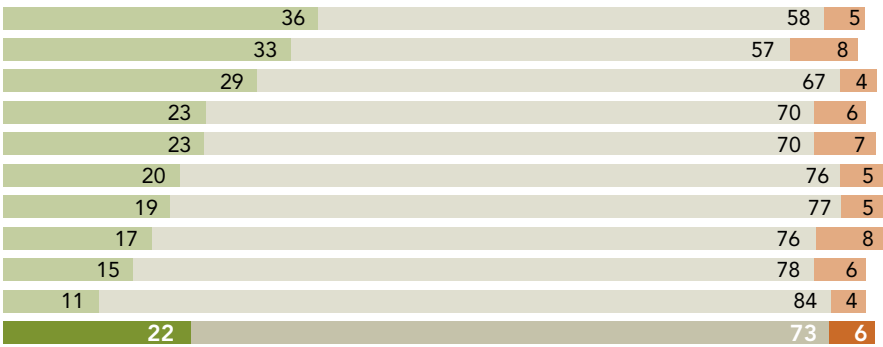

23

715
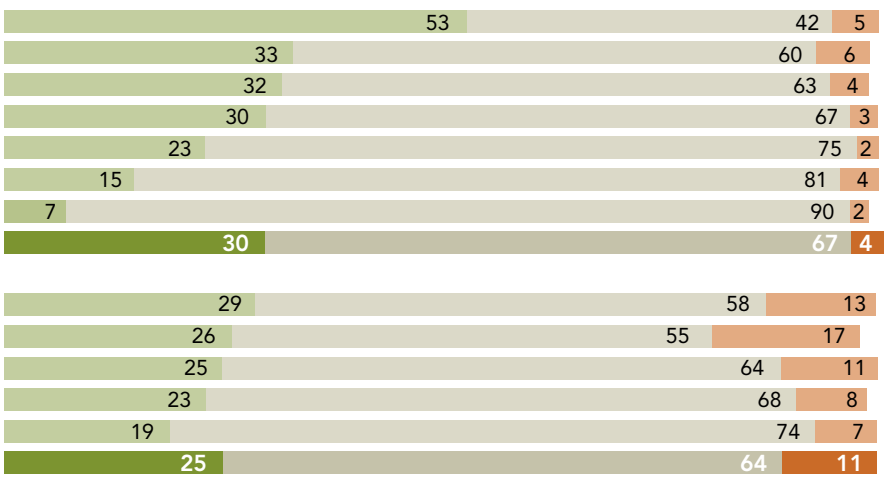

Good Day

Typical Day

Bad Day

Source: Pew Research Center, based on Spring 2017 Global Attitudes Survey. Cited in Johnson 2018. Note: Respondents were asked whether they would describe their day as "typical," "particularly good," or "particularly bad." 
Figure 3.11 Burkinabes' Satisfaction with Economy, 2016 (\%)

a. Burkinabe perceiving 2016 economic situation as worse, same, or better than last 10 years (\%)

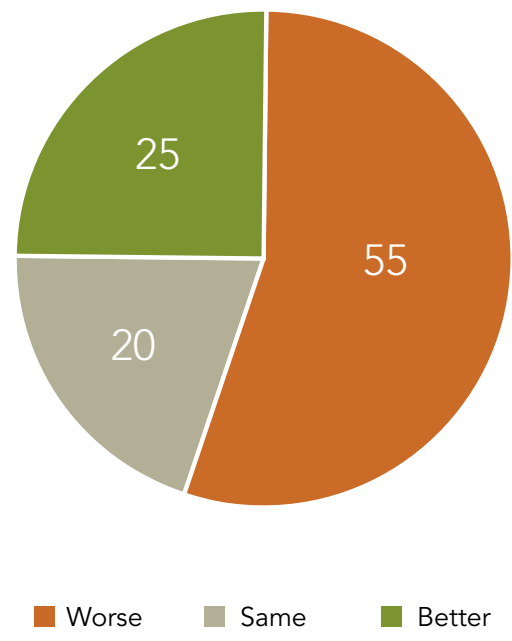

b. Burkinabe believing 2016 economic situation will improve in 2017-18 (\%)

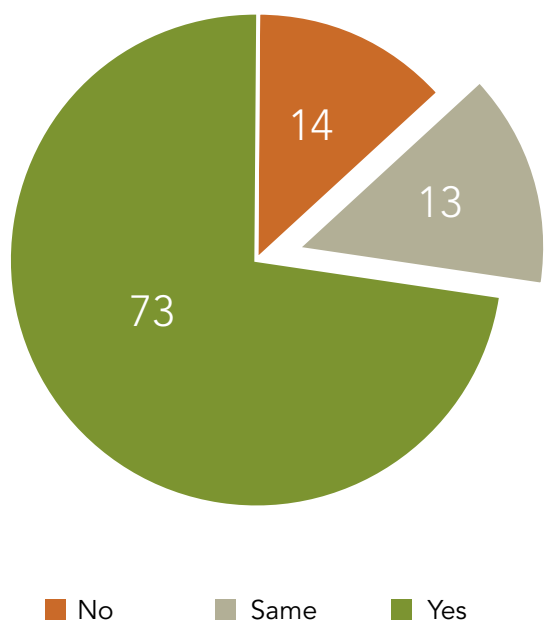

Source: World Bank 2017a.

108 CHAPTER 3 HOW DOES SOCIAL EXCLUSION PLAY OUT IN AFRICA? 


\section{Concluding Reflections}

Chapter 3 shows the ways in which social exclusion plays out - the structures and processes that aid and abet its impact. It also draws attention to attitudes and perceptions as they pertain to generalized views about social inclusion and exclusion. It shows that social structures and processes-both formal and informal—affect social exclusion in myriad ways. These structures and processes are mechanisms that uphold and solidify social exclusion. If we can make a dent in them, we have moved closer to social inclusion. Therefore, it is important to understand how these formal and informal mechanisms can impede the best efforts of governments and societies.

Feelings and perceptions may be difficult to measure, but they can matter for policy and practice in much the same way that polls matter for politicians during an election or that score cards matter for service delivery. In tandem with robust impact evaluations and administrative data, feelings and perceptions can gauge the extent to which existing policies are accomplishing their objectives. In some cases, an evaluation may show that a policy is successful, but people's perception of it may be negative. In other cases, perception data provide government with information about how implementing bodies and service providers are being perceived and what policy or implementation tweaks may lead to greater success. A survey of perceptions also can help governments create a better communication plan, instill confidence among citizens, and show that governments care. In sum, if we understand the conduits through which exclusion plays out, we are in a better place to design policies and programs that will strengthen inclusion.

Attitudes and prejudices in African countries resemble those in other countries. The relationship between attitudes and objective outcomes in African countries is not always clear cut, but attitudes can indicate areas of exclusion. Finally, large groups of people feel left out by the state and the elites. These groups are disenchanted with the state, but this feeling does not seem to affect their overall outlook. Evidence from different sources points to heightened hope and optimism across many African countries. 


\section{Notes}

1 Wangari Maathai, Nobel Lecture, Oslo, Norway. December 10, 2004. https:// www.nobelprize.org/prizes/peace/2004/maathai/26050-wangari-maathai-nobellecture-2004/.

2 Starting with the first iteration of the Mines and Works Act in 1911 (World Bank 2018b, 12).

3 This could be related to the fact that same-sex relations were decriminalized in France after the French Revolution but remained a criminal act in Britain from the early 16th century until 1967. See Hyde 1970, 147-48; Copley 1989.

${ }^{4}$ Note that this is the terminology used in the World Values Survey. The World Bank generally refers to lesbian, gay, bisexual, transgender, and intersex (LGBTI) people (https://www.worldbank.org/en/topic/sexual-orientation-and-gender-identity).

5 See http://id4d.worldbank.org.

${ }^{6}$ Over 80 percent of men between their early 30s and early 80 s are married. By contrast, the share of married women peaks approximately age 30 and then drops below 80 percent just after age 40 . By age 65 , there are as many widowed women as married women, and 80 percent of women are widowed by age 80 . The number of divorced also is higher for women than for men at all ages (Djuikom and van de Walle 2018).

7 In particular, women experience lower levels of body mass index (BMI) and higher rates of underweight (Djuikom and van de Walle 2018).

8 The overall gain from not becoming a widow and remaining married is equivalent to about six to seven years of schooling, depending on the nutritional indicator used. Approximately four to six years of education would be needed to compensate for divorce (Djuikom and Van de Walle 2018).

9 Albinism is a noncontagious, genetically inherited condition that most commonly results in the lack of melanin pigment in the hair, skin, and eyes.

10 This terminology is used in the World Values Survey. The World Bank generally refers to lesbian, gay, bisexual, transgender, and intersex (LGBTI) people (https:// www.worldbank.org/en/topic/sexual-orientation-and-gender-identity).

${ }^{11}$ The WVS also includes "drug addicts," people of a different race, people who have AIDS, "heavy drinkers," and unmarried couples living together.

${ }^{12}$ The WDI measure gross female tertiary school enrollment. Gross enrollment ratio is the ratio of total enrollment, regardless of age, to the population of the age group who officially corresponds to the level of education shown. Tertiary education, whether or not to an advanced research qualification, normally requires, as a minimum condition of admission, the successful completion of education at the secondary level. See https://data.worldbank.org/indicator/SE.TER.ENRR.FE. 
${ }^{13}$ Gross enrollment ratio is the ratio of total enrollment, regardless of age, to the population of the age group who officially corresponds to the level of education shown. This explains why percentages can exceed 100. Gross enrollment ratios indicate the capacity of each level of the education system, but a high ratio may reflect a substantial number of over-age children enrolled in each grade because of repetition or late entry rather than a successful education system. The net enrollment rate excludes over- age and under-age students and more accurately captures the system's coverage and internal efficiency. Differences between the gross enrollment ratio and the net enrollment rate show the incidence of over- age and under-age enrollments. See https://data.worldbank.org/indicator/SE.TER.ENRR.FE.

${ }^{14}$ Only 22 percent of Europeans said their day was good (Johnson 2018). 



\section{Toward Greater Inclusion in Africa}

There will be failures along the way, for the world will not change overnight. But we have seen change in our lifetimes, and the world will continue to change in ways that affect us all. ${ }^{1}$

-Ellen Johnson Sirleaf, 2011

Africa has made enormous progress toward economic development and social inclusion, as previous chapters have shown. This progress testifies to a truism: change toward social inclusion is possible. The innovations, policies, and programs in Africa serve as lessons across countries in the continent and for other regions grappling with similar issues. In some cases, change is inevitable. But it can also be painful and difficult. Change is always complex and political and may create new excluded groups. For instance, the focus on female secondary education in many countries, notably in the Caribbean, meant that boys at the secondary level were left behind. In other cases, where refugees have settled in large numbers and have come with higher human capital endowments than their host communities, the hosts have felt afraid and anxious about jobs, services, and voice. Social inclusion is not a linear process. Progress can stall for unanticipated reasons, but it may pick up again. Groups who once were disempowered may gain power and upstage earlier dominant groups, who in turn may work to impede progress toward social inclusion because it hurts their interests. Social inclusion is, as World Bank (2013) states, always work in progress. 
Investing in social inclusion must be a conscious choice by societies and governments, begun with a clear understanding of the costs and benefits. Investing in an inclusive society is not free and needs concerted action to transform the investment into a win for all. Social programs, for instance, can be expensive and have an impact on fiscal sustainability. Governments often need to make trade-offs, either by cutting costs on other initiatives or by raising taxes. There may be political costs as well, as initiatives that focus on historically excluded groups can upset power relations. Governments and politicians need to craft clear social contracts with citizens to ensure support for social inclusion. There are examples the world over of citizens willing to pay for a more inclusive society. The most powerful form of support is through the fiscal realm, whereby citizens pay taxes that they know will fund policies and programs for greater social inclusion. In Brazil, Mexico, and Nepal, for instance, there is strong support for social protection programs; and in Bangladesh, poverty reduction is recognized as a national priority, with the elite supporting antipoverty initiatives (Hossain and Moore 1999).

How does change take place? Who are the main actors? What are the channels through which progress toward social inclusion is achieved? What can we learn for the future and for the countries that want to make greater progress? We draw from the World Bank's social inclusion framework (World Bank 2013) and address inclusion in markets, services, and spaces. Inclusion how? Here we repeat what we state earlier in this report: by raising the ability, opportunity, and dignity of individuals and groups most likely to be left out. Chapter 4 outlines some of the policy and program efforts that other African countries are making to pursue social inclusion. Because documenting process can help others in their quests to design workable solutions, this report focuses on some innovations and solutions that African countries have tried. Chapter 4 has two parts: the first focuses on the actors who drive change and the second on interventions in the form of policies, programs, and projects that have been implemented or for which there are impacts to share.

\section{Who Drives Change, and How?}

Multiple actors and processes can lead to change toward social inclusion, but the state has the preeminent responsibility and is the dominant actor (World Bank 2013).

The preeminent role of the state as the driver and propeller of change towards inclusion is well recognized. It can intervene for social inclusion through three conduits. The first is to create an enabling environment for social inclusion, such that citizens have the freedom to exercise their choice and to innovate for better outcomes and processes. The second is to design legislation, policy and programs 
that directly or indirectly affect social inclusion. The third is to ensure implementation and enforcement of the legal and policy framework. All these roles are underpinned by the nature of the state, the degree of openness of the polity and the vision that the state and citizens share. The strength of both formal and informal institutions is critical for the success of state-led actions.

-World Bank 2013, 200

There are other important drivers of change toward social inclusion in Africa, as elsewhere. These drivers include a host of nonstate actors: religious groups, NGOs, the private sector, and, most importantly, organizations of historically subordinated groups. Lasting change usually comes when state and nonstate actors join forces. Elites often are part of both state and nonstate actions and play a critical role in propelling social inclusion. The importance of the HIV/AIDS epidemic in many parts of the continent presents an interesting example. What started as attention to a public health emergency quickly moved to identifying affected groups. They included, among others, gay and bisexual men and other men who have sex with men (MSM), widows, and orphans. The attention to sexual orientation in many African countries was legitimized because it was linked to a public health crisis, and groups previously invisible were rendered visible. This is not to say that stigma no longer exists, and sometimes the stigma may only have changed form. Nevertheless, the epidemic was a catalyst. It presented an opportunity that enabled previously excluded groups to mobilize and be partners in the change that policy and programs propelled. Through the process of attacking the epidemic, governments and civil society co-opted elites and community members alike. Box 4.1 shows that the stigma against shopkeepers who had HIV decreased considerably in Eastern and Southern Africa.

Regardless of which actor sponsors a program that is intended to promote social inclusion, few programs can succeed without community ownership. Communities that own the movement toward social inclusion and can visualize a new society for themselves are most likely to be invested in the success of such programs. Relatedly, the accountability of the state and service providers to citizens and communities often forms the crux of success. Conversely, when programs are designed without community involvement or are top down, they may take longer to take off and even face resistance from the community. The process of abolishing female genital mutilation (FGM) in Burkina Faso is an illustrative case (box 4.2). Together with criminalizing the practice in 1997, the government implemented a broad array of measures that promoted community ownership of the change. In addition to training lawyers, judges, police, and security officers to ensure their buy-in, the government supported "community patrols" who raised awareness of the harmful consequences of FGM and informed communities of its criminalization. 
Box 4.1 Talking About Change: Stigma and Discrimination in Africa

Figure B4.1.1 Stigma and Discrimination in Eastern and Southern Africa, 2000-2016 (\%)

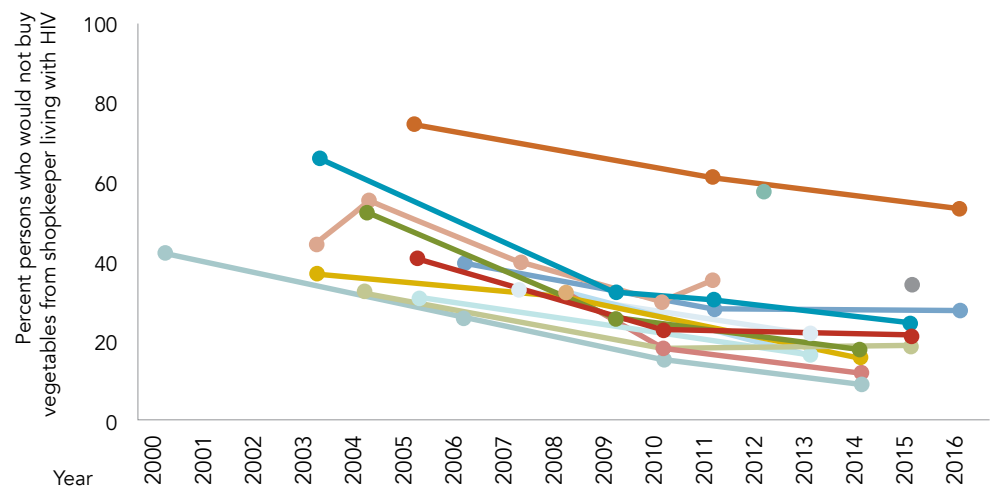
- Angola
- Botswana
- Comoros
- Eswatini $^{\mathrm{a}}$
Ethiopia

- Kenya

- Rwanda

- Lesotho

- Tanzania

- Malawi

- Uganda

- Mozambique

Zambia

- Namibia

- Zimbabwe

We know from the experience of the HIV/AIDS epidemic spreading information and knowledge regarding HIV/ that stigma and discrimination are not immutable; AIDS. The partnership between governments, advocacy these have been significantly reduced in Eastern and groups, the private sector, international agencies, Southern Africa. Although this may partly reflect the scientists, researchers, and medical practitioners was reduction in the number of infections and deaths from the foundation of this change. the disease, it also signifies the victory of campaigns.

Source: UNAIDS 2018a.

Note: Persons surveyed were males and females ages 15-49.

a. Female respondents only. 
Examples of communities driving change exist across the world in areas as diverse as reproductive health, education, infrastructure, environment, and employment, both in the context of decentralized governance and as standalone initiatives. The community-based rehabilitation (CBR) model for persons with disabilities is known to have positive outcomes, especially in remote areas. Various organizations have come together to build the CBR Africa Network (CAN) and sponsor several country-specific and local initiatives. There are other examples as well. A review of the effectiveness of interventions that focus on gender-based violence (GBV) found that participatory, multiple stakeholder supported discussion around gender relationships and the acceptability of violence encouraged shared decision-making among family members and nonviolent behavior and tended to show great success (Ellsberg and others 2015). One way to secure ownership by communities is to give them the power to make local decisions and set budget priorities for themselves. Box 4.3 highlights the case of participatory budgeting in West Pokot in the wake of Kenya's thrust toward devolution. Also of note is the Local Governance and Service Delivery Project (LOGOSEED) in South Sudan, which engages communities to ensure that project investments reflect their needs and that service delivery transcends social divisions. In its mobilization process, the project focuses on reaching diverse ethnic groups, women, youth, persons with disabilities, displaced people, and returnees (Vemuru and Karim 2017).

High levels of within-community trust and social capital are likely to be associated with support for programs that promote social inclusion. Rhea (2014) describes the successful reintegration of ex-combatants across the Great Lakes Region (GLR) and the positive role that communities play. Although community members consistently reported high levels of fear regarding the return of ex-combatants before their arrival, few report having such fears after the ex-combatants return. Community members surveyed described positive contributions that ex-combatants make to communities, and both community members and excombatants tended to report high levels of overall trust in the community and improvement in trust over time. In Democratic Republic of Congo, in contrast to other countries in the GLR, both ex-combatants and community members perform weaker across almost all indicators of reintegration processes. A core challenge in the Democratic Republic of Congo is that communities display weaker levels of social capital and social cohesion. The broader societal shift toward peace and development that appears to have catalyzed ex-combatants' reintegration in other GLR countries is diminished in the context of continued local violence and insecurity in the eastern Democratic Republic of Congo. Therefore, programs that also invest in building community cohesion and trust are likely to show better results than those that proceed from an assumption that communities are a panacea to intractable problems. 


\section{Box 4.2 Talking About Change: Female Genital Mutilation}

Figure B4.2.1 Female Genital Mutilation in Burkina Faso, 1998-2015

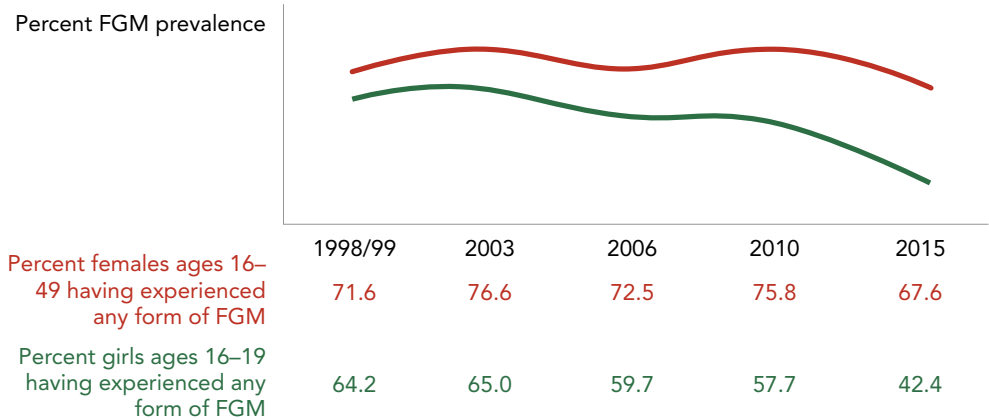

Sources: UNFPA Regional Office for West and Central Africa 2018, based on DHS (Demographic and Health Survey); MICS (Multiple Indicator Cluster Survey); EMC (Continuous Multisectoral Survey).

Note: $F G M=$ female genital mutilation.

Figure B4.2.2 Prevalence of Female Genital Mutilation in Eight African Countries

\begin{tabular}{lll} 
Country & Women ages 45-49 (\%) & Girls ages 15-19 (\%) \\
\hline High-prevalence countries & & \\
\hline Guinea & 99.6 & 94.0 \\
Mali & 83.9 & 83.1 \\
Gambia, The & 75.9 & 76.3 \\
Sierra Leone & 97.8 & 74.3 \\
Mauritania & 75.2 & 65.9 \\
\hline Medium-prevalence countries & & \\
\hline Burkina Faso & 87.4 & 42.4 \\
Guinea-Bissau & 45.2 & 41.9 \\
Senegal & 26.0 & 20.6 \\
\hline Low-prevalence countries & & \\
\hline Nigeria & 35.8 & 15.3
\end{tabular}

Sources: UNFPA (United Nations Population Fund), based on Demographic and Health Surveys (DHS); Continuous Multisectoral Survey (EMC); and Multiple Indicator Cluster Survey (MICS). Burkina Faso data is from the 2015 EMC conducted by the National Institute of Statistics and Demography in Burkina Faso. 
Burkina Faso has seen the most striking drop in female genital mutilation (FGM) over the decades of 2000 and 2010 (figure B4.2.1). But the first efforts to end FGM go back a long time and were not particularly successful to start. Catholic missionaries during colonization tried unsuccessfully to put an end to FGM by threatening to excommunicate those who practiced it, and under the First Republic in the 1960s awareness-raising campaigns against the practice were met with strong resistance by the traditional and customary chieftainship.

Several developments in the late 1970s began to garner support for abolishing FGM and highlight the role of partnerships between civil society, government, the judiciary, and communities. These included the denunciation of FGM by nongovernmental organizations, women's associations, and the media; a national radio broadcast condemning FGM and disseminating information of the harm done by the practice; and a series of governmental anti-FGM campaigns and seminars covered by national radio, television, and newspapers from the 1980s onward. The government then institutionalized the fight against FGM by establishing an interministerial committee in 1990, which was charged with coordinating resources and activities promoting the elimination of FGM in Burkina Faso. In 1997, FGM was criminalized in Burkina Faso, and the implementation of the law has since been accompanied by stronger enforcement as well as normative change. These measures have included training lawyers, judges, police, and security officers to become advocates against FGM; sending patrols into communities to raise awareness of harmful consequences and of the criminalization of the practice; as well as the translation of the law into local languages, wide distribution of the law in communities, and establishment of a telephone hotline for people to anonymously report cases of FGM. Even before criminalization of FGM, there was a national telephone helpline called "SOS Excision" that people could call to report cases; approximately 70 percent of cases before the courts start with a tip via this phone line. Cases also are reported at police stations and customs offices, through religious leaders and local administrators, and directly to the Permanent Secretariat (SP) for the National Council for the Fight against the Practice of Excision (CNLPE). Table B4.2.1 details prevalence of FGM in several African countries.

Source: UNFPA 2018. 


\section{Box 4.3 Participatory Budgeting in West Pokot, Kenya}

After a nationwide mandate to devolve governance and increase civic participation in planning, budgeting, and service monitoring, West Pokot, a pastoral community in north Kenya, became one of the first counties to introduce participatory budgeting (PB). The initiative was part of the West Pokot government's resolve to increase its citizen outreach and participation in the planning and budgeting process by moving meetings from the ward level to remote sublocations and encouraging the participation of women in a largely patriarchal society.

In the West Pokot pastoral community women tend to defer to the decisions made by their male counterparts. This practice was reflected in past budget consultations, when very few women attended budget meetings. When women did attend, they sat separately from the men and endorsed the projects proposed by men without direct involvement.

Following trainings in partnership with the World Bank in October 2015 and January 2016, the county government of West Pokot committed 32 percent of its development budget to be decided by citizens in PB meetings that specifically targeted women. The initial results and outcomes of the PB have been positive. Women's participation in budget consultation meetings increased. Women prioritized improving maternal health care services, accessibility to water, and early childhood education. Men focused on improving roads, livestock and agricultural services and on the construction of cattle dips. The projects that citizens selected in the PB process are being implemented or are in the pipeline.

The Kenya Participatory Budgeting Initiative (KPBI) is being implemented under the Kenya Accountable Devolution Program.

Sources: Omolo 2017; Finch and Omolo 2015. 


\section{Programs and Policies toward Social Inclusion: Reflections on the African Experience}

Most countries in Africa, as elsewhere, have a plethora of policies, programs, and projects to advance social inclusion. These policies may be targeted to certain groups or areas, or they may be universal, accessible to everyone. The effectiveness of particular programs varies by country, context, and initiative. At the highest level, constitutions of most countries guarantee equality and basic freedoms. At the next level, broad-vision documents, manifestos, and pronouncements give a more defined indication of the priorities of a government. Further down are policies, which lay out directives and show the clearer path of a government's focus on social inclusion. Many policies signal the groups whom they privilege, or ignore, by their silence on certain topics or groups or by the intensity of implementation of certain policies. So, although policies may not actively exclude individuals or groups, the policies may do so passively, either by not expressly indicating who is included or by not investing adequate resources or attention to implementation. ${ }^{2}$ As pointed out earlier, many policies are political, and their implementation is even more so. Well-crafted policies have clear rules, guidelines, and implementation plans and mechanisms. Under policies, there often are programs that highlight reforms by sector or subsector. As previously described, the policy literature in Africa tends to focus on poverty reduction, response to humanitarian emergencies, and food security. In addition, and especially in countries and contexts wracked by conflict, governments and donor partners have rightly focused on basic services, security, and livelihoods. This section reflects on some of the policy and programmatic interventions that advance social inclusion, based on our definition of it.

How do policies in Africa deal with social identity, which often is fraught with political and social implications?

There's no dispensing with identities, but we need to understand them better if we can hope to reconfigure them, and free ourselves from mistakes about them that are often a couple of hundred years old. Much of what is dangerous about them has to do with the way identities-religion, nation, race, class, and culture-divide us and set us against one another.... They are the lies that bind.

-Anthony Appiah, 2018.

In contexts in which ethnicity or race has historically been implicated in divisions and tensions, or has been otherwise political, whether at the societal or national level, the state may consciously move away from an attention to ethnicity. Several 
countries in Africa have emphasized civic citizenship and national identity over ethnic or parochial identities. For instance, chapter 3 notes that the majority of those surveyed by the Afrobarometer tended to identify more with their national identities than their ethnic identities. Nevertheless, most countries address at least some identities-most commonly, gender, age, location, and occupation-via targeted programs or special provisions. Social protection programs are a case in point and are discussed later in this section.

One way of focusing on specific individuals or groups is through affirmative action or quotas. Special provisions for individuals and groups are common in OECD and non-OECD countries alike. Although sometimes controversial, especially in the context of stubborn group-based inequalities, affirmative action policies are still considered among the more effective policy mechanisms (Langer and others 2016). Many African countries have affirmative action policies for women and persons with disabilities. In its 1995 Constitution, Uganda enshrined a quota system for Parliament stating that Parliament should include a woman representative in every district, as well as representatives from the army, youth, workers, persons with disabilities, and "other groups as Parliament may define" (Article 78). Similar provisions were made to ensure seats for women in local government (Muriaas and Wang 2012,311). South Africa, of course, has the most prominent and comprehensive set of initiatives:

While the Constitution of 1996 appeared to favor the 'soft' form of transformation through training and mentoring, the Employment Equity Act of 1998 focused on quotas, or targets: all employers of firms with more than 50 people have to ensure equitable representation of all race groups according to population demographics. Employers are required to give preferential treatment to black candidates. They also have to develop an "equity plan" for the Department of Labour, and there are fines for not meeting targets. The broad-based black economic empowerment (BBBEE) legislation of 2007 also imposed quotas for black executives. (World Bank 2018f, 15)

Some evidence suggests that affirmative action has had positive effects on wages and led to growing returns to education for black South African men (Burger and others 2016). A recent paper finds tentative evidence from Ghana, Kenya, Nigeria, and Uganda that attitudes toward redistribution are favorable overall, suggesting that affirmative action policies may well have popular support in some African countries (Langer and others 2016).

Another way to address social identities, sometimes referred to as "special groups," is to nest a focus on them within universal access programs such as in health or education. Health programs in several countries give special attention to groups 
including children, adolescents, the elderly, or pregnant women. Uganda has committed to inclusive education and in 2006 passed the Persons with Disability Act, which requires institutions of higher learning to eliminate barriers to accessibility and prohibit discrimination (Emong and Eron 2016; Roberts Otyola and others 2017). Similarly, the government of Ghana has had specific targets to educate learners with disabilities since 2013 (Ametepee and Anastasiou 2015). The government's current Inclusive Education Policy establishes several measures, from adjusting educational infrastructure and teacher training in diversity and nondiscrimination to the tailoring of curricula to different educational needs. The policy is accompanied by a costed action plan to facilitate its implementation.

Often, and especially when ethnicity or religion is divisive, governments may prefer to name the geographic region in which a certain group is concentrated. Programs can be geographically targeted to regions that may need special attention. Nigeria, for example, has between 250 and 400 different ethnic groups, depending on which criteria are applied. Following various political reforms to ensure the representation of ethnic and regional groups, in 1996 Nigeria established the Federal Character Commission (FCC) to oversee the implementation of affirmative action not only in government administration but also in social services, infrastructure development, and the private sector. The Federal Civil Service (FCS) instituted a geopolitical quota based on territorial states and zones but was silent on ethnicity and religion. Despite criticism of the quota system, the FCC seems to have made important contributions. It provides an avenue to resolve peacefully conflicts over both ethnic and regional representation because disgruntled groups tend to approach the FCC or the FCC Committees of both Houses of the National Assembly to investigate claims and seek concrete data or remedies. The FCC also generates the data through which representation can be assessed and monitored. Finally, it has been argued that the FCC has moved the culture of bureaucratic recruitment toward greater diversity (Mustapha 2009).

\section{Legal Provisions and Reforms}

Although laws can be discriminatory, they also are one of the most potent agents of social change. African countries have wide-ranging legal and constitutional provisions aimed at social inclusion. For instance, over the past decade, Africa has seen a surge in reforms that promote gender equality, from laws that address workplace sexual harassment to laws that address domestic violence (box 4.5). In fact, Africa has been a global leader, having implemented the most reforms promoting gender equality of any region world-wide. Also notable are the countries that have explicitly acknowledged SOGI equality. In South Africa such equality was written into the Constitution. Mozambique and the Seychelles recently decriminalized same-sex relations (2015 and 2016, respectively). Other countries do not criminalize based on sexual orientation at all. ${ }^{3}$ The Botswana Supreme Court 


\section{Box 4.4 Legal Reform for Women in Africa}

Africa has implemented the most reforms promoting gender equality of any region globally, with 71 reforms over the last 10 years. Over 50 percent of these reforms changed laws that affected gender-based violence (GBV). Burundi, Comoros, Rwanda, São Tomé and Príncipe, and Zambia all introduced laws that addressed both workplace sexual harassment and domestic violence. Among the top reforming economies in the region over the past decade have been Democratic Republic of Congo, Guinea, Malawi, Mauritius, São Tomé and Príncipe, and Zambia (box figure B4.4.1).

Figure B4.4.1 Improvement in Women, Business and the Law Index, 20092018

Change in score between WBL 2009 and WBL 2018

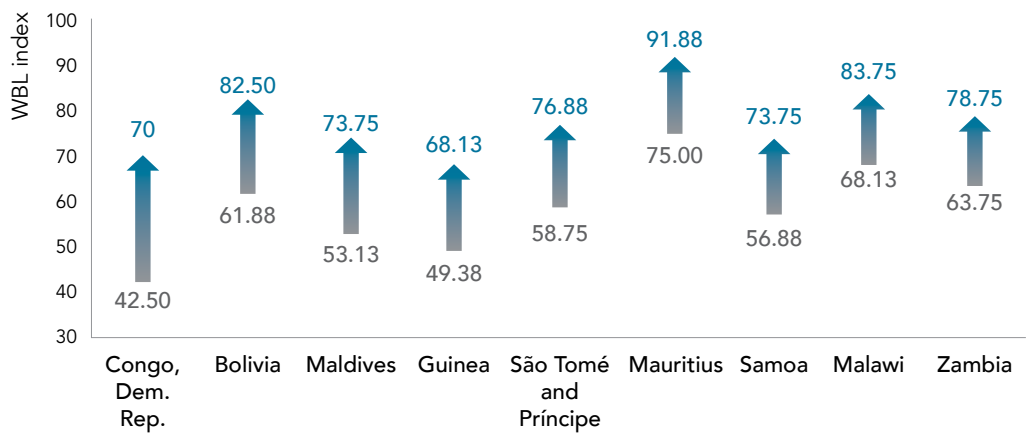

Country

Source: World Bank 2018g, 11, based on Women, Business and the Law database. Note: $\mathrm{WBL}=$ Women, Business and the Law database. 
Democratic Republic of Congo saw the largest increase in its Women, Business and the Law index (from 42.5 in 2009 to 70.0 in 2018). Improvements in DRC were based on reforms allowing married women to register businesses, open bank accounts, sign contracts, get jobs, and choose where to live in the same way as men can. The legal requirement for wives to obey their husbands was removed, as were restrictions on women working in specific industries such as mining, manufacturing, and construction. DRC also introduced gender nondiscrimination laws in employment and access to credit.

Mauritius began reforms in 2008 by introducing civil remedies for sexual harassment at work, prohibiting the dismissal of pregnant workers, introducing paid paternity leave, and prohibiting discrimination in access to credit based on gender. In 2013 the government mandated equal remuneration for work of equal value and in 2015 increased the length of paid maternity leave from 12 to 14 weeks. Due to these reforms, Mauritius' score increased by 16.88 points. Between 2009 and 2018, the female labor force participation rate rose by 6.82 percent relative to that of males.

São Tomé and Príncipe introduced a domestic violence law in 2009; implemented a workplace sexual harassment law that included criminal penalties in 2012; and reformed its retirement laws for men and women to entitlement to full pension benefits, and equalized the mandatory retirement age for men and women in 2014. The country's score increased by 58.75 percent. Between 2009 and 2018, the female labor force participation increased by 1.75 percent relative to that of males.

Source: World Bank 2018g. 
ruled in 2017 that its Constitution requires the government to legally recognize transgender people's gender self-identification. Namibia's courts interpreted their 1963 law on registrations of births, marriages, and deaths as allowing official recognition of gender change. Other laws ban all or some forms of anti-LGBTI discrimination. Countries that ban some forms of this discrimination include Angola, Botswana, Cabo Verde, Mauritius, Mozambique, and the Seychelles; South Africa bans all forms. Another 10 African countries have supported LGBTI rights in declarations to the UN General Assembly or the UN Human Rights Council. These countries are Cabo Verde, Central African Republic, Gabon, Guinea-Bissau, Mauritius, Rwanda, São Tomé and Príncipe, Seychelles, Sierra Leone, and South Africa. Although different from decriminalization of same-sex relations, reforms to family laws across the world are also instructive. Hallward-Driemeier and Gajigo (2013) analyzed the effects of such changes for women in Ethiopia, where the change required both spouses' consent in the administration of marital property. This reform removed the ability of one spouse to deny permission to the other to work outside the home. Simultaneously, a change raised the minimum age of women to marry, which strengthened women's bargaining position within the household because older women usually have greater power. Where the reform has been enacted, women are also more likely to work outside the home, employ more educated workers, and work in paid and full-time jobs, after controlling for time and location effects.

Law and custom are inextricably linked. Regarding land ownership, both formal and customary laws wield great influence. Providing land titles or de facto recognition of land use patterns of historically excluded groups can be effective in increasing their inclusion and enhancing their dignity. Women in many societies, including in Africa, face multiple barriers to owning land. Making them joint holders in land redistribution or resettlement projects or reserving land use quotas can increase their access to opportunities, for example, in agricultural labor markets, while at the same time empowering them. Similarly, recognizing the customary rights of indigenous peoples over their native lands and strengthening their representation in land negotiations is as much about creating opportunity for these groups to use the land as it is about recognition (World Bank 2013, 216). For example, Mozambique's 1997 land law allows oral evidence to be used in land tribunals. As literacy rates are low among poor and marginalized groups in rural areas, this measure proved critical to enabling their participation in land registration procedures (FAO 2010; cited in World Bank 2013). In Kenya, the decision of the African Commission on Human and Peoples' Rights to recognize the ownership rights of Endorois (agropastoralists) helped this group gain greater access to their ancestral lands around the Lake Bogoria Game Reserve, which the group traditionally used for cattle grazing and to perform their religious and cultural rites (Abraham 2012; cited in World Bank 2013, 217). Nevertheless, enforcement of laws can be challenging for several reasons, not least because enforcement 
agencies often reflect exclusionary norms and attitudes. In South Sudan, despite the fact that the 2009 Land Act and the 2011 Transitional Constitution of South Sudan (TCSS) recognize women's equal rights to land and property, perceptions that women cannot own land independently of husbands or male relatives remain widespread among land administrators in both statutory and customary systems (Marzatico 2014, 15). The disregard of customary land practices in the formalization of land rights can also exacerbate exclusion and become a source of conflict.

Rwanda's far-reaching land reforms in the context of its national reconciliation had strong effects on women's access to land markets and on their overall power. Legislative reform first eliminated bias against female land ownership and was followed by the 2005 Organic Land Law (OLL), which established a single statutory system of land tenure and ended the dualism of customary and formal tenure systems. In 2010 Rwanda introduced a nationwide land tenure regularization (LTR) program, a first-time land adjudication and registration process that was imagery-based and low cost. As a result of the reforms, womenwith or without legal marriage certificates-were more likely to be registered as owners alone or jointly with their spouses, and women's rights to mortgage or lease land increased substantially. The LTR not only achieved impressive numbers of registrations in fewer than three years but also improved the perceptions of women's land rights. The perceived rights for females to be registered as claimants (alone or jointly) on parcels owned by married couples increased from 33 percent to 67 percent-94 percent, depending on the program area (Ali and others 2011; Ali and others 2015).

\section{Social Programs}

Well-designed and implemented programs across the globe have changed the face of social exclusion. Of these, social safety nets (SSNs) have a historical track record of shielding households from the negative effects of shocks and, more recently, of building household and community assets. Such programs started in Africa in response to food crises and humanitarian emergencies and still complement emergency responses to crises or shocks, consequently reducing the cost and increasing the effectiveness of humanitarian action. Social safety nets often provide ready vehicles through which to intervene in crises. In response to the Ebola emergency, governments leveraged the existing modest programs and scaled up cash transfers and public works programs (Beegle and others 2018, 67). Over time, Africa has become a leader in the design and delivery of social safety nets. These programs run the entire gamut, from cash transfers of various hues to food transfers, school feeding programs, public works, social pensions, emergency response programs, and programs that build human capital (through health and education). Every country in the region has at least one SSN program. The average number of programs per country is 15 . The numbers range from 2 in Republic of Congo and Gabon to 56 in Burkina Faso and 54 in 
Chad. African countries now spend on average 1.2 percent of their gross domestic product (GDP) on SSNs, close to the global average of 1.6 percent. Figure 4.1 shows the mix of safety net programs in Africa by region, income level, fragility, resource status, and drought exposure. The results are expected: low-income countries, those that are fragile, those exposed to drought, and those lacking in resources are more likely to have emergency programs with some cash transfers. Richer countries, on the other hand, tend to have food-based programs and social pensions. Public works are more common in countries that have low levels of drought exposure and those with better resource endowment, and in West African countries.

A new generation of social safety net programs goes beyond poverty reduction to enhance the dignity of recipients. Among Africa's many innovations, this new generation of social safety nets stands out. Their rapid and successful expansion is unique in the developing world. Beyond addressing income poverty and strengthening human capital, evidence is growing that social safety nets can promote social inclusion and the dignity of recipients. Orphans, other vulnerable children, and recipients with disabilities in Kenya, Mozambique, and Zambia reported that cash transfers raised their sense of self-confidence and dignity, gave them the ability to be more assertive, and enhanced their perception of future wellbeing (Attah and others 2016; Handa and others 2014a, 2014b; Haushofer and Shapiro 2013; Jones and others 2016; Seidenfeld, Handa, and Tembo 2013; all cited in Beegle and others 2018,24). Although many of the same positive outcomes associated with social protection programs also obtain in other regions of the world, the scale of these programs in African countries and the vast proportions of the population that they reach makes their social inclusion related externalities particularly noteworthy.

Since the social inclusion framework emphasizes not only ability and opportunity, but also the dignity of individuals and groups, it is opportune to ask: What are the channels through which SSNs enhance the dignity of individuals and groups? In Ghana, safety net programs have reduced the stigma of helplessness among persons with disabilities; in Lesotho and Zimbabwe, they have enabled children to go to school well dressed and clean; and, in Malawi, they have helped raise the social status of the poorest (Attah and others 2016; MacAuslan and Riemenschneider 2011; Oduro 2014; all cited in Beegle and others 2018, 163). Recipients of SSNs also are more able to meet their social obligations and engage in relationships that involve reciprocity, such as paying church tithes or funeral group fees, contributing to savings groups, or attending weddings (Pavanello and others 2016). Each of these elements raises the status of previously more dependent individuals and families, thus enhancing pride and dignity. 
Figure 4.1 Social Safety Net Programs in Africa (\%)

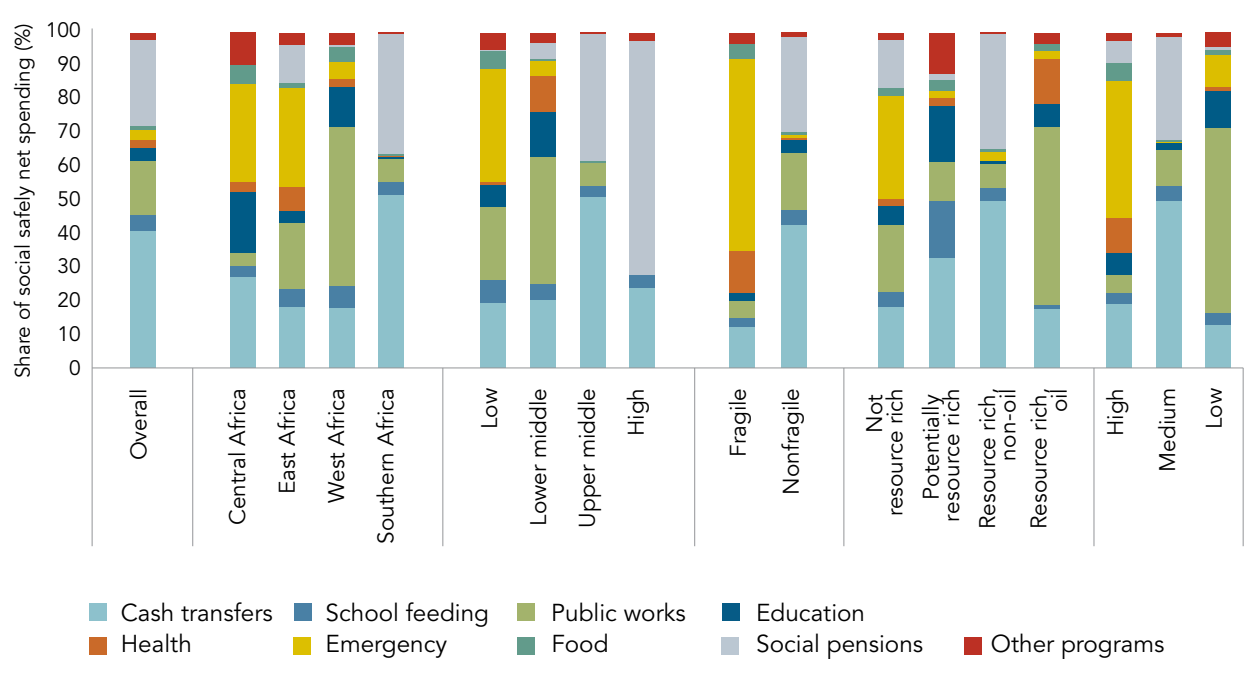

Source: Beegle and others 2018, 8.

A broad array of programs that can be loosely classified as "empowerment programs" often are targeted to historically excluded groups and can have large positive impacts. In Uganda, the Empowerment and Livelihood for Adolescents (ELA) program was developed and implemented by Building Resources Across Communities (BRAC) to provide training for small-scale enterprises and education for health and reduction of risky behaviors. Tracking 4,888 girls over a period of two years, Bandiera and others (2013) found that (a) the program increased the likelihood of girls engaging in income-generating activities by 32 percent; (b) selfreported condom use by those who were sexually active increased by 50 percent; (c) fertility rates dropped by 26 percent; and (d) there was a 76 percent reduction in adolescent girls reporting having had sex against their will during the past year. Importantly, the combined program (livelihood training plus health education) was more successful than most other interventions that focused exclusively on either life skills or livelihood skills. In Uganda, the World Bank supports the Nkingo girls' clubs in Kemwenge and Kabarole. Run by BRAC, these clubs offer safe spaces and training in empowerment and life skills, as well as entrepreneurship and financial literacy training. The girls' clubs also offer access to sexual health, family planning, and legal aid. Evaluation of the Kenya Cash Transfer for Orphans and Vulnerable Children, a national unconditional cash transfer program, after four years of the program found a 5 percentage point reduction in the likelihood of pregnancy among females aged 12 to 24 , but no reduction in early marriage. The authors 


\section{Box 4.5 In the Sahel: Focus on Young Women}

The Sahel has a tough terrain and faces multiple challenges, ranging from extreme poverty to conflict, desertification, and low institutional capacity. It also has a very young population. In Mauritania, 30 percent of the population is under 10 years, and over 44 percent is under 15 years. Young people have limited education and skills, and finding a job is difficult. In addition, the Sahel also has some of the world's highest rates of child marriage, with adolescent girls being disproportionately affected. Early marriage thwarts their growth, development, agency, human capital accumulation, and overall life chances. Niger has the world's highest prevalence of child marriage at 75 percent, followed by Chad, with the world's third highest at 68 percent, and Mali at 55 percent, the world's fifth highest.

Initiated by the presidents of Burkina Faso, Chad, Côte d'Ivoire, Mali, Mauritania, and Niger, the Sahel Women Empowerment and Demographic Dividend (SWEDD) is financed by the World Bank, with implementation supported by the United Nations Population Fund (UNFPA). The project has used several innovations toward attaining its objective of empowering women and adolescent girls through access to quality reproductive, child, and maternal health services and helping boost the capacity of local partners. For instance, the project has garnered the support of religious leaders on child marriage, maternal and child health, family planning, girls' education, gender-based violence (GBV), and elevating women's agency. In yet another initiative, the project gives bicycles, school kits, and sanitary kits to girls, and grains and foodstuffs to their families. The project also organizes coaching classes in select subjects so that girls can keep up in school. Finally, the project trains young women in nontraditional trades and in some areas has given them tractors, which both augment their incomes and give them status and power in the community.

Sources: World Bank, "Getting Religious and Traditional Leaders on Board in the Sahel to End Harmful Practices against Girls, https://www.worldbank.org/en/news/ feature/2018/06/28/getting-religious-and-traditional-leaders-on-board-in-the-sahelto-end-harmful-practices-against-girls World Bank, "Mali: Using Bikes to Get to School and Stay in School," https://www.worldbank.org/en/news/feature/2018/07/25/a bikefor-school-in-mali. 
posit that the impacts resulted from increased school enrollment and financial stability of the household as well as delayed age at first sex (Handa and others 2015; cited in Chakravarty and others 2017). Box 4.6 casts a spotlight on the Sahel Women Empowerment and Demographic Dividend (SWEDD) project, which spans Burkina Faso, Chad, Côte d'Ivoire, Mali, Mauritania, and Niger and focuses on the drivers of the exclusion of young women.

Empowerment programs that combine multifaceted assistance have proven useful to survivors of physical and sexual violence. Because violence tends to be accompanied by psychological trauma, survivors often need a combination of medical treatment, health counseling, and psychosocial support in addition to legal or paralegal assistance. At the same time, economic empowerment for survivors often is a key factor in reducing their economic dependence on the perpetrators and improving resilience to violence. Experience from the World Bank's engagement around GBV shows that collaboration among law enforcement, legal aid services, health care organizations, public health programs, educational institutions, and agencies devoted to social services and economic development has the deepest impacts. Appendix C presents examples of World Bank engagement with GBV in various African countries.

Fostering normative and attitudinal change also has been at the heart of a range of national service programs that have been implemented in countries like Ghana, Kenya, and Nigeria. Some countries in Africa and globally have programs that require citizens, particularly young people, to undertake community service or live in a different part of the country for a time. The typical objective of such programs is to develop a sense of national identity and civic responsibility. Nigeria, for instance, has implemented such a program for over four decades, sending university graduates to different regions of the country for a mandatory one year of national service through the National Youth Service Corps (NYSC). Recent evidence suggests that this exposure to diverse groups within the country can foster a stronger sense of connection to the country as a whole. In Nigeria, participants in national service seem to develop greater national pride and more positive attitudes toward their country. Participants also are more likely to live outside their ethnic region seven years after the program. At the same time, such programs also may highlight distinctions among ethnic groups. The same Nigerian study suggests that participants in the NYSC are more positive toward their own ethnic group but not toward other ethnic groups following the program. The research also finds that participants are more likely to have closest friends from their own ethnic group (Okunogbe 2018). 


\section{Box 4.6 Reintegration for Ex-combatants in DRC and Liberia}

In 2008-09, a pilot project began in the Democratic Republic of Congo, in Kindu, Maniema, called Strengthening Socio-Economic Reintegration Opportunities for Vulnerable Households of Ex-combatants Demobilized through the PNDDR (National Program for Disarmament, Demobilization, and Reintegration). This pilot provided (a) support for income-generating activities; (b) basic skills (literacy/numeracy) and household budget management training; (c) support to create or strengthen associations; and (d) information and sensitization around sexual and gender-based violence (SGBV) and referral to SGBV services. Although the evaluation did not attribute causality, it suggested that, first, the project activities contributed to higher asset and household ownership and better nutritional outcomes. Second, the levels of confidence in other ex-combatants within the community, including male combatants, had increased by 44 percent since the beginning of the project in 2008. Third, the evaluation found that project beneficiaries were more informed about SGBV and related services than nonbeneficiary ex-combatants.

In another intervention that targeted ex-combatants, the Liberian Ministry of Public Works, with support from UNMIL (United Nations Mission in Liberia), UNDP (United Nations Development Programme), and the World Bank, initiated a labor-intensive employment scheme to rehabilitate roads. This intervention offered some 8,000 jobs to ex-combatants and war-affected youth. Rates of both crime and domestic violence came down in areas in which these programs were implemented. Participants also reported that they have invested the income from these jobs in other revenue-generating activities.

Sources: African Union Disarmament, Demobilisation and Reintegration Capacity Program 2014; World Bank LOGiCA 2013.

\section{Other Interventions That Promote Inclusion in Markets, Services, and Spaces}

As examples in previous sections show, technology is one of the most powerful means of deepening social inclusion. However, as examples in previous sections show, technology can exacerbate exclusion as well. Nevertheless, important instances of technology's positive role deserve mention. Lack of access to credit affects some groups more that it does others, and innovations that provide access may have larger benefits for groups who start from a lower economic base. Although empirical evidence on the economic and social impacts of M-PESA-a money transfer system operated by Kenya's largest cellular phone provider-and similar technologies is new and sparse, the indications are that it has positive effects for the poorest, and for women in particular. At the same time, however, 
its impact on individual savings may be limited (Van Hove and Dubus 2019). Suri and Jack (2014) find that the use of M-PESA can effectively improve the resilience of poor households to income shocks. In a 2016 paper, Suri and Jack argue that access to M-PESA in Kenya had reduced poverty, particularly for female-headed households. A recent evaluation of an experiment randomizing the promotion and registration of mobile savings accounts among women microentrepreneurs in Tanzania finds that women saved substantially more through the mobile accounts and that additional business training bolsters this effect (Bastian and others 2018).

Financial inclusion enabled by mobile savings accounts also opens new markets to women because women may be able to obtain more microloans through their mobile accounts, an additional service provided by the product. Although no significant evidence was found that these impacts translated to greater investment, sales, or profits, there was some evidence of business expanding through the

\section{Box 4.7 Building Infrastructure Does Not Ensure That It Will Be Used}

The existence of a separate toilet is not enough to ensure usage by women and girls. Privacy, cleanliness, safety, and availability of water matter. Women and girls with disabilities face additional challenges due to limitations in mobility. Even when water and sanitation facilities for females exist, they may not be accessible to females with disabilities, intensifying the context of their disadvantage.

A survey of 62 primary schools in rural western Kenya found that 84 percent of them had separate latrines for girls, but 77 percent of these did not lock, and only 13 percent had water in or near the latrine. Furthermore, only 10 percent of schools reported always providing sanitary pads to girls. In most schools, disposal arrangements for used sanitary pads were not adequate (Alexander and others 2014). These findings underscore the importance of toilets as "package deals" to ensure usage, especially by female students and employees, and even for women in public places.

The differential needs of women and girls become pronounced when they are menstruating. In Nigeria, approximately 25 percent of women seem to lack the requisite privacy for toileting needs. However, there is a high degree of variation. For example, 85 percent of women in Lagos reported having everything they need to manage their menstruation; only 37 percent in Kaduna State did. There also are differences across urban and rural areas. Approximately 88 percent of women in Nigeria have no handwashing facilities on their premises; 92 percent of rural women report the same (World Bank 2017c). Similar conditions obtain for women in many other countries across Africa and Asia.

Source: Das 2017. 
creation of profitable secondary businesses, as well as evidence of improvements in women's empowerment and subjective well-being (Bastian and others 2018). Finally, as noted, the Internet has provided huge opportunities for the inclusion of previously excluded groups in markets, services, and spaces. Amplifying voice is one benefit. Innovative methods of using information and communication technology to solicit anonymous responses to questions have become increasingly popular. In Tanzania and South Sudan, two pilot initiatives referred to as "Listening to Africa" have been highly successful in collecting panel data via mobile phone interviews. Evaluations suggest that the method is cost effective, with low attrition rates even after more than 30 rounds of interviews (Croke and others 2012).

The importance of interconnected services for all groups, especially those who are at risk, needs to be underscored. For instance, the provision of services often goes hand in hand with infrastructure. Yet, merely building infrastructure often has limited effectiveness for universal access. Box 4.7 draws out the importance of a bundle of interventions that need to accompany building toilets so that girls, women, and persons with disabilities can use them. Box 4.4 demonstrates the importance of interconnected interventions to enable ex-combatants to reintegrate in their communities. In each case, programs intended for previously excluded groups need careful ex ante analysis that shows why the groups were excluded and what can be done to rectify past wrongs. Ultimately, building systems to ensure that the right interventions are designed, implemented, and evaluated is critical to success. A useful example are the systems that provide identity documents to citizens and residents so that they can access services that are due them. As discussed, the lack of identity documentation is a key obstacle for many excluded groups.

However, providing such documents often has significant administrative ramifications and involves infrastructure and setting up delivery systems. One initiative to propel the inclusion of all in the identity systems of countries in Africa is the World Bank Group's ID4D (Identification for Development) initiative. Under this initiative, to date, analyses have been conducted in 17 African countries: Botswana, Cameroon, Chad, Democratic Republic of Congo, Côte d'Ivoire, Ethiopia, Guinea, Kenya, Liberia, Madagascar, Morocco, Namibia, Nigeria, Rwanda, Sierra Leone, Tanzania, and Zambia. The objective has been to evaluate countries' identity ecosystems and facilitate collaboration with governments for future work (World Bank 2017c).

Indigenous knowledge systems and local languages and customs constitute the intellectual and cultural spaces of historically subordinated groups and are intrinsic to their dignity and pride. Their indigenous patrimonies also facilitate groups' access to markets and services. One study in Lushoto District in northern Tanzania shows the importance of integrating the indigenous knowledge of 
weather forecasting with the Tanzania Meteorological Agency (Mahoo and others 2015). Language is a key marker of social identity, and those who speak minority languages often lag in schooling, jobs, and other endowments. Growing evidence suggests that the language of instruction (LOI) can help or hinder learning outcomes, especially of children who speak minority languages. For instance, Ethiopia's comprehensive LOI policy mandated the use of the mother tongue as the language of instruction in grades one through eight. The policy also stipulated primary teacher training in the relevant language. Although all students learn Amharic as a national language, English may be introduced if desired by the state. Prior to 1994, all Ethiopian students were taught in Amharic. The policy seems to have been successful.

One analysis found that children who were taught in their mother tongue for 8 years of primary education outperformed those who received instruction in the mother tongue for only 5 years and in English in the upper primary grades (Heugh and others 2007; cited in Bashir and others 2018). Another study in Guinea-Bissau and Niger assessed transitional bilingual programs that were piloted in selected schools. This study found that students in Niger who started in their mother tongues were able to read and write better even in their second language. The strongest positive effects in both countries were for rural children and girls in the bilingual programs. The programs also garnered the support of parents (Hovens 2002). In general, making information accessible to those who communicate in languages and mediums that are distinct from those of the majority is an important step toward social inclusion. Accessibility to information also is a step toward increased accountability of the state and service providers. For persons with disabilities, as several programs the world over have shown, this service is indispensable to their ability to access information.

In addition to knowledge systems and making information accessible, several initiatives also have focused on the quality and quantity of data for better analysis. Some of these initiatives focus on better data on poverty, human development, and other outcomes. Chapter 2 shows that the availability of data led to analyses that brought out the nuances of disadvantage based on disability status. All too often, such data disaggregated by social group are hard to come by, as are data on exclusionary processes. The World Bank's Gender Innovation $\mathrm{Lab}^{4}$ both collects granular data on cognitive skills, bias, discrimination, and other aspects; and evaluates the impact of experimental interventions. A range of other data platforms now follow open data principles and make data public. For example, as cited above, Croke and others (2012) show how high-frequency panels can be collected using mobile phone interviews. Finally, the role of geospatial data is important to understand the 
intersection of social and spatial exclusion. Across Africa, initiatives to collect better data and make them accessible have proliferated, as more and more analysts and activists realize the importance of data. However, we emphasize that data are merely the raw material for insight. Governments and international organizations also need to invest in better and more rigorous analysis of social inclusion.

Historical wrongs often are the foundations of present-day exclusions. These wrongs can be corrected by several means, one of which is symbolic acts. Truth and reconciliation commissions are an increasingly common mechanism employed globally, including in Africa, to overcome past conflicts and divisions. In South Africa, the post-apartheid Truth and Reconciliation Commission (TRC) ${ }^{5}$ instituted during the transition to democracy was intended help overcome the legacy of apartheid and racial divisions. Rwanda established its National Unity and Reconciliation Commission (NURC) ${ }^{6}$ in 1999. In Mauritius, the Truth and Justice Commission was established in 2009 to address the legacy of slavery and to investigate the dispossession of land. In the Gambia, the Truth, Reconciliation and Reparations Commission (TRRC) was sworn in in October 2018. However, reconciliatory processes are complex, and their implementation is politically sensitive. What constitutes "truth" and "reconciliation" in the wake of conflict is likely contested by different groups, and openly addressing historic wrongs can trigger renewed tensions and may be traumatic for survivors of violence (Broneus 2010). There also are no clear international norms for the powers or standards of proceedings for such commissions (OHCHR 2006). Other symbolic acts include renaming streets and monuments, and in the process acknowledging the historical wrongs and elevating the identities of those who have been wronged.

\section{Concluding Reflections}

Chapter 4, and indeed the entire report, highlights the role of diverse actors in the progress toward social inclusion. The state, of course, is the preeminent among these, but there are other important drivers of change. Non-state actors, citizens, and communities who exercise agency to effect change are powerful vehicles for social inclusion. As is well-known across the world, programs and projects that are anchored in, and derive leadership from, the community are more likely to succeed. Moreover, when the state and service providers are moored by systems that make them accountable to citizens and communities, these providers garner both community ownership and greater likelihood of success. Technology, for instance, is one of the most powerful means of deepening social inclusion and enhancing accountability to communities and citizens. However, governments and other actors also must realize the risks that technology can pose for those who do not have access to this potent medium. Finally, programs that acknowledge that 
some communities and groups may feel left out by the state and their elites, and make genuine efforts to correct the perception, can both change outcomes toward social inclusion and rebalance power relations.

Chapter 3 discusses that belief systems, superstitions, stigmas, and other practices present daunting barriers to the inclusion of certain groups. Chapter 4 highlights several initiatives that effected change in such processes and practices. For example, the stigma of HIV is still strong in many parts of the world. Similarly, FGM, which holds importance for some groups, also violates the very personhood of women and girls and makes them less likely to achieve their potential. For policies and programs, such beliefs and practices matter. They stymie the abilities, opportunities, and dignity of certain groups, and are costly across society. These beliefs and practices also can permeate and influence the ways in which the state and service providers interact with historically excluded groups. Nevertheless, it is important to note that such beliefs, norms and practices, often considered to be insurmountable barriers to achieving inclusion, are known to change.

In sum, Chapter 4 draws attention to the myriad reforms, policies, programs, and projects that advance social inclusion and emphasizes the importance of design and implementation of such interventions. An illustrative list of interventions is summarized in table 4.1. Table 4.1 outlines the domains in which change is intended and examples of actions taken by various countries toward social inclusion. Finally, investing in social inclusion often comes with financial, administrative, and political costs. The benefits often outweigh the costs, depending on the context. Therefore, to secure a win-win outcome, the state and society need a clear social contract and a transparent enactment and implementation of legal and administrative steps toward social inclusion. 


\begin{tabular}{|c|c|c|c|}
\hline $\begin{array}{l}\text { Domain of } \\
\text { inclusion }\end{array}$ & $\begin{array}{l}\text { Channel for } \\
\text { intervention }\end{array}$ & $\begin{array}{l}\text { Illustrative actions targeting } \\
\text { those most likely to be left } \\
\text { behind }\end{array}$ & $\begin{array}{l}\text { Illustrative examples of policies, } \\
\text { programs, and projects }\end{array}$ \\
\hline \multicolumn{4}{|l|}{ MARKETS } \\
\hline \multirow[t]{3}{*}{ Labor } & $\begin{array}{l}\text { Legal } \\
\text { provisions } \\
\text { enabling } \\
\text { access to } \\
\text { the labor } \\
\text { market }\end{array}$ & $\begin{array}{l}\text { Ensuring access of } \\
\text { excluded groups to } \\
\text { jobs and their ability to } \\
\text { open bank accounts and } \\
\text { businesses. } \\
\text { - Removing the obligation } \\
\text { of women to obey their } \\
\text { husbands. } \\
\text { - Lifting restrictions on } \\
\text { women working at night. } \\
\text { - Enshrining } \\
\text { nondiscrimination } \\
\text { in employment law } \\
\text { (including hiring, pay, and } \\
\text { promotions). } \\
\text { Banning harassment at } \\
\text { work. } \\
\text { Establishing legal remedies } \\
\text { for sexual and other } \\
\text { forms of harassment in } \\
\text { employment. } \\
\text { Prohibiting dismissal of } \\
\text { pregnant employees. } \\
\text { - Establishing paid maternity } \\
\text { and paternity leave. }\end{array}$ & $\begin{array}{l}\text { Congo, Dem. Rep. of Reforms } \\
\text { of family code to improve gender } \\
\text { equality; gender nondiscrimination } \\
\text { reforms in employment. } \\
\text { Zambia Gender Equity and } \\
\text { Equality Act; establishment of } \\
\text { Gender Equality Commission. } \\
\text { Ethiopia Reforms of property law, } \\
\text { requiring both spouses' consent } \\
\text { in the administration of marital } \\
\text { property; simultaneous change } \\
\text { to raise women's minimum age of } \\
\text { marriage. } \\
\text { Burundi, Comoros, Mauritius, } \\
\text { Rwanda, São Tomé and Príncipe, } \\
\text { and Zambia Laws against } \\
\text { workplace sexual harassment and } \\
\text { domestic violence. } \\
\text { Mauritius Prohibition of dismissal } \\
\text { of pregnant workers; introduction } \\
\text { of paid paternity leave; extension } \\
\text { of paid maternity leave. }\end{array}$ \\
\hline & $\begin{array}{l}\text { Affirmative } \\
\text { action and } \\
\text { quotas }\end{array}$ & $\begin{array}{l}\text { Implementing measures to } \\
\text { attract, develop, and retain } \\
\text { individuals from historically } \\
\text { disadvantaged groups. } \\
\text { - Considering job quotas for } \\
\text { underrepresented groups. } \\
\text { - Establishing data and } \\
\text { monitoring and evaluation } \\
\text { systems to monitor and } \\
\text { assess impact of affirmative } \\
\text { action. } \\
\text { - Setting up institutions that } \\
\text { can address grievance. }\end{array}$ & $\begin{array}{l}\text { South Africa } 1998 \text { Employment } \\
\text { Equity Act and } 2003 \text { broad-based } \\
\text { black economic empowerment } \\
\text { legislation for "Blacks (including } \\
\text { African, Coloured [mixed race] and } \\
\text { Indians), women and people with } \\
\text { disabilities"(Burger and Jafta 2010). } \\
\text { Nigeria Federal Character } \\
\text { Commission (FCC) established in } \\
\text { 1996. Oversees implementation of } \\
\text { affirmative action in bureaucracy, } \\
\text { social services, infrastructure } \\
\text { development, and the private } \\
\text { sector. }\end{array}$ \\
\hline & $\begin{array}{l}\text { Skills and } \\
\text { training }\end{array}$ & $\begin{array}{l}\text { Supporting income- } \\
\text { generating activities for } \\
\text { excluded groups (ex- } \\
\text { combatants, youth, and } \\
\text { women). } \\
\text { - Developing soft and hard } \\
\text { skills training. }\end{array}$ & $\begin{array}{l}\text { Congo, Dem. Rep. of Strengthen- } \\
\text { ing socioeconomic reintegration } \\
\text { opportunities for vulnerable house- } \\
\text { holds of ex-combatants demobi- } \\
\text { lized through the PNDDR. } \\
\text { Liberia Ministry of Public Works } \\
\text { (with support from UNMIL, UNDP, } \\
\text { and WB) initiated labor- intensive } \\
\text { employment scheme to rehabilitate } \\
\text { roads, offering jobs to ex- } \\
\text { combatants and war-affected youth. }\end{array}$ \\
\hline
\end{tabular}


Table 4.1 continued

\begin{tabular}{|c|c|c|c|}
\hline $\begin{array}{l}\text { Domain of } \\
\text { inclusion }\end{array}$ & $\begin{array}{l}\text { Channel for } \\
\text { intervention }\end{array}$ & $\begin{array}{l}\text { Illustrative actions targeting } \\
\text { those most likely to be left } \\
\text { behind }\end{array}$ & $\begin{array}{l}\text { Illustrative examples of policies, } \\
\text { programs, and projects }\end{array}$ \\
\hline $\begin{array}{l}\text { Labor } \\
\text { (continued) }\end{array}$ & $\begin{array}{l}\text { Skills and } \\
\text { training } \\
\text { (continued) }\end{array}$ & $\begin{array}{l}\text { Training small-scale } \\
\text { enterprises targeted at } \\
\text { specific groups, such as } \\
\text { women. }\end{array}$ & $\begin{array}{l}\text { Uganda Empowerment and } \\
\text { Livelihood for Adolescents (ELA) } \\
\text { program. }\end{array}$ \\
\hline Financial & $\begin{array}{l}\text { Mobile } \\
\text { financial } \\
\text { technology }\end{array}$ & $\begin{array}{l}\text { Prohibiting discrimination } \\
\text { in access to credit and } \\
\text { financial transactions and } \\
\text { implementing enforcement } \\
\text { systems. } \\
\text { - Providing access to } \\
\text { financial technology } \\
\text { ("fintech") to those who } \\
\text { have been traditionally } \\
\text { "unbanked." } \\
\text { - Training for the use } \\
\text { of mobile finance } \\
\text { products; providing } \\
\text { business skills training for } \\
\text { microentrepreneurs. }\end{array}$ & $\begin{array}{l}\text { Congo, Dem. Rep. of } \\
\text { and Mauritius Gender } \\
\text { nondiscrimination laws regarding } \\
\text { access to credit. } \\
\text { Kenya Introduced M-PESA, a } \\
\text { money transfer system, in } 2007 \text {. } \\
\text { By } 2018,96 \text { percent of households } \\
\text { outside Nairobi had at least one } \\
\text { M-PESA account. } \\
\text { Tanzania Business Women } \\
\text { Connect (BWC) program. }\end{array}$ \\
\hline \multirow[t]{2}{*}{ Land } & $\begin{array}{l}\text { Legal } \\
\text { provisions } \\
\text { for land } \\
\text { ownership }\end{array}$ & $\begin{array}{l}\text { Establishing gender parity } \\
\text { in inheritance and land } \\
\text { ownership laws. } \\
\text { Providing land titles or } \\
\text { de facto recognition of } \\
\text { land use and recognizing } \\
\text { customary rights of } \\
\text { excluded groups. }\end{array}$ & $\begin{array}{l}\text { Rwanda Legislative reform first } \\
\text { eliminated bias against female } \\
\text { land ownership, followed by the } \\
2005 \text { Organic Land Law (OLL) to } \\
\text { establish a single statutory system } \\
\text { of land tenure and end the dualism } \\
\text { of customary and formal tenure } \\
\text { systems. } \\
\text { Kenya Decision of the African } \\
\text { Commission on Human and } \\
\text { Peoples' Rights to recognize the } \\
\text { ownership rights of Endorois } \\
\text { (agropastoralists) to their ancestral } \\
\text { lands around the Lake Bogoria } \\
\text { Game Reserve. }\end{array}$ \\
\hline & Land reform & $\begin{array}{l}\text { Enabling redistribution } \\
\text { through land reforms as by } \\
\text { making excluded groups } \\
\text { (women, indigenous } \\
\text { groups) joint landholders } \\
\text { in land redistribution and } \\
\text { resettlement projects. } \\
\text { - Reserving land use quotas. } \\
\text { - Strengthening the } \\
\text { representation of women } \\
\text { and indigenous persons in } \\
\text { land negotiations. } \\
\text { Facilitating participation } \\
\text { of excluded groups in } \\
\text { procedures, such as by } \\
\text { allowing oral evidence in } \\
\text { land tribunals. }\end{array}$ & $\begin{array}{l}\text { Mozambique } 1997 \text { land law allows } \\
\text { oral evidence to be used as part of } \\
\text { land tribunals. } \\
\text { Rwanda } 2010 \text { nationwide land } \\
\text { tenure regularization (LTR) } \\
\text { program. }\end{array}$ \\
\hline
\end{tabular}




\begin{tabular}{|c|c|c|c|}
\hline $\begin{array}{l}\text { Domain of } \\
\text { inclusion }\end{array}$ & $\begin{array}{l}\text { Channel for } \\
\text { intervention }\end{array}$ & $\begin{array}{l}\text { Illustrative actions targeting } \\
\text { those most likely to be left } \\
\text { behind }\end{array}$ & $\begin{array}{l}\text { Illustrative examples of policies, } \\
\text { programs, and projects }\end{array}$ \\
\hline \multicolumn{4}{|l|}{ SERVICES } \\
\hline \multirow[t]{4}{*}{$\begin{array}{l}\text { Cross- } \\
\text { cutting } \\
\text { services }\end{array}$} & $\begin{array}{l}\text { Documenta- } \\
\text { tion }\end{array}$ & $\begin{array}{l}\text { Ensuring that all } \\
\text { groups have relevant } \\
\text { documentation to access } \\
\text { services. }\end{array}$ & $\begin{array}{l}\text { World Bank Group-supported } \\
\text { ID4D initiative (Botswana, } \\
\text { Cameroon, Chad, the Democratic } \\
\text { Republic of Congo, Côte d'Ivoire, } \\
\text { Ethiopia, Guinea, Kenya, Liberia, } \\
\text { Madagascar, Morocco, Namibia, } \\
\text { Nigeria, Rwanda, Sierra Leone, } \\
\text { Tanzania, and Zambia). }\end{array}$ \\
\hline & $\begin{array}{l}\text { Emergency } \\
\text { responses } \\
\text { to protect } \\
\text { vulnerable } \\
\text { groups }\end{array}$ & $\begin{array}{l}\text { Scaling up cash transfer } \\
\text { and public works programs. }\end{array}$ & $\begin{array}{l}\text { Multicountry responses to Ebola } \\
\text { emergency, extreme weather } \\
\text { events, and conflict. }\end{array}$ \\
\hline & $\begin{array}{l}\text { Engaging } \\
\text { commu- } \\
\text { nities and } \\
\text { training } \\
\text { govern- } \\
\text { mental } \\
\text { authorities }\end{array}$ & $\begin{array}{l}\text { Training regional and } \\
\text { municipal governments in } \\
\text { participatory budgeting. } \\
\text { Requiring and enabling } \\
\text { participation of excluded } \\
\text { groups (such as women, } \\
\text { pastoralist groups) in } \\
\text { budget consultation } \\
\text { meetings. }\end{array}$ & $\begin{array}{l}\text { Kenya Participatory budgeting in } \\
\text { West Pokot. } \\
\text { South Sudan Local Governance } \\
\text { and Service Delivery Project } \\
\text { (LOGOSEED). }\end{array}$ \\
\hline & $\begin{array}{l}\text { Targeted } \\
\text { attention } \\
\text { to his- } \\
\text { torically } \\
\text { excluded } \\
\text { groups }\end{array}$ & $\begin{array}{l}\text { Ensuring equal rights to } \\
\text { quality services. } \\
\text { Prohibiting } \\
\text { discrimination in } \\
\text { services. } \\
\text { - Establishing monitoring } \\
\text { and enforcement } \\
\text { mechanisms. } \\
\text { Making services free and } \\
\text { compulsory. }\end{array}$ & $\begin{array}{l}\text { Nigeria Federal Character } \\
\text { Commission (FCC) oversees } \\
\text { affirmative action, including in } \\
\text { social services. } \\
\text { Ghana Inclusive Education Policy. } \\
\text { Uganda Persons with Disability } \\
\text { Act } 2006 \text {. } \\
\text { Tanzania Primary education } \\
\text { made both free and compulsory. } \\
\text { Kenya Cash Transfer for } \\
\text { Orphans and Vulnerable } \\
\text { Children. }\end{array}$ \\
\hline Education & Accessibility & $\begin{array}{l}\text { Ensuring that educational } \\
\text { infrastructure is accessible } \\
\text { to persons with disabilities. } \\
\text { - Adapting education systems } \\
\text { to ensure the inclusion of all } \\
\text { learners, in particular those } \\
\text { with special educational } \\
\text { needs, including physical } \\
\text { accessibility of schools. } \\
\text { - Promoting Universal Design } \\
\text { for Learning (UDL) and } \\
\text { learner-friendly school } \\
\text { environments to enhance } \\
\text { the quality of education for } \\
\text { all learners. }\end{array}$ & Ghana Inclusive Education Policy. \\
\hline
\end{tabular}




\begin{tabular}{|c|c|c|c|}
\hline $\begin{array}{l}\text { Domain of } \\
\text { inclusion }\end{array}$ & $\begin{array}{l}\text { Channel for } \\
\text { intervention }\end{array}$ & $\begin{array}{l}\text { Illustrative actions targeting } \\
\text { those most likely to be left } \\
\text { behind }\end{array}$ & $\begin{array}{l}\text { Illustrative examples of policies, } \\
\text { programs, and projects }\end{array}$ \\
\hline $\begin{array}{l}\text { Education } \\
\text { (continued) }\end{array}$ & $\begin{array}{l}\text { Teacher } \\
\text { training and } \\
\text { curriculum } \\
\text { develop- } \\
\text { ment }\end{array}$ & $\begin{array}{l}\text { Training teachers to } \\
\text { respond to diverse } \\
\text { educational needs. } \\
\text {. Providing teacher training } \\
\text { in local languages. } \\
\text { Considering bilingual } \\
\text { education. } \\
\text { Ensuring that curricula are } \\
\text { designed in a way that } \\
\text { is sensitive to excluded } \\
\text { groups. }\end{array}$ & $\begin{array}{l}\text { Ethiopia Language-of-instruction } \\
\text { (LOI) policy. } \\
\text { Ghana Inclusive Education Policy. } \\
\text { Guinea-Bissau and Niger Pilots of } \\
\text { transitional bilingual programs. }\end{array}$ \\
\hline \multicolumn{4}{|l|}{ SPACES } \\
\hline Physical & $\begin{array}{l}\text { Safety } \\
\text { in public } \\
\text { places }\end{array}$ & $\begin{array}{l}\text { Generating forums such as } \\
\text { women's and girls' clubs } \\
\text { that provide safe spaces for } \\
\text { survivors of gender-based } \\
\text { violence and offer access to } \\
\text { sexual health services, legal } \\
\text { aid, and empowerment } \\
\text { training. }\end{array}$ & $\begin{array}{l}\text { Uganda BRAC Nkingo girls' clubs } \\
\text { in Kemwenge and Kabarole. }{ }^{a}\end{array}$ \\
\hline $\begin{array}{l}\text { Political } \\
\text { and social }\end{array}$ & $\begin{array}{l}\text { Consti- } \\
\text { tutional } \\
\text { and legal } \\
\text { provisions }\end{array}$ & $\begin{array}{l}\text { Explicitly acknowledging } \\
\text { equal status and rights } \\
\text { of different groups in the } \\
\text { government constitution. } \\
\text { Creating legal provisions } \\
\text { to institutionalize equality } \\
\text { and inclusion of formerly } \\
\text { excluded groups. } \\
\text { Establishing quota for } \\
\text { excluded groups, as with } \\
\text { political representation. }\end{array}$ & $\begin{array}{l}\text { South Africa LGBTI equality in } \\
\text { constitution. } \\
\text { Mozambique and Seychelles } \\
\text { Decriminalized same-sex relations } \\
\text { (2015 and 2016, respectively). } \\
\text { Botswana } 2017 \text { Supreme Court } \\
\text { decision requires government } \\
\text { to legally recognize transgender } \\
\text { people's gender self- identification. } \\
\text { Namibia Courts' decision to allow } \\
\text { official recognition of gender } \\
\text { change. } \\
\text { Bans on anti-LGBTI discrimination } \\
\text { (Angola, Botswana, Cabo } \\
\text { Verde, Mauritius, Mozambique, } \\
\text { Seychelles, South Africa). } \\
\text { Kenya Domestic violence law. } \\
\text { Uganda } 1995 \text { Constitution (Art.78) } \\
\text { stating that Parliament should. } \\
\text { include a woman representative } \\
\text { in every district as well as } \\
\text { representatives from the army, } \\
\text { youth, workers, persons with } \\
\text { disabilities, and "other groups as } \\
\text { Parliament may define." }\end{array}$ \\
\hline
\end{tabular}




\begin{tabular}{|c|c|c|c|}
\hline $\begin{array}{l}\text { Domain of } \\
\text { inclusion }\end{array}$ & $\begin{array}{l}\text { Channel for } \\
\text { intervention }\end{array}$ & $\begin{array}{l}\text { Illustrative actions targeting } \\
\text { those most likely to be left } \\
\text { behind }\end{array}$ & $\begin{array}{l}\text { Illustrative examples of policies, } \\
\text { programs, and projects }\end{array}$ \\
\hline \multirow[t]{2}{*}{$\begin{array}{l}\text { Political } \\
\text { and social } \\
\text { (continued) }\end{array}$} & $\begin{array}{l}\text { Changing } \\
\text { social norms } \\
\text { and tackling } \\
\text { discrimina- } \\
\text { tion }\end{array}$ & $\begin{array}{l}\text { Building coalitions among } \\
\text { government, civil society, } \\
\text { judiciary, and communities. } \\
\text { - Promoting information } \\
\text { campaigns, such as through } \\
\text { national radio broadcasts, } \\
\text { television, newspapers, and } \\
\text { social media. } \\
\text { - Putting in place systems } \\
\text { to ensure participation of } \\
\text { multiple stakeholders. } \\
\text { Fostering community buy- } \\
\text { in through ongoing contact } \\
\text { and conversation with } \\
\text { communities. } \\
\text { - Ensuring that the law } \\
\text { is understood by all; } \\
\text { translation of law, rules, } \\
\text { and procedures into local } \\
\text { languages. } \\
\text { Training and fostering } \\
\text { normative change among } \\
\text { state personnel (including } \\
\text { lawyers, judges, police, and } \\
\text { security officers. } \\
\text { Providing space for } \\
\text { movements that advocate } \\
\text { for excluded groups to } \\
\text { engage on policy reform. }\end{array}$ & $\begin{array}{l}\text { Congo, Dem. Rep. of } \\
\text { Strengthening socioeconomic } \\
\text { reintegration opportunities for } \\
\text { vulnerable households of ex- } \\
\text { combatants demobilized through } \\
\text { the PNDDR. } \\
\text { Burkina Faso Criminalization } \\
\text { of FGM and measures for } \\
\text { enforcement and normative } \\
\text { change. } \\
\text { Information campaigns around HIV } \\
\text { across the region. }\end{array}$ \\
\hline & $\begin{array}{l}\text { Opportu- } \\
\text { nities for } \\
\text { intergroup } \\
\text { cohesion }\end{array}$ & $\begin{array}{l}\text { Sending young citizens to } \\
\text { live in different regions of } \\
\text { the country. } \\
\text { Considering truth and } \\
\text { reconciliation commissions } \\
\text { (TRCs) to overcome } \\
\text { conflict. }\end{array}$ & $\begin{array}{l}\text { Nigeria National Youth Service } \\
\text { Corps (NYSC). } \\
\text { TRCs in The Gambia, Mauritius, } \\
\text { Rwanda, and South Africa. }\end{array}$ \\
\hline
\end{tabular}




\begin{tabular}{|c|c|c|c|}
\hline $\begin{array}{l}\text { Domain of } \\
\text { inclusion }\end{array}$ & $\begin{array}{l}\text { Channel for } \\
\text { intervention }\end{array}$ & $\begin{array}{l}\text { Illustrative actions targeting } \\
\text { those most likely to be left } \\
\text { behind }\end{array}$ & $\begin{array}{l}\text { Illustrative examples of policies, } \\
\text { programs, and projects }\end{array}$ \\
\hline & $\begin{array}{l}\text { Empower- } \\
\text { ment and } \\
\text { dignity }\end{array}$ & $\begin{array}{l}\text { Establishing cash transfers } \\
\text { and other social protection } \\
\text { programs that boost self- } \\
\text { confidence and imbue a } \\
\text { sense of dignity. } \\
\text { - Using social media and } \\
\text { technology to amplify } \\
\text { voices of excluded groups. } \\
\text { - Promoting reproductive } \\
\text { rights and services. } \\
\text { - Enabling survivors of } \\
\text { gender-based violence to } \\
\text { report anonymously. }\end{array}$ & $\begin{array}{l}\text { Kenya, Mozambique, and Zambia } \\
\text { Cash transfer programs. } \\
\text { South Sudan and Tanzania } \\
\text { "Listening to Africa" initiative. } \\
\text { Sahel Women Empowerment and } \\
\text { Demographic Dividend (SWEDD). } \\
\text { Uganda BRAC Empowerment and } \\
\text { Livelihood for Adolescents (ELA) } \\
\text { program. } \\
\text { Community-based rehabilitation } \\
\text { (CBR) for persons with disabilities. }\end{array}$ \\
\hline & $\begin{array}{l}\text { Better data } \\
\text { and analysis }\end{array}$ & $\begin{array}{l}\text { Collecting better } \\
\text { disaggregated data } \\
\text { on social groups and } \\
\text { processes } \\
\text { - Promoting platforms that } \\
\text { make data public } \\
\text { Fostering innovations } \\
\text { in data collection, such } \\
\text { as high frequency data } \\
\text { collection through mobile } \\
\text { phones } \\
\text { - Investing in geospatial data } \\
\text { and other forms of big data } \\
\text { - Encouraging and financing } \\
\text { better analysis }\end{array}$ & $\begin{array}{l}\text { World Bank's Gender Innovation } \\
\text { Lab } \\
\text { Listening to Africa initiative }\end{array}$ \\
\hline
\end{tabular}

a. Via the Supporting Children's Opportunities through Protection and Empowerment Project, implemented by the Ministry of Gender, Labor and Social Development.

Note: $\mathrm{BRAC}=$ Building Resources Across Communities; FGM = female genital mutilation; ID4D = Identification for Development; LGBTI = lesbian, gay, bisexual, transgender, and intersex; PNDDR = National Program for Disarmament, Demobilization, and Reintegration; UNDP = United Nations Development Programme; UNMIL = United Nations Mission in Liberia; WB = World Bank. 


\section{Notes}

1 From E.J. Sirleaf, 2011, “A Voice for Freedom!” Nobel Lecture, Oslo. https://www. nobelprize.org/prizes/peace/2011/johnson_sirleaf/26166-ellen-johnson-sirleafnobel-lecture-2011.

2 For a discussion of active and passive exclusion, see A. Sen (2000).

3 Benin, Burkina Faso, Central African Republic, Democratic Republic of Congo, the Republic of Congo, Côte d'Ivoire, Djibouti, Equatorial Guinea, Gabon, GuineaBissau, Lesotho, Madagascar, Mali, Niger, São Tomé and Príncipe, Seychelles, and South Africa do not criminalize same-sex relations.

4 See https://www.worldbank.org/en/programs/africa-gender-innovation-lab.

5 See https://www.justice.gov.za/trc/ for more about the South African TRC.

6 For more about NURC, see http://www.nurc.gov.rw/index.php?id=69. 


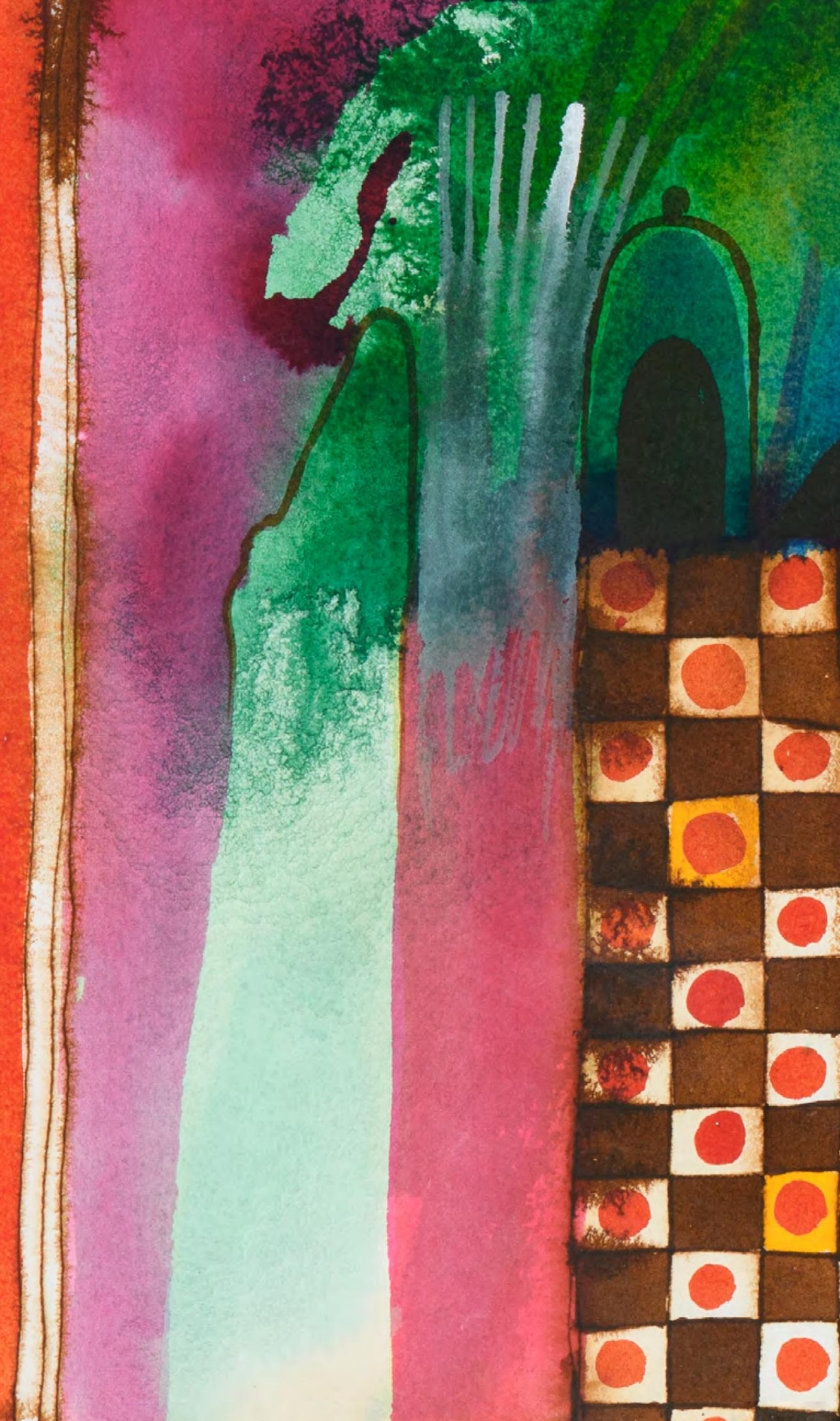





\section{Final Reflections}

\section{Main Messages}

1. Africa has seen significant progress towards social inclusion in the past few decades, in many areas moving at a pace faster than seen globally.

2. Some groups and areas have been left out of the progress in Africa and continue to remain at risk. Social inclusion helps us understand who is left out, from what, in what ways, and why.

3. Social inclusion draws attention to the drivers of poverty in Africa and explains that while we need to focus on poverty, this is only a starting point to end the exclusion.

4. Structures and processes that aid and abet social exclusion often have historical and cultural roots.

5. Areas that are affected by conflict and fragility stand out as having the poorest outcomes related to social inclusion. Conversely, peace and security matter for social inclusion.

6. Societies incur significant costs from social exclusion. Yet, achieving social inclusion also has costs. Therefore, investing in social inclusion has to be a conscious choice for states and societies.

7. With a strong social contract, social inclusion in Africa is eminently within reach, as hundreds of initiatives across the continent demonstrate. 
This report identifies barriers to social inclusion and presents pathways to inclusion across countries in Africa. It defines social inclusion as the process of improving the terms for individuals and groups to take part in society. It asserts that inclusion in markets, services, and spaces is the foundation for shared prosperity (World Bank 2013). The report highlights that impacts on poverty and human capital deficits can be achieved only when we identify who is likely to stay poor, how, and why. It focuses on social structures and processes, an understanding of which helps get to the core of how exclusion plays out. Without this understanding, many of the solutions we employ to address social inclusion are likely to fail or to meet with resistance.

The Africa Region of the World Bank has developed its new Regional strategy. This report contributes to the priority areas of the strategy by using the social inclusion lens to focus on, among others, women's empowerment, digital technology, fragility, and climate change. The report also shows that Africa is not alone in some of the challenges of social exclusion. These issues affect all countries and regions-OECD (Organisation for Economic Co-operation and Development) and non-OECD. There are areas in which some of the fastest progress globally has been in African countries. Examples include reforms of laws that enable women's participation in markets, that enhance women's safety and security, and laws that end the discrimination against individuals in same-sex relationships. The report also describes instances in which norms and practices that often are implicated in governmental resistance to change have been transformed. Movement toward the abolition of female genital mutilation (FGM) in Burkina Faso, and the growing de-stigmatization of persons with HIV or with disabilities are three illustrations of this transformation. Finally, Africa is home to some of the most powerful innovations toward social inclusion. M-PESA, a money transfer system operated by a cell phone provider in Kenya, and a new generation of social safety net programs stand out.

\section{SOCIAL INCLUSION}

The process of

improving the terms for

individuals and groups

to take part in society

The process of improving the ability, opportunity and dignity of people disadvantaged on the basis of their identity to take part in society 


\section{To summarize, this report accomplishes the following:}

- It places social inclusion front and center in an analysis of Africa's achievements and the challenges the region faces in poverty reduction and human capital formation.

- The report takes an interdisciplinary approach, using evidence from varied sources and bringing empirical weight to issues that often are debated through advocacy and contestation.

- It addresses with granularity of who is left out, from what, and how. The report garners and integrates evidence on historically invisible groups such as persons with disabilities, persons with albinism, some women, refugees, migrants, LGBTI persons, certain ethnic and occupational groups, persons who live in "lagging areas," and especially young people. It further focuses on the intersectionality of social identity.

- The report is grounded in the experience of African countries but also shows that Africa's social inclusion challenges are neither unique nor exceptional.

- It shows the channels through which individuals and economies may incur costs of social exclusion. These costs may be direct or indirect, short or long term. Cumulatively, the costs can impede the best efforts of governments and societies.

- It provides examples of the remarkable innovations that abound in Africa and of the policy and programmatic movement toward social inclusion. The report shines a light on African examples in which deeply entrenched social and cultural norms and practices have been changed.

- Finally, the report asserts that social inclusion must be a conscious choice for societies and their governments. Inclusion must be based on a clear social contract that recognizes both the costs and benefits of policies and interventions to move toward it. 


$$
\text { APPENDIXES }
$$




\section{Appendix A \\ Engaging around Social Inclusion with World Bank Partners in Africa}

The World Bank has an ongoing dialogue about social inclusion with diverse counterparts across Africa. Governments have been particularly interested in integrating social inclusion in the design of policies and in indicators and methods that assess social inclusion impacts of policies. Perhaps the largest set of consultations took place around the Environmental and Social Framework (ESF), from general discussions on nondiscrimination to those that addressed specific identity groups. Other conversations took place on policy issues that included provision of water and sanitation, services for persons with disabilities, albinism, trends in internal displacement, women's participation in the labor market, gender-based violence, and the reintegration of excombatants. Examples follow.

In 2014, the World Bank organized a week-long workshop for 44 representatives from government agencies, Parliaments, civil society, and academics at Lake Victoria in Uganda This workshop had been requested following previous trainings on country social analysis (CSA) and poverty and social impact analysis (PSIA) during which social inclusion was explicitly addressed.

On End Poverty Day (EPD) in October 2017, the World Bank's Africa Region brought together civil society organizations (CSOs), academics, government officials, media, and World Bank staff from country offices across the Region for a day of discussions through an interactive video conference on mobility and social inclusion.

Water and Social Inclusion was the theme of a December 2017 discussion and training session convened remotely for 36 participants from client governments and water and sanitation service providers in Kenya, Malawi, Mozambique, Zambia, and Zimbabwe. The session was held by videoconference following a request from the World Bank's partner governments for practical training on integrating social inclusion and gender into "water writ large."

Finally, World Bank teams have strong partnerships with civil society, academia, and regional entities such as the African Union (AU) and the African Development Bank (AfDB), as well as with bilateral donors and other grant-making organizations. Especially following enunciation of the Leave No One Behind agenda, most of these partners have exhorted the World Bank to engage more intensively on social inclusion.

Sources: World Bank Social Development Department, 2014, "Understanding Social Inclusion: Uganda Training Note"; Gender, Social Inclusion and Water Training, 2017, Internal notes; http://pubdocs.worldbank.org/en/527241508179463441/Social-Inclusion-in-Africa-English.pdf; http://www.worldbank.org/en/region/afr/brief/social-inclusion-in-africa. 


\section{Appendix B \\ Social Inclusion in the World Bank's Environmental and Social Framework}

Social inclusion has a place of pride in the new World Bank Environmental and Social Framework (ESF), which has applied to World Bank Group (WBG) projects since October 2018. At the start, much was said about the step forward that the ESF represented, including specific attention to a broad range of issues including labor, stakeholder engagement, and social inclusion. Regarding social inclusion, Environmental and Social Standards (ESS) require borrowers to pay explicit attention to both the identification of disadvantaged or vulnerable groups and the mitigation of risks and impacts to them in relation to a range of project risks and impacts and stakeholder engagement. The ESF also places obligations on World Bank staff that are detailed in the Bank Directive, "Addressing Risks and Impacts on Disadvantaged or Vulnerable Individuals or Groups.” The Bank Directive requires World Bank staff to take specific steps regarding the review of the environmental and social assessment conducted by the borrower; to participate in consultation activities, as appropriate; and to review the borrower's information (or information the World Bank itself has gathered) on risks and impacts to these populations.

This explicit and across-the-board articulation of, and attention to, vulnerabilitywith responsibilities placed on both the borrower and the World Bank-integrates social inclusion more tightly into the design and implementation of investment project financing. In addition, the ESF implementation presents an opportunity for the World Bank and its borrowers to build on, and deepen, past work on social inclusion. The Bank Directive necessitates the expansion of a knowledge base, both internally and among World Bank clients, on characteristics of the disadvantaged and excluded, on the factors that contribute to exclusion within certain project contexts, and, importantly, on how social inclusion can be operationalized. Ultimately, the ESF will expand the space available for developing knowledge on how social inclusion can be advanced through WBG-financed projects. 


\section{Appendix C \\ Addressing Gender-Based Violence in Africa: Snapshot of World Bank Engagement}

Interventions that support behavioral and normative change often are crucial to sustain the impacts of social inclusion policies and programs. For gender-based violence (GBV), for instance, severely unequal power relations between men and women, reflected in attitudes, beliefs, and behaviors that exclude women, often are deeply entrenched. Addressing these ingrained causes of GBV requires long-term engagement and an explicit focus on changing gender norms. Comparing different forms of prevention and awareness-raising activities, global evidence shows that the most promising results come from integrated approaches that include community outreach and participatory workshops and promote reflection and debate-including with boys and men.

The World Bank supports programs to counter GBV through financing, technical assistance, and research. The following illustrative projects provide financing to address GBV.

- Regional-Great Lakes Emergency Sexual and Gender-Based Violence and Women's Health Project in Burundi, Democratic Republic of Congo, and Rwanda and at the International Conference of the Great Lakes Region.

- Democratic Republic of Congo-Prevention and mitigation of sexual and genderbased violence (SGBV) in North and South Kivu Project. Focused on testing innovative pilots that support prevention and delivery of holistic services to women, children, and men survivors of SGBV.

- Democratic Republic of Congo-Gender-Based Violence Prevention and Response Project. Focused on the prevention of and response to GBV in 38 health zones in North Kivu, South Kivu, Maniema, and Tanganyika provinces.

- Somalia-Somalia Inclusive Community Resilience and GBV pilot-tested economic empowerment initiatives paired with GBV prevention and response services.

- Uganda-Strengthening Social Risk Management and Gender-Based Violence Prevention and Response Project, a multisectoral intervention.

- Gender-based violence interventions linked to forced displacement-Under the Development Response to Displacement Impacts Project (covering Djibouti, Ethiopia, Kenya, and Uganda), implementation of interventions and subprojects under the three investment components: basic social services and economic infrastructure, environmental and natural resources management, and traditional and nontraditional livelihoods. The interventions and subprojects will be gender-informed and contribute to GBV prevention and response among target beneficiaries of the project. Operational guidance is being developed for Kenya that will be extended to the other countries. 


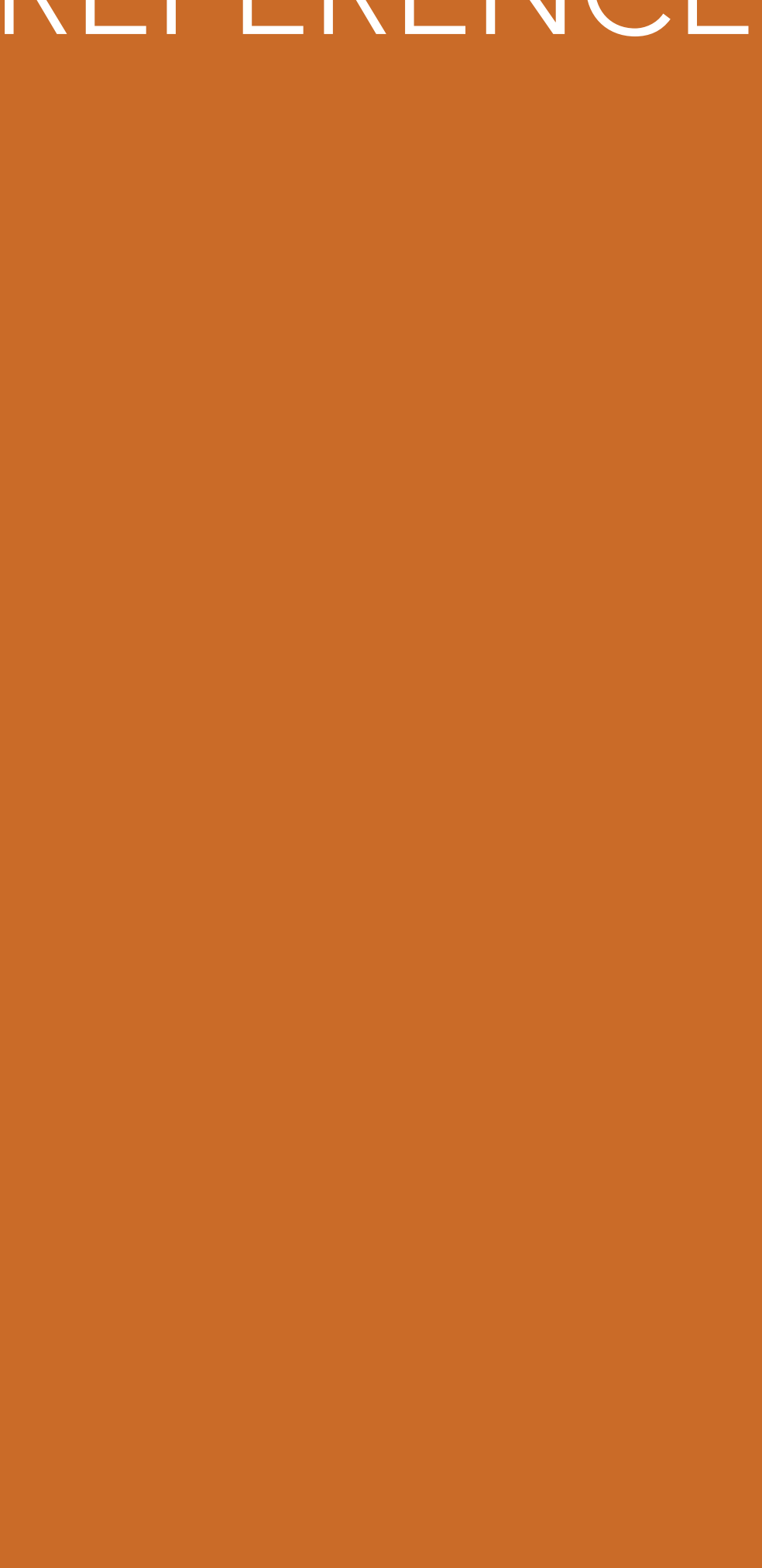

(n)

$$
\text { REFERENCES }
$$

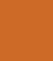




\section{REFERENCES}

Abraham, K.S. 2012. Kenya at 50: Unrealized Rights of Minorities and Indigenous Peoples. London: Minority Rights Group International.

AFIC (Africa Freedom of Information Centre). The State of Right to Information in Africa Report in the Context of the Sustainable Development Goals: Citizens' Access to Information; A Tool to Build Trust and Address Corruption. Kampala, Uganda: AFIC. https://africafoicentre.org/download/the-state-of-the-right-to-information-inafrica-report $-2017 /$ ? wpdmdl=915\&refresh=5d65a8baa0fed1566943418 (accessed September 1, 2019).

African Union Disarmament, Demobilisation and Reintegration Capacity Program. 2014. Reintegration Operational Guidelines. Addis Ababa: African Union Commission. http://www.peaceau.org/uploads/au-operational-guidance-note-on-reintergration. pdf (accessed September 3, 2018).

Ajibade, I., G. McBeah, and R. Bezner-Kerr. 2013. "Urban Flooding in Lagos, Nigeria: Patterns of Vulnerability and Resilience among Women." Global Environmental Change 23: 1714-25.

Alexander, K., C. Oduor, E. Nyothach, K. Laserson, N. Amek, A. Eleveld, and M. Ombok. 2014. "Water, Sanitation and Hygiene Conditions in Kenyan Rural Schools: Are Schools Meeting the Needs of Menstruating Girls?" Water 6 (5): 1453-66.

Ali, D.A., K. Deininger, and M. Goldstein. 2011. "Environmental and Gender Impacts of Land Tenure Regularization in Africa: Pilot Evidence from Rwanda." Africa Region Gender Practice Policy Brief 2: 1-3. https://openknowledge.worldbank.org/ bitstream/handle/10986/25527/755600BRI0ARGP00Box374337B00PUBLIC0. pdf? sequence $=1 \&$ is-Allowed $=($ accessed September 2, 2019).

Ali, D.A., K. W. Deininger, M. P. Goldstein, and E. LaFerrara. 2015. "Empowering Women through Land Tenure Regularization: Evidence from the Impact Evaluation of the National Program in Rwanda." Development Research Group Case Study. World Bank, Washington, DC. http://documents.worldbank.org/curated/ en/241921467986301910/pdf/97833-BRI-PUBLIC-Box391490B-ADD-SERIESTITLE-See-73154.pdf (accessed September 9, 2019).

Ametepee, L.K., and D. Anastasiou. 2015. "Special and Inclusive Education in Ghana: Status and Progress, Challenges and Implications." International Journal of Educational Development 41: 143-52.

Appiah, K.A. 2018. The Lies That Bind: Rethinking Identity. New York: Liveright Publishing.

Attah, R., V. Barca, A. Kardan, I. MacAuslan, F. Merttens, and L. Pellerano. 2016. "Can Social Protection Affect Psychosocial Wellbeing and Why Does This Matter? Lessons from Cash Transfers in Sub-Saharan Africa.” Journal of Development Studies 52 (8): $1115-31$.

Bandiera, O., N. Buehren, R. Burgess, M. Goldstein, S. Gulesci, I. Rasul, and M. Sulaiman. 2013. "Empowering Adolescent Girls in Uganda." Africa Region Gender Practice Policy Brief 4: 1-4. 
Bashir, S., M.Lockheed, E. Ninan, and J.-P.Tan. 2018. Facing Forward: Schooling for Learning in Africa. Washington, DC: World Bank. https://openknowledge.worldbank.org/ bitstream/ handle/10986/29377/9781464812606.pdf? sequence=14\&isAllowed=y (accessed September 10, 2019).

Bastian, G., I. Bianchi, M. Goldstein, and J. Montalvao. 2018. "Short-Term Impacts of Improved Access to Mobile Savings, with and without Business Training: Experimental Evidence from Tanzania." CGD Working Paper 478. Center for Global Development, Washington, DC. https://www.cgdev.org/sites/default/files/short-termimpacts-improved-access-mobile-savings-business-training.pdf (accessed September 3, 2019).

Baxter, D., and A. Burrall. 2011. "Moving to Catch up: Migration of Ex-combatants in Uganda" Transnational Demobilization and Reintegration Program. Washington, DC: World Bank. https://openknowledge.worldbank.org/bitstream/ handle/10986/26809/661010WP00PUBL0ation0Study0Nov02011.pdf?sequence $=1 \&$ isAllowed $=y$ (accessed August 24, 2019).

Beegle, K., and L. Christiaensen, eds. 2019. Accelerating Poverty Reduction in Africa. Washington, DC: World Bank.

Beegle, K., L. Christiaensen, A. Dabalen, and I. Gaddis. 2016. Poverty in a Rising Africa. Washington, DC: World Bank.

Beegle, K., A. Coudouel, and E. Monsalve, eds. 2018. Realizing the Full Potential of Social Safety Nets in Africa. Washington, DC: World Bank and Agence Française de Développement. http:// documents.worldbank.org/curated/ en/657581531930611436/pdf/128594-PUB-PUBLIC. pdf (accessed September 2, 2019).

Berg, A.G., and J.D. Ostry. 2011. "Inequality and Unsustainable Growth: Two Sides of the Same Coin?” IMF Staff Discussion Note 11/08. International Monetary Fund, Washington, DC. https://www.imf.org/external/pubs/ft/sdn/2011/sdn1108.pdf (accessed August 26, 2019).

Bhorat, H., A. Cassim, G. Masumbu, K. Naidoo, and F. Steenkamp. 2015. Youth Employment Challenges in Zambia: A Statistical Profile, Current Policy Frameworks and Existing Interventions. Ottawa: International Development Research Centre.

Bourdillon, M. 2017. "Thinking about Street Children and Orphans in Africa: Beyond Survival." In 'Children Out of Place' and Human Rights, ed. A. Invernizzi, M. Liebel, B. Milne, and R. Budde, 51-62. New York: Springer.

Broneus, K. 2010. "The Trauma of Truth Telling: Effects of Witnessing in the Rwandan Gacaca Courts on Psychological Health.” Journal of Conflict Resolution 54 (3): 408-37.

Brunori, P., F. Palmisano, and V. Peragine. 2016. "Inequality of Opportunity in Sub-Saharan Africa.” Policy Research Working Paper 7782. World Bank, Washington, DC.

Buckup, S. 2009. "The Price of Exclusion: The Economic Consequences of Excluding People with Disabilities from the World of Work." Employment Working Paper 43. International Labour Organization, Geneva. https://www.ilo.org/employment/ Whatwedo/Publications/working-papers/WCMS_119305/lang-en/index.htm (accessed August 26, 2019). 
Buehren, N., P. Gonzalez, and A. Copley. 2019. "What Are the Economic Costs of Gender Gaps in Ethiopia?” Gender Innovation Policy Initiative. World Bank, Washington, DC. http:// documents.worldbank.org/curated/en/245781553488459640/pdf/ What-Are-the-Economic-Costs-of-Gender-Gaps-in-Ethiopia.pdf (accessed August $28,2019)$.

Burgard, S. 2004. "Race and Pregnancy-Related Care in Brazil and South Africa." Social Science and Medicine 59 (6): 1127-46.

Burger, R., and R. Jafta. 2010. "Affirmative Action in South Africa: An Empirical Assessment of the Impact on Labour Market Outcomes." CRISE Working Paper 76. Centre for Research on Inequality, Human Security and Ethnicity, Oxford. https://pdfs. semanticscholar. org/2e65/43d1998b29d99d3bf3b4532a79a33c4c28bd.pdf (accessed September 3, 2019).

Burger, R., R. Jafta, and D. von Fintel. 2016. "Affirmative Action Policies and the Evolution of Post-Apartheid South Africa's Racial Wage Gap.” WIDER Working Paper 2016/66, United Nations University World Institute for Development Economics Research (UNU-WIDER), Helsinki. https:/www.econstor.eu/ bitstream/10419/146259/1/859857573.pdf (accessed September 2, 2019).

Burns, C. 2012. "The Costly Business of Discrimination: The Economic Costs of Discrimination and the Financial Benefits of Gay and Transgender Equality in the Workplace. Washington, DC: Center for American Progress". https:// cdn.americanprogress.org/wp-content/uploads/ issues/2012/03/pdf/lgbt_biz_ discrimination.pdf (accessed August 26, 2019).

Calderon, C., G. Kambou, V. Korman, M. Kubota, and C. Cantu Canales. 2019. “An Analysis of Issues Shaping Africa's Economic Future.” Africa's Pulse 19. Washington, DC: World Bank.

Cavalcanti, T. V., and J. Tavares. 2015. "The Output Cost of Gender Discrimination: A Model-Based Macroeconomic Estimate.” Economic Journal 126 (590): 109-34.

Chakravarty, S., S. Das, and J. Vaillant. 2017. "Gender and Youth Employment in SubSaharan Africa: A Review of Constraints and Effective Interventions.” Policy Research Working Paper 8245. World Bank, Washington, DC. http://documents. worldbank.org/curated/en/725431511188618886/pdf/WPS8245.pdf (accessed September 3, 2019).

Choi, J., M. Dutz, and Z. Usman. 2019. The Future of Work in Africa: Harnessing the Potential of Digital Technologies for All. Washington DC: World Bank.

P. Connor and J. M. Krogstad. 2018. "Record Number of Forcibly Displaced People Lived in Sub-Saharan Africa in 2017," Pew Research Center, Washington DC, https:// www.pewresearch.org/fact-tank/2018/08/09/record-number-of-forcibly-displacedpeople-lived-in-sub-saharan-africa-in-2017/ (accessed June 18, 2020).

Copley, A. 1989. Sexual Moralities in France 1780-1980: New Ideas on the Family, Divorce, and Homosexuality. An Essay on Moral Change. London: Routledge.

Corno, L., N. Hildebrandt, and A. Voena. 2016. "Weather Shocks, Age of Marriage and the Direction of Marriage Payments.” Working Paper 40. Università Cattolica del Sacro Cuore, Dipartimento di Economia e Finanza (DISCE), Milano. 
Croke, K., A. Dabalen, G. Demombybes, M. Giugale, and J.G.M. Hoogeveen. 2012. "Collecting High Frequency Panel Data in Africa Using Mobile Phone Interviews." Policy Research Working Paper 6097. World Bank, Washington, DC.

Cruz-Inigo, A. E., B. Ladizinski, and A. Sethi. 2011. "Albinism in Africa: Stigma, Slaughter and Awareness Campaigns.” Dermatologic Clinics 29: 79-87.

Das, M. 2016. "Social Inclusion in Macro-Level Diagnostics: Reflecting on the World Bank Group's Early Systematic Country Diagnostics.” Policy Research Working Paper 7713. World Bank, Washington, DC. http://documents.worldbank.org/curated/ en/361801467991929675/pdf/Social-Inclusion-in-macro-level-diagnosticsreflecting-on-the-World-Bank-Groups-early-systematic-country-diagnostics.pdf (accessed August 28, 2019).

2017. The Rising Tide: A New Look at Water and Gender. Washington, DC: World Bank. https://openknowledge.worldbank.org/handle/10986/27949 (accessed August 24, 2019).

Das, M., and S. Majumdar. 2019. "What Does Social Inclusion Mean for a Resilient City? A policy Note on Urban Floods?” World Bank, Washington DC.

Demirgüç-Kunt, A., L. Klapper, D. Singer, S. Ansar, and J. Hess. 2018. The Global Findex Database 2017. World Bank, Washington, DC.

Djuikom, M.A., and D. van de Walle. 2018. "Marital Shocks and Women's Welfare in Africa.” Policy Research Working Paper 8306. World Bank, Washington, DC.

Eide, A.H., and M. Loeb. 2006. "Living Conditions among People with Activity Limitations in Zambia: A National Representative Study.” Oslo: SINTEF.

Eide, A.H., and T. Mmatli. 2016. "Living Conditions among People with Disability in Botswana." Trondheim, Norway: SINTEF Technology and Society. https://www. sintef.no/globalassets/ sintef-teknologi-og-samfunn/rapporter-sintef-ts/sintefa27196-botswanawebversion.pdf (accessed September 1, 2019).

Ellsberg, M., D. J. Arango, M. Morton, F. Gennari, S. Kiplesund, M. Contreras, and C. Watts. 2015. "Prevention of Violence against Women and Girls: What Does the Evidence Say?" Lancet 385 (9977): 1555-66.

Emong, P., and L. Eron. 2016. "Disability Inclusion in Higher Education in Uganda: Status and Strategies." African Journal of Disability 5 (1): 193. https://www.ncbi.nlm.nih. gov/pmc/articles/PMC5433449 (accessed September 4, 2019).

Essoungou, A.-M. 2013, "The Rise of Civil Society Groups in Africa." Africa Renewal. December. https://www.un.org/africarenewal/magazine/december-2013/rise-civilsociety-groups-africa (accessed August 24, 2019).

Etang-Ndip, A., J.G.M. Hoogeveen, and J. Lendorfer. 2015. “Socioeconomic Impact of the Crisis in North Mali on Displaced People.” Policy Research Working Paper 7253. Poverty Global Practice Group, World Bank, Washington, DC. http://documents. worldbank.org/curated/ en/892311468184426978/pdf/WPS7253.pdf (accessed August 26, 2019).

Ferreira, F.H.G., C. Lakner, M.A. Lugo, and B. Özler. 2014. "Inequality of Opportunity and Economic Growth: A Cross-Country Analysis.” Policy Research Working Paper 6915. World Bank, Washington, DC. http://documents.worldbank.org/curated/ en/171051468336289614/pdf/WPS6915.pdf (accessed August 28, 2019). 
Filmer, D. 2008. "Disability, Poverty, and Schooling in Developing Countries: Results from 14 Household Surveys." World Bank Economic Review 22 (1): 141-63. http://siteresources.worldbank.org/DISABILITY/ Resources/280658-1239044853210/5995073-1246917324202/Disability_ Poverty_and_Schooling_in_Developing_Countries.pdf (accessed September 1, 2019).

Filmer, D., and L. Fox. 2014. Youth Employment in Sub-Saharan Africa. Washington DC: World Bank Group and Agence Française de Développement. https:// openknowledge.worldbank.org/bitstream/handle/10986/16608/9781464801075. pdf? sequenc (accessed September 10, 2019).

Finch, C.M., and A.A. Omolo. 2015. "Building Public Participation in Kenya's Devolved Government: Overview of Key Challenges and Opportunities for Enhancing Participation in Newly Devolved Institutions and Systems. A Summary of the Working Paper Series." Working Paper 1: "Overview Note: Kenya School of Government, Centre for Devolution Studies.” World Bank, Washington, DC. http:// documents.worldbank.org/curated/en/458231467997561854/pdf/94497-NWP. pdf (accessed on September 2, 2019).

Flatø, M., R. Muttarak, and A. Pelser. 2017. "Women, Weather, and Woes: The Triangular Dynamics of Female-Headed Households, Economic Vulnerability, and Climate Variability in South Africa." World Development 90: 41-62.

FRA (European Union Agency for Fundamental Rights). 2015. Cost of Exclusion from Healthcare: The Case of Migrants in an Irregular Situation. Vienna: FRA. https://fra. europa.eu/sites/default/files/fra_uploads/fra-2015-cost-healthcare_en.pdf (accessed August 28, 2019).

Graham, C., and M. Hoover. 2006. "Optimism and Poverty in Africa: Adaptation or a Means to Survival?” Preliminary version. Brookings Institution, Washington, DC. https://www. brookings.edu/wp-content/uploads/2016/06/20061005.pdf (accessed August 26, 2019).

Hallward-Driemeier, M., and O. Gajigo. 2013. "Strengthening Economic Rights and Women's Occupational Choice: The Impact of Reforming Ethiopia's Family Law.” Policy Research Working Paper 6695. World Bank, Washington, DC. http:// documents.worldbank.org/ curated/en/259861468021600567/pdf/WPS6695.pdf (accessed September 9, 2019).

Han, E., and J. O’Mahoney. 2014. "British Colonialism and the Criminalization of Homosexuality." Cambridge Review of International Affairs 27 (2): 268-88.

Handa, S. 2014. “Subjective Well-Being, Risk Perceptions, and Time Discounting: Evidence from a Large-Scale Cash Transfer Programme.” Innocenti Working Paper 2014-02. UNICEF Office of Research, Florence. https://www.unicef-irc.org/publications/ pdf/wp2014_02_ashu_martorano_fin.pdf (accessed September 3, 2019).

Handa, S., B. Martorano, C.T. Halpern, A. Pettifor, and H. Thirumurthy. 2014. "The Government of Kenya's Cash Transfer Program Reduces the Risk of Sexual Debut among Young People Age 15-25.” PLOS ONE 9 (1): e85483.Handa, S., A. Peterman, C. Halperne, A. Pettifor, and H. Thirumurthy. 2015. "Impact of the Kenya Cash Transfer for Orphans and Vulnerable Children on Early Pregnancy and Marriage of Adolescent Girls." Social Science and Medicine 141: 36-45. 
Haushofer, J., and J. Shapiro. 2013. "Household Response to Income Changes: Evidence from an Unconditional Cash Transfer Program in Kenya." Working Paper. Abdul Latif Jameel Poverty Action Lab, Massachusetts Institute of Technology, Cambridge, MA. https://www. poverty-action.org/sites/default/files/publications/Haushofer_ Shapiro_UCT_2013.pdf (accessed September 9, 2019).

Heugh, K., C. Benson, B. Bogale, and M.A.G. Yohannes. 2007. "Final Report: Study on Medium of Instruction in Primary Schools in Ethiopia." Study commissioned by the Ministry of Education, Federal Democratic Republic of Ethiopia, Addis Ababa.

Hill E., R. Hess, R. Aborigo, P. Adongo, A. Hodgson, C. Engmann, and C.A. Moyer. 2014. “'I Don't Know Anything about Their Culture': The Disconnect between Allopathic and Traditional Maternity Care Providers in Rural Northern Ghana." African Journal of Reproductive Health 18, (2) 36-45.

Hong, E.S., H. Zeeb, and M.H. Repacholi. 2006. "Albinism in Africa as a Public Health Issue."

BMC Public Health 6: 212.

Hoogeveen, J.G. 2005. “Measuring Welfare for Small but Vulnerable Groups: Poverty and Disability in Uganda." Journal of African Economies 14 (4): 603-31.

Hoogeveen, J.G., E. Tesliuc, R. Vakis, and S. Dercon. 2004. A Guide to the Analysis of Risk, Vulnerability and Vulnerable Groups. Washington, DC: World Bank.

Hossain, N., and M. Moore. 1999. "Elite Perceptions of Poverty: Bangladesh.” IDS Bulletin $30(2)$.

Hovens, M. 2002. "Bilingual Education in West Africa: Does It Work?” International Journal of Bilingual Education and Bilingualism 5 (5): 249-66. http://citeseerx.ist. psu.edu/viewdoc/download?doi=10.1.1.119.456\&rep=rep1\&type=pdf $\quad$ (accessed September 3, 2019).

Hsieh, C.-T., E. Hurst, C.I. Jones, and P.J. Klenow. 2013. "The Allocation of Talent and U.S. Economic Growth.” NBER Working Paper 18693. National Bureau of Economic Research, Cambridge, MA. https://www.nber.org/papers/w18693.pdf (accessed August 28, 2019).

Hunt, V., D. Layton, and S. Prince. 2015. "Diversity Matters.” McKinsey \& Company. https://www. mckinsey.com/ /media/mckinsey/business\%20functions/organization/ our \%20insights/why\%20diversity \%20matters/diversity\%20matters.ashx (accessed September 10, 2019).

Hunt, V.D., S. Prince, S. Dixon-Fyle, and L. Yee. 2018. Delivering through Diversity. McKinsey $\&$ Company. https://www.mckinsey.com/ /media/McKinsey/Business $\% 20$ Functions/Organization/Our\%20Insights/Delivering\%20through\%20diversity/ Delivering-through-diversity_full-report.ashx (accessed September 11, 2019).

Hyde, H.M. 1970. The Love That Dared Not Speak Its Name: A Candid History of Homosexuality in Britain. Boston: Little, Brown and Company.

Johnson, C. 2018. "'Particularly Good Days' Are Common in Africa, Latin America and the U.S." Pew Research Center, Washington, DC. http://www.pewresearch. org/fact-tank/2018/01/02/particularly-good-days-are-common-in-africa-latinamerica-and-the-u-s). Jones, N., A.H. Bassam, P. Pereznieto, and K. Sylvester. 2016. "Transforming Cash Transfers: Citizens' Perspectives on the Politics of Programme Implementation." Journal of Development Studies 52 (8): 1207-24. 
KNBS (Kenya National Bureau of Statistics). 2015. Kenya Integrated Household and Budget Survey 2015-2016. Ministry of Devolution and National Planning, Republic of Kenya, Nairobi. http://statistics.knbs.or.ke/nada/index.php/catalog/88 (accessed August 24, 2019).

Lall, S.V., J.V. Henderson, and A. Venables. 2017. Africa's Cities: Opening Doors to the World. Washington, DC: World Bank.

Lamichhane, K., and Y. Sawada. 2013. "Disability and Returns to Education in a Developing Country." Economics of Education Review 37: 85-94.

Langer, A., F. Stewart, and M. Schroyens. 2016. "Horizontal Inequalities and Affirmative Action: An Analysis of Attitudes towards Redistribution across Groups in Africa." WIDER Working Paper 2016/119. United Nations University World Institute for Development Economics Research (UNU-WIDER), Helsinki.

Lawson, D.W., M. Borgerhoff Mulder, M.E. Ghiselli, E. Ngadaya, B. Ngowi, S.G.M. Mfinanga, K. Hartwig, and S. James. 2014. "Ethnicity and Child Health in Northern Tanzania: Maasai Pastoralists Are Disadvantaged Compared to Neighbouring Ethnic Groups.” PLOS ONE 9 (10): e110447. https://doi.org/10.1371/journal. pone.0110447 (accessed September 10, 2019).

Lekalake, R., and E. Gyimah-Boadi. 2016. "Does Less Engaged Mean Less Empowered? Political Participation Lags among African Youth, Especially Women.” Policy Paper 34. Afrobarometer.org.

Lereya, S.T., W.E. Copeland, E.J. Costello, and D. Wolke. 2015. "Adult Mental Health Consequences of Peer Bullying and Maltreatment in Childhood: Two Cohorts in Two Countries." Lancet Psychiatry 2 (6): 524-31. https://www.thelancet.com/ journals/lanpsy/article/PIIS2215-0366(15)00165-0/fulltext (accessed August 28, 2019).

Loeb, M., and A.H. Eide. 2004. "Living Conditions among People with Activity Limitations in Malawi: A National Representative Study.” Report STF 78 A044511. Oslo: SINTEF.

Loeb, M., A.H. Eide, J. Jelsma, M.K. Toni, and S. Maart. 2008. "Poverty and Disability in Eastern and Western Cape Provinces, South Africa.” Disability and Society 23 (4): 311-21.

Lund, P.M. 2001. "Health and Education of Children with Albinism in Zimbabwe." Health Education Research 16 (1): 1-7.

Maathai, W. 2004. Nobel Lecture. Oslo, Norway. December 10. https://www.nobelprize. org/prizes/ peace/2004/maathai/26050-wangari-maathai-nobel-lecture-2004.

MacAuslan, I., and N. Riemenschneider. 2011. "Richer but Resented: What Do Cash Transfers Do to Social Relations?" IDS Bulletin 42 (6): 60-66.

Mahoo, H., W. Mbungu, I. Yonah, J. Recha, M. Radeny, P. Kimeli, and J. Kinyangi. 2015. "Integrating Indigenous Knowledge with Scientific Seasonal Forecasts for Climate Risk Management in Lushoto District in Tanzania.” CCAFS Working Paper 103. CGIAR Research Program on Climate Change, Agriculture and Food Security, Copenhagen. https://cgspace.cgiar.org/bitstream/handle/10568/56996/Working\%20 Paper\%20103.pdf (accessed September 3, 2019). 
Male, C., and Q.T. Wodon. 2017. “Disability Gaps in Educational Attainment and Literacy. The Price of Exclusion.” Disability and Education Series. World Bank and Global Partnership for Education, Washington, DC. http://documents.worldbank.org/ curated/en/396291511988894028/ pdf/121762-replacement-PUBLIC-WorldBankGapsInEdAttainmentLiteracy-Brief-v6.pdf (accessed August 28, 2019).

Marrero, G.A., and J.G. Rodríguez. 2013. “Inequality of Opportunity and Growth.” Journal of Development Economics 104: 107-22.

Marzatico, F. 2014. "Challenges of Land Governance in the Making of a New Nation: Experiences from South Sudan.” Paper presented at 2014 World Bank Conference on Land and Poverty, Washington, DC. On file with authors.Maystadt, J.-F. and P. Verwimp. 2014. "Winners and Losers among a Refugee-Hosting Population." Economic Development and Cultural Change 4 (62): 769-809.

Mbonu, N.C., B. van den Borne, and N.K. De Vries. 2009. "Stigma of People with HIV/ AIDS in Sub-Saharan Africa: A Literature Review." Journal of Tropical Medicine 2009: PMC2836916. https://www.ncbi.nlm.nih.gov/pmc/articles/PMC2836916 (accessed August 28, 2019).

Milazzo, A., and D. van de Walle. 2017. "Women Left Behind? Poverty and Headship in Africa."

Demography 54 (3): 1119-45.

Mitra, S. 2008. "The Recent Decline in the Employment of Persons with Disabilities in South Africa: 1998-2006." South African Journal of Economics 76 (3): 480-92. . 2018. Disability, Health and Human Development. New York: Palgrave.

Mitra, S., A. Posarac, and B. Vick. 2011. "Disability and Poverty in Developing Countries: A Snapshot from the World Health Survey." Washington, DC: World Bank. http:// siteresources.worldbank.org/SOCIALPROTECTION/Resources/SP-Discussionpapers/Disability-DP/1109.pdf (accessed September 10, 2019).

.2013. "Disability and Poverty in Developing Countries: A Multidimensional Study." World Development 41: 1-18.

Mizunoya, S., S. Mitra, and I. Yamasaki. 2016. “Towards Inclusive Education: The Impact of Disability on School Attendance in Developing Countries.” Innocenti Working Paper 2016-03. Office of Research, UNICEF, Florence. https://www.unicef-irc. org/publications/pdf/ IWP3\%20-\%20Towards\%20Inclusive\%20Education.pdf (accessed September 1, 2019).

Morgon Banks, L., and S. Polack. 2015. The Economic Costs of Exclusion and Gains of Inclusion of People with Disabilities: Evidence from Low and Middle Income Countries. International Centre for Evidence in Disability and London School of Hygiene and Tropical Medicine, London. https://www.iapb.org/wp-content/ uploads/CBM_Costs-of-Exclusion-and-Gains-of-Inclusion-Report_2015.pdf (accessed August 28, 2019).

Mulcahy, K., and U. Kollamparambil. 2016. "The Impact of Rural-Urban Migration on Subjective Well-Being in South Africa.” Journal of Development Studies 52 (9): 1357-71. 
Munoz Boudet, A.M., P. Buitrago, B.L. de la Brière, D. Newhouse, E. Rubiano Matulevich, K. Scott, and P. Suarez-Becerra. 2018. "Gender Differences in Poverty and Household Composition through the Life-Cycle: A Global Perspective.” Policy Research Working Paper 8360. World Bank, Washington, DC.

Muriaas, R.L., and V. Wang. 2012. "Executive Dominance and the Politics of Quota Representation in Uganda." Journal of Modern African Studies 50 (2): 309-38.

Mustapha, A.R. 2009. "Institutionalizing Ethnic Representation: How Effective Is Affirmative Action in Nigeria?” Journal of International Development 21: 561-76.

Nöstlinger, C., D. Rojas Castro, T. Platteau, S. Dias, and J. Le Gall. 2014. "HIV-Related Discrimination in European Health Care Settings." AIDS Patient Care and STDs 28 (3): 155-62.

Odinkalu, C., and M. Kadiri. 2014. "Making Progress on Freedom of Information in Africa." Open Society Justice Initiative (blog), August 13. https://www.justiceinitiative.org/ voices/making-progress-freedom-information-africa (accessed September 1, 2019).

Oduro, R. 2014. "Beyond Poverty Reduction: Conditional Cash Transfers and Citizenship in Ghana." International Journal of Social Welfare 24 (1): 27-36.

Ogude, H. 2018. "The Impact of Refugee Presence on Host Populations in Tanzania: A Desk Review." World Bank and UNHCR (United Nations High Commissioner for Refugees), Washington, DC.

OHCHR (Office of the United Nations High Commissioner for Human Rights). 2006. Ruleof-Law Tools for Post-Conflict States: Truth Commissions. New York and Geneva: United Nations. https://www.un.org/ruleoflaw/files/ruleoflaw-TruthCommissions_ en.pdf (accessed September 3, 2019).

Okunogbe, O.M. 2018. "Does Exposure to Other Ethnic Regions Promote National Integration? Evidence from Nigeria.” Policy Research Working Paper 8606. World Bank, Washington, DC. http://documents.worldbank.org/curated/ en/210921539090964091/pdf/WPS8606.pdf (accessed September 9, 2019).

Omolo, A. 2017. “West Pokot County Participatory Budget Hearings (Kenya).” https:// participedia.net/en/cases/west-pokot-county-participatory-budget-hearings-kenya.

Ostry, J., J. Alvarez, R. A. Espinoza, and C. Papageorgiou. 2018. "Economic Gains from Gender Inclusion: New Mechanisms, New Evidence.” IMF Staff Discussion Note 18/06. International Monetary Fund, Washington, DC. https:/www.imf.org/en/ Publications/Staff-Discussion-Notes/Issues/2018/10/09/Economic-Gains-FromGender-Inclusion-New-Mechanisms-New-Evidence-45543 (accessed August $28,2019)$.

Pavanello, S., C. Watson, W. Onyango-Ouma, and P. Bukuluki. 2016. "Effects of Cash Transfers on Community Interactions: Emerging Evidence." Journal of Development Studies 52 (8): 1147-61.

Pew Research Center. 2017. Spring 2017 Global Attitudes Survey. Pew Research Center, Washington, DC. https://www.pewresearch.org/global/dataset/spring-2017-surveydata/.

2018a. Analysis of United Nations High Commissioner for Refugees (UNHCR) data. Washington, DC. http://www.pewresearch.org/fact-tank/2018/08/09/ record-number-of-forcibly-displaced-people-lived-in-sub-saharan-africa-in-2017 (accessed August 24, 2019). 
2018b. "Internet Connectivity Seen as Having Positive Impact on Life in SubSaharan Africa, but Digital Divides Persist.” Washington, DC. https://www. pewresearch.org/global/2018/10/09/internet-connectivity-seen-as-havingpositive-impact-on-life-in-sub-saharan-africa (accessed October 7, 2019).

Rhea, R.W. 2014. A Comparative Study of Ex-Combatant Reintegration in the African Great Lakes Region: Trajectories, Processes, and Paradoxes. Washington DC: World Bank. https://openknowledge.worldbank.org/handle/10986/20748 (accessed August 26, 2019).

Rigaud, K.K., A. de Sherbinin, B.R. Jones, J.S. Bergmann, V.W.C. Clement, K.J. Ober, J. Schewe, S. Adamo, B. McCusker, S. Heuser, and A. Midgley. 2018. Groundswell: Preparing for Internal Climate Migration. Washington, DC: World Bank.

Roberts Otyola, W., G.M. Kibanja, and M.M. Anthony. 2017. "Benefits of Inclusive Education for Visually Impaired Students in Public Universities in Uganda." American Journal of Education and Practice 2 (1): 30-42.

Salisbury, T. 2016. "Education and Inequality in South Africa: Returns to Schooling in the Post-Apartheid Era." International Journal of Educational Development 46: 43-52.

Sankoh, O., S. Sevalie, and M. Weston. 2018. “Mental Health in Africa.” Lancet Global Health 6 (9): 954-55. https://www.thelancet.com/journals/langlo/article/PIIS2214109X(18)30303-6/fulltext (accessed August 28, 2019).

Say, L., and R. Raine. 2007. "A Systematic Review of Inequalities in the Use of Maternal Health Care in Developing Countries: Examining the Scale of the Problem and the Importance of Context." Bulletin of the World Health Organization 85 (10): 81219.Scheil-Adlung, X.enia, ed. 2015. Global Evidence on Inequities in Rural Health Protection: New Data on Rural Deficits in Health Coverage for 174 Countries. Geneva: ILO (International Labour Organization).

Seidenfeld, D., S. Handa, and G. Tembo. 2013. Zambia's Child Grant Program: 24-Month Impact Report. Washington, DC: American Institutes for Research. https://assets. publishing.service.gov.uk/government/uploads/system/uploads/attachment_data/ file/304213/Zambia-Child-Grant-Prog-24-Month-Impact-Report1.pdf (accessed September 3, 2019).

Sen, A. 2000. "Social Exclusion: Concept, Application and Scrutiny." Social Development Papers 1.

. 2008. "Violence, Identity and Poverty" Journal of Peace Research 45 (1): 5-15.

Asian Development Bank (ADB), Manila. https://www.adb.org/sites/default/files/ publication/29778/social-exclusion.pdf (accessed September 9, 2019).

Silal, S., L. Penn-Kekana, H. Bronwyn, S. Birch, and D. McIntyre. 2012. "Exploring Inequalities in Access to and Use of Maternal Health Services in South Africa." BMC Health Services Research 12 (1): 120.

Silver, L. and C. Johnson. 2018. "Internet Connectivity Seen as Having Positive Impact on Life in Sub-Saharan Africa” Pew Research Center, Washington, DC. https://www. pewresearch.org/global/2018/10/09/internet-connectivity-seen-as-having-positiveimpact-on-life-in-sub-saharan-africa/.

Sirleaf, E.J. 2011. “A Voice for Freedom!” Nobel Lecture. Oslo, Norway. https://www. nobelprize.org/prizes/peace/2011/johnson_sirleaf/26166-ellen-johnson-sirleafnobel-lecture-2011. 
Sprague, L., S. Simon, and C. Sprague. 2011. "Employment Discrimination and HIV Stigma: Survey Results from Civil Society Organisations and People Living with HIV in Africa." African Journal of AIDS Research 10 (Suppl. 1): 311-24.

Stiglitz, J. 2016. “Inequality and Economic Growth.” The Political Quarterly 86 (1): 134-55. https://onlinelibrary.wiley.com/doi/pdf/10.1111/1467-923X.12237.

Suri, T., and W. Jack. 2016. "The Long-Run Poverty and Gender Impacts of Mobile Money.” Science 354 (6317): 1288-92.

Suzuki, E., and H. Kashiwase. 2017. "New Child Mortality Estimates Show that 15,000 Children Died Every Day in 2016." World Bank Data Blog. October 19. https://s. worldbank.org/opendata/new-child-mortality-estimates-show-15000-childrendied-every-day-2016.

Tacoli, C., G. McGranahan, and D. Satterthwaite. 2015. "Urbanisation, Rural-Urban Migration and Urban Poverty." International Institute for Environment and Development Working Paper, IIED, London. https://pubs.iied.org/pdfs/10725IIED. pdf (accessed September 1, 2019).

Taş, E.O., M.E. Reimão, and M.B. Orlando. 2014. "Gender, Ethnicity, and Cumulative Disadvantage in Education Outcomes.” World Development 64: 538-53.

Turner, A. 2013. "The Business Case for Racial Equity.” W.K. Kellogg Foundation and Altarum Institute, Battle Creek, MI.

UNAIDS (Joint United Nations Programme on HIV/AIDS). 2018a. Miles to Go: Closing Gaps, Breaking Barriers, Righting Injustices. Geneva: UNAIDS. https://www. unaids.org/sites/ default/files/media_asset/miles-to-go_en.pdf (accessed September 9, 2019).

2018b. UNAIDS Data 2018. Geneva: UNAIDS.

UN DESA (United Nations Department of Economic and Social Affairs) Population Division. 2014. World Urbanization Prospects: The 2014 Revision. Highlights. New York: United Nations. https://population.un.org/wup/Publications/Files/WUP2014Highlights.pdf (accessed September 1, 2019).

2017a. World Ageing Report 2017. New York: United Nations.

2017b. World Family Planning 2017: Highlights. New York: United Nations. http:// www. un.org/en/development/desa/population/publications/pdf/family/WFP2017_ Highlights.pdf

.Population Division. 2018. "2018 Revision of World Urbanization Prospects.” United Nations, New York. https://www.un.org/development/desa/publications/2018revision-of-world-urbanization-prospects. html.

Population Division. 2019. World Urbanization Prospects: The 2018 Revision (ST/ESA/SER.A/420). New York: United Nations. https://population.un.org/wup/ Publications/Files/WUP2018-Report.pdf (accessed February 22, 2020).

2019. World Population Prospects 2019: Highlights. New York: United Nations. https:/population.un.org/wpp/Publications/Files/WPP2019_Highlights.pdf (accessed September 10, 2019). 
UN DESA (United Nations Department of Economic and Social Affairs) Statistics Division. 2015. "Proportion of Urban Population Living in Slums." Millennium Development Goals Indicators. https://unstats.un.org/unsd/mdg/SeriesDetail.aspx? srid=710 (accessed August 22, 2019).

UNDP (United Nations Development Programme). 2016. Human Development Report 2016. New York: UNDP. http://hdr.undp.org/sites/default/files/2016_human_ development_report.pdf.

UN DPI (United Nations Department of Public Information). 2018. Nelson Mandela: Excerpts from Speeches 1961-2008; In His Words. New York: United Nations. https://www.un.org/en/events/mandeladay/assets/pdf/mandela100-booklet.pdf (accessed August 24, 2019).

UNFPA (United Nations Population Fund) 2018. "Analysis of Legal Frameworks on Female Genital Mutilation in Selected Countries in West Africa." UNFPA, Regional Office for West and Central Africa, Dakar. https://sierraleone.unfpa.org/sites/default/files/ pub-pdf/EN-UNFPA-ANALYSIS-ON-FGM_0.pdf (accessed September 2, 2019).

UNGA (United Nations General Assembly). 2013. "Technical Cooperation for the Prevention of Attacks against Persons with Albinism.” Human Rights Council, Resolution 24/33. New York: United Nations.

.2015. "Transforming Our World: The 2030 Agenda for Sustainable Development." Resolution 70/1. UNGA, New York. https://www.un.org/ga/search/view_doc. asp? symbol=A/RES/70/1\&Lang=E.

UN-Habitat (United Nations Human Settlements Programme). 2014. State of African Cities 2014: Reimagining Sustainable Urban Transitions. Nairobi: UN-Habitat.

van de Walle, D. 2013. “Lasting Welfare Effects of Widowhood in Mali.” World Development 51: 1-19.

Van Hove, L., and A. Dubus. 2019. "M-PESA and Financial Inclusion in Kenya: Of Paying Comes Saving?" Sustainability 11 (3): 568. https://www.mdpi.com/20711050/11/3/568/htm (accessed September 3, 2019).

Vemuru, V., and Z.F. Karim. 2017. Assessment of the Community Engagement Methodology: South Sudan Local Governance and Service Delivery Project. Washington, DC: World Bank.

Wellenstein, A., and V. Stanley. 2018. "Three Things to Know about Women's Land Rights Today.” World Bank Blogs. https://blogs.worldbank.org/sustainablecities/threethings-know-about-women-s-land-rights-today (accessed September 1, 2019).

Whitaker, B.E. 2002. "Refugees in Western Tanzania: The Distribution of Burdens and Benefits among Local Hosts.” Journal of Refugee Studies 15 (4): 339-58.

WHO (World Health Organization). 2018. "Global Health Estimates 2016: Disease Burden by Cause, Age, Sex, by Country and by Region, 2000-2016.” WHO, Geneva. https:// www. who.int/healthinfo/global_burden_disease/estimates/en/index1.html (accessed September 11, 2019). 
Wike, R., K. Simmons, M. Vice and C. Bishop. 2016. “In Key African Nations, Widespread Discontent with Economy,Corruption: But Most Are Optimistic about Future in South Africa, Nigeria, Kenya.” Pew Research Center, Washington, DC. https://www. pewresearch.org/global/2016/11/14/in-key-african-nations-widespread-discontentwith-economy-corruption.Wodon, Q.T., and B. de la Brière. 2018. "Unrealized Potential: The High Cost of Gender Inequality in Earnings." Cost of Gender Inequality Notes Series, World Bank, Washington, DC.

Wodon, Q.T., C. Male, A. Nayihouba, A. Onagoruwa, A. Savadogo, A. Yedan, J. Edmeades, A. Kes, N. John, L. Murithi, M. Steinhaus, and S. Petroni. 2017. "Economic Impacts of Child Marriage: Global Synthesis Report.” Conference ed. World Bank, Washington, DC. http://documents.worldbank.org/curated/en/530891498511398503/ pdf/116829-WP-P151842-PUBLIC-EICM-Global-Conference-Edition-June-27.pdf (accessed March 10, 2020).

World Bank. 2013. Inclusion Matters: The Foundation for Shared Prosperity. Washington, DC: World Bank.

2014. Youth Employment in Sub-Saharan Africa. Washington, DC: World Bank.

2015. “Madagascar: Systematic Country Diagnostic.” World Bank, Washington, DC. http:// documents.worldbank.org/curated/en/743291468188936832/MadagascarSystematic-country-diagnostic (accessed September 1, 2019).

2016. "Guinea-Bissau: Turning Challenges into Opportunities for Poverty Reduction and Inclusive Growth.” Systematic Country Diagnostic. World Bank, Washington, DC. http:// documents.worldbank.org/curated/en/100721467968248103/ pdf/106725-CSD-P155168-IDA-SecM2016-0127-IFC-SecM2016-0078-MIGASecM2016-0076-Box396273B-PUBLIC-disclosed-7-5-16.pdf (accessed August 22, 2019).

. 2017a. "Burkina Faso: Priorities for Ending Poverty and Boosting Shared Prosperity; Systematic Country Diagnostic.” World Bank, Washington, DC. http:// documents. worldbank.org/curated/en/950551492526646036/pdf/SCD-Finalapril-10-FINAL-002-de-002-04132017.pdf (accessed August 22, 2019).

2017b. "Republic of Benin Systematic Country Diagnostic: Priorities for Ending Poverty and Boosting Shared Prosperity." World Bank, Washington, DC.

2017c. "The State of Identification Systems in Africa: Country Briefs." World Bank, Washington, DC. http://documents.worldbank.org/curated/ en/298651503551191964/pdf/119065-WP-ID4D-country-profiles-report-finalPUBLIC.pdf (accessed September 3, 2019).

2017d. The World Bank Environmental and Social Framework. Washington, DC: World Bank. http://pubdocs.worldbank.org/en/837721522762050108/ Environmental-and-Social-Framework.pdf (accessed August 22, 2019).

- 2018a. Atlas of Sustainable Development Goals 2018: From World Development Indicators. Washington, DC: World Bank.

2018b. Pathways for Peace: Inclusive Approaches to Preventing Violent Conflict. Washington, DC: World Bank.

2018c. "A Place-Based Typology to Prioritize and Coordinate Investments across Regions in Kenya.” Diagnostic Note. February. World Bank, Washington, DC. 
2018d. "Republic of Guinea: Overcoming Growth Stagnation to Reduce Poverty." Systematic Country Diagnostic. World Bank, Washington, DC. http:// documents.worldbank.org/curated/en/830641522072107327/pdf/Guinea-SCDfinal-03222018.pdf (accessed August 22, 2019).

2018e. "Republic of Liberia Systematic Country Diagnostic: From Growth to Development: Priorities for Sustainably Reducing Poverty and Achieving MiddleIncome Status by 2030." World Bank, Washington, DC. http://documents.worldbank. org/curated/en/585371528125859387/pdf/LBR-SCD-draft-10-06012018.pdf (accessed on August 22, 2019).

. 2018f. "Republic of South Africa Systematic Country Diagnostic. An Incomplete Transition: Overcoming the Legacy of Exclusion in South Africa." World Bank, Washington, DC. http://documents.worldbank.org/curated/ en/815401525706928690/pdf/WBG-South-Africa-Systematic-Country-DiagnosticFINAL-for-board-SECPO-Edit-05032018.pdf (accessed August 22, 2019).

2018g. Women, Business and the Law 2018. Washington, DC: World Bank. http:// pub-docs.worldbank.org/en/999211524236982958/WBL-Key-Findings-WebFINAL-2.pdf (accessed August 26, 2019).

. 2019a. Africa's Pulse, No. 20, October 2019: An Analysis of Issues Shaping Africa's Economic Future. Washington, DC: World Bank. https://openknowledge. worldbank.org/handle/10986/32480

2019b. Supporting Africa's Transformation. World Bank Africa Strategy for 20192023. http://pubdocs.worldbank.org/en/485321579731572916/AFREC-StrategyTrifold-Brochure.pdf (accessed 21 April 2020).

World Bank. LOGiCA (Learning on Gender and Conflict in Africa). 2013. "Reintegration Opportunities for Vulnerable Households of Ex-Combatants Demobilized through PNDDR: An Overview of the Socioeconomic Situation of Pilot Project Beneficiaries Two Years Following Project Closure; Maniema, Democratic Republic of Congo." Working Paper 3. World Bank, Washington, DC. http://documents.worldbank.org/curated/en/149711468026124790/ pdf/860580NWP0Box30GICA0WorkingPaperNo3.pdf (accessed September 3, 2019).

World Bank and Oxford University Press. 2006. World Development Report 2006: Equity and Development. Washington, DC: World Bank. http://documents.worldbank.org/ curated/en/435331468127174418/pdf/322040World0Development0Report02006. pdf (accessed August 22, 2019).

Yassien, M. 2019. "From Education to Startup Support, Let's Get Ready for the Digital Economy!" Youth Transforming Africa World Bank Blog, April 11. https://blogs. worldbank.org/youth-transforming-africa/education-startup-support-lets-get-readydigital-economy (accessed September 10, 2019). 


\section{Interior Photos}

\section{Overview}

El Anatsui, One Out of a Crowd, 1993, tempera on carved hardwood. Artist from Ghana. Image courtesy of the World Bank Group Art Program.

\section{Chapters 1 and 2}

Ahmed Abushariaa, Purple Lady, 2005, watercolor, ink. Image courtesy of the World Bank Group Art Program.

\section{Chapter 3}

Ahmed Abushariaa, Blue Lady, watercolor, ink. Image courtesy of the World Bank Group Art Program.

\section{Chapter 4}

Ahmed Abushariaa, Palm Tree, 2005, watercolor, ink. Image courtesy of the World Bank Group Art Program.

\section{Chapter 5}

Ibiyinka Olufemi Alao, Omonoba, 2001, tempera. Image courtesy of the World Bank Group Art Program. 
(4) WORLD BANK GROUP 